Studies in African Linguistics

Volume 40, Numbers 1\&2, 2011

\title{
AUXILIARY VERB CONSTRUCTIONS IN THE LANGUAGES OF AFRICA
}

\author{
Gregory D. S. Anderson \\ Living Tongues Institute for Endangered Languages \\ National Geographic Society
}

\begin{abstract}
Auxiliary verb constructions-constructions with two or more elements of verbal origin, one of which expresses functional semantic categories-are widespread among the languages of Africa. In the following discussion, I present a typology of inflection in auxiliary verb constructions [AVCs] in the languages of Africa. While there are several macro-patterns of distribution seen in the various African languages, only a small selection are presented in some detail here, viz. the doubled and split/doubled inflectional patterns, along with the fusing of subject markers and TAM/polarity auxiliaries into so-called tensed pronouns that are relatively more common in AVCs across the languages of the continent than in most other parts of the world.
\end{abstract}

Before launching into the presentation, a few terminological issues should be clarified. Inflection is here understood in its usual sense to mean the formal encoding ${ }^{1}$ of

Thank you to University of Manchester for funding my Eleme field work in Nigeria, and to my primary consultant Enu Obare Ekakaa wanenu for your good nature and patience. Thank you to National Geographic Society Missions Programs for their role in funding a portion of the research for this study. Thanks to Living Tongues Institute for Endangered Languages for its support of this research. All of this support is gratefully acknowledged. I would also like to thank Dr. Oliver Bond in particular and the audiences of WOCAL 4 and ACAL 37 for comments on earlier presentations of this material. I would also like to thank the Editor of the journal and three anonymous referees for cogent and insightful comments and critiques which were invaluable in making this final version a much better study. Finally, thanks to Oliver Anderson for editorial assistance. All errors of course remain the responsibility of the author. ${ }^{1}$ By 'formal encoding' I mean what is usually a morphological instantiation of this process with a segmental morpheme. However, functional categories can be encoded by something other than a bound segmental morpheme, as this would exclude several things that must count equally as inflection from any defensible cross-linguistic position. In the specific case of 
grammatical or functional properties of a well-formed utterance. With respect to the verb in African languages, this includes the indexation of tense, aspect, referent categories (person, number, gender), etc. Auxiliary verb is understood in the way it has been in the specialist literature in the last two decades (Heine 1993, Kuteva 2001, Heine and Kuteva 2002, Anderson 2006) rather neutrally as: a verbal element on a diachronic form-function continuum standing between a fully lexical verb and a bound grammatical affix. Auxiliary verb construction is defined by Anderson (2006:7) as "a mono-clausal structure minimally consisting of a lexical verb element that contributes lexical content to the construction and an auxiliary verb element that contributes some grammatical or functional content to the construction". The present investigation adopts this understanding of this term.

Some comments should be offered on the database that constitutes the foundation for this study of auxiliary verb constructions in the languages of Africa. I have my own specific criteria for a maximal ideal sample in a typological study such as this, but it is informed by many different approaches to language sampling that have been offered in the literature (e.g., Bell 1978, Nichols 1986, Dryer 1989, 1992, 2009, Rijkhoff et al. 1993, Rijkoff and Bakker 1998, Perkins 2001, Blake 2001, Song 2001 just to name a

African languages, tonally marked inflection is found not infrequently in Moru-Ma'di or Nilotic languages, and one most certainly does not want to exclude these languages nor these structures from the sets of those that express the grammaticalized functional categories that represent 'inflection' as usually understood. Furthermore, such functional elements can be fully dependent, partially integrated or independent phonologically from other parts of the construction (either the auxiliary verb and/or the lexical verb). Thus, it is compeletely irrelevant whether an obligatory functional inflectional exponent must be considered an affix or a clitic, etc., in the analysis of a particular language, as this has nothing to do with the functional semantic properties of the exponent, but rather with its phonological or phrasal prosodic properties. Thus I am hesitant to use the expression 'morphologically encoded by a fully phonologically dependent segmental element' although this is the only way to honestly formulate this, because such a phrase is both overly narrow as well as cumbersome, and anything else does not constitute 'morphological' encoding in a conventional or pretheoretical understanding of that term.

${ }^{2}$ Auxiliary verb is thus in some very broad sense a functional element, but may eventually drift semantically into an empty element that serves only as a placeholder of other (obligatory) grammatical or inflectional content as has happened in a number of languages, e.g., the South American language Jarawara (Dixon 2002). This is what has happened in various northern African languages like Zaghawa/Beria, Tama and Kanuri with a light verb stem (deriving from) 'say', as well as Fur and Aiki (also in Tama) with 'do' as the light verb stem; see sections 4.1 or 13 below for examples. 
few). Based on recent and on-going work of mine relating to the quantization of linguistic diversity and the threat thereto (Anderson and Harrison 2006, Anderson 2010, in preparation), I use a quasi-standard sampling level that I call the genetic unit, which is roughly equivalent to the Germanic or Romance language families. As such, I identify more relevant sampling levels than has been (until recently) traditional with regards to Africa, though more researchers appear to be moving in that direction (Güldemann 2008, Dimmendaal 2001a, 2008, Sands 2009).

In addition to the largest possible number of genetic units that I sought representative data from, my sample also includes, where merited and possible, data from multiple members of the same genetic unit. This is because these genetic units display particularly noteworthy or robust and varied systems of auxiliary constructions, and not incorporating this kind of micro-variation within genetic units would have led to a less comprehensive and informative database. Thus, there are many languages in the database representing the large Bantu family, as well as multiple representatives of the Chadic and Nilotic families.

By my reckoning there are over one hundred potential genetic units and unclassified languages to be used in a maximally representative typological linguistic sample of African languages. Other researchers naturally may have their own valid criteria for determining a different ideal number of sampling units in a maximally representative sample. I have data in this corpus from roughly ninety such genetic units. For investigating the structure of auxiliary verb constructions and verbal tense/aspect systems, the data currently available to me is of a type that is insufficient to be included in this sample from approximately a dozen of the genetic units in Africa. All but one of these are/were in central or west Africa, mainly in Nigeria, but also Cameroon, Ghana, Côte d'Ivoire, and Chad. These genetic units are Akpes, Akokoid and Ayere-Ähàn, all spoken in a compacts area in Nigeria, the barely remembered (possibly Kwa) language Dompo and the apparently now extinct and unclassified [M]Pre ${ }^{t}$ of Ghana, the similarly named and likewise unclassified Mbre of Côte d'Ivoire, Dakoid languages of the Nigeria/Cameroon border region, and the nearly extinct Jalaa-an unclassified language (or possible linguistic isolate) of Nigeria. The last three may represent genetic units that are remnants of a former fragmentation zone in western and central Africa (along with at least the lexical substrate in Kujargé, also not included in this sample) that pre-dates the various expansions of the component core and peripheral families of the Macro-Sudan Belt (Güldemann 2008; see 12 below). There are, of course, genetically unclassifiable languages in Africa as well, such as the Creole languages Sango or Kituba, or Pidgin varieties like Kenyan Pidgin Swahili, all three of which are included in the sample. Lastly, I have perhaps somewhat abitrarily excluded Meroïtic from this sample due to a 
low level of confidence in my ability to distinguish the relative merits of the various and quite different interpretations that have been offered of the materials from this extinct and still unclassified language of northeast Africa (Rilly 2010).

The corpus represents approximately 500 different speech varieties coming from over ninety different genetic units of Africa, plus the three genetically unclassifiable languages mentioned above. This set of genetic units in my database includes the main representatives of the Nilo-Saharan phylum as traditionally understood: Saharan, Songhay, Fur, Berta, Kunama, Maban, Gumuz, Koman, Kuliak, Kado, the families of the East Sudanic stock: Daju, Jebel, Nera, Nilotic, Nubian, Nyimang, Surmic, Taman, and Temein, and of the Central Sudanic stock: Bongo-Bagirmi, Kresh-Aja, Lendu, Mangbetu, Mangbutu-Efe, Moru-Madi.

The corpus also includes the small families and isolates once conventionally called 'Khoisan’ or ‘click' languages: Hadza, Juu, łHoan, Khoe, Sandawe, and Tuu.

The main branches of the Afroasiatic phylum are included in my corpus: Berber, Chadic (West Chadic , East Chadic, Biu-Mandara Chadic), Cushitic (Northern, Southern, Eastern), Egypto-Coptic, Omotic (Northern, Southern), and Semitic (EthioSemitic or Southern, and Western).

The corpus includes almost all of the many families and stocks (formerly included) within the enormous Niger-Congo phylum for which sufficient data are available: LekoNimbari, Mbum-Day, Waja, Jen (Bambukic), Limba-Mel Atlantic, Bak Atlantic, Senegambian Atlantic, Cangin Atlantic, Eastern Senegal-Guinea Atlantic, Bijago, Dogon, Gur, Heiban Kordofanian, Ijoid, Katla, Kru, Gbe, Kulango-Lorhon, Potou-Tano Kwa, Ga-Adangme, E. Mande, S. Mande, W. Mande, Rashad Kordofanian, Talodi Kordofanian, Northern and Southern 'Bantoid' sub-families (Mambiloid, Tiv, Tikar, Ndemli, Mbe, Mbam, Mamfe(Nyang), Grassfields, Ring, Mbam-Nkam, Ekoid, E. Beboid, W. Beboid), Bendi, [Narrow] Bantu, Okoid, Nupoid, Jukunoid, Yoruboid, Edoid, Idomoid, Igboid, Cross River, Kainji, Ega, Plateau subgroups and Senufic; the corpus also includes all six of the branches of Ubangi, which some researchers have now excluded from Niger-Congo altogether (Dimmendaal 2008), represented in my corpus, including Gbaya Ubangi, Mba Ubangi, Ngbaka Ubangi, Ngbandi Ubangi, Sere Ubangi, and Zande Ubangi.

I also have data in the corpus from moribund Ongota, which may or may not be classified as an isolate branch of Afroasiatic, or may rather be an isolate language. Shabo-like Ongota also a critically endangered language of Ethiopia-has a similar status within Nilo-Saharan, i.e., it is classified as either as an isolate branch within the phylum or a language isolate. 
Finally, the corpus includes data from two enigmatic and as yet unclassified languages of central Africa: Bangi Me of Mali and Laal of Chad. See Appendix 1 for an alphabetic list of the languages along with the countries they are spoken in and the sources consulted in constructing the corpus and Appendix 2 for the master list of languages in the corpus classified according to their genetic unit.

That complex morphological verb forms derive from fused auxiliary formations and that these often reflect earlier syntactic patterns has been known in African linguistics at least since Givón $(1971,1975)$. All types of AVCs can be fused into complex verb forms when looking at African languages as a whole. Generally, the relative order of AUX and $\mathrm{V}$ are relatively stable across genetic units, reflecting as they do the phrasal syntax that is dominant; see Appendix 2 for a list of basic and variant orders found in AVCs and fused complex verbs deriving from AVCs among the languages of my corpus. Note however that constructions counter to norms of the language's phrasal syntax may not infrequently be anomalous in other ways (e.g. have 'LEX-headed' patterns, see 1.2 below); they may also show other, enlightening processes of grammaticalization than do the formations that represent more typical AVC structures for the language or its genetic unit.

In the following sections I present a typology of auxiliary verb constructions in African languages. In section 1 I first present the notions of head and dependent in the grammar of AVCs, and briefly touch on the best known inflectional pattern of AVCs, the 'AUX-headed construction' (1.1), as well as the less well known 'LEX-headed' pattern (1.2). In section 2, I present data showing the 'doubled' inflectional pattern, in African languages. In Section 3, I present data representing what have been called (Anderson 1999, 2000, 2006) the 'split' (3.1) and 'split/doubled' patterns (3.2). In section 4, I give an overview of both the common source $>$ target (or content $>$ functional) semantic developments seen in African AVCs (4.1) and of the common syntactic source constructions that typically yield AVCs in African languages (4.2). In Section 5, I look at how complex verb forms derive from former AVCs in African languages and show variation in inflectional pattern or degree of phonological integration or fusing. Sections 6-9 examine four genetic units in more detail, offering a sample profile of constructions found in them. These include Bantu (6), Chadic (7), Khoe (8), and Nilotic (9). Sections 10-14 offers profiles of several linguistic areas or regions in Africa. This includes languages of the following five linguistic areas, representing four old or more recent spread zones of varying size and one fragmentation or residual zone. The four spread zones include Tanzanian Rift Valley (10), 'Ethiopia' (11), the Macro-Sudan Belt (12), the 'Sahara' (13) and the fragmentation zone is represented by the languages of the Nuba Hills (14). Section 15 summarizes the findings. 


\section{Inflection in Auxiliary Verb Constructions in African languages}

Auxiliary verb constructions represent a fundamental part of both grammar and cognition, such that similar strategies of verb-verb sequencing are employed by language users to encode functional semantic structure across unrelated languages. AVCs are midpoints in a continuum of grammaticalization of the well-known type in (1):

(1) lexical verb $[+$ syntagma $]>$ auxiliary verb $[+$ lexical verb $]>$ affix [-verb head- $](>\varnothing)$

AVCs exhibit definable trends both in their origins and in their subsequent historical developments. The grammaticalization paths of AVCs encompass developments pertaining to the semantic, (morpho)syntactic, and prosodo-phonological characteristics of the lexical and auxiliary verbs involved. In other words, the well-known tendencies embodied in the grammaticalization path in (1) collapse logically independent but interconnected functional, phonological and morphotactic hierarchies.

Although it is not the primary focus of this presentation, it is worth mentioning what AVCs function to encode in African languages. The wide range of functional categories encoded through AVCs in the languages of Africa include the expression of various tense (2), mood (3), and aspect and Aktionsart (4)-(5) categories (e.g. progressive, habitual, completive, imperfective); see also section 4.1 below for common functional targets associated with the auxiliation of specific, frequently grammaticalized lexemes in AVCs in African languages. ${ }^{3}$

\footnotetext{
${ }^{3}$ Note that at various historical layers, grammaticalized auxiliary verb structures underlie many of the tense, mood and aspectual markers found in the Bantu languages that have ended up in the Tense/Aspect position of the Bantu verbal template (see below and Berger 1939, Guthrie 1948, 1967/1971, Dammann 1956, 1971, 1978, Cole 1959, 1961, Meeussen 1967, Cope 1971, Lafon 1982, Goldsmith 1984, Heine 1991, 1994, Drolc 1992, Blench 1993, Wald 1997, Ehret 1999, Hewson et al. 2000, Maho 2001, 2003, Hewson \& Nurse 2001, Nurse and Philippson 2006, Nurse 2008; cf. also Beutner 1886). While it is beyond the scope of the present study, it is precisely a historically layered approach to grammaticalization that can help shed light on some of the issues that remain controversial in Bantu, e.g. the many functions of $*_{-} k a-\left(\right.$ and $\left.*_{-} a-\right)$; this investigation is currently underway.
} 
(2) Birom [Plateau]

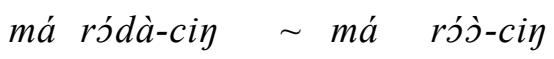

1 FUT-dig 1 FUT-dig

'I will dig (today)' (Bouquiaux 1970: 309)

(3) a. Ogbronuagum (Bukuma) [Cross River]

n-dó-né o-gíle

1-FUT-AUX FUT[:1]-do

'I can do (it).' (Kari 2000: 40)

b. Ogbronuagum (Bukuma)

abá tó-né ó-yíle

they FUT-AUX FUT:PL-do

'They can do (it).' (Kari 2000: 40)

(4) Siluyana [Bantu K31]

ba-nu ba-li ba-tenda

PL-person 3PL-AUX 3PL-work

'the people are working' (Givón 1971: 148)

(5) $\underline{\text { Godie }}[\mathrm{Kru}]$

$k-\tilde{a}^{2} \quad y i^{2}$

PROG-1 come

'I am coming' (Marchese and Gratrix 1974 : 272; GOD 4)

In addition, a few African languages make use of a negative auxiliary verb construction, e.g. Lango (6) or Hung'an (7). 
(6) Lango [Nilotic]

$$
\begin{array}{lll}
a ́ n & \grave{a} \text {-pe } & \grave{a} \text {-cámò réc } \\
\text { I } & \text { 1-NEG.AUX } & \text { 1-eat:PRF fish } \\
\text { 'I didn't eat the fish.' (Noonan 1992: 143) }
\end{array}
$$

(7) $\underline{\text { Hung[']an [Bantu H42] }}$

$$
\begin{aligned}
& \text { tu-Ø-khoon-ak ku-mon } \\
& \text { 1PL-NEG.AUX-IPFV INF-see } \\
& \text { 'we don't see, don't think so' (Nurse 2008: 183) neg.aux < 'fail' }
\end{aligned}
$$

Finally, although not well-known, AVCs may have 'adverbial' functions in African languages as well, as in Eleme of Nigeria (8). That is, what corresponds to certain kinds of adverbial modificational notions in better known European languages may be formally encoded by an auxiliary verb structure in Eleme, such as the verb Pot?, which means 'very'.

(8) Eleme [Ogonoid Cross River]

i. j̀-Pots tfá-î $\varepsilon p \dot{~}$

2-AUX run-2PL afraid

'you became very afraid' (Anderson 2006: 37)



3-AUX-3PL run afraid

'they became very afraid' (Anderson 2006: 37)

1.1 Heads, Dependency and Inflectional Patterns. The encoding of inflectional categories, that is, the morphosyntax, and the syntactic head/dependency relationship of the two verbal elements in an auxiliary verb construction largely reflects those same relationships in the input/source construction that gave rise to the AVC. There are at least three types of such source constructions in African languages, broadly speaking, that yield AVCs, viz., embedded/nominalized structures, serialized structures, and clause- 
chained structures. Within each of these broad types, several sub-types need to be realized, each with their own specific developmental consequences, see 4.2 below. ${ }^{4}$

The embedded/nominalized structure is by far the best known source construction type for AVCs, and is the only one that appears in studies that focus on European and Asian languages (as much work in syntactic and diachronic linguistic theory does, e.g. Harris and Ramat 1987, Lightfoot 1979, Vincent 1982, Bentley and Eythorsson 2004 et seqq.). In these AVCs, the auxiliary verb appears to be the inflectional or morphosyntactic head (cf. Zwicky 1985, 1993, Hudson 1987), as well as the syntactic head, and the lexical verb often appears in an overtly dependent or nominalized form (sometimes marked by phonologically null Ø-morphs). These AVCs often result from embedded complement structures or nominalized forms used with copular verbs. Although the auxiliary verb is the syntactic and morphosyntactic (or inflectional) head, it is clearly semantically not the 'head' of the expression, which, for example, predicates of an event of 'seeing', in the following AVC from Bantu Bukusu, not one of 'being':

(9) Bukusu $\quad$ [Bantu E31]

$$
\begin{aligned}
& \text { bá-lì } \quad x \hat{u} \text { :-bón-a } \\
& \text { 3PL-AUX INF-see-FV } \\
& \text { 'they see' (Aksenova 1997: 17) }
\end{aligned}
$$

much like English I have gone predicates of an event of 'going', not an event of 'having'.

Syntactically, the auxiliary element in 'regular' AVCs serves as the head, with the lexical verb encoded as dependent through the use of the infinitive structure. The lexical verb may even remain the syntactic complement of a nominal prepositional phrase in an AVC. Thus, various preposition-plus-nominalized verb structures are attested across a range of different African languages, and indeed must be reckoned among the most common sources for progressive constructions cross-linguistically, e.g., 'be at', 'be with' being two of the most common among African languages. Such formations have lexical verbs as PP complements in Bantu Umbundu or Central Sudanic Ngambay-Moundou with copular (positional) verbs serving as the inflectional and syntactic heads of the construction.

${ }^{4}$ Givón (2009) suggests just two, embedded and serialized. Based on parameters of finiteness and (often asyndetic) coordinate/subordinate status, I reckon three such input structures, for the details of which see below. 
(10) $\underline{\text { Umbundu }}$ [Bantu R10]

$$
\begin{array}{lll}
\text { tu-li } \quad \boldsymbol{l} \text { ' } \boldsymbol{o k \boldsymbol { k } \text { -lya }} \\
\text { 1PL-AUX with } \quad \text { INF-eat:FV } \\
\text { 'we are eating' (Heine and Reh 1984: 125; Valente 1964: 281) }
\end{array}
$$

\title{
(11) Ngambay-Moundou [Bongo-Bagirmi]
}

\author{
$m-\hat{i} \mathbf{s} \bar{\imath} / m-\boldsymbol{a} \boldsymbol{r} \quad \boldsymbol{m b} \overline{\boldsymbol{a}} \quad \boldsymbol{k}$-ùsà $\quad d \bar{a}$ \\ 1-AUX/1-AUX for NOM-eat meat \\ 'I am eating meat' (Heine and Reh 1984: 126; Vandame 1963: 94) \\ [NB: two different AUX variants, same structural AVC]
}

As is well known, the auxiliary verb typically tends to occupy the position in the verb phrase that the lexical verb would occupy if it appeared alone in an inflected form, i.e., as if it were functioning as the syntactic and inflectional heads of the verb phrase. ${ }^{5}$ Extrapolating on this data alone, it is clear that syntactically and inflectionally, the auxiliary verb appears to have assumed the 'head' status in an AUX-headed construction, but not semantically (already discussed by Zwicky 1985, Mufwene 1991, etc.). Thus, the (morpho)syntax and semantics of a construction need to be distinguished for AVCs at least, regardless of what framework of analysis within which this may be formalized. Not only do syntax and semantics need to be kept separate but interdependent in an architecture of grammar, but a set of functional categories which have generally been subsumed under either or both of these domains also need to be kept separate and autonomous from both with respect to AVCs. These functional categories (or morphosyntax) too show complex distributional phenomena and properties independent from both syntactic and lexical/content semantic properties in auxiliary verb constructions. In fact, it will turn out that (all?) such relations of 'headedness' and 'dependency' are gradient or scalar within AVCs, and individual constructions may show tendencies to one or other end of the continuum, that is, they may show increasing or decreasing degrees of 'canonical' headedness/dependency, but all points in between on

\footnotetext{
${ }^{5}$ Assuming, of course, that such main-verb-only structures are permitted in the language, as they do in fact appear to be in all African languages consulted so far, except possibly some Mande languages where the 'predicative marker' which is often an auxiliary form historically is obligatory.
} 
the continuum might be occupied by other constructions in the language or (un)related languages. In other words, the 'grammar' of AVCs, is generally one of degree, scale, or relative values, but not absolute discrete values or concepts per se.

For the sake of terminological consistency and convenience, I use the following notions of 'headedness' to characterize AVCs (although, as above, acknowledging the non-discrete qualities thereof): the syntactic head or phrasal head, the semantic head and the inflectional head or morphosyntactic head. For the most part, the syntactic head is the auxiliary verb, and the semantic head is the lexical verb (with some periods of ambiguity, especially in AVCs with serialized and 'light' verb input structures). Considering the distribution of the properties of the putative inflectional head on the other hand yields five macro-patterns, all well attested in African languages:

a. AUX-headed > Auxiliary Verb is the inflectional head

b. Doubled > Auxiliary Verb and Lexical Verb are inflectional co-heads

c. Split

$>$ Inflectional features split among Lexical Verb and Auxiliary Verb

d. Split/Doubled > Some features show doubled pattern, others split pattern

e. LEX-headed > Lexical Verb is inflectional head

(Auxiliary Verb often analyzed as particle; may have 'clause-level' inflection)

In terms of linear or phrasal syntax, the relative order of auxiliary verb and lexical verb in the AVC string generally follows the same order of Verb and Object in the clause. Thus, SOV languages tend to have V Aux structure while SVO and VSO typically have Aux V structure. However, in a small number of Bantu languages, e.g. Langi (F33), that show SVO basic clause structure, most AVCs in the language show the typical Bantu pattern of Aux V, but some AVCs have the syntactic pattern of V Aux (Dunham 2004), so deviations from these norms are found; note also that Dinik (Affiti) of the Nyimang family in Sudan has AUX V order but SOV clausal syntax.

In the following sections of 1.1, I discuss dependent forms of lexical verbs in AVCs and I briefly exemplify some of the multiple sub-types of the AUX-headed inflectional pattern in African languages. In 1.2 I briefly touch on LEX-headed pattern of inflection in AVCs, leaving a more detailed discussion of this very important type to a future presentation. In sections 2 and 3 of this study I concentrate on categories b-d in (12) and exemplify constructions showing the doubled, split and split/doubled patterns.

The data concerning the distribution of inflectional encoding properties of the auxiliary verb $[\mathrm{AV}]$ and the lexical verb $[\mathrm{LV}]$ in auxiliary verb constructions suggest that there is a need to distinguish between their morphosyntactic and syntactic features. 
Specifically, AVCs may show either a consistent discrete inflectional head (as in LEXheaded, AUX-headed and even perhaps the co-headed formations exhibited by the doubled inflectional pattern) or these characteristics may appear in a diffuse or split manner across the two components of the construction (the auxiliary verb and the lexical verb, for which see 3 below). However it is important to note that regardless of the inflectional pattern, the auxilary verb tends to serve as the syntactic/phrasal head of the construction. The syntactic dependency marking on the lexical verb generally represents residual effects of the shift from a bi-clausal complement (or conjunctive and some kinds of serialized) structure to a mono-clausal phrasal structure that accompanies the process of auxiliation.

While the lexical verb tends to be a syntactic dependent on the auxiliary verb phrasal head, the actual form of the lexical verbs in such AVCs can range from (quasi-)fully finite to fully non-finite, with varying degrees on this continuum also represented. This 'dependent' marking may be formally encoded by the morphology, by the (morpho)phonology, or syntactically. All these factors make it is possible to speak of not only degrees of headedness inflectionally, but degrees of dependency, with respect to the structural relationships (however construed or formalized) between auxiliary verbs and lexical verbs within and across the AVCs of a given language. ${ }^{6}$

Examples of several different formal means in which a (lexical) verb can be marked as 'dependent' within AVCs are offered below. Note that this tendency to mark a lexical verb as dependent in an AVC holds true regardless of the inflectional pattern that an AVC is found within. It is not the case, however, that all functional complex verb predicates require lexical verbs to be marked as dependent. Different formal means of marking a lexical verb as dependent typically co-occur predominantly with certain subtypes of inflectional patterns and result from specific structural configurations in the source constructions.

Lexical verbs may be overtly nominalized, adjectivalized or adverbialized through some kind of infinitive, participle, gerund/converb or verbal noun form which constitutes a morphololgically marked syntactically dependent form (albeit one that may be realized by a null-morph in the case of bare stem 'infinitives'). AVCs in a given language may differ with respect to whether argument-encoding morphology is permitted or not on the lexical verb, whether there is (independent) marking of TAM forms, (independently motivated) negation, on the lexical verb, etc. The variability of these factors helps explain

\footnotetext{
${ }^{6}$ See Givón (1990) for more on degrees of finiteness.
} 
some of the typological variation seen among various sub-types of split, doubled and split/doubled patterns discussed in 2 and 3 below.

Other means of marking a lexical verb as dependent in an AVC include the use of irrealis, subjunctive, etc. morphology on the lexical verb to encode its non-finiteness or non-finalness, or at least its lesser finiteness. ${ }^{7}$ Anderson (2006) calls this the modal subordination sub-type within AVCs. Another means of marking a lexical verb as dependent in an AVC includes the lexical verb encoding nominal properties not generally associated with finite verbs, such as happens with gender agreement in participial forms of lexical verbs in Romance languages and Gimira, see below. Dependent-marked forms may also exhibit the phonological properties of nouns (e.g. a tonal pattern), or may appear in a syntactic position otherwise licensed for nouns, as in Kru (or Germanic) languages. ${ }^{8}$

Most of the means of marking a lexical verb as dependent in an AVC are found in one or another construction when viewing the languages of Africa comparatively. A lexical verb in a dependent form in an AUX-headed pattern deriving from an embedded complement is of course the best known auxiliary structure and is well represented in numerous sub-types across the languages of the continent. For example, infinitive forms of lexical verbs may be found in certain Somali varieties in AUX-headed AVCs.

\footnotetext{
${ }^{7}$ See Bisang (2001) for why these modal forms are to be considered less finite in a scale of finiteness than corresponding indicative/declarative forms; cf. Carlson (1992) for a different view of subjunctive and finiteness in African languages. See also the articles in Nikolaeva (2007) for recent thoughts on different approaches to finiteness in grammar (and degrees and types of finiteness in various languages).

${ }^{8}$ See Marchese (1986) for discussion and examples; see also Claudi (1988) for a different view. Note also the similarity between the S-Aux-O-V-[Other] order proposed for ProtoNiger-Congo (Gensler 1994; Childs 2005) and the order SVOO in double object constructions, as in the following Kisi forms:
}
(a) i. Kisi [S. Atlantic]
ii. Kisi [S. Atlantic]

$\begin{array}{llll}\text { ò } & \text { ké } & \text { yá } & \text { tòòlúláy } \\ \text { she } & \text { give } & \text { me } & \text { support } \\ \mathrm{S} & \mathrm{V} & \mathrm{O} & \mathrm{O}\end{array}$

'she gave me support'

(Childs 2005: 8)

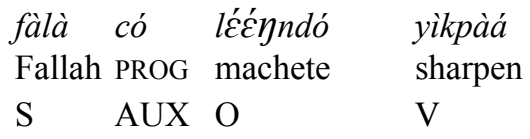

'Fallah is sharpening the machete' 
(13) Dabarro Somali

sheen-ow heesho

bring-INF AUX:1

'I keep bringing.' (Heine and Reh 1984: 124)

(14) Mudung Somali

kari-n $\bar{h} a y-s-a y$

cook-INF AUX-2-PST

'You kept cooking.' (Heine and Reh 1984: 124)

Constructions with an infinitive-marked lexical verb are extremely common in Bantu languages, e.g., the Bukusu form in (9) above or the Xhosa (15) far future form below. According to Nurse (2008), these so-called compound constructions were likely to have been present in Proto-Bantu as well.

(15) Xhosa (Bantu S41)

ndi-ya $\quad \boldsymbol{k} \boldsymbol{u}$-hamba

1-AUX INF-travel:FV

'I shall travel in the far future.' (Batibo 2005: 8) AUX < 'go'

Participial forms of dependent lexical verbs are found in AUX-headed AVCs in such Cushitic languages as Oromo of Wellega or Afar.

(16) a. Oromo of Wellega

adeemaa(n) jira

go:PRTCPL AUX:PRS

'He is going.' (Gragg 1976: 189) 
b. Oromo of Wellega

adeemaa hin-jiru

go:PRTCPL NEG-AUX:PRS.NEG

'He isn't going.' (Gragg 1976: 189)

(17) a. $\underline{\text { Afar }}$

oko'me-h su'gelen

eat-PRTCPL AUX:1.PST/PRF

'I had eaten' (Bliese 1976: 147)

b. Afar

yub'le-h su'gele

see-PRTCPL AUX:PRF:FUT

'he will have seen'(Bliese 1976: 147)

The familiar Romance-type of AVC with partially dependent 'participial'-type adjectival or nominal forms of lexical verbs showing gender agreement is rare in African languages (and really elsewhere other than certain well-known European languages). The one clear example of such a structure in my database of 500 African languages representing the full spectrum of geographic and genetic diversity of the continent is from the Omotic language Gimira (Benchnon). Both the lexical verb in a 'past participle' form and the inflected auxiliary verb encode the feminine gender of the subject (note that only the auxiliary verb, as the inflectional head, encodes the inflectionally relevant functional categories of tense/aspect (possibly expressed on both the lexical and auxiliary verbs), person and number). ${ }^{9}$

(18) Gimira (Benchnon) [Omotic; Ethiopia]

$$
\begin{aligned}
& w u^{1} s^{3} \quad \operatorname{han}^{3} k^{\prime 4} \quad y i s^{4} \operatorname{tar}^{4} g^{2} n e^{3} \\
& \text { she:SUBJ go:PST.PRTCPL:F AUX:PST:NEG:3F } \\
& \text { 'she was not going'(Breeze 1990: 31) }
\end{aligned}
$$

\footnotetext{
${ }^{9}$ In a sense this is thus like a kind of split/doubled inflectional pattern, see 3.2 and 11 below.
} 
Generalized adverbial dependency marking is encoded on a lexical verb in an AVC deriving from a subordinate/dependent clause in Eleme.

(19) Eleme

è-bo-rîru e-ma: àdádzi j̀nne
3-should-3PL-PRTCL DEP-bringAdaji gift
'They should bring Adaji a gift.'
(Bond 2006; Bond and Anderson 2003)

The so-called juncture element in various Khoe languages might also have originally represented a structure of this type (Vossen 1997, Güldemann and Vossen 2000). It may be found within synchronically bipartite AVCs as in Naro.

(20) $\underline{\text { Naro }}$ [Khoe; Botswana]

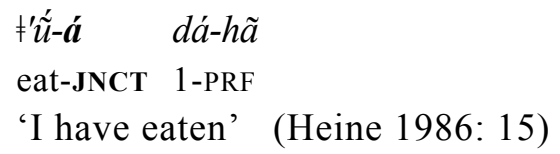

Co-negative forms, that is, dependent negative forms of lexical verbs that co-occur grammaticalized in combination with a negative auxiliary, are found in such African languages as Majang.

(21) Majang
$k u-k o-t-a$
Daaki $k \varepsilon t-\varepsilon d \quad k \varepsilon \varepsilon t$
NEG-PST-1-OBJ
Daaki chop-NEG tree
'Daaki did not chop a tree for me' (Unseth 1991: 120) 
A number of Bantu languages, particularly those of southern Africa like S21 Venda, as well as D28 Holoholo, make use of a co-negative form in the final vowel position of the verbal template, e.g. $-i{ }^{10}$

(22) a. Bantu S21 Venda

ndi-thi-nga-divhi

1-NEG-POT-know:FV $\mathbf{V}_{\text {CONEG }}$

'I shall not know' (Batibo 2005: 7) 'we don't chop' (Nurse 2008: 269) b. Bantu S21 Venda

\author{
a-ri-Ø-rém-i
}

NEG-1 PL-TA-chop-FV ${ }_{\text {CONEG }}$

(23) Bantu G42 Swahili

tu-li-kuwa ha-tu-fanyi

1PL-PST-AUX NEG-1 PL-do:FV ${ }_{\text {CONEG }}$

'we weren't doing anything' (Aksenova 1997: 21)

(24) a. Bantu D28 $\underline{\text { Holoholo }}$

a-to-Ø-lól-i

NEG-1 PL-TA-look-FV $\mathbf{V}_{\text {CONEG }}$

'we won't look $\left\{F_{1}\right\}$ ' (Nurse 2008: 269)

b. Bantu D28 $\underline{\text { Holoholo }}$

a-to-ká-lól-i

NEG-1 PL-FUT 2 -look-FV CONEG $_{\text {I }}$

'we won't look $\left\{\mathrm{F}_{2}\right\}$ ' (Nurse 2008: 269)

The pattern of a copular ( $>$ auxiliary) verb in combination with a prepostional (often locative or comitative/instrumental) phrase that includes a nominalized form of a lexical verb is a widespread and common pattern often found in progressive functions in a range of African languages (Heine and Reh 1984), as mentioned and already exemplified above

\footnotetext{
${ }^{10}$ Note that co-negative forms in Bantu occur in a construction-specific manner with negatives, whether the negative marker is at the pre-subject marker or in the pre-prefix outermost/leftmost position in the verb template as in all forms above except (22a), or with negative prefixes that occur at the negative (prefix position class -4 ) position, as in (22a).
} 
in Umbundu and Ngambay-Moundou, and again in 4.2 and 6 below in a range of Bantu languages. For a full list of AUX-headed inflectional patterns in AVCs in the African languages of my corpus see Appendix 3.

Lexical verbs may be grammaticalized in two different 'dependent' forms in different AUX-headed AVCs within a given individual language even with one and the same auxiliary. For example in Torrend's (1891) Southern African Bantu 'Kafir' (Xhosa), the auxiliary verb $-y a$ appears in an AUX-headed structure in two different functions depending on the form of the lexical verb. If the lexical verb is unmarked (or Ø-marked), then the construction means present progressive, but if the lexical verb is in the infinitive form (prefix $k u$-), then the construction has a future meaning.

(25) a. Xhosa

ndi-ya bona
1-AUX see:FV
'I am seeing' (Torrend 1891: 242)

b. Xhosa

ndi-ya ku-bona

1-AUX INF-see:FV

'I shall see' (Torrend 1891: 242)

African languages are hardly alone in showing multiple different functions associated with AVCs that use the same auxiliary source verb, grammaticalized into different embedded or complement structures with different dependent forms of a lexical verb. Compare in this regard English 'be' in its progressive $(b e+V$-ing) and passive functions $($ be $+V$-ed/en):

(26) a. English

Bill was killing the gorilla $\{$ be...-ing $>>$ progressive

\section{b. English}

Bill was killed by the gorilla $\{$ be...-ed/en $\}$ [+by-phrase] $>>$ passive

or the inchoative vs. benefactive structures found in such Siberian Turkic languages as Tuvan (Anderson and Harrison 1999, Anderson 2004), associated with the use of the 
same auxiliary verb ber 'give' with two different, constructionally determined and specified converb (dependent adverbial) forms of lexical verbs:

(27) a. Tuvan [Turkic; Siberia]

biz-ip ber-di-m
write-CV AUX-REC.PST-1
'I wrote (it) for someone else'
(Anderson 2006: 68 ) b. Tuvan

bizi-(j) ber-di-m

read-CV AUX-REC.PST-1

'I began to write'

Note that other inflectional patterns also show the lexical verb in these (and other) types of dependent forms, reflecting the [high degree of] syntactic head status of the auxiliary in AVCs, regardless of (the degree of) its inflectional head status (full, partial, none). These are addressed in the relevant sections ( 2 and 3 ) below.

Note that there is considerable variation within not only genetic units but individual languages as well with respect to the inflectional pattern seen across different AVCs. Of course, one pattern may well be dominant in a given language or genetic unit. When constructions exist that differ from this dominant syntactic or morphosyntactic configuration in the language, possible explanations for this type of variation include the differing origins of the constructions (e.g., verb complement vs. serialized origins), or also the argument-structure or functional properties of the grammaticalized elements concerned.

It is also important for the reader to remember that the absence of various formations from either my corpus or in my presentation of that data does not necessarily mean that a given construction is unattested or impossible in that language, just lacking in the data source(s), in the former instance, or simply not included for various practical considerations, in the latter.

1.2 On LEX-headed AVCs in African languages. The LEX-headed AVC (Anderson 2006) is a formation in which an unchanging grammatical 'particle' is grammaticalized in the same syntactic position and in the same kind of functions that one typically finds associated with auxiliary verbs within AVCs cross-linguistically, and that also historically appears to derive from an eroded or frozen auxiliary verb. As the inflectional head, the lexical verb element is inflected for all the obligatory inflectional categories (except of course the one that the auxiliary encodes), but the uninflecting auxiliary remains the syntactic or phrasal head, and the lexical verb may therefore be only semifinite, or appear in a construction-specific dependent form. In African languages, LEX- 
headed AVCs typically arise from eroded doubled inflectional forms, or from formations that had a dummy/expletive subject and clausal complement, see 5 below.

The LEX-headed pattern is well represented in African languages and typically encodes such categories as FUT, PRF, or PROG. It is not uncommon in languages such as Mödö (28) of the Bongo-Bagirmi family, or the Kuliak language Ik (29).

(28) $\underline{\text { Mödö }}$

tí mó-kj̀nyì yí

FUT 1-rescue you

'I will rescue you' (Persson and Persson 1991: 19)

(29) $\underline{\mathrm{Ik}}$

kó-iá ak bié-é ho

go-1 PRF outside-DAT house

'I have gone outside the house' (König 2002: 26)

Despite its lack of (synchronically active) inflection, the auxiliary verb in LEX-headed structures is, like auxiliary verbs generally are, usually the syntactic head of the resulting construction. This syntactic head status of the auxiliary may be encoded by the use of dependent verb morphology on the otherwise inflected lexical verb, e.g. use of irrealis or subjunctive mood marking. An example of this comes from Bantu Sukuma[-Kiiya], where the hodiernal future is in a now LEX-headed construction, probably derived from an original doubled pattern with phonological erosion of the subject marker on the auxiliary and with a subjunctive (modally subordinate) marked dependent lexical verb (Nurse 2008: 171).

(30) Bantu F21 Sukuma (-Kiiya)

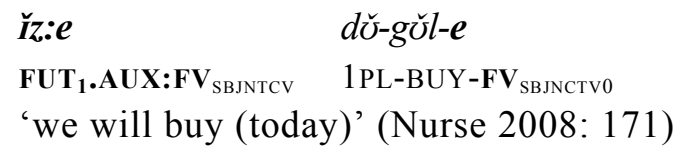


It seems likely that the development of the LEX-headed future AVC in Bantu G60 Kerewe also derived from the common verb 'come' as in Sukuma above, but with the lexical verb in the $-a$ final vowel form, not the 'dependent' modal form in $-e$.

(31) Bantu G60 Kerewe

saa tu-gula

FUT 1PL-BUY:FV

'we will buy' (Kießling et al. 2008: 201)

Comparative evidence suggests that the variation in the following Mbay form may show an originally doubly-inflected (or split/doubled), that has been eroded or clipped to yield the LEX-headed construction:

(32) a. Mbay [Bongo-Bagirmi]

b. Mbay

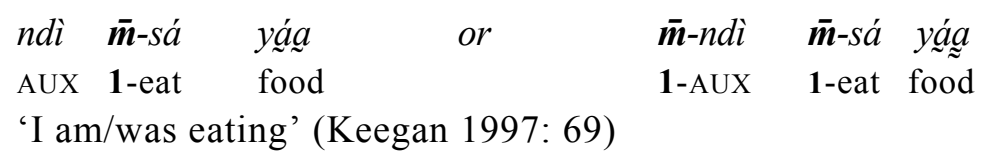

Its sister language Gula Sara shows a LEX-headed formation with a dependent lexical verb (appearing in the infinitive form); note that the first person plural form in the same TAM-form is a doubly-headed formation. ${ }^{11}$

(33) Gula Sara

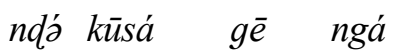

AUX INF:eat PL thing

'they/you all are eating' (Nougayrol 1999: 137)

\footnotetext{
${ }^{11}$ Note that some verbs have doubled inflection with just first singular subjects in Gworok (Kagoro) of the southcentral Plateau family (Adwiraah 1989).
} 
(34) Gula Sara

$$
\begin{aligned}
& z \bar{\partial}-n d \bar{\partial} \quad z-\bar{u} s \bar{a} \quad \bar{l} \quad n g a ́ \\
& \text { 1PL-AUX 1PL-eat EXCL thing } \\
& \text { 'we are eating' (Nougayrol 1999: 137) }
\end{aligned}
$$

The negative past in the Surmic language Tennet uses a negative particle derived from a negative verb that took a modal dependent form of the lexical verb in what is now a subtype of LEX-headed formation with a modal dependent-marked but subject-inflected

\begin{tabular}{|c|c|c|c|c|}
\hline$n n i$ & anná & $k-i-c i n$ & Lok $\underline{\text { úlli }}$ & balwáz \\
\hline NEG & 1SG:NOM & 1-SBJNCTV-see & Lokuli & yesterday \\
\hline
\end{tabular}
lexical verb.

(35) Tennet

A similarly clear typologically parallel example of a LEX-headed AVC with a modal dependent marked lexical verb may be seen in the Kwerba language of Papua, Indonesia. Here the lexical verb, although the inflectional head, reflects its syntactic dependent status by appearing in the modally dependent irrealis form.

(36) Kwerba [Dani-Kwerba; Indonesia]

nano wïre b-ang-ku-m
we.DL PROG PRS-DL-go-IRR
'we two are going' (De Vries and De Vries 1997: 22)

An example of a LEX-headed construction with an infinitive-marked but subject encoding lexical verb in Bongo of the Macro-Sudan Belt is offered in (714) below in section 12. Other African languages with LEX-headed formations include Temein and Katla of the Nuba Hills (see section 14 for examples), and various northern Saharan languages (section 13). LEX-headed AVCs show the same types of origins and further historical developments into complex verb forms that typify AVCs of other inflectional patterns; see sections 4 and 5 below. For a list of LEX-headed inflectional patterns in AVCs in the African languages of my corpus see Appendix 4. 


\section{Doubled Inflection}

One salient way in which a number of the languages of Africa stand out in comparison to better known Eurasian languages is the doubled inflectional pattern of AVCs. In this, there is often doubled subject marking, less commonly double marking of other functional categories (e.g. TAM categories), together with, or in lieu of, doubled subject marking.

The doubled inflectional pattern is here analyzed as a complex predicate structure with a functional element (= auxiliary verb) and a content element (= lexical verb), in which the lexical verb and the auxiliary verb share inflectional head status. That is, they are inflectional co-heads, a state which necessitates a pleonastic or redundant multiple encoding of all the relevant functional semantic/inflectional features, which therefore must appear with both components of the AVC (the auxiliary verb and the lexical verb). Note that this doubled inflectional pattern says nothing about the syntactic head status of the auxiliary verb or lexical verb in such formations. As is typical with AVCs, the syntactic head of the construction tends to be the auxiliary verb, and the semantic head the lexical verb.

In some minimally to moderately inflected languages, a doubled subject marking structure is characteristic of auxiliary verb constructions. In this, subject marking is encoded on both the lexical verb and auxiliary verb components of the AVC. Such a formation is found in S. Bantoid Noni, the Lendu language Ngiti and the Biu-Mandara Chadic language Muyang.

(37) a. Noni

$$
\begin{array}{lll}
\text { me } & \eta \text {-géć } & \eta \text {-gwè } \\
\text { I } & 1 \text {-HAB } & 1 \text {-fall } \\
\text { 'I usually fall' (Hyman 1981: 89) }
\end{array}
$$

b. Noni

$$
\begin{aligned}
& \text { me m-bèé } \quad y \text {-gwe } \\
& \text { I 1-Aux } 1 \text {-fall } \\
& \text { 'I would have fallen' or 'I almost fell' or 'I am about to fall' or 'I am } \\
& \text { almost falling' (Hyman 1981: 90) }
\end{aligned}
$$


(38) Ngiti

nyì $\boldsymbol{n y}$-àtsŭ $\quad \boldsymbol{n y}$-ikpe

you 2-AUX:PRF:PRS 2-cough:PRF:PRS

'you were on the point of coughing' (Kutsch Lojenga 1994: 191)

(39) a. Muyang

nay a-bu a-ra
3SG 3-AUX 3-come
'he is coming'

(Smith 2002: 13) b. Muyang

$$
\begin{aligned}
& \text { nu nə-bu nə-zum } \\
& \text { I 1-AUX 1-eat } \quad \text { something } \\
& \text { 'I'm just eating something' }
\end{aligned}
$$

(Smith 2002: 13)

In Noni, long strings of AVCs that each require the next verb to be in a subject-marked form can be found, yielding sentences like the following where first person markers occur on all six verbs.

(40) Noni

$$
\begin{aligned}
& \text { me n-t’̀ n-ge m-béc̀ m-bvǔ n-yúú } \eta \text {-kfun wan } k \varepsilon \\
& \text { I 1-AUX 1-AUX 1-AUX } \text { still> }_{1} \text { 1-AUX } \text { again }>_{1-A U X} 1 \text {-hit child NEG } \\
& \text { 'I had still not ever hit the child' (Hyman 1981: 87) }
\end{aligned}
$$

The doubled inflectional pattern in AVCs is widespread and recurrent across a huge and diverse range of Bantu languages. Nurse (2008) offers numerous examples of doublyinflected compound constructions. Most of these appear to show the split/doubled inflectional pattern (with split tense, aspect, object and negative marking, see 3.2 below) rather than doubled inflection per se, but double subject marking is relatively common in Bantu AVCs. A62 Yambasa (41) for example shows doubled inflection in the progressive present, while M14 Lungu (42) has a fully doubly inflected form in the near future progressive. 
(41) Bantu A62 Yambasa

a-lé a-núun-ə

3-AUX 3-watch-FV

'he is watching'

(Nurse 2008: 141)
(42) Bantu M14 Lungu

$$
\begin{aligned}
& \text { tw-áá-shá tw-áá-lim-a } \\
& \text { 1PL-TA-AUX 1PL-TA-farm-FV } \\
& \text { 'we'll soon be farming' }
\end{aligned}
$$

(Nurse 2008: 163)

In the above languages, there is a formal identity of the subject markers, suggesting a possible mechanical copy of the elements from one into another, historically or underlyingly. No such analysis is desirable for a number of reasons. For one, formal identity between the two elements is not obligatory across the markers encoding functional categories reflecting the doubled inflectional pattern (which includes subject and/or TAM categories primarily). Indeed, it is not uncommon for different paradigmatic sets of markers to be used in the grammar of a given language, and individual lexical and auxiliary verbs may require inflectional markers from these different (lexically or morphosyntactically definable) sets. Thus, the following form from Oromo of Wellega reflects in the same sense a doubled pattern as the Ngiti, Dyola or Yambasa forms above, although there is no formal identity across the markers used to encode the obligatory (and doubly realized) inflectional categories. ${ }^{12}$

(43) Oromo of Wellega

k'ab-a t'ur-e

have-3M.PST AUX-3M.PST

'he had' (Gragg 1976: 185)

Double-marking of non-subject categories is rare in African languages, but is found to a limited degree. Doubled negation is found in Twi for example:

\footnotetext{
${ }^{12}$ Note also in this regard the variation between $y$-vs. $a$ - third animate singular markers in various Bantu languages. Thank you to an anonymous referee for drawing my attention to this fact.
} 
(44) Twi

$o-n-n y \tilde{a} \quad m-m a-e$

he-NEG-AUX NEG-come-PST

'he has not yet come' (Lord 1993: 219; Christaller 1881: 335)

Tonally-marked non-past may appear in a doubled inflectional structure in the MoruMa'di language Ma'di.

(45) Ma'di [Moru-Ma'di]

$$
\begin{aligned}
& m a ́ ~ ' k \bar{s} \quad \text { 'mū } \\
& \text { I NPST:AUX NPST:go } \\
& \text { 'I'm about to go' (Blackings and Fabb 2003: 165) }
\end{aligned}
$$

A construction with double marking of both subject and future tense, that is, a fully doubled inflectional structure, is found in Bantu languages like Kirundi.

(46) Kirundi (J61/D62)

niya azaná ubwă:tsi bw'ínzu tu-zo:-ba tú-zo:-sáka:ra inzu if 3-bring thatch of.house 1PL-FUT-AUX 1PL-FUT-thatch house 'if they would bring the thatch (tomorrow), we will thatch the house' (Botne 1986: 307)

Note that the doubled subject pattern need not be manifested in a structure with synchronically bound inflectional markers. Rather, analytic doubled subject marking of the type reported in the unclassified language Laal (47) of Chad is not uncommon in African AVCs as well, particularly among the languages of the Macro-Sudan Belt, or at least in many analyses of these languages. See 12 for more discussion of this kind of structure. 
(47) Laal [Unclassified; Chad]

Pìn $c \bar{I} \quad$ Pìnníni $k \dot{t} \quad y \bar{a}: n$
elle AUX elle $\quad$ venir à corps+son(n.)
elle vient auprès de lui’ (Boyeldieu 1982: 184)

Although inter-related, frequently parallel and collapsed into one continuum, bondedness or phonological integration and functional specialization or 'grammaticalization' must be acknowledged as logically independent parameters in the well known grammaticalization path in (1) above. Thus, something can be more grammaticalized than it is phonologically integrated and vice versa. ${ }^{13}$

As already mentioned, there are a number of ways in which verbs may be marked as (morpho)syntactically dependent in African languages. The use of nominalizing or adverbializing morphology on lexical verbs in the AUX-headed pattern of inflection in African AVCs was briefly exemplified above. Other strategies for marking verbs as dependent include the use of particular modal verb forms, or tonal alternation, i.e. phonological means, or movement/dislocation, that is syntactically marked dependency, etc.

Because auxiliary verbs tend to be the syntactic heads of their constructions and/or verb phrases, regardless of the particular macro-pattern of inflection associated with that AVC (that is whether they are the inflectional head, co-head, dependent, etc.), it should perhaps come as no surprise that AVCs of the doubled inflectional pattern may also appear with a dependent marked lexical verb. Given the possibility of multiple independent factors co-varying in such structures, each in some way diverging (or conforming) to 'standard' finite declarative structures, a yield of constructions that reflect varying degrees of syntactic headedness is to be expected.

\footnotetext{
${ }^{13}$ The so-called lexical suffixes of Salish would be an example of elements that show a high degree of phonological integration, but largely retain there content semantics, generally without showing functional specialization or grammaticalization. Grammatical 'particles' thus would reflect the opposite end of the spectrum with a high level of functionality and low degree of phonological integration. Therefore I make no special consideration of inflectional clitics, which merely represent mid-points on the bondedness or phonological integration continuum between fully free-standing $>$ tightly bound $>$ fully eroded that characterizes elements undergoing grammaticalization. One exception to this is when the clitics target specific phrasal hosts, e.g. words on the left edge or second position of the clause, regardless of part of speech, rather than specific components of an AVC, i.e., the lexical verb or the auxiliary verb. In this case, the resulting patterns may mimic other patters, a phenomenon I call a 'pseudo-pattern'. For more on this see relevant discussions below.
} 
In Kinyarwanda and the Nupoid language Gade, subject markers are phonologically/tonally marked as dependent on lexical verbs, even though the subject inflection itself is doubled.

(48) a. Kinyarwanda

b. Kinyarwanda

$\begin{array}{ll}\boldsymbol{b a} \boldsymbol{a} \text {-hor-a } & \boldsymbol{b} \hat{\boldsymbol{a}}-\text { SOm- } a \\ \text { 3PL-AUX-ASP } & \text { 3PL:DEP-read-ASP }\end{array}$

'they might be reading'

(Kimenyi 1980: 9) ba-raar-a b̂a-som-a

3PL-AUX-ASP 3PL:DEP-read-ASP

'they are always reading'

(49) $\underline{\text { Gade }}$

baa cịcì, bàà sị gị́zè

3PL AUX 3PL.DEP buy yam

'they should still be buying yams'

(Sterk 1994: 18)

A combination of phonological/tonological and modal subordination patterns are seen in various Kana AVCs. For example, some categories, like the first singular subject, exist in tonally related pairs (50a), while other pairs, like the third singular subject markers, show both tonological and segmental differences (50b).

(50) a. Kana

b. Kana [Ogonoid; Nigeria]

\begin{tabular}{|c|c|c|c|c|}
\hline ḿ-sá & $\grave{\boldsymbol{m}}-d z \bar{l} g \bar{e}$ & Legbo & $e ́$-sá & $\grave{a}-l \underline{u}$ \\
\hline 1DEF-AUX & 1OPT-snatch & Legbo & 3DEF-AUX & 3.OPT-come \\
\hline $\begin{array}{l}\text { 'I may sna } \\
\text { (Ikoro } 199\end{array}$ & $\begin{array}{l}\text { tch her' } \\
6: 196)\end{array}$ & $\begin{array}{l}\text { 'Legb } \\
\text { (Ikoro }\end{array}$ & $\begin{array}{l}\text { may join us } \\
996: 196)\end{array}$ & later' \\
\hline
\end{tabular}

In Nilotic languages like Teso/Ateso, dependent subjunctive subject forms have a distinctly different shape than the nearly isofunctional indicative subject forms. 
(51) $\underline{\text { Ateso }}$
a-bu ke-ner
1-AUX.PST 1SBJNCTV-say
'I said'

(Heine and Reh 1984: 104; Hilders and Lawrance 1956: 14)

Doubly subject marked future AVCs commonly reflect modal subordination of the lexical verb in Bantu languages. Modal subordination of a lexical verb in a doubly subject marked construction is found in a future form in L34 Hemba (52) encoded by the final vowel $-e$ (subjunctive) on the lexical verb.

(52) L34 $\underline{\text { Hemba }}$

$$
\begin{array}{ll}
\text { tu-sw-a } & \text { tu-tal-e } \\
\text { 1 PL-AUX-FV } & 1 \text { PL-see-FV } \\
\text { 'we will see' } &
\end{array}
$$$$
\text { (Aksenova 1997: 34) }
$$

Infinitive marked lexical verbs with doubled subject marking may be found in individual Bantu languages such as P21 [Ci] Yao and N30 Chichewa. In other words, the lexical verbs in the AVCs share two main features of finite structures in the language, while simultaneously bearing an overt indicator of nominalization.

(53) a. Bantu P21 $\underline{\text { Yao }}$

$$
\begin{array}{ll}
\text { nge } & n \text {-gu-wona } \\
\text { NEG:1 } & 1 \text {-INF-see:FV }
\end{array}
$$

'I don't see'

(Torrend 1891: 233) b. Bantu P21 $\underline{\text { Yao }}$

$$
\begin{aligned}
& n g u \quad \text { tu-ku-wona } \\
& \text { NEG:1PL 1PL-INF-see:FV } \\
& \text { 'we don't see' }
\end{aligned}
$$

(54) Bantu N30 Chichewa

a-khala a-ku-gwir-a

3-stay 3-INF-work-FV

'he has been working ...' (Bentley and Kulemeka 2001: 33) 
Adverbial or nominalized dependency may be found in the following doubled subject construction in the Venda continuative with a dependent marked lexical verb and the final vowel $-a$.

(55) Venda [Bantu; South Africa, Zimbabwe]

vha-dzula vha-tshi-vhala

3PL-CONT 3PL-DEP-read

'they always/continously read' (Heine 1993: 38)

Note that only a percentage of doubled inflectional AVCs would ever show any kind of overt dependency morphology as only a moderate percentage of them derive historically from embedded structures. Many such doubled inflectional AVCs rather arise via a process of functional semantic specialization of serialized formations. A summary of the kinds of doubled patterns mentioned above and the languages exemplifying the sub-pattern is offered in Table-1. For a full list of doubled inflectional patterns in the African languages of my corpus see Appendix 5.

$\underline{\text { Pattern }}$

Doubled subject inflection

Doubled subject + TAM inflection

Doubled TAM inflection

Doubled subject + DEP.SUBJ.phon

Doubled subject + MOD.dep

Doubled subject + ADV/NOM.DEP
Language[s] Exemplified

Ngiti, Mbay, Babungo, Siluyana, Dyola, Yambasa

Oromo of Wellega, Siswati, Kirundi, Lungu

Ma'di

Kana, Kinyarwanda

Hemba, Kana, Tumbuza, Lungu

Venda, Yao, Chichewa

\section{Table 1: Doubled Inflectional Patterns in Select African Languages}

When viewed synchronically, it appears that a given AVC in certain languages may show variation with respect to the inflectional pattern associated with it. Thus, it is not uncommon to find variation between AUX-headed and doubled inflectional patterns in 
African languages. Historically speaking this reflects several different factors. In some instances this may be explained by particular predicates licensing complements that reflect varying degrees of finiteness. For example, Surmic Mursi allows either derived nominalized complements or semi-finite verbal complements with a modal/dependent subject marking, with one and the same predicate, both of which may enter into a grammaticalization relationship with their original attendant matrix predicate.

(56) a. Mursi [Surmic; Sudan, Ethiopia]

b. Mursi

kì-hìni wu-cen
1-want go-vN
'I want to go'

(Turton and Bender 1976: 552)

\author{
kì-hìì $\quad \boldsymbol{k u}$-curo \\ 1-want 1SBJNCTV-wash \\ 'I want to wash'
}

The Kuliak language So[o] (or Tepes) of Uganda shows roughly approximate variation to that seen in Mursi between semi-finite and infinitive complements with certain verbs.

(57)
a. So [Kuliak, Uganda]
b. $\underline{\text { So }}$
cám-I(s)a gá-ớg éù or
DES-1 go-INF home
'I want to go home'

$$
\begin{array}{lrl}
\text { cám-I(s)a } & \text { mo-gá-sa } & \text { éù } \\
\text { DES-1 } & \text { NAR-go-1 } & \text { home } \\
\text { 'I want to go home' } &
\end{array}
$$

(Heine and Reh 1984: 135)

Indeed, with some grammaticalized AVCs in a single language it is possible for the following material to constitute either an embedded verb complement sequence or a serialized structure, i.e. with a either a non-finite or finite 'complement'. Such is the case in the Bak Atlantic language Diola Fogny. According to Heine and Reh (1984) and Heine (1993) such variation reflects two different syntactic and cognitive schema that have led to this variable grammaticalization, viz. 'serial periphrasis' (yielding the doubled pattern) and 'PP-periphrasis' (yielding the AUX-headed structure). Thus, the doubled pattern may show variation with the AUX-headed pattern in an isofunctional formation using the same auxiliary verb. This is the case in the following AVC in Diola Fogny. Put differently, the lexical verb is either in a dependent-head relationship with the lexical verb (the AUXheaded pattern) or in an inflectional co-headed (or co-subordinate) relationship (the doubled pattern), (morpho)syntactically speaking, but the function of the construction remains the same. 
(58) Diola Fogny [N. Atlantic; Senegal/Gambia]
i-lakò fu-ri
or
i-lakò i-ri
1-AUX INF-eat
1-AUX 1-eat
'I was eating'
'I was eating'
(Heine 1993: 46)
(Heine 1993: 46)

In Ngambay-Moundou of the Bongo-Bagirmi family, certain positional verbs allowed complements to appear in either a quasi-finite serialized structure or a nominalized structure serving as the complement to a prepositional element. The result is the same: there appears to be isofunctional structures using the same auxiliary verb that allow either an AUX-headed or a doubled inflectional pattern.

(59) a. Ngambay-Moundou

$$
\begin{aligned}
& m \text {-îs } \quad m \text {-ús } \bar{a} \quad d \bar{a} \\
& \text { 1-AUX 1-eat meat } \\
& \text { 'I am eating meat' }
\end{aligned}
$$

c. Ngambay-Moundou

$\begin{array}{lll}m \text {-ár } & m \text {-ús } \bar{a} & d \bar{a} \\ \text { 1-AUX } & \text { 1-eat } & \text { meat }\end{array}$

'I am eating meat' b. Ngambay-Moundou

$$
m-\hat{\imath} s \bar{\imath} \quad m b \bar{a} \quad k \text {-ùsà } d \bar{a}
$$

1-AUX for NOM-eat meat

'I am eating meat'

d. Ngambay-Moundou

$$
\begin{array}{llll}
m-a ́ r & m b \bar{a} & k \text {-ùs à } & d \bar{a} \\
\text { 1-AUX } & \text { for } & \text { NOM-eat } & \text { meat }
\end{array}
$$$$
\text { 'I am eating meat' }
$$

(Heine and Reh 1984: 126; Vandame 1963: 94-96)

Another different example of this can be seen in the Shambala future, which may appear in an AUX-headed construction with an infinitive marked lexical verb, or in a doubled subject form with the lexical verb in the modally dependent $-e$ subjunctive form. Variant forms of this type with nearly the same meaning are common in Bantu languages, and often express different degrees of futurity or certainty (or pastness). 
(60) a. Shambala $(G 23)$

$\boldsymbol{n i - i n g - a} \quad \boldsymbol{k u}$-kund-a
1-FUT-FV INF-hope-FV
'I will hope'

(Aksenova 1997: 34) b. Shambala

$$
\begin{aligned}
& \text { ni-ing-a } \boldsymbol{n i - k u n d - e} \\
& \text { 1-FUT-FV 1-hope-FV } \mathbf{S B J N T C V}_{\text {SBJ }} \\
& \text { 'I will hope' }
\end{aligned}
$$

When viewed comparatively, it is sometimes the case that two Bantu languages will exhibit pattern variation in etymologically related constructions with an isofunctional auxiliary, e.g. past progressive or imperfect in 'Kafir' (Xhosa) and Tonga as reported by Torrend (1891), where the former has a split/doubled pattern (see 3.2 below) and the latter an AUX-headed one.

(61) 'Kafir'/Xhosa (S41) cf.

ba-a-li ba-lia
3PL-PST-AUX 3PL-eat:FV
'they were eating'
(Torrend 1891: 246)

(62) Tonga (S62)

ba-a-li $\quad \boldsymbol{k} \boldsymbol{u}$-lia

3PL-PST-AUX INF-eat:FV

'they were eating'

Systematic variation can be seen both across different AVCs within a single language, and across different lexically-defined sub-classes of lexical verbs with one and the same auxiliary, yielding what looks like a paradigmatic split in inflectional pattern across isofunctional (and nearly isomorphic) AVCs. Thus in Kabba, a Bongo-Bagirmi language from the Central African Republic (Moser 2005), there are two sub-classes of $k$-initial verb stems, one that loses the initial $k$ - and one that retains it when conjugated. 
(63) Kabba [C. Sudanic] paradigmatic splits

\begin{tabular}{|c|c|c|}
\hline PFV.1SG & $\frac{\text { Laugh /kòko/ }}{\boldsymbol{m} \text {-kòko }}$ & $\frac{\text { Give } / k \text {-àra/ }}{\boldsymbol{m} \text {-aro }}$ \\
\hline PFV.2SG & $\boldsymbol{e}$-kòko & $\varnothing$-arz \\
\hline PFV.3SG & ń-kòko & $n$-áro \\
\hline PFV.1PL & $\grave{n}-k o ̀ k o$ & $\boldsymbol{j}$-àro \\
\hline PFV.2PL & $\boldsymbol{e}$-kòko-je & $\varnothing$-arə-je \\
\hline PFV.3PL & ń-kòko & $\boldsymbol{d}$-árz-je \\
\hline
\end{tabular}

(Moser 2005: 281)

The perfective (63) is a straightforward simplex morphological structure in Kabba, with two mostly overlapping sets of subject prefixes found directly on the verb stem with the two conjugational classes. The imperfective and future forms are encoded through AVCs with the auxiliaries $-a w$ and $-a$ respectively. The future (64) is an AUX-headed AVC for both classes (except with $2^{\text {nd }}$ plural subjects), but the $k$ - is retained in both verbal subclasses.

(64) $\underline{\text { Kabba }}$

$\begin{array}{lll}\text { FUT.1SG } & \boldsymbol{m} \text {-á kòko } & \boldsymbol{m} \text {-á kàrə } \\ \text { FUT.2SG } & \varnothing \text {-á kòko } & \text { Ø-á kàrə } \\ \text { FUT.3SG } & \boldsymbol{n} \text {-á kòko } & \boldsymbol{n} \text {-á kàrə } \\ \text { FUT.1PL } & \boldsymbol{j} \text {-à kòko } & \boldsymbol{j} \text {-á kàr } \\ \text { FUT.2PL } & \varnothing \text {-á kòko-je } & \varnothing \text {-á kàrə-je } \\ \text { FUT.3PL } & \boldsymbol{d} \text {-á kòko } & \boldsymbol{d} \text {-á kàrə }\end{array}$

(Moser 2005: 281)

In the imperfective (65) on the other hand, the verbs that keep $k$ - throughout their paradigms, like kòko 'laugh', show a typical AUX-headed pattern in the imperfective AVC, with subject marked only on the auxiliary (except in the 2PL which is always marked by a suffix or enclitic on the lexical verb yielding what appears to be a LEX- 
headed pattern). Verbs with mobile $k$ - conversely lose the $k$ - and show a doubled subject inflectional pattern. ${ }^{14}$

(65) $\underline{\mathrm{Kabba}}$

$\begin{array}{lll}\text { IPFV.1SG } & \boldsymbol{m} \text {-aw kòko } & \boldsymbol{m} \text {-aw } \boldsymbol{m} \text {-arə } \\ \text { IPFV.2SG } & \emptyset \text {-aw kòko } & \emptyset \text {-aw Ø-arə } \\ \text { IPFV.3SG } & \boldsymbol{n} \text {-áw kòko } & \boldsymbol{n} \text {-áw } \boldsymbol{n} \text {-árə } \\ \text { IPFV.1PL } & \boldsymbol{j} \text {-àw kòko } & \boldsymbol{j} \text {-àwj-àrə } \\ \text { IPFV.2PL } & \emptyset \text {-aw kòko-je } & a w a r \partial-j e \\ \text { IPFV.3PL } & \boldsymbol{d} \text {-áw kòko } & \boldsymbol{d} \text {-áw d-ára-je }\end{array}$

(Moser 2005: 281)

These Kabba constructions are tabulated in (66).

(66) $\underline{\text { Kabba }}$

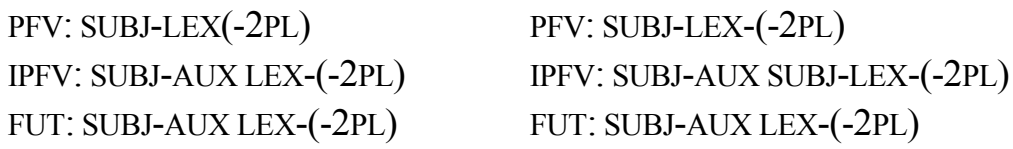

Lastly, LEX-headed AVCs may alternate with doubly inflected AVCs synchronically or may develop from such a structure over time. An example of the former type may be seen in the following Mbay formations, a Bongo-Bagirmi language of Chad, where LEXheaded inflection alternates with doubled inflection in isofunctional structures using the same auxiliary verbs.

\footnotetext{
${ }^{14}$ Note that the verb 'give' has also been grammaticalized in Kabba in numerous functions including as a benefactive voice marker. In this function, it keeps it object marking capabilities, and thus appears in a split/doubled pattern when conjugated, with the auxiliary taking subject and object marking, the lexical verb just subject alone. For more on split/doubled inflection, see 3.2.
}

(b) i. Kabba

$$
\begin{aligned}
& \text { m-ínga dèné } m \text {-ar-ć } \\
& \text { 1-find wife 1-BEN-3 } \\
& \text { 'I found a wife for him' } \\
& \text { (Moser 2005: 285) }
\end{aligned}
$$

ii. Kabba

$$
\begin{aligned}
& \grave{n} \text {-gáji } \dot{\partial} r \quad j \text {-àr } r \text {-ć } \\
& \text { 1PL-crush stone 1PL-BEN-3 } \\
& \text { 'we crush stone for him' } \\
& \text { (Moser 2005: 286) }
\end{aligned}
$$


(67) Mbay (C. Sudanic, Chad)

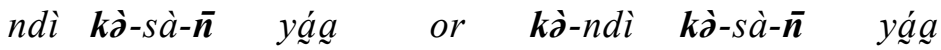

AUX 1PL-eat-PL food 1PL-AUX 1PL-eat-PL food

'we are/were eating' (Keegan 1997: 69)

$\underline{\text { Pattern Variation }}$

Doubled subject $\sim$ AUX-headed [+INF]

Doubled subject $\sim$ LEX-headed
Language[s]

Diola Fogny, Shambala,

Kabba IPFV

'Kafir' vs. Tonga

Mbay

\section{Table 2: Variation with Doubled Inflectional Patterns}

2.2 Dependent marked auxiliary verbs. Although it is not common, due to the range of structures that may give rise to (mainly doubly inflected) AVCs in such African language families as Bantu (and a small range of other, non-African languages such as Mbyá Guarani (Dooley 1990)), ${ }^{15}$ there are a small number of AVCs in which there are dependent-marked auxiliary verbs, particularly with the doubled inflectional pattern. Examples of originally dependent-marked auxiliary verbs in an AVC in a Bantu language can be seen in F21 Sukuma and possibly S32 N. Sotho and E22 Haya as well. In

\footnotetext{
${ }^{15}$ An example of Mbya Guarani form is offered in (c) below, where the auxiliary verb is dependent marked as a serialized verb, meaning it is dependent on the preceding (lexical) verb:

(c) Mbya Guaraní [Tupi-Guaraní; Paraguay, Brazil]
}

ha'e rire je o-arõ o-kua-py
ANAPH after HEARSAY 3-wait 3-AUX.PL-SERIALIZED
'after that they all waited for him'

(Dooley 1990: 479) 
Sukuma, originally subjunctive forms of auxiliary verbs are found grammaticalized in a doubly subject marked future progressive construction.

(68) Bantu F21 Sukuma

$$
\begin{aligned}
& d v-\beta i i z-\boldsymbol{e} \quad d v-l_{I I-g o ́ l a} \\
& \text { 1PL-AUX-FV } \mathbf{S B J N C T V}_{\text {SBN }} \text { 1PL-TA-buy:FV } \\
& \text { 'we'll be buying' (Nurse 2008: 299) }
\end{aligned}
$$

Bantu S32 Northern Sotho (Sepedi) has dependent marked auxiliaries in the future perfect and past perfect forms.

(69) a. Bantu S32 N. Sotho

$$
\begin{array}{ll}
r e-\varnothing-b-e & r e-\varnothing \text {-rek-ile } \\
1 \text { PL-TA-AUX-FV } & \text { 1PL-TA-buy-FV } \\
\text { 'we had bought' } &
\end{array}
$$

b. Bantu S32 N. Sotho

$$
\begin{array}{ll}
\text { re-tlo- } b-\boldsymbol{e} & \text { re- } \varnothing \text {-rek-ile } \\
\text { 1 PL-FUT-AUX-FV } & \text { 1PL-TA-buy-FV } \\
\text { 'we will have bought' } & \text { (Nurse 2008: 157) }
\end{array}
$$

In the Bantu E22 Haya negative future perfect, the negative-marked auxiliary verb appears in the subjunctive (possibly co-negative) form.

(70) Bantu E22 Haya

$$
\begin{array}{ll}
\text { ti-tuu- } b \text {-é } & t w \text {-áá-guz-ire } \\
\text { NEG-1PL-AUX } & \\
\text { 'we will not have bought yet' } & \text { (Nurse 2008: 201) }
\end{array}
$$


Dependent marked auxiliaries are not widely attested among the languages of the world, but the above mentioned African forms are not unique. ${ }^{16}$ Overall however, given that auxiliaries tend to be the syntactic head of their constructions, it is safe to say that dependent marked auxiliaries are fairly uncommon cross-linguistically as a whole. A special investigation of these unusual formations remains a goal of future research.

\section{Split and Split-Doubled Inflection}

3.1 True Split Patterns. The AUX-headed (and LEX-headed) and doubled patterns are relatively easy to explain if one assumes that there is a morphosyntactic head-dependency relation between the lexical verb and auxiliary verb (however formalized or construed). Up to this point in the discussion this has been called the inflectional head, with it and its

${ }^{16}$ A perhaps even clearer example of a dependent marked co-negative auxiliary verb in an AVC may be seen in Oromo varieties, for example in the following formations in Harar Oromo (d), where the co-negative suffix on the inflectional head, here the auxiliary verb in this AUX-headed construction is clearly the same as the dependent verb marker $-u$, seen in (e).

(d) i. Harar Oromo (Cushitic; Ethiopia)

inníi déem-úu-ti $n$-jirr-u

he go-VN-TI NEG-AUX.PRS.PROG.M-DEP

'he is not going' (Owens 1985: 73)

ii. Harar Oromo
isii-n déem-úu-f hin-jirat-t-u
she-NOM go-VN-DAT NEG-AUX.PRS.PROG.F-F-DEP
'she will not be going' (Owens 1985: 73)

(e) i. Harar Oromo

ii. $\underline{\text { Harar Oromo }}$

$\begin{array}{ll}\text { ha d'úf-u } u & \text { isii-n nama xan béet-t-u sún arkite } \\ \text { JUSSIVE come-DEP } & \text { she-NOM personas know-F-DEP that saw:F:PST } \\ \text { 'let him come' } & \text { 'she saw the person whom she knows' } \\ \text { (Owens 1985: 79) } & \text { (Owens 1985: 86) }\end{array}$

Oromo of Wellega has similar structures in the negative with a dependent co-negative form on the auxiliary verb (see (16)). 
dependents largely conceived of (if not actually explicitly formalized as such) in a configuration roughly analogous to the head-dependent relation(s) that exists between auxiliary and lexical verb elements syntactically. The inflectional head has been argued to be the auxiliary in the AUX-headed AVC (and the lexical verb in the LEX-headed one). On the other hand, there appears to be some kind of conjunct-headed or flat-branching structure necessary to explain the feature sharing that exists in the doubled pattern.

While a discrete notion of inflectional head would therefore be theoretically appealing, given the scalar characteristics of most if not all features of AVCs, it is perhaps not a great shock that the absolute discreteness of the 'inflectional head' is not supported. Indeed, while so far I have only presented constructions that behave in a quasi-well-formed manner in order to elucidate the autonomous nature of inflectional/functional semantic, syntactic and lexical semantic features of AVCs, this was done in anticipation of examining even more complex phenomena that various African languages offer. With this in mind, I now turn to a presentation of some data that do not behave in a pre-theoretically predicted manner, but nevertheless remain consistent across several languages, as well as reflect demonstrable trends with respect to their diachronic sources, and with parallels to languages outside of Africa as well.

In the split inflectional pattern (Anderson 1999, 2000, 2006), the verbal inflections that are obligatory to render the form morphosyntactically well-formed, i.e. the encoding of functional semantic properties in these constructions-the criteria that serve as the basis for determining the inflectional head-are split between the lexical verb and the auxiliary verb. That is, some functional categories are encoded only on the lexical verb, others only on the auxiliary verb. When there are two completely distributionally distinct sets of categories/formal markers, then true split systems are found. More frequently however, there is partial overlap, such that some categories show truly split distribution and others show doubled patterning. True split inflectional patterns are not overly common in AVCs in African languages, but the split/doubled systems, where some categories are limited to either the lexical verb or the auxiliary verb, while others appear with both verbs simultaneously, occur relatively more frequently in African languages than elsewhere (see 3.2 below).

Cross-linguistically, perhaps the most common split inflectional patterns attested in AVCs is one in which the morphological index of object appears with the lexical verb component while that for the subject appears with the auxiliary verb. There are a small number of West African languages that exhibit this split inflectional pattern in AVCs:
(71) Split Construction-1:
Subject+Auxiliary Verb
Object+Lexical Verb 
These languages include the Ogonoid Cross River language Eleme and its close sister language Kana, and Bolanci of the Chadic family. Note that the syntactic/phrasal order is that of auxiliary followed by lexical verb in these constructions (as typically characterizes AVCs in these languages).

(72) Eleme

غ̀bai $r \varepsilon$-do-do-rõ né-e ìs $\tilde{a}$

$1 \mathrm{pl}$ 1PL-REDPL-AUX.PRS-APPL give-3sg book

'we are still giving him books' (Field Notes)

(73) $\underline{\text { Kana }}$ (Cross-River/Ogonoid; Nigeria)

$\boldsymbol{m}$-wèè $\overline{\boldsymbol{a}}-k \bar{u} \bar{e}$
1-PST 2-call
'I called you' (Ikoro 1996)

(74) Bolanci (Western Chadic, Nigeria)

'n-jii 'unda-kó

1-AUX call-2OBJ

'I call you' (Lukas 1971: 128)

The formal realization of the pattern is identical in Eleme and Bolanci, and different in Kana, a distribution which suggests separate independent developments in the two Ogonoid Cross River languages. It is clear that these two seemingly similar developments reflect rather heterogeneous origins. In Eleme, the distribution follows from the syntactic structure of the source constructions, which probably reflects the grammaticalization of an original nuclear serialized formation with an intransitive $V_{1}$ and a transitive $V_{2}$ (see 4.2 below), while in Kana, the particular realization of the elements appears to be morphophonologically motivated: the object-encoding elements are clitics that target that position, not the lexical verb per se, as the following example shows: 
(75) $\underline{\text { Kana }}$

$$
\begin{aligned}
& \boldsymbol{m} \text {-wēè } \overline{\boldsymbol{a}} \text {-dáb mùc̀ } \\
& \text { 1-PST 2-MOD see } \\
& \text { 'I was able to see you' (Ikoro 1996) }
\end{aligned}
$$

This complex auxiliary structure (a past capabilitive) is of the shape SUBJ-AuxV $V_{1}$ OBJ$A u x V_{2}$ LexV, with the subject appearing as an initial proclitic and the object as a second position proclitic on the second auxiliary. Thus, although Eleme and Kana share structures that show a[n apparent] split distribution in certain auxiliary structures, only Eleme reflects a split structure motivated by the morphosyntactic structure of the original source (serialization) formation, while Kana reflects the particular prosodo-phonological properties of the argument encoding elements themselves. Chadic Bolanci likely reflects the similar macro-areal trends as does Eleme in the development of such a split structure.

(76) Kana

$$
\text { Subject-AV Object-[L]V }
$$

(77) Eleme

$$
\text { Subject-AV LV-Object }
$$

(78) Bolanci

$$
\text { Subject-AV LV-Object }
$$

Another common split system in AVCs involves the marking of negation. Various Afroasiatic languages of 'Ethiopia' (see 11 below) show a range of split systems with respect to the distribution of negative inflection in AVCs. For example, in Omotic Gimira negative/dependent-marked lexical verbs appear followed by a tense- and subject-marked auxiliary (in two different AVCs), while in Cushitic Harar Oromo a negative- and tensemarked lexical verb is followed by a subject-encoding auxiliary.

(79) Gimira (Benchnon)

$$
\begin{aligned}
& \mathrm{ta}^{1} n a^{3} \mathrm{ha}^{4} \mathrm{mar}^{4} \mathrm{gu} \mathrm{u}^{3} \quad y i \mathrm{~s}^{3} \mathrm{tu}^{2} e^{3} \\
& \text { I } \text { go:NEG.PRTCPL AUX:PST:1 } \\
& \text { 'I had not gone' (Breeze 1990: 32) }
\end{aligned}
$$


(80) Harar Oromo

xaléesá hin-déem-ne ture

yesterday NEG-go-PST AUX:1

'I didn't go yesterday' (Owens 1985: 74)

(81) Gimira

(82) Harar Oromo
LV-NEG

NEG-LV-TENSE
AV-TENSE/SUBJ

AV-SUBJ

Note that the syntactic/phrasal order of elements is V Aux here, as is typical of languages of the macro-Ethiopia region.

Another split system that is idiosyncractic to a particular African language is one attested in the Leko-Nimbari language Doyayo. Here lexical verbs encode tense/aspect categories but other inflectional categories appear with the auxiliary verb.

(83) Doyayo

$$
\begin{aligned}
& m i^{3} g i^{2}-s-i-g \quad k a a ́-k o ́ \\
& \text { I AUX-BEN-EPN-3 weep-PRS } \\
& \text { 'I'm crying to him' (Wiering and Wiering 1994: 75) }
\end{aligned}
$$

3.2 Split/Doubled Patterns. As mentioned in section 2 above, by far the most common doubled inflectional pattern seen in AVCs in African languages (and cross-linguistically) is one with doubled subject marking. Perhaps then it should come as no surprise that the category that is typically doubled in split/doubled inflectional patterns in AVCs is also the subject. In fact, the most common split/doubled patterns differ from corresponding split inflectional patterns by the doubling of the subject. Thus, one relatively common split/doubled pattern consists of one in which the subject appears doubled, but object is encoded only on the lexical verb which subcategorizes for it.

(84) Split/Doubled Construction 1: SUBJ-AV SUBJ-LV-OBJ

For example, examine the following construction from Doyayo. 
(85) Doyayo

$\boldsymbol{h i ^ { 1 }} \quad d a^{3} \quad \boldsymbol{h i} \quad t a a^{3}-b \boldsymbol{e}^{1}$

3PL POT 3PL shoot-1

'they might shoot me' or 'I might get shot'

(Wiering and Wiering 1994: 222)

Although phonologically quasi-independent (Elders 2004), the subject marker appears both before the auxiliary verb and the lexical verb in these Doyayo sentences, while the (perhaps) bound object marker occurs only with the lexical verb that subcategorizes for it.

Bantu Lamba shows a variant of this pattern in the following AVC, with the object prefix only encoded on the lexical verb, but with doubled subject and tense marking.

(86) Split/Doubled Construction: SUBJ-TA-AV SUBJ-TA-OBJ-LV

(87) M54 Lamba

$\boldsymbol{n}-\overline{\boldsymbol{a}}-\mathrm{li} \quad \boldsymbol{n}-\overline{\boldsymbol{a}}-\boldsymbol{m u}$-wona lēlo
1-PST-AUX 1-PST-3-see:FV today
'I have seen him today' (Botne 1986: 307; Doke 1938: 305)

Its sister language Kuri[y]a shows yet another slight variant on this basic split/doubled inflectional theme. In the following construction, both the lexical verb and the auxiliary appear in the $-e$ subjunctive form (i.e. in a co-headed or co-subordinate relationship), with doubled subject marking, the auxiliary encoding tense and the lexical verb indexing the grammatical object.

(88) Kuriya variant: Subject-Tense-AV-e Subject-Object-LV-e

(89) $\underline{\text { Kuri[y]a }}$ (E43)

$$
\begin{aligned}
& n e=\boldsymbol{n}-\mathrm{ra}-\mathrm{c}-e^{n-b a-h-e} \text { etara } \\
& \text { this }=\mathbf{1} \text {-FUT-AUX-FV } \text { SB,NCTV }_{\text {1-3PL-give-FV }} \text { SB,INCTV lamp } \\
& \text { 'I will give them the lamp' (Aksenova 1997: 20) }
\end{aligned}
$$

Another split/doubled pattern attested in a range of AVCs across various African languages is one in which the subject appears doubled, tense on the auxiliary, but 
negative is found only on the lexical verb. This is thus much like the form found in Gimira above, only with doubled subject marking. Such a formation is found in the following Swahili and Ejagham AVCs. Note that the lexical verb appears in the conegative $-i$ form in Swahili. For more on negation in Bantu see Kamba Muzenga (1981, 2005), Maho (2007) or Güldemann (1999). ${ }^{17}$

(90) Split/Doubled Construction 2: Subj-TAM-AV Neg-Subj-LV-CONEG

(91) Swahili (G42)

$$
\begin{array}{ll}
\text { tu-li-kuwa } \quad \text { ha-tu-fany- } i \\
\text { 1PL-*AUX>TA-INF:AUX } & \text { NEG-1PL-do-NEG } \\
\text { 'we weren't doing anything' (Aksenova 1997: 21) }
\end{array}
$$

Ogbronuagum (Bukuma) and Ibibio of Nigeria conversely show constructions with a negative on the auxiliary verb but doubled subject marking in the following manner:

(92) Split/Doubled Construction 2B: Subj-Neg-AV Subj-LV

(93) Ogbronuagum (Bukuma)

$$
\begin{array}{ll}
\text { n-ń-née } & \text { o-yíle } \\
\text { 1-FUt.NEG-AUX:1:NEG } & \text { 1-do } \\
\text { 'I can't do (it)' (Kari 2000: 40) }
\end{array}
$$

(94) Ibibio

$$
\begin{array}{llll}
\text { Udèmé } & \boldsymbol{i} \text {-kí-tóoñoké } \quad \text { i-táñ ikộ ǹté ábooñ } \\
\text { Udeme } & \text { CNC-PST-start:NEG } & \text { CNC-talk word like chief } \\
\text { 'Udeme didn't start to talk like a chief' (Essien 1987: 154) }
\end{array}
$$

In the past progressive in the Bantu language Hemba, tense is found on the auxiliary, but subject is doubly marked in various AVCs. Note that this construction differs from the

\footnotetext{
${ }^{17}$ There is also of course systematic difference in the templatic position of negative marking on verbs in numerous Bantu languages between main and subordinate clauses.
} 
doubled inflectional pattern seen in the future in Hemba mentioned in (52) above, where the lexical verb rather appears in the marked modal $-e$ final vowel form.

(95) Hemba: Subj-TAM-AV Subj-LV[- $a]$

(96) $\underline{\text { Hemba }}$ [Bantu]

$$
\begin{aligned}
& \text { tw-a-li } \quad \boldsymbol{t u}-t i b-a \quad \text { muti } \\
& \text { 1PL-TNS-AUX 1PL-cut-FV tree } \\
& \text { 'we were cutting the tree' (Aksenova 1997: 27) }
\end{aligned}
$$

Another complex split/doubled pattern that is slightly different from the Hemba one above is found in the Bantu language Nkore-Kiga (Nyankore) of Uganda. Here subject is doubled as is common in Bantu AVCs and remote past tense is encoded on the auxiliary, but progressive aspect is marked on the lexical verb. This kind of split with tense marked on the auxiliary verb and aspect on the lexical verb is very common in Bantu languages (Nurse 2008).

(97) Nkore-Kiga Past Progressive: Subj-Rem.Pst-AV Prog-Subj-LV[-a]

(98) Nkore-Kiga

$\begin{array}{ll}\boldsymbol{n} \text {-ka-ba } & \boldsymbol{n} \boldsymbol{i} \text {-n-teera enanga } \\ \text { 1-REM.PST-AUX } & \text { PROG-1-play:FV organ }\end{array}$

'I was playing the organ' (Taylor 1985: 161)

In the Ekoid Bantu language Ejagham, the durative is encoded by doubled subject marking with the lexical verb appearing in the 'imperfective' - $a$ form, presumably related to the 'indicative' or 'neutral' final vowel of Narrow Bantu languages mentioned numerous times throughout this presentation with respect to the form of lexical verbs in various Bantu AVCs (Nurse 2007a, 2007b, 2008). This could therefore either be considered a doubled subject inflectional pattern (perhaps at least historically) or a split/doubled one. 
(99) Ejagham (Ekoid Bantu)

à-nyánè à-chòr-á

3SG.PFV-AUX 3SG.PFV-speak-IPFV

'she is still talking' (Watters 2000: 196)

Two different split/doubled patterns may be found in AVCs in Bantu languages involving doubled subject marking and a lexical verb in the -ile perfect form. The two types differ as to the locus of tense inflection. In one type, found in the Xhosa AVC listed in (100), the tense marking is found on the auxiliary-the typical Bantu distribution. In the other type, represented by the Ciyao AVC given in (101), the lexical verb also bears the tense prefixes.

(100) Xhosa (Bantu; South Africa)

nd-a-ye ndi-theth-ile

1SG-TA-AUX 1SG-speak-PRF

'I had spoken (long ago)' (Heine 1993: 108)

(101) Ciyao

ngá-li juvávééceeté sooní pélé-po tu-li tw-a-más-ilé

not-AUX REL:3:speak:ASP again that.time 1PL-AUX 1PL-PST-finish-ASP

góná

sleep

'no one spoke again, that was after we had gone to sleep'

(Botne 1986: 305; Whiteley 1966: 214)

(102) Xhosa: SUBJ-TAM-AV SUBJ-LV-ile $e_{\text {PRF }>}$

(103) Ciyao: SUBJ-AV SUBJ-TAM-LV-ile $e_{<\mathrm{PRF}>}$ 
Note that the -ile 'perfect' (Berger 1938, Voeltz 1980) is here considered to represent a type of 'final-vowel marking', as it appears in the so-called final vowel position of lexical verbs in Bantu auxiliary structures. ${ }^{18}$

Lexical verbs may of course also be marked as dependent in a split/doubled inflectional AVC, much as they may be in other inflectional patterns; this reflects the syntactic headedness of the auxiliary in the construction, despite the split characteristics of it morphosyntactically. That is, although not the sole inflectional (or morphosyntactic) head of the construction, the auxiliary verb in the following Kemantney formation retains its status as syntactic head, and licenses a dependent form of the lexical verb component of the AVC in an adverbially dependent gerund form, e.g., is of the form in (104a):

(104) a. LEX-SUBJ-GER AUX-SUBJ-TAM

(104) b. Kemantney (Qemant)



$$
\begin{aligned}
& \text { you sell-2-GER AUX-2-PST } \\
& \text { 'you had sold' (Leyew 2003: 194) }
\end{aligned}
$$

In Afar, lexical verbs appear in a modally subordinate form with doubled subject marking and aspectual marking on the auxiliary (105a).

$$
\text { a. SUBJ-LEX-DEP<-SBNCTV> AUX-SUBJ-ASP }
$$

(105) b. Afar

$\boldsymbol{t}$ - ' $^{\prime}$ am- $\boldsymbol{u} \quad$ way-'t-a
2-eat-SBJNCTV AUX-2-IMPF
'you are about to eat'

(Bliese 1976: 147) c. $\underline{\text { Afar }}$

$$
\begin{aligned}
& \text { 'gen-n-u way- 'n-a } \\
& \text { go-1PL-SBJNCTV AUX-1PL-IMPF } \\
& \text { 'we are about to go' }
\end{aligned}
$$

\footnotetext{
${ }^{18}$ The last traditional position in the Bantu verbal complex is sometimes called the final vowel [FV]; this delineates the right edge of the inflectional stem. Sometimes these vowels have particular aspectual and/or modal properties in individual Bantu languages, and possibly Proto-Bantu as well (Nurse 2007a, 2007b, 2008). This FV position interacts with elements at the TA position and with auxiliary structures in particular, so is of particular relevance to our discussion.
} 
Auxiliary verb constructions of the split/doubled inflectional type may also appear with dependent marked lexical verbs in Bantu languages. As mentioned above, in Kinyarwanda, the negative future progressive has a negative dependent form of the lexical verb with doubled subject marking.

(106) a. SUBJ-TAM-AUX

SUBJ-NEG.DEP-LEX: $a$

(106) b. Kinyarwanda

$$
\begin{aligned}
& \text { ábáana ba-zaa-ba ba-da-sóm-a } \\
& \text { children 3PL-FUT-AUX } \\
& \text { 3PL-NEG.DEP-read-FV } \\
& \text { 'the children won't be reading' (Kimenyi 1979: 189) }
\end{aligned}
$$

Finally, Eleme has several AVCs in which a lexical verb may be marked by the general 'adverbial' subordination or dependency marker $e$ - in split/doubled formations, with doubled subject, applicative marked only on the auxiliary and object marked on the lexical verb.

(107) a. SUBJ $_{\triangle \mathrm{NUMB}>}-\mathrm{AUX}-[2 \mathrm{PL}]-\mathrm{APPL} \quad$ DEP-LEX-SUBJ

(107) b. Eleme

$\grave{o}-d o-i-r u \tilde{u}$

e-gbòi-i

$\grave{\varepsilon} t \int \tilde{u}$

2-be.PRS-2PL-APPL DEP-stitch-2PL clothes

'you are stitching clothes (for someone)' (Bond 2006)

c. Eleme

ò-bo-í-ru e-ma:-i àdádżi j̀ncne

2-should-2PL-APPL DEP-bring-2PL Adaji gift

'you should bring Adaji a gift' (Bond 2006) 


\section{d. Eleme}

òbàù bo-r-e-nć-í-e ǹs ã

2PL should-APPL-DEP-give-2PL-3SG book

'you should give him a book' (Bond 2006)

A range of different conjugations in Eleme show a curious systematic split between inflection with second plural subjects, where subject person is marked as a prefix on the auxiliary, but subject person/number and aspect is encoded by a suffix on the lexical verb, and a pattern found with third plural subjects where subject person is marked by a prefix on the auxiliary but subject person/number as a suffix on the auxiliary verb, and aspect is marked by a suffix on the lexical verb as usual. For more on these formations, see Bond $(2006,2010)$.

(108) a. Eleme

$\grave{o}$-bere $\quad k \varepsilon$-á-í

2-PRF slaughter-HAB-2PL goat

'you used to slaughter goats'

(Bond 2006) b. Eleme

$$
\begin{aligned}
& \text { è-bere-rí } k \varepsilon \text {-á } \\
& \text { 3-PRF-3PL slaughter-HAB goat } \\
& \text { 'they used to slaughter goats' }
\end{aligned}
$$

For a full list of split and split/doubled inflectional patterns in AVCs in the African languages of my corpus, see Appendix 6.

\section{Sources for AVCs in African Languages}

In section 4 I present the left edge of the grammaticalization continuum for AVCs (109):

(109) lexical verb $[+$ syntagm $]>$ auxiliary verb $[+$ lexical verb $]>\ldots$.

This left edge concerns two aspects of the development of AVCs, namely functional semantic specialization and syntactic shift from embedded/complement, serialized or clause-chained constructions into mono-clausal AVCs. I sketch the semantic developments of AVCs in 4.1, and I exemplify the types of syntactic constructional sources for AVCs in African languages and the sub-types of inflectional patterns these each typically yield in 4.2 . 


\subsection{Common source-target lexical > functional semantic specialization in AVCs.} Auxiliary verb constructions derive from other complex structures through the specialization of originally content verbal semantics into the expression of functional or grammatical categories. The processes of semantic specialization that accompany grammaticalization in African languages have been examined in a range of studies by Bernd Heine (1991, 1994) and his colleagues (e.g. Heine and Reh 1984, Heine, Claudi and Hünnemeyer 1991, Heine 1993) and grammaticalization issues also feature in works by such Africanists as Arnold (1981), Botne (1986, 1990, 1993, 1999, 2003a, 2003b, 2006), Nsuka Nkutsi (1986), Emanation (1992), Miehe (1992), Creissels (1998a/b, 2000, 2002, 2003, et al. 2008), Güldemann (1996, 1998, 1999, 2003, 2005 2010b), and Ameka (2005) and in general works on the development of tense/aspect systems as well (e.g., Bybee and Dahl 1989, Bybee et al. 1991, Harris and Campbell 1995, etc.). The semantic developments of a number of auxiliary structures in African languages are discussed and exemplified extensively in many of these works, and the interested reader is referred to them for more details than can be offered here.

Although the mechanisms of metaphorical extension that occur in the process of auxiliation (Kuteva 2001, Sweetser 1988) are complex and often show the confluence of several independent factors, some generalizations about the development of lexical verbal semantics to functional semantics can be made. Certain source-target semantic correlations are particularly common in African languages, e.g. motion semantics yielding future tense (deriving from 'go' and 'come'). Furthermore, functional paths of 'regrammaticalization' or 'further grammaticalization', that is, the shift into other functional domains of constructions already having functional properties, may be seen in closely related varieties of particular African languages, for example i) in the developments attested across Somali varieties which derive from 'keep', viz., first to durative in Dabarro Somali and Mudung Somali, to progressive in (the dialect forming the basis of) Standard Somali and finally to present in Jiddu Somali, or ii) the shifts from verb focus $>$ progressive $>$ general present $>$ non-past characteristic of various Bantu languages exemplified below $<$ ('be at') and in 6.1 (see also Güldemann 2003).

With respect to languages of Africa, I have (non-exhaustively) listed some of the more common of these developments from content $>$ functional semantics (or source $>$ target semantics) in AVCs in Table 3 below. 
Table 3

\begin{tabular}{|c|c|c|}
\hline$\underline{\text { SOURCE }}$ & TARGET & LANGUAGE[S] \\
\hline ABANDON & Terminative & Kxoe \\
\hline ARRIVE & Ability & Koranko \\
\hline $\mathrm{BE}$ & Progressive & Mamvu, Nkonya, Somali \\
\hline BEGIN & Inceptive & Lingala \\
\hline BRING & Future & Nandi \\
\hline \multirow[t]{5}{*}{ COME } & Future & Lotuko, Pare, Luguru, Lango, So, Kru lgs \\
\hline & Potential & Doyayo \\
\hline & Perfect & Teso \\
\hline & Habitual & Ndebele \\
\hline & Passive & Maasai \\
\hline COME.FROM & Near Past & Jiddu, Teso, Sotho, Klao \\
\hline \multirow[t]{2}{*}{ COME.TO } & Proximative & Tchien Krahn ['almost'] \\
\hline & Unaccomplished & Swahili \\
\hline Copula + LOC & Progressive & $\begin{array}{l}\text { Tyurama, Godié, Maninka, Egyptian } \\
\text { Arabic, Lingala and many Bantu languages }\end{array}$ \\
\hline DO/MAKE & Causative & Lendu, Moru \\
\hline FAIL.TO & Negative & Somali \\
\hline FALL & Passive & Tonga \\
\hline FINISH & Completive & Engenni, Mambila \\
\hline GET & Perfect & Twi \\
\hline \multirow[t]{2}{*}{ GIVE } & Applicative & Efik, Kxoe \\
\hline & Causative & Luo \\
\hline \multirow[t]{3}{*}{$\mathrm{GO}$} & Progressive & Xhosa, Ewe \\
\hline & Perfect & Doyayo, Ciyao \\
\hline & Future & Bari, Sotho, Lele, Tonga, Kru languages \\
\hline \multirow[t]{4}{*}{ KEEP } & Continuative & Waata Oromo \\
\hline & Progressive & Standard Somali \\
\hline & Present & Jiddu Somali \\
\hline & Durative & Dabarro Somali, Mudung Somali \\
\hline KNOW & Habitual & Moré \\
\hline \multirow[t]{3}{*}{ LEAVE } & Completive & Kxoe, Nama \\
\hline & Egressive & Lingala ['stop'] \\
\hline & Progressive & Kirma \\
\hline LIE & Durative & Beja \\
\hline
\end{tabular}




$\begin{array}{lll}\text { LIVE/STAY } & \begin{array}{l}\text { Progressive } \\ \text { Durative }\end{array} & \text { Kisi, Chadian Arabic } \\ & \text { Labitual } & \text { Benin Ewe, Nkore-Kiga } \\ \text { REMAIN } & \text { Durative } & \text { Kxoe } \\ & \text { Progressive } & \text { Kikongo } \\ & \text { Habitual } & \text { Ewe } \\ & \text { Probable Future } & \text { Oromo of Wellega (+NEG) } \\ \text { RETURN } & \text { Iterative } & \text { Sotho } \\ \text { SAY } & \text { Future } & \text { Beja } \\ \text { SIT } & \text { Progressive } & \text { Diola Fogny, Mamvu, Kxoe, Umbundu, } \\ & & \text { Mbodomo } \\ & \text { Habitual } & \text { Kanakuru, Shona }\end{array}$

Table 3: Common source-target pairs in African AVCs

Some sample forms reflecting these source $>$ target combinations are offered below.

\section{'come'}

As is obvious from the above list, one particularly salient and common verb used as an auxiliary in African languages, more common even than it is in other areas of the world, where it is still fairly common, is the deictic motion verb 'come'. Typically this is grammaticalized to encode a future function. This is found in languages across many genetic units and areas. Thus one finds 'come' as a source for futures in such a diverse array of languages as Shatt Daju (110) or the Nilotic languages Lango (111) and Lotuko (112), plus Kru languages, not exemplified here.

(110) a. Shatt Daju

$$
\begin{array}{llll}
\text { agönay } & a-w u \eta & a-s i-e \quad \text { iya } \\
\text { I } & \text { 1.INDEF-AUX 1.DEF-eat-e meat } \\
\text { 'I shall eat meat' (Tucker and Bryan 1966: 240) }
\end{array}
$$


b. Shatt Daju

$$
\begin{array}{lll}
\text { agönay } & a-w u \eta \quad k a-s i \\
\text { I } & 1 . I N D E F-a u x & 1 . D E F-e a t \\
\text { 'I shall have eaten meat' (Tucker and Bryan 1966: 240) }
\end{array}
$$

(111) Lango

dákô bíno $\quad$ nénô
woman 3:AUX:HAB see:INF
'the woman will see' (Noonan 1992: 126)

(112) Lotuko

$$
\begin{aligned}
& \text { a-ttu ni letcn } \\
& \text { 1-FUT I go:INF } \\
& \text { 'I'll leave immediately' } \\
& \text { (Heine and Reh 1984: 132; Muratori 1938: 161ff.) }
\end{aligned}
$$

A future marker deriving from 'come' is also attested in a number of central African Bantu languages like G22 Pare (113), G35 Luguru (114) or J60/D61 Kinyarwanda (115); see 6 for more on the future in Bantu.

\section{(113) G22 Pare}

$n i-z a-e t-a$

1-FUT-bring-FV

'I will bring (it)'

(Botne 1990: 191; Nurse 1979a, 1979b)

\section{(114) G35 Luguru}

$$
\text { tu-tso-yul-a }
$$$$
\text { 1PL-FUT-buy-FV }
$$

'we will buy'
(115) a. Kinyarwanda

$$
\begin{aligned}
& \text { a-za gu-kora } \\
& \text { 1-FUT INF-work } \\
& \text { 'he will work (later today)' } \\
& \text { (Botne 1990: 190; Hurel 1911) } \\
& \text { a-za-kora } \\
& \text { 1-FUT-work } \\
& \text { 'he will work (after today)' }
\end{aligned}
$$

\section{b. Kinyarwanda}


'Come' as a source for the grammaticalization of future tense is also a characteristic feature of the Bongo-Bagirmi language Fer (Kara) of Central African Republic (116).

(116) Fer [Kara]
$\dot{m} \bar{i} \quad k \grave{l}^{\prime} \quad \grave{s} \quad \dot{n}^{*}$
I AUX:1 INF:come with him
'I will come with him' (Boyeldieu 1987: 73)

In the following sentences from the Kuliak language So[o] (Tepes), multiple uses of the verb 'come' in both lexicalized and grammaticalized functions are seen. The stem ác retains its lexical meaning 'come' in the first form in (117). In the second sentence it rather shows two different grammaticalized uses. One is as an auxiliary encoding future tense in an AUX V configuration. Its second function in the So form below is a common target for grammaticalization of an originally serialized use of 'come' to mark ventive action that is also found in a number of other African languages (e.g., Tama or Pero), realized in So as a suffix synchronically.

(117) $\underline{\text { So }}$

$$
\begin{array}{lrl}
\text { ác-ìsa } & >\text { ác-ísa } & \text { gúg-ác } \\
\text { come-1 } & \text { FUT-1 } & \text { transfer-VENT } \\
\text { 'I come' } & \text { 'I shall buy' (Heine and Reh 1984: 39) }
\end{array}
$$

West African languages also make use of 'come' as a future marker. It has become a future affix synchronically in the Kwa language Ewe, but remains a freestanding auxiliary in a similar function in Manding.

(118) Ewe

ye-á-vá

3-FUT-come

'he will come' (Heine and Reh 1984: 38) á FUT < vá 'come' 
(119) $\underline{\text { Manding }}$

sísanán bénà kúma bàna dówere kàn
jetzt 1PL FUT reden Krankheit andere PP
'jetzt werden wir über eine Krankheit sprechen'

(Tröbs 2009: 47; Dumestre 2003: 207) bénà <-nà 'come'

Constructions with 'come' may be grammaticalized into a wide range of other functions when looking across the broad spectrum of African language. One such function is the marker of prospective tense/aspect, i.e., 'be about to X'. Such a construction with doubled inflection involves the auxiliary 'come' in this function in Biu-Mandara Chadic Muyang of Cameroon.

(120) Muyang

$$
\begin{aligned}
& \dot{a}-r(\bar{a}) \quad \dot{a} \text {-ż̀m } \quad \text { उ̧ām } \\
& \text { 3-AUX } \quad 3 \text {-eat } \quad \text { thing } \\
& \text { 'he's about to eat something' (Smith 2010: 103) }
\end{aligned}
$$

A similar function in a LEX-headed structure is found in Khwe in an atypical (for Khwe) AUX V configuration, presumably deriving from $\mathrm{V}_{1}$ of a nuclear serial structure (see 4.2 below).

(121) Khwe

$$
\begin{aligned}
& n \mid \tilde{l}\left\|^{\|}\right\| \text {c̀c-khòè-hè } y \grave{a} \quad \| \text { 'ó-à-tè } \\
& \text { DEM female-person-3SG.F come die-I-PRS } \\
& \text { 'this woman is about to die' }
\end{aligned}
$$$$
\text { (Aikhenvald 2006: 8; Killian-Hatz 2006: 117) }
$$

As future represents a kind of quasi-modal-cum-tense category, perhaps it is not surprising then that individual African languages have also grammaticalized modal constructions that use the auxiliary 'come'. Thus a potential mood is created by an AVC that derives from 'come' in Doyayo of Cameroon (exemplified in 82 above). In the Òkó language of Nigeria, a type of deontic modal form is attested using the auxiliary verb 'come' in the following example: 
(122) Òkó

$$
\begin{aligned}
& b e-k e ̀-c a \quad b e-y o \\
& \text { 3PL-ASP-come 3PL-go } \\
& \text { 'they should leave' (Akerejola 2008: 177) }
\end{aligned}
$$

Perfect and past forms are also potential targets for a grammaticalized AVC using the auxiliary verb 'come' in various African languages. Indeed, 'come' may yield perfect forms in languages closely related to ones where 'come' has been grammaticalized as a future. Thus in East Nilotic [A]Teso 'come' has yielded a perfect or past tense formation (51), repeated here as (123), while in its close sister language Lotuko it has a future function, see (112) above.

(122) $[\underline{\mathrm{A}] T \text { Teso }}$

$\begin{array}{ll}\boldsymbol{a} \text {-bu } & k e-n e r \\ \text { 1-AUX.PST } & \text { 1SBJNCTV-say } \\ \text { 'I said' } & \end{array}$

(Heine and Reh 1984: 104; Hilders and Lawrance 1956: 14)

Similarly, an AVC with the auxiliary verb 'come' has developed into a bound perfect suffix form in Bambara (124). Note that the cognate auxiliary became rather a marker of future in its sister language Manding (119):

(124) $\underline{\text { Bambara }}$

$\begin{array}{ll}\text { fúrakcla } & n \grave{a}-n a \quad \text { só } \\ \text { Heilkundiger } & \text { kommen-PFV Haus }\end{array}$

'Der Heilkundige kam nach Hause' (Tröbs 2009: 216)

Other functions of 'come' can be found in Table-3.

\section{'go'/ 'leave'}

The paired verb of 'come', viz. 'go' (also in the form of 'leave') has similarly been grammaticalized in a range of functions across various African languages. Like 'come', 
one common function of AVCs involving 'go' is to create future formations. This may have a simple future meaning or an immediate or intentional future meaning (much like English 'I am going to stay'). In the role of a simple future, 'go' is found for example in Kara of the Bongo-Bagirmi family and in the Surmic language Murle of Sudan and Ethiopia.

(125) $\underline{\text { Kara }}$

$$
\begin{aligned}
& \text { ma'ba ko } \\
& \text { 1-AUX cultivate } \\
& \text { 'I will cultivate' (Santandrea 1970: 156) }
\end{aligned}
$$

(126) a. Murle

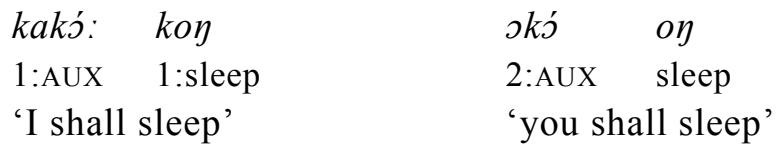

b. Murle

(Tucker and Bryan 1966: 384)

The Ju language !Xun of the Angola/Namibia/Botswana border region shows a similar grammaticalization of a verb meaning 'go' into a future function.

(127) a. ! Xun

$\dot{u}+\bar{a} \quad$ go + relational $>\quad o ́-a ́ \quad$ FUT

(König and Heine 2001: 28)

b. $\underline{\text { Xun }}$

ha má $n \|$ |an óá $g \mid \grave{e}$

CLS1 TOP later FUT come

'he'll come later' (König and Heine 2001: 34)

A final example of a simple future function associated with the auxiliary 'go' can be found in the Kado languages Krongo and Katcha of Sudan, both within AUX-headed configurations. 
(128) Krongo

$m$-ákká $\quad k$-áadìyà

3F-FUT.AUX INF:LOC-come

'she will come' (Reh 1985: 188)

(129) $\underline{\text { Katcha }}$
$n-a r-a a \quad \underline{t}-\rho \varepsilon$
1/2-FUT-1 INF-drink
'I shall drink' (Tucker and Bryan 1966: 309)

The immediate future functions of AVCs involving the verb 'go' can be found in a range of languages as well. Thus, the Maban language Masalit of Chad and Sudan reflects this immediate future function of 'go' in the following split/doubled AVC:

(130) $\underline{\text { Masalit }}$

$$
\begin{aligned}
& \text { g-oosiy } \quad \text { - } a y-\varepsilon \\
& \text { 2-know:BASE.II 2-go-PRS } \\
& \text { 'you are going to know' (Edgar 1989: 23) }
\end{aligned}
$$

Gula Zara is another language of central Africa that show a very similar functional realization of AVCs with 'go' in an immediate or intentional future function, though in both of these languages the AVC is of the familiar AUX-headed type.

\section{(131) Gula Zura}

$$
\begin{array}{ll}
m a ́-n \bar{a} ' & k \bar{s} \quad c a ́ \\
\text { 1-AUX } & \text { INF:eat thing } \\
\text { 'I am going to eat' } & \text { 'I will eat' } \\
\text { (Nougayrol 1999: 129) } &
\end{array}
$$

Future is perhaps the most common or frequent meaning but not the only function associated with the use of this verb as an auxiliary. Like 'come', 'go' may also be used in the function of perfect marker, as in the following sentence from Doyayo: 
(132) Doyayo

$$
\begin{aligned}
& b e^{l} \quad r e^{3} \quad b e^{l} \quad t s^{4} m s^{l} \quad g s^{l} \quad y a^{4} \\
& 1 \text { go } 1 \text { devour-2 ANAPH Q } \\
& \text { 'would I then eat you up?' (Wiering and Wiering 1994: 217) }
\end{aligned}
$$

Finally, using an auxiliary originally meaning 'leave', the Gur language Kirma has developed an AVC with a progressive function.

\section{(133) $\underline{\text { Kirma }}$}

$$
\begin{aligned}
& \text { mi ta mi wo } \\
& 1 \text { AUX } 1 \text { eat } \\
& \text { 'I am eating' (Heine and Reh 1984: 117; Prost 1964: 56) }
\end{aligned}
$$

For other functions of 'go' see Table 3.

'be'

Another cross-linguistically common auxiliary verb that is certainly well-represented among the languages of Africa is the verb 'be'. Its most typical grammaticalized function is one in an AVC expressing progressive. ${ }^{19}$ A split-inflected negative progressive formation with 'be' can be considered a family level feature of the Rashad Kordofanian genetic unit, attested in Rashad, Tagoi, and Tumale.

(134) Rashad

$$
\begin{aligned}
& \text { yifas k-eyc } y \text {-cn } \\
& \text { I meat NEG-eat 1-AUX } \\
& \text { 'I am not eating meat' } \\
& \text { (Tucker and Bryan 1966: 297) }
\end{aligned}
$$

\footnotetext{
19 ' $\mathrm{Be}$ ' + a locative is the most typical path for progressives in Africa as elsewhere. Some of these 'be' forms here might well be better interpreted as 'be at' or 'be' + LOC formations which are presented separately in brief below.
} 
(135) Tagoi

$$
\begin{aligned}
& \text { yigIn yifi k-eyak } \quad y \text { - } \varepsilon n \\
& \text { I meat NEG-eat } 1 \text {-AUX } \\
& \text { 'I am not eating meat' (Tucker and Bryan 1966: 297) }
\end{aligned}
$$

(136) Tumale

$$
\begin{aligned}
& \text { ygi } \quad \text {-alma } \quad \text {-en } \\
& \text { I NEG-gather 1-AUX } \\
& \text { 'I am not eating meat' (Tucker and Bryan 1966: 297) }
\end{aligned}
$$

A wide range of central and west African languages show progressive formations using the verb 'be'. Such languages include Muyang and the Sere Ubangi language Ndogo.

(137) Muyang

$$
\begin{aligned}
& \text { ţ̄-bù tá-rā } \\
& \text { 3PL-AUX 3PL-come } \\
& \text { 'they are coming' (Smith 2010: 103) }
\end{aligned}
$$

(138) $\underline{N d o g o}[\mathrm{ndz}]$

yí kú zoo

3 PROG eat:V.LNGTH

'he is eating' (Santandrea 1961:26)

Note that these each show a different inflectional pattern, despite showing similar functional semantics and source verbs: Muyang (137) has a doubled pattern, Ndogo (138) shows an AUX-headed structure, while Mamvu in (139) below, a language of the Mangbutu-Efe genetic unit of Democratic Republic of Congo, on the other hand reflects a LEX-headed formation. 
(139) $\underline{\mathrm{Mamvu}}$

$$
\begin{aligned}
& \text { òro' } m a{ }^{\prime}<\text { *òro-ná ma } \\
& \text { go:1 AUX }
\end{aligned}
$$

'I am going'

(Heine and Reh 1984: 126; Vorbichler 1971: 248-50)

Donno So Dogon has a similar progressive formation. Note that the negative shows variation between an AUX-headed formation like the corresponding positive form (140), or has variable split negative marking (141) similar to the forms in Rashad Kordofanian above. Nevertheless, regardless of where the negative marker is realized, the lexical verb appears in the dependent $-u$ form in this Donno So formation:

\section{(140) Donno So Dogon}

$$
\begin{aligned}
& g \varepsilon n d \varepsilon-u \quad w \supset-m \\
& \text { regarder-DEP } \quad \text { AUX-1 } \\
& \text { 'je suis là regardant' (Prost 1969a: 78) }
\end{aligned}
$$

(141) a. Donno So Dogon

$$
\begin{array}{lll}
g \varepsilon n d \varepsilon-u \quad \text { wo-lo- } m \sim & g \varepsilon n d \varepsilon-l \varepsilon-u & \text { wo- } m \\
\text { regarder-DEPAUX-NEG-1 } & \text { regarder-NEG-DEP } & \text { AUX-1 } \\
\text { 'je ne suis pas regardant' } & \text { (Prost 1969a: 78) }
\end{array}
$$

Other West African languages show progressive formations that also derive from an auxililary verb 'be', e.g. the Gur language Tyurama.

(142) Tyurama (Gur)

me na me wu
I AUX I eat
'I am eating',

(Heine and Reh 1984: 117; Prost 1964: 103; 105)

Probably the next most common function of 'be' as an auxiliary verb, if that is what one should properly call such a formation, is as a dummy stem that serves as anchor for 
expressing obligatorily encoded formally realized grammatical categories. This may be used to express past or present tense, subject, etc. in a range of different languages. Thus a 'dummy' use of 'be' may stand at the origin of the following construction in Sese Gumuz.

\section{(143) Sese Gumuz}

amam gàc'ay bàgà mara biid biimbaya
they before people many 3PL:AUX 3PL:always.dancing
'in former times many people used to dance' (Uzar 1989: 378)

In Orig of the Rashad Kordofanian family and in Tira of Heiban Kordofanian, the verb 'be' seems to serve as a means for encoding tense in the case of Orig, or as an anchor for the noun class 'agreement' marker in Tira.

(144) a. Orig

tùgán $\quad k$-àyá $\quad \eta$-cn
he NEG-drink $\quad 3$-AUX.PRS
'he does not drink'
(Schadeberg and Elias 1979: 52)

b. Orig

$\begin{array}{lll}\text { tùgán } & k \text {-àyá } & \text { Írìn } \\ \text { he } & \text { NEG-dance } & \text { AUX.PST } \\ \text { 'he did not drink' } & \end{array}$

Note that in Tira the AVC has been fused into a complex verb form, while the formation in Orig remains a free-standing bi-partite auxiliary construction.

(145) a. Tira

ì g-a-ya-nóna

1.DEF CLSFR.SG-ASP-2OBJ-See:INDEF

'I see you'

(Stevenson 2009: 35) [NB: INDEF > S-O-V] b. Tira

ay $\quad g-a-\eta i-n \supset n a$

2.DEF CLSFR.SG-ASP-1OBJ-See:INDEF

'you see me'

Other 'dummy' uses of 'be' within larger structures to serve as anchors for obligatory inflectional material are found in Masalit, where tense is encoded on the auxiliary, but subject is doubly encoded in a split/doubled construction: 
(146) a. Masalit

$$
\begin{aligned}
& \text { g-oos-o } \quad j \text {-iy- } \varepsilon \\
& \text { 2-know-PRTCPL 2-be-PRS } \\
& \text { 'you knew' }
\end{aligned}
$$

(Edgar 1989: 29) b. Masalit

$$
\begin{aligned}
& \text { g-oos-gede } \quad j \text {-iy- } \varepsilon \\
& \text { 2-know-NEG } \quad \text { 2-be-PRS } \\
& \text { 'you didn't know' }
\end{aligned}
$$

In Igboid Echie of Nigeria on the other hand, the auxiliary 'be' encodes all the obligatory grammatical elements in an AUX-headed configuration (with a phonologically 'dependent' marked lexical verb).

(147) Echie

$$
\begin{array}{lll}
\grave{j} \text {-dì-Ì } & \text { zà:a } & \text { vl̀̀ } \\
\text { 3-AUX-NEG } & \text { sweep:Ovs house } \\
\text { 's/he did not sweep the house' }
\end{array}
$$

(Ndimele 2003: 51)

Other functions are attested with grammaticalized uses of 'be', such as future tense in the Yulu language of the Bongo-Bagirmi family. This has been fused together with the subject pronoun yielding what appears to be a tense-encoding pronoun synchronically in the language; for more on these important and characteristically African structures see sections 5 and 12 below).

(148) $\underline{\text { Yulu }}$

ma $l \varepsilon^{\prime} \varepsilon$

1:FUT INF:go

'I shall go' (Santandrea 1970: 25)

Of course on occasion other functional semantics are yielded when a construction involving the (locational) verb 'be' is used when examining all African languages. Thus in the unclassified Shabo language, a perfect form of this auxiliary verb has developed a past tense function in complex AVCs. 
(149) $\underline{\text { Shabo }}$

debe-k am-kus
3.PRF $>$ PST come-PRS.PRF
'he has come' (Teferra 1991: 382)

In the function of a perfect, 'be' has also been grammaticalized in the Cushitic language Alaaba. However, this element has been further incorporated into the verbal complex as a verbal suffix synchronically, yielding a complex verb form of the following type:

(150) $\underline{\text { Alaaba }}$

Pán(i) t’iz-zhóom(i)

1SG:NOM become.sick-1SG:PRF

'I am sick' (Schneider-Blum 2009: 65) /-yóom-/ <be>

\section{'be.LOC' > progressive > present}

As mentioned above, a locational component combined with 'be' typically lies at the heart of progressive formations in African languages. Indeed, some of the examples above might upon further investigation to properly belong to this subtype of 'be.LOC'derived auxiliary formations. In the southern African language łHoan, either a member of the Ju family or an unclassified/isolate language, the progressive marker derives from the locational copula 'be (in)':

(151) $¥ \underline{\text { Hoan }}$

$$
\begin{aligned}
& m a \text { 'a tsi tcon-!ka'e ci kyeama-qa } \\
& \text { I PROG see people } \quad \text { POSs dog-PL } \\
& \text { 'I see the people's dogs' (Collins 1998: 19) }
\end{aligned}
$$

In Kresh, subject and auxiliary 'be.at' have fused into a single element, which functions as a progressive formation in the language, when combined with a dependent marked lexical verb in an AUX-headed structure. 
(152) $\underline{\text { Kresh }}$

$$
\begin{aligned}
& \check{a} \quad \text { lówó } \quad n \hat{I} \\
& \text { AUX.3 [DER:]walk the } \\
& \text { 'he is/was walking' (Brown 1991: 338) }
\end{aligned}
$$

As is frequently the case with progressive formations, this construction appears to be developing a general present meaning as well in Kresh.

(153) $\underline{\text { Kresh }}$

$\check{a} \quad(y) \tilde{s}$ shó $\eta b \tilde{a} y \tilde{a} \quad(n \hat{I})$

AUX.3 DER:eat maize the

'they are eating maize' or 'they eat maize' (Brown 1991: 338)

Ewe is another language which derives a progressive from a locational 'be.at' verb in combination with an explicit locative marker. Thus, in the following sentence, the auxiliary - le 'be.at' combines with the dependent 'progressive' marker $\dot{m}$ that derives from a locative marker in *me. This exemplifies what Heine and Reh (1984) and Heine (1993) call the nominal periphrasis channel of the grammaticalization of auxiliary verb constructions.

(154) Ewe

$$
\begin{aligned}
& \text { me-le } \quad n \dot{u} \quad d u-\dot{m} \\
& \text { 1-AUX.INCOMPL thing eat-PROG } \\
& \text { 'I am eating' (Heine and Reh 1984: 38) }
\end{aligned}
$$

The Chadic language Buduma shows another structure that clearly reflects this locative formation with the verbal noun form of the lexical verb accompanied by the preposition 'at':

(155) Buduma

a-kol a jai-ni

3.PRS-be at seat-VN

'he is/was sitting' (Pawlak 2001: 376; Lukas 1939: 55) 
The progressive formation in Maninka has an explicit locative marking on the lexical verb formally realized as a postposition.

(156) Maninka

a yé nà lá

he AUX come at

'he is coming' (Heine and Reh 1984: 123)

Lastly, the Bantu language Umbundu likewise reflects the use of 'be' grammaticalized in a construction expressing progressive semantics, not using a locational element, but rather an assocative preposition 'with' instead; see (10) above for an example.

\section{The positional verbs 'sit' and 'stand'}

The positional verbs 'sit' and 'stand' (as well as 'lie' not explicitly examined here) are also not infrequently grammaticalized within AVCs in African languages (see also Newman (ed.) 2002). An auxiliary verb construction with 'sit' has developed into a progressive formation in Gula Méré. Note that this has been grammaticalized within two different inflectional patterns in Gula Méré, either in a doubled inflectional pattern (157), or in an AUX-headed one (158):

(157) Gula Méré

má-ndá $m$-úsā nj̀
1-AUX 1-eat thing
'I am eating'

(Nougayrol 1999: 137)
(158) Gula Méré

$$
\begin{aligned}
& \text { má-ndá kūsá nj̀ } \\
& \text { 1-AUX INF:eat thing } \\
& \text { 'I am eating' }
\end{aligned}
$$

Shatt Daju also uses a construction involving the verb 'sit' to encode progressive functional semantics. Similar to the first Gula Méré form, this is embedded within a doubled inflectional pattern in Shatt Daju. 
(159) Shatt Daju

$$
\begin{aligned}
& \text { agönay } a-n j-u \quad \text { a-si-e iya } \\
& \text { I } \quad 1 . I N D E F-A U X-u \\
& \text { 'I am eating meat' } \\
& \text { (Tucker and Bryan 1966: } 240 \text { ) }
\end{aligned}
$$

The Bantu language Umbundu has a formation using 'sit' in the function of a progressive in an AUX-headed configuration using 'with' before the dependent-marked lexical verb.

(160) $\underline{\text { Umbundu }}$

$$
\begin{aligned}
& \text { wa-kala l' oku-papala } \\
& \text { 3-AUX with INF-play } \\
& \text { 'he was playing' } \\
& \text { (Heine and Reh 1984: 125; Valente 1964: 281) }
\end{aligned}
$$

Progressive is not the only function found with grammaticalized uses of 'sit' in African languages. Thus the irrealis marker in Goemai of Nigeria derives from 'sit':

(161) Goemai

$$
\begin{array}{llll}
\text { t'ong } & j i \quad k a t & a & \text { mmoe } \\
\text { IRR } & \text { SG.M.LOG find } & \text { FOC } & \text { what }
\end{array}
$$

'what would he find?'

(Hellwig 2006: 105)

Similar to 'sit', 'stand' not infrequently has been grammaticalized in constructions that encode progressive semantics. Such a formation underlies the progressive in the following variant sentences from Ngambay-Moundou. Note that this AVC is variably either doubly inflected or in an AUX-headed configuration. 
(162) a. Ngambay-Moundou

$\begin{array}{llllll}m \text {-ár } & m \text {-ús } \bar{a} \quad d \bar{a} & m \text {-ár } & m b \bar{a} & k \text {-ùsà } & d \bar{a} \\ \text { 1-AUX 1-eat meat } & 1-\mathrm{AUX} & \text { for } & \text { NOM-eat } & \text { meat } \\ \text { 'I am eating meat' } & & & & \end{array}$

b. Ngambay-Moundou

(Heine and Reh 1984: 126; Vandame 1963: 94-96)

According to Killian-Hatz (2008), the present tense suffix -tè (163) in Khwe derives from t $\varepsilon$ 'stand, stay'. As mentioned above, it is common for present tense markers to derive from progressive formations cross-linguistically (Bybee et al. 1994), African languages being no exception in this regard. The use of this element in Khwe likewise speaks to its possible original function as a progressive marker (164).

(163) Modern Khwe

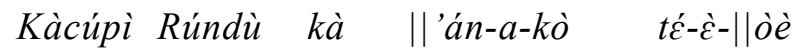

$\mathrm{K} \quad \mathrm{R}$ LOC live-DEP.II-CV be-DEP.I-HAB

'Kacupi lives in Rundu'

(Killian-Hatz 2008: 50)

(164) Modern Khwe

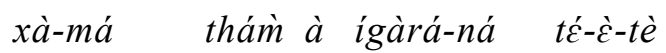

DEM-3M letter O write-DEP.II stay-DEP.I-PRS

'he is writing a letter'

(Killian-Hatz 2008: 305)

\section{'stay'/'remain'}

The use of the verb meaning 'stay' or 'remain' in the function of a continuous or durative or progressive is relatively widespread among African languages. Such a formation with 'remain' is at the heart of the continuous element in Kxoe (Khwe). 
(165) $\underline{\text { Kxoe }}$

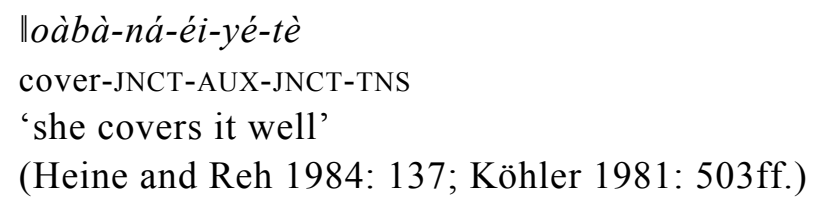

The auxiliary verb 'stay' has been grammaticalized within constructions to mark continuous or progressive action in Kunama as well. Note that this appears in a synchronic bi-partite AUX-headed AVC in Kunama with one class of verbs (represented by 'go', (166)), but appears in a doubly inflected form with others (represented by 'tell', (167)).

(166) a. Kunama

b. Kunama

\begin{tabular}{|c|c|c|c|}
\hline$g a-n$ & go-na-no & $g a-n$ & $g o-n a-k i$ \\
\hline go-DEP & AUX-1-PRS & go-DEP & AUX-1-AC \\
\hline 'I am g & $\begin{array}{l}\text { ng' } \\
\text { nd Brv }\end{array}$ & 'I was $g$ & oing' \\
\hline
\end{tabular}

(167) a. Kunama

b. Kunama

na-sasa go-na-no

na-sasa go-na-ki

1-tell AUX-1-PRS

1-tell AUX-1-AOR

'I am telling'

'I was telling'

(Tucker and Bryan 1966: 344)

Sandawe shows a functionally similar construction to mark progressive that derives from a verb meaning 'stay'.

(168) a. Sandawe




b. Sandawe

$t^{h} \hat{a}-s \grave{a} \quad i e ́-\sim '$
run-3FSG.RLS.PGN AUX-CNNCTV
'she is running'
(Eaton 2003: ex. 13)

Kolokuma Ijo presents a last example of the grammaticalized use of a verb meaning (at least in part) 'stay' to function as a progressive marker.

(169) Kolokuma Ijo

$$
\begin{aligned}
& \text { a bó-a timi-mi } \\
& \text { she come-NEG AUX.CONT-PST } \\
& \text { 'she was not coming' } \\
& \text { (Williamson 1965: 74-75) }
\end{aligned}
$$

Note that progressive/continuous semantics are not the only developments possible from a construction that involves a verb meaning 'stay' etymologically. Thus the habitual suffix in Standard Ewe derives from such a verb.

(170) Standard Ewe

$$
\begin{aligned}
& \text { me-yí-na } \\
& \text { 1-go-HAB } \\
& \text { 'I habitually go' } \\
& \text { (Heine and Reh 1984: 119) }
\end{aligned}
$$

\section{'do'/'make'}

The verb meaning 'do' or 'make' is also not uncommonly used as an auxiliary in African languages. The functional semantics it encodes varies significantly across the different languages. Thus in \|Ani of the Khoe family, it appears to have been grammaticalized as a prospective tense/aspect marker: 
(171) ЏAni
tá-khòè ||ga-khòè ||'ó-|xغ̀ hìn-à-tà
old-person FEM-person die-INT PROSP-II-PST
'the old woman was about to die'
(Heine 1999: 22)

In Temein on the other hand, its function is more like a type of intentional future:

(172) Temein

$$
\begin{aligned}
& \text { ya-m-a ya-lam ntct isaatın } \\
& \text { 1-AUX-FIN 1-eat.DEP meat tomorrow } \\
& \text { 'I am going to eat meat tomorrow' } \\
& \text { (Tucker and Bryan 1966: 259) }
\end{aligned}
$$

In Otoro belonging to the Heiban Kordofanian genetic unit, an auxiliary meaning 'do' is used in a complex AVC with a negative auxiliary to mark unaccomplished but expected action:

(173) Otoro

$\begin{array}{llc}l i-j i & l i-m i r \varepsilon & l \text {-ate } \\ \text { CLSFR.PL-people } & \text { CLSFR.PL-AUX.DEP.ASP CLSFR.PL-NEG.AUX } \\ & n \\ \text { li-ma-rithe } & n \\ \text { CLSFR.PL-PRF-dance.DEP.ASP CONEG }\end{array}$

'people have not yet danced' (Stevenson 2009: 258)

In languages of the Sahara region (see section 13), light verb formations are relatively common. ${ }^{20}$ Unsurprisingly, some languages of this region use 'do' as the inflectable light verb stem. One such language is the Maban language Aiki (aka Runga):

\footnotetext{
${ }^{20}$ See Schultze-Berndt (2006) for a different view on the nature of what are here called 'light' verbs.
} 
(174) Aiki [Runga]

$$
\begin{aligned}
& \text { àndèi tèné cákám mbá-t-áry-è } \\
& \text { goat he to.sell 2-3-AUX-ASSRTV } \\
& \text { 'he sold you his goat' (Nougayrol 1989: 57) }
\end{aligned}
$$

\section{'want'}

Another relatively common verb grammaticalized within AVCs in African languages is 'want'. This verb typically expresses one of three categories in African languages: prospective tense/aspect, future tense, or necessitative mood. In a prospective tense/aspect function, 'want' is used in such languages as \|Ani.

(175) a. $\underline{\text { Ani }}$

$$
\begin{aligned}
& \text { tá-khòè ||ga-khòè ||'ó-|xغ̀ ka-ra-tà } \\
& \text { old-person FEM-person die-INT PROSP-II-PST } \\
& \text { 'the old woman was about to die' (Heine 1999: 21) }
\end{aligned}
$$

b. $\Perp$ Ani



$$
\begin{aligned}
& \text { DEM-M:SG tree-M:SG fall-INT PROSP-PRS }
\end{aligned}
$$

'that tree is about to fall' (Heine 1999: 21)

In Lango a functionally similar form is attested (176). Note that the verb 'want' may also appear in a complement-taking structure that maintains its lexical meaning in Lango as well (177).

(176) Lango

mítô ç̀m

3:AUX:HAB eat:INF

'he's about to eat'

(Noonan 1992: 139) cf. (177) Lango

ámìttò cc̀m

1 :want:PROG eat:INF

'I want to eat'

(Noonan 1992: 139) 
The necessitative modal function of an AVC using 'want' may be seen in the following Masalit formation. $^{21}$

(178) Masalit

$$
\begin{aligned}
& \text { g-oosiy-to } \quad n \text {-ind- } \varepsilon \\
& \text { 2-know.base.II-PRTCPL2-want-PRS } \\
& \text { 'you need to know' (Edgar 1989: 29) }
\end{aligned}
$$

Of course the most typical grammaticalized use of 'want' cross-linguistically is as an auxiliary to form future tenses. This is what is the source of the future prefix in S. Nilotic Nandi of Kenya.

(179) a. Nandi

$m \hat{a}-a:-k a s$

AUX-1-hear

'I will hear it'

(Creider and Tapsubei Creider 1989: 112) b. Nandi

$m \hat{a}-k e-k a s$

AUX-1PL-hear

'we will hear it' c. Nandi

$m \hat{a}-a:-k a ́ s-e ́$

AUX-1-listen-ASP

'I will be listening'

\section{'be lacking'/'be absent'}

Various African languages make use of a negative auxiliary. One relatively straightforward source for such a functional element is a verb meaning 'be lacking' or 'be absent'. This verb has been grammaticalized as a negative auxiliary in Katcha of the Kado family and Otoro of the Heiban Kordofanian family.

(180) a. Katcha

$$
\begin{array}{ll}
\text { tal-aa } & n \text {-asala } \\
\text { NEG-1 } & 1 / 2 \text {-look }
\end{array}
$$

'I do not look'

(Tucker and Bryan 1966: 310)

b. $\underline{\text { Katcha }}$

$$
\text { tal-əyっ } \quad k \text {-asili }
$$

NEG-1PL PL-dance

'we do not dance' c. Katcha

$$
\begin{aligned}
& \text { tal-syo } k \text {-ag-asili } \\
& \text { NEG-1PL PL-ASP-dance } \\
& \text { 'we did not dance' }
\end{aligned}
$$

\footnotetext{
${ }^{21}$ The extension of 'want' to 'need' here is so minimal that one may argue that this is in fact not really an example of an AVC, but an idiomatic use of this verb in its lexical function.
} 
(181) $\underline{\text { Otoro }}$
yigw-ate gwu-dhiro no
1 CLSFR.SG-NEG.AUX CLSFR.SG-sleep CONEG
'I do/did not sleep (Stevenson 2009: 239)

'say'

The last verb I address in brief here is the characteristically African use of a[n auxiliary or light] verb whose etymological meaning is 'say'. In a large part of northern and eastern Africa, 'say' has taken on a central role in the verbal grammar (e.g., Cyffer 1991, Cohen et al. 2002). In some it serves as a type of light verb base to make inflectable verbs. In part this was motivated historically by the preponderance of ideophones in the languages, and the straighforward use of a light verb meaning 'say' with such forms. However, many ideophones have become lexicalized to express basic verb stems that one might not expect ideophones to express like 'go' or 'see' in some of these languages. In Saharan languages like Kanuri, most verbs inflect by an inflected form of 'say' fused into a larger verbal complex.

(182) a. $\underline{\text { Kanuri }}$

$$
\begin{aligned}
& \text { /lè-n-k-ìn/ } \rightarrow \text { léngîn } \\
& \text { go-say-1-IMPF } \\
& \text { 'I am going/will go/go' } \\
& \text { (Hutchison 1981: 90) }
\end{aligned}
$$

b. $\underline{\text { Kanuri }}$

$$
\begin{aligned}
& \text { /lè-s-n-ìn/ } \rightarrow \text { lèjîn } \\
& \text { go-3-say-IMPF } \\
& \text { 'she is going/will go/goes' }
\end{aligned}
$$

(183) a. Kanuri

$$
\begin{aligned}
& \text { lè-n-ganà } \\
& \text { go-say-1:PRF } \\
& \text { 'I have gone' } \\
& \text { (Hutchison 1981: 120) } \\
& \text { lè-n-gí }
\end{aligned}
$$

c. $\underline{\text { Kanuri }}$
b. Kanuri$$
l \grave{e}-n-g \hat{e}-n y i
$$$$
\text { go-say-1:PRF-NEG }
$$

'I have not gone'

Its sister languages like Zaghawa show similar formations; see Cyffer (1991) for more details on the history of 'say' as a light verb in Saharan verbal diachrony. 
(184) Zaghawa

$$
\begin{aligned}
& \text { nó:-gêe-n-Í } \\
& \text { see-3PL-AUX-TA } \\
& \text { 'they see' (Cyffer 1991: 81) }
\end{aligned}
$$

Other languages show use of 'say' as a common inflectable verb stem, e.g. Nera of Eritrea.

(185) $\underline{\text { Nera }}$

$$
\begin{aligned}
& \text { kal-nu wa:l-n-ay-t-o } \\
& \text { eat-GER AUX-GER-AUX-PST-3 } \\
& \text { 'he was eating' (Thompson 1976a: 489) }
\end{aligned}
$$

Cushitic languages like Beja and Bilin show formations that are quite similar to the Saharan family forms structurally. In Bilin, like Kanuri and Zaghawa, the forms have been univerbated into large complexes.

(186) a. Bilin

wǔh-jăkwn
shout-say:1:PRS
'I shout'

(Böhm 1983: 42) b. Bilin

wǔh-jĭrăkw

shout-say:2:PRS

'you shout'

Dongolese Nubian is like Bilin and the Saharan languages, with a large fused complex, the last portion of which etymologically is an inflected form of 'say'.

(187) Dongolese Nubian

ingu fadl-ếran

these stay-say:3PL.IMPF

'these are staying'

(Cohen et al. 2002: 241; Armbruster 1960: 246) 
Tama actually reflects both patterns, one where 'say' maintains its phonological wordhood (Type-A) and one where it is fused into a larger complex. In Tama the first type seems to be used with synchronically identifiable ideophones like wut 'fall' (cf. English 'thud') while the second type seems to be used with inflectable stems, and possibly developed on analogy with the ideophonic formation. The result is that the former structure reflects an AUX-headed pattern (188), while the latter one represents a fused doubled pattern (189).

(188) $\underline{\text { Tama }}$

ànáá-tá wút nú-クó

down-LOC fall 1SG:say-PRF

'I fell down to the ground' (Dimmendaal 2009a: 314)

(189) Tama

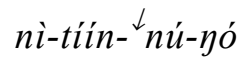

1SG-dream-1SG:Say-PRF

'I dreamed' (Dimmendaal 2009a: 314)

Note that the use of 'say' as an auxiliary is not restricted to northern and eastern African languages, but may also be found in southern African Bantu languages like Shona, here with a doubled subject pattern.

(190) Shona

$\begin{array}{llll}\text { wa-ti } \quad \text { wa-mbo-enda } & \text { ku-Ingirandi } & \text { here } \\ \text { 2SG:PRF-AUX } & \text { 2SG.DEP.ANT-at.first-go } & \text { LOC-England } & \mathrm{Q} \\ \text { 'have you ever (yet) been to England } & & \\ \text { (Güldemann 2002: 263; Dale 1972: 77) }\end{array}$

For more on use of $t i$ as an auxiliary in such Bantu languages as Tumbuka, and the types of structures this auxiliary is embedded within typically in Bantu languages, see 6 below. 
4.2 Constructional sources for AVCs in African languages. As alluded to throughout the preceding sections, two of the basic sources for AVCs in African languages (and cross-linguistically for that matter) are i) verb complement structures, in which case one speaks of a diachronic process of clausal union as these were originally bi-clausal formations, with two events, two propositions, etc., and ii) serial verb constructions (SVC), in which (for some such SVCs), the component sequential elements are considered parts of a semantic event whole, and thus not individuated propositionally. Givón (2009) has called these the only two constructional sources for the range of complex predicate types that I have been here calling AVCs. However, at least one other constructional source type exists for AVCs. This reflects what has been called the clause chaining construction (Anderson 2006). The difference among all three of these constructional source pools for AVCs lies in the nature of the relationship between the two original verbal elements that yield the grammaticalized construction.

In embedded or complement structures, there is a syntactic head-dependency relation between the two clauses in a complex structure, i.e. one verb/clause is subordinate and often non-finite or semi-finite, or at least in some way marked to indicate that it somehow relatively lower in (scalar) finiteness or in a dependency (or c-command) relationship with the original complement-taking head (now auxiliary) verb.

In serialized structures, notions such as co-headedness or co-subordination or pseudocomplementation have been offered to hold for the relationship between $V_{1}$ and $V_{2}$ in (different sub-types of) serialized structures, if this latter concept can even be adequately defined cross-linguistically; see Bisang (1995), Bril (2004), Senft (2004), Crowley (2002), Aikhenvald (1999) Aikhenvald and Dixon (2006) for various somewhat recent perspectives. The elements have equal syntactic status even if prosodically or inflectionally one of the verbs in a serialized structure, often referred to as $\mathrm{V}_{1}$ or $\mathrm{V}_{2}$, has more prominence or 'head' status.

In clause-chained formations, the verbs specialized as lexical verbs in AVCs (or indeed auxiliaries in some languages) are marked as coordinate. Based on these two 'features', finiteness and coordinatedness, we can distinguish the three major constructional input sources for the complex predicate structures here called AVCs.

Source Construction Type

Serial Verb Construction [SVC]

Verb Complement Construction [VCC]

Clause-Chaining Construction [CCC]
Features of $* \mathrm{~V}_{1 / 2} \geq \mathrm{AV}$

+ finite, (-coordinate)

-finite, (-coordinate)

+coordinate, $( \pm$ finite $)$ 
4.2.1 Serialized Structures. I assume in the following presentation, as indeed much current research on verb serialization does, that there are several broadly definable patterns of the [epi]phenomenon known as verb serialization that for which, at least for the sake of descriptive convenience and consistency, I use here the following terms primarily derived from the Role and Reference Grammar based literature (e.g. Van Valin and LaPolla (2000)) on SVCs: nuclear serialization, core serialization, same subject serialization, switch subject serialization, and ambient serialization. Although I do not assume the formalism or even certain of the basic tenets of that particular framework of syntactic analysis, it turns out that these labels show significant correlation to the various inflectional types of auxiliary verb constructions that result from SVCs.

Anderson (2006: 303-304) defines various serialized verb construction categories as follows:

nuclear serialization:

Difficult to distinguish from verb compounding.

Tight bond between $V_{1}$ and $V_{2}$.

Aspectual categories belong to this layer

(Foley and Olson 1985).

core serialization:

Elements may intervene between $\mathrm{V}_{1}$ and $\mathrm{V}_{2}$.

Argument categories belong to core layer of clause.

same subject:

When $V_{1}$ and $V_{2}$ share the same subject in a serialized formation

switch subject:

Usually involves an intransitive and transitive verb, with subject of one being the object of the other (e.g., hit die $>$ kill), but refers to any serialized formation in which there is no subject co-reference.

ambient serialization:

When no argument is shared between $\mathrm{V}_{1}$ and $\mathrm{V}_{2}$.

Expresses 'generalized states' (Crowley 2002).

May have 'clausal' subject marking. 
Note that it is not always a priori clear what constitutes a serial verb construction (cf. Lord 1993, Aikhenvald 1999, Aikhenvald 2006) in a given language or much less across all African languages viewed comparatively, just as auxiliary verb constructions cannot be identified as discrete entities per se. Indeed, given the processes by which one verbverb sequence slides into another from a functional perspective, a certain amount of ambiguity is possible if not expected with respect to any given formation or sets of formations in a particular language or group of language (this is also true for example with AVCs arising from embedded or complement structures, as with certain newly emergent AVCs in English). Thus, one researcher may consider a particular verb-verb combination an SVC and another may call a similar or identical form an AVC based upon arbitrarily assigned subjective criteria. However, as a verb in a serial verb constuction specializes and assumes the role of encoding functional categories (e.g. encoding TAM categories), some ambiguity will be present, with both constructional interpretations possible in certain individual instances in association with a given formation. ${ }^{22}$ To be sure, this is to be expected. ${ }^{23}$ As Kuteva (2001: 138) states:

each link of the grammaticalization chain represents a stage of the auxiliation process, where the preceding and the succeeding functions, and their respective linguistic expressions, coexist side by side. Thus there is an intermediate stage of overlapping marked by semantic ambiguity, formal ambiguity, or both.

Note that Lord (1993) recognizes both verbal and nominal paths of development for SVCs in African languages. One example of the latter (nominal) type of development may be seen in the following Akan formation. The fully adpositional status of the

\footnotetext{
${ }^{22}$ For example English I am going to work is ambiguous between literal motion + complement and intentional future AVC readings, while I am going to stay here really only has the functional interpretation.

${ }^{23}$ De Lancey already in (1991:15) explicitly recognized the potential deictic serialization origin ('go and X', 'come and X') for certain kinds of AVCs in TibetoBurman languages.
}

"In any language which regularly produces verb chains of the sort that we are claiming form the breeding ground for serialization constructions, there will regularly be formed chains of motion verbs for which no sequenced-event interpretation is pragmatically or even semantically available ...it is the semantically unitary nature of sequences such as these which motivates the development of a uni-clausal syntactic construction." 
element is betrayed by it still retaining some vestigial or residual traits of its (quasi-finite) verbal status in a serialized formation, such as the ability to take negation, albeit nonindependently motivated negation, i.e., it is doubly-marked (pleonastic) negation.

(194) Akan

Kofi n-ye adwuma m-ma Amma

Kofi NEG-do work NEG-for $<$ give $>$ Amma

'Kofi does not work for Amma'

(Seuren 1990: 18; Schachter 1974: 266)

Ewe has similarly grammaticalized the use of an original serial structure as an adpositional benefactive marker. These elements appear to stand somewhere between full verbs and full adpositions in Akan, but may be considered more adpositional in Ewe, at least in the following example.

(195) Ewe

$$
\begin{array}{llll}
\text { me-wò dò vévié ná } & \text { dodókpò lá } \\
\text { 1-do work hard for } \text { give> } & \text { exam DEF } \\
\text { 'I worked hard for the exam' } & \text { (Blake 1994) }
\end{array}
$$

À propos to the serialized origin of different inflectional patterns in African AVCs, the following generalizations can be made: doubled subject forms, as in Steswana (196) and Ngambay-Moundou (197), or split/doubled inflectional patterns with object-marking restricted to lexical verbs but with doubled subject marking as in Doyayo (198), commonly arise from core serialized structures with intransitive and transitive $V_{2}$ components, respectively.

(196) a. Setswana

re-nê re-tsamaya

1PL-AUX 1PL-go.away

'we are already going away'

(Setshedi 1974: 14) b. Setswana

$$
\begin{aligned}
& \text { re-nê re-setse re-tsamaya } \\
& 1 \text { PL-AUX } 1 \text { PL-AUX } 1 \text { PL-go.away } \\
& \text { 'we were already going away' }
\end{aligned}
$$


(197) a. Ngambay-Moundou

$\begin{array}{llll}m \text {-î̀ } m \text {-ús } \bar{a} \quad d \bar{a} & m \text {-ár } & m \text {-úsa } & d \bar{a} \\ \text { 1-AUX 1-eat meat } & 1 \text {-AUX } 1 \text {-eat meat } \\ \text { 'I am eating meat' } & \text { 'I am eating meat' } \\ \text { (Heine and Reh 1984: 126; Vandame 1963: 94-96) }\end{array}$

That the auxiliary formation is derivable from the serialized form is clear in the Doyayo examples below (where the source deictic serial verb for the potential is obvious), and it is also relatively straightforward to see how a split/doubled inflectional pattern with this structure might arise from such a core serialized structure where $\mathrm{V}_{2}$ is transitive and object encoding. Thus, the sequence of the last two verbs in (198) in a serial structure is identical to the auxiliated formation in (199).

(198) Doyayo

$\boldsymbol{h \boldsymbol { i } ^ { l }} \quad z a^{1} \quad \boldsymbol{h \boldsymbol { i } ^ { 1 }} \quad z a a^{13} \boldsymbol{h \boldsymbol { i } ^ { 1 }} \quad$ lo-m

3PL POT 3PL come 3PL bite-2

'they might come bite you' (Wiering and Wiering 1994: 221)

(199) Doyayo

$$
\begin{aligned}
& \begin{array}{llllll}
\boldsymbol{b} \boldsymbol{e}^{1} & r e^{3} & \boldsymbol{b} \boldsymbol{e}^{1} & t \jmath^{4}-\boldsymbol{m o} \boldsymbol{o}^{1} & g o & y a^{4}
\end{array} \\
& 1 \text { AUX } 1 \text { devour-2 ANAPH Q } \\
& \text { 'would I then eat you up' } \\
& \text { (Wiering and Wiering 1994: 217) }
\end{aligned}
$$

The relatively uncommon pattern (at least in Africa) with subject marked only on the auxiliary $\left(<* \mathrm{~V}_{1}\right)$ but with the lexical verb encoding object $\left(<\mathrm{V}_{2}\right)$, derives generally from a (usually nuclear) serialized formation. An example of this comes from Eleme, where split inflectional AVCs bear obvious morphological resemblance to serialized structures in the language. 
(200) Eleme

$$
\begin{aligned}
& \text { غ̀bai } r \varepsilon \text {-do-do-rõ né-e ìsã } \\
& 1 \text { PL 1PL-REDPL-be.PRS-APPL give-3SG book } \\
& \text { 'we are still giving him books' (Bond 2006) }
\end{aligned}
$$

(201) Eleme

$$
\begin{aligned}
& \text { àbà ba-bere tfú ǹsã no né-e } \\
& \text { 3PL 3PL.DEF-PRF take book DEM give-3SG } \\
& \text { 'they have picked up the book and given it to him' (Bond 2006) }
\end{aligned}
$$

4.2.2 Complement Structures. A number of different clause combining strategies can yield auxiliary verb constructions among African languages. The development of auxiliary verb constructions from subordinated verb complement sequences-in which the reanalysis of a subordinate/nominalized lexical complement and an original finite verb which has undergone functional specialization to an auxiliary, results in a unified, monoclausal structure-is one that has been frequently discussed in the theoretical literature on diachronic syntax in general (e.g. Harris and Campbell (1995), Harris and Ramat (1987), etc.)

The most common source of AUX-headed AVCs is an embedded, subordinate complement structure of the lexical verb. These often nominalized or adverbialized forms of verbs become co-specialized with auxiliary verbs that derive from complement taking predicates, both intransitive and transitive ones. ${ }^{24}$ Numerous examples of this have been offered above, with clause-union derivations approximately similar to that offered for the Swahili perfect in (220) below.

\footnotetext{
${ }^{24}$ Claudi (1988: 63) discusses how AVCs emerge (except those that arise in a serialized srtucture) when a nominalized verb is put into a complement position. If the former *matrix (now $>$ auxiliary) verb is transitive, then the verbal complement is put into the position of an object complement. If it is intransitive, then it is realized as an adverbial phrase complement (or genitive complement of nominalized verb). However, this does not exactly work out, as nominalized infinitive complements can be found even with intransitive original matrix verbs, as in the Lotuko and Lango forms cited, which derive from common directional and positional verbs that frequently enter into grammaticalization processes as auxiliaries.
} 
While doubled inflectional patterns in AVCs not infrequently derive from core serialized structures, they may also derive from embedded or complement structures as well. This is the sub-type of doubled pattern where there is some kind morphological marker of subordination in the lexical verb (or, if the reader prefers, on the original dependent/subordinate clause).

Take for example, the development of doubled inflectional forms in Teso/Ateso, an Eastern Nilotic language. Ateso has verb-initial structure and therefore, as a syntactically 'well-behaved' Nilotic language, it has Aux (S) V order that came from an original V (S) Complement structure. Subjects of embedded complements of most original verbal complement governing matrix verbs in Teso/Ateso (the soon-to-be auxiliary) appear in a $k$-initial dependent/subject form. Thus, doubled subject inflection with a dependentmarked lexical verb arises from asyndetic subordination and semi-finite inflectional structures.

(202) a. Teso/Ateso

a-bu $\boldsymbol{k a}$ - $d u k$

1-PST 1SBJNCTV-build

'I built'

b. Teso/Ateso

(Heine and Reh 1984: 185; Hilders and Lawrance 1956: 29-30)

The formal similarity of such AVCs with synchronic embedded structures with 'modal subordination' in Ateso is clear: 
(203) a. $\underline{\text { Teso/Ateso }}^{25}$

$\begin{array}{lll}\text { a-losi eoy oduka ka-gwel } & \text { amunyu } \\ \text { 1-go I } & \text { store 1SBJNCTV-buy } & \text { salt } \\ \text { 'I am going to the shop to buy salt' } & \\ \text { (Hilders and Lawrance 1956: 28) } & \end{array}$

b. Teso/Ateso

a-koto nes ko-bu
1-want him 3SBJNCTV-come
'I want him to come' (Hilders and Lawrance 1956: 30)

Split/doubled patterns of two different types may arise from such embedded verbal complement constructions [VCC] in African languages. The first type consists of an original intransitive matrix verb and a transitive complement verb where the matrix verb yields the auxiliary verb and the complement verb the lexical verb in the resulting AVC. Both take the argument inflection they subcategorize for, yielding subject marking alone on the auxiliary but both subject-marking and object-marking on the lexical verb.

(204) Mbay
$\boldsymbol{m}-\bar{a} \quad \boldsymbol{m}$-él-á tàa lò-í
1-AUX 1-tell-3 words of-2
'I'll tell him what you said' (Keegan 1997: 116)

${ }^{25}$ These can also take infinitive complement, which would if grammaticalized, yield AUXheaded AVCs in Ateso as well. Thus these two forms are also grammatical variants in Ateso:

(f) $\underline{\text { Ateso }}$

a-losi eop oduka a-gwel amunyu 1-go I store INF-buy salt

'I am going to the shop to buy salt'

(Hilders and Lawrance 1956: 28, 30) $\underline{\text { Ateso }}$

a-koto nes a-bunere 1-want him INF-come:INF 'I want him to come' 
(205) Bantu M54 Lamba



The other type of split/doubled pattern that may arise from an embedded complement structure is one in which negative appears only on the lexical verb. This kind of structure arises when the scope of negation is originally on the complement, not the matrix verb, even if semantically speaking this scope difference is difficult or impossible to tease apart in the AVC itself. Such a structure probably underlies the following Ejagham formation. Note that the original complement status, albeit in a semi-finite structure, is encoded by the use of the embedded or non-initial subject marking, here formally indexed, as discussed above, by tonal alternation of the subject marker itself.

(206) Ejagham [Ekoid Bantu]

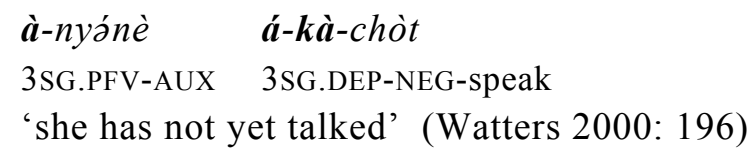

Finally, while the auxiliary verb in the LEX-headed pattern is unchanging generally, it may have frozen morphology reflecting its input source. One not uncommon phenomenon of such a type is the use of a expletive/dummy subject inflection on the auxiliary reflecting its former status as the verb of an original clause with a dummy/expletive subject and a clausal complement, with the now unchanging auxiliary retaining this original frozen $\left(3^{\text {rd }}\right.$ person) subject inflection. Such a situation is found for example in the following Acholi formation.

(207) *EXPL.SUBJ-VB + Complement (SUBJ-VB) > AUX + SUBJ-LV (LEX-headed pattern)

(208) Acholi

in omyero i-cam mot

you [3:]AUX 2-eat slowly

'you should eat slowly'

(Heine 1993: 41) [omyero < *o-myero 3-be.suitable/fit.PST] 
4.2.3 Coordinate source structures. Doubled AVC formations may arise from asyndetic coordination structures as well. ${ }^{26}$ Setshedi (1974) recognizes two functional types of verb-verb collocations in Bantu Setswana, which are identical formally. The first type the author calls a compounded predicate but would here be called a doubled inflectional AVC, with doubled subject marking (209a). The second verb is the clear semantic head of the expression, with the first verb serving to ground the event type coded by the second verb in a broader communicative discourse space, i.e. it serves as a functional specifier or operator, modifying the predication of an event of arriving. In (209b) on the other hand, the two verbal elements remain semantically distinct but coterminous or simultaneous events, neither of which predicates per se of the other, but rather both of which serve as semantic co-heads of a complex event, akin in semantic inter-relatedness of the event sub-parts found in serialized structures. This Setshedi (1974) calls a series of complete predicates, and I would call asyndetic coordination.

(209) a. Setswana

ba-tloga bá-goroga
3PL-AUX 3PL $_{<\mathrm{DEP}>\text {-arrive:FV }}$
'they will soon arrive'

(Setshedi 1974: 16) b. Setswana

ba-tsamaya bá-bua
3PL-walk 3PL $_{<\text {DEP>-talk:FV }}$
'they walk and talk'

These are semantically somewhat different than canonical serial structures as they don't involve either temporally sequenced and/or logically connected events or a decomposition of a complex event type into a series of interdependent event component types (e.g., kill $<$ hit + die or bring $<$ take + come), but rather two logically independent predicates, just one in this context that happen to be unified into a single utterance or reported sequence of events (or simultaneous ones in this case). Importantly however, the two constructions are basically indistinguishable in form, as one verb precedes the other in linear syntax, and the second verb must apparently appear with a 'dependent' subject form, regardless of the semantics (function+event or event+event) of the resulting structure.

\footnotetext{
${ }^{26}$ How and if these differ form core serialized structures and/or series chained (semi-finite) predicates either in a theoretical or language-specific manner remains a subject for future research.
} 
Finally, although quite uncommon in African languages, same subject or clausechaining constructions [CCC] may also give rise to AUX-headed structures in such African languages as Twi or Dizi (Maji).

(210) Twi

$w-a-n y \tilde{a} \quad \boldsymbol{a}-b \grave{a}$

he-PRF-AUX SEQ-come

'he has come now' (Lord 1993: 219; Christaller 1875: 335)

(211) Dizi (Maji)

yaàbà sı-te sis-te de-go

man see-ss hear-ss PRS.AUX-3[M]

'the man sees and hears' (Allan 1976b: 391)

Other formations with a CCC origin in non-African languages include one variant of the self-benefactive (or 'subject version') construction in Tofa (Anderson 2004), an endangered language of south-central Siberia and in various Yuman languages of the American Southwest like Mojave.

(212) Tofa [Turkic; Siberia]

dilyi oluk bar-up brcece yfpyl tùt-kaf al-yan

Fox right.away go-CV one hazel.grouse catch-Ss AUX-PST

'right away Fox went and caught himself one hazel grouse'

(Rassadin 1994: 198)

(213) Mojave [Yuman; USA]

hatcoq P-ka?a:-k P-a?wi:-m

dog 1-kick-ss 1-AUX-RLS

'I kicked the dog'

(Langdon 1978; Langacker 1998: 41; Mithun 1999: 581) 
Note that although most common in OV/V Aux languages, the CCC strategy is found in $\mathrm{VO} /$ Aux $\mathrm{V}$ languages as well (Twi). A summary of the types of developments discussed above may be found in Table 4:

Nuclear SVC $>$ Split Eleme

Core SVC $>$ Split/Doubled Doyayo

Core SVC $>$ Doubled Tswana, Ngambay-Moundou (Ejagham?)

VCC $>$ AUX-headed Anywa, Umbundu

VCC $>$ Doubled Ateso, (Ejagham?)

CCC $>$ AuX-headed Twi, Dizi

CCC $>$ Doubled Tswana

Table 4: Source $>$ target construction sets in African AVC development

A schematic of the source-target relations between AVCs and other complex predicate types is offered in Figure 1.

\section{Bi-clausal}

Verb + Complement Structures Serial Verb Constructions
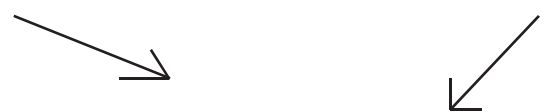

Auxiliary Verb Constructions

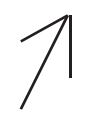

Clause Chaining Constructions

Mono-Clausal

Figure 1: Verbal Origins of Auxiliary Verb Constructions 


\section{Prosodo-phonological integration and complex verbs deriving from AVCs}

In this section I discuss the right edge of the grammaticalization path of AVCs, namely the point where the components of the formerly bipartite AVC are univerbated or fused through prosodo-phonological integration (and often erosion) into complex verb forms in developments of the types shown in (214) and (215). ${ }^{27}$

(214) From Aux V structure... $>$ [auxiliary verb $]_{\mathrm{w}}[\text { lexical verb }]_{\mathrm{w}}>[\text { affix-verb }]_{\mathrm{w}}$

(215) From V Aux Structure ... $>$ [lexical verb $]_{\mathrm{w}}[\text { auxiliary verb }]_{\mathrm{w}}>[\text { verb-affix }]_{\mathrm{w}}$

In 5.1, I offer some comments on how the constructional features of AVCs can be reflected in the structure of complex verb forms. In 5.2, I mention a characteristically African development of subject-auxiliary fusing. Later, in 6.8, I offer some data showing that different stages on the grammaticalization path reflecting different stages in the prosodo-phonological integration of the elements in the AVC > complex verb shift can be seen when looking at data in related Bantu languages or in variants of one and the same Bantu language.

5.1 Complex verb forms from AVCs in African languages. As is well-known, one of the most common sources crosslinguistically of tense, aspect, and mood morphology is an auxiliary verb construction (see Givón 1971, 1975, Haas 1977 for discussions pre-dating most literature on grammaticalization). The constructional morphosyntax of the earlier stages of a language can sometimes be recovered by examination of the attested complex verb forms. Note that the AVC that gave rise to a given complex verb form in a language may have represented any of the five macro-patterns of inflection mentioned above. In

\footnotetext{
${ }^{27}$ A precise delineation of what exactly constitutes a phonological vs. a morphological (verb) word is far from a closed issue in African languages in general, and even the core concepts are disputed or differently analysed and interpreted in different academic traditions. Nowhere is this more problematic or relevant than in the analysis of various Bantu, Bantoid, and other non-Bantu languages languages of West Africa. Often the anglophone literature will analyze strings as component affixes within single words, while francophone literature considers these to be strings of phonological words. As Nurse (2008: 169) puts it "Francophone countries in West Africa have a strong francographic convention to write as separate words what would be written as one word in the anglographic tradition." A similar observation was made by Creissels (2005: 45) with respect to determing the bound nature of object and subject markers in various African languages.
} 
other words, one finds fused forms from former AUX-headed or LEX-headed AVCs, from doubled structures and indeed from split and split/doubled patterns as well.

Of course being statistically the most common AVC pattern, the AUX-headed pattern is the source of complex inflected verb forms in languages from across the African continent. Such languages include virtually every eastern, central, and southern African Bantu language (see below), or Cushitic languages like Beja and individual Somali varieties, including standard Somali.

(216) Bedauye (Beja)

$$
\text { tam-ání }<? a-n i ̀
$$

eat-1.AUX

'I eat'

(Hudson 1976b)
(217) Standard Somali

keen-ay-a(a)

bring-AUX-IMPF: 1

'I bring'

(Heine and Reh 1984: 124)
(218) Jiddu Somali

jeel-aas-ta

beat-AUX-2PL

'you (pl) are beating'

Complement structures underlie complex verb forms derived from AVCs of this 'AUXheaded' type. This may be typified by the following well-known Swahili derivation from Heine and Reh (1984):

(219) a. pre-Swahili

$\begin{array}{lll}\text { *mtoto a-meele } \quad \boldsymbol{k} \boldsymbol{u} \text {-ja }> & \text { mtoto a-me-kuja } \\ \text { CL.I.child 3-finish:PRF INF-come:FV } & \text { child 3-PRF-INF:come:FV } \\ \text { 'the child has come' } & & \text { 'the child has come' }\end{array}$

(Heine and Reh 1984: 102) 
(220)

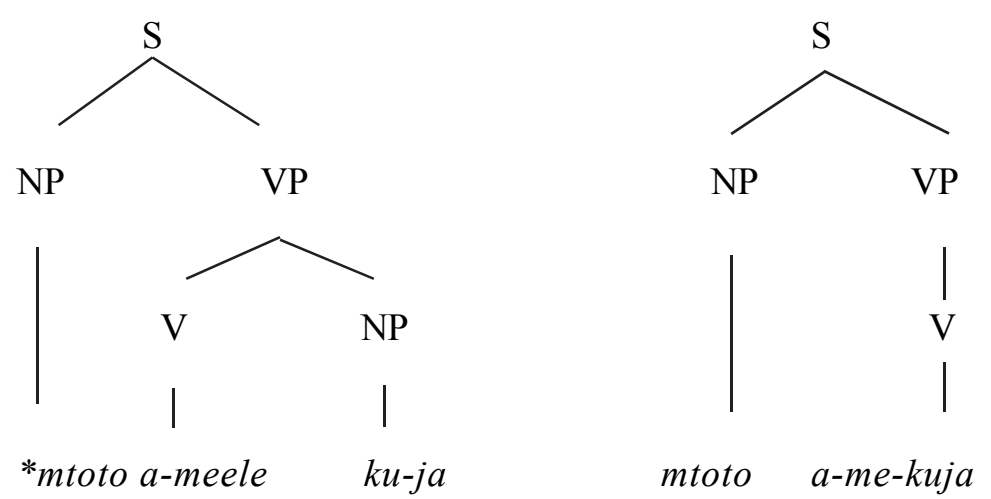

(Heine and Reh 1984: 102)

Further, an AUX-headed structure with an infinitive marked dependent form of the lexical verb that has been fused into a complex verb form of this sort lies at the heart of synthetic verb forms in a wide range of Bantu languages. The original auxiliary, sometimes altered and/or fused with the infinitive prefix, appears in the so-called TA prefix position (Nurse 2008) or position class -2 (two to the left of the root position) of the verbal complex. ${ }^{28}$ Various end-stages of this can be seen across the various Southern Bantu languages.

\footnotetext{
${ }^{28}$ Bantu verb structure recognizes a number of different templatic positions, the details of which has generated its own body of Bantu-specialist and theoretically oriented literature, (e.g., Ashton 1944, Grégoire 1979, Baker 1985, Hyman 1994, 2003, 2007, Alsina 1999, Good 2005, Nurse and Philippson 2006, Maho 2007, 2008, McPherson and Paster 2009). Thus Meeussen (1967) recognizes the following structure of the Bantu verbal template with 9-11 slots:
}

(g) pre/initial-initial-post/initial-formative-limitative-\{infix-radical-suffix.extension\}pre/final-final[.vowel]-post/final

while Nurse (2008: 40) is a recent consolidation that identifies 9 slots in the template, a root slot, up to five prefix slots and three suffixal ones.

(h) pre/SM-SM-NEG - -TA-OM- $\sqrt{ }+$ EXT-FV-post/FV

$-5-4-3-2-10+1+2+3$

Auxiliaries are clearly a highly important part of Bantu verbal structure both synchronically and diachronically, with the position class TA or -2 being a particularly common place for grammaticalized and fused former auxiliaries or AVCs to end up in (the next most common place being the pre-SM or -5 postion class), Nurse (2008) however pays 
little attention to these formations in this otherwise excellent study of the tense/aspect systems of Bantu. His understanding of the term auxiliary verb is clearly non-standard when he speaks of 'patently ungrammaticalized auxiliaries' (2008: 92), given that auxiliaries are by definition grammaticalized entities.

AVCs have been a manifestly important part of Bantu grammar for millennia, and it is likely that certain specific formations might be recoverable for the proto-language, e.g. Nurse (2008: 250) even suggests that the past progressive in Bantu was probably formed by a 'compound construction' (= AVC). To be sure, synchronic bipartite AVCs are found in probably all Bantu languages, some of considerable antiquity in the family, and, as just mentioned, most TA forms derive from such structures. According to Nurse (2008: 170-171), certain languages and areal zones within Bantu show a great propensity for univerbated former AVCs at the TA position, e.g. Zones C, H, R (except R30), E50, M50, M60, D42, E42, E43, E60, G20, K10, and M54 (Nurse 2008: 60), while synchronically bipartite AVCs or compound constructions are common in D60, E10, E20, E30 \{Great Lakes\}; G30, G60 (central and southern Tanzania); R30, S30, S40 (southern Africa), Ewondo, Cewa and Sena and in the restructured contact varieties or lingue franche Swahili and Kituba. A particularly extreme example of stacking of morphemes representing former auxiliaries at the TA position in the verbal template can be seen in Nande (D42) form tu-né-mu-ndi-syá-tá-sya-ya-ba-king$u l$-ir-an-is-i-á-ky-ô 'we will make it possible one more time for them to open it for each other (Nurse 2008: 175).

There is also an entire sub-field of studies devoted to the phonological or prosodic properties of the Bantu verb stem, not just its morphosyntactic and morphotactic features, e.g. Kisseberth (1984), Hyman (1989), Mutaka (1994), Odden (1996) or Myers (1998) ; see also Nurse (2008). Thus, one speaks of the root plus the derivational voice extensions $[\sqrt{ }+\mathrm{EXT}]$ as the derivational stem (and this constitutes the domain of vowel height harmony), of the sequence $[\sqrt{ }+$ EXT-FV] as the inflectional stem (and this represents the domain of nasal harmony, reduplication, V-coalescence), while the sequence of [OM- + EXT-FV] is considered to be the macro-stem or super-stem (and it is here that tonal phenomena are relevant). Everything to the left of the OM is considered the inflectional string by the phonological tradition and this together with the post-FV position to the right of the FV constitute the morphological, if not phonological, verb word. 
(221) Zulu

ngi-zoo-ku-thanda

1-FUT-INF-love:FV

'I shall love' < *za uku-

(Batibo 2005: 4)
(222) Sepedi (N. Sotho)

$$
\text { o-tlo-reka }
$$

3-FUT:INF-buy:FV

'he will buy' <*-tla $(\mathrm{g}) \mathrm{o}$ -

(Batibo 2005: 4)

(224) Venda

ke-tlilo-reka

ndi-doo-vhona

1-FUT:PRF:INF-buy:FV

1-FUT:INF-see:FV

'I shall have bought'

(Batibo 2005: 4) <*-tl-ile (g)o-
'I shall see'

(Batibo 2005: 4) <*-da (k)u-

Languages with fused forms deriving from the doubled inflectional pattern include Omotic Hamer and Chadic Pero. In Hamer both the original lexical verb and original auxiliary verb were marked by the descriptive aspect marker, all subsequently fused into a single form synchronically.

(225) $\underline{\text { Hamer }}$

ena kum-i-d-i
people eat-DESCR-AUX-DESCR
'the people have eaten'
(Lydall 1976: 422)

The ventive form in West Chadic Pero probably originated from an orientational/directional AVC deriving itself from an original deictic serialized formation ( $<$ 'come X'). Note also that the subject is doubly marked with intransitive futures (at least first and second person subjects are) in a circumfixal like SUBJ.PFX-X-SUBJ.SFX combination, with a recapitulative or 'intransitive copy pronoun' (see 7 below for more). With transitive verbs, the suffixal marker encodes rather the grammatical primary object in Pero (i.e. SUBJ.PFX-X-OBJ.SFX). 
(226) $\underline{\text { Pero }}$

$n \grave{\text {-tà-}-m e ̀-t u ̀-e ́ e-n o ̀ ~}$

1-FUT-return-VENT-AUGM-1

'I will return' (Frajzyngier 1989: 118)

(227) a. Pero

tà-píl-tù-ée-nò

FUT-buy-VENT-AUGM-1

's/he will buy for me' (Frajzyngier 1989: 111)

[tábílléenò]

b. Pero

cì-tà-wát-tù-ée-nò

2F-FUT-come-VENT-AUGM-1

'you should bring for me' (Frajzyngier 1989: 111)

[cèRàwáttéenò]

c. $\underline{\text { Pero }}$

nì-mún-(í)nà-ée-cù

1-give.COMPL.VENT-PREPRO-3PL

'I gave them' (Frajzyngier 1989: 112)

[nìmúnnéjù]

Split inflectional constructions are rare in African languages and complex verb forms resulting from them are correspondingly not well attested in this macro-areal group of languages. An example of a split fused structure however can be found in Chadic Gidar of the Nigeria/Cameroon border region. In the fused future formation, subject was found on the original auxiliary verb (now the future tense-marker), while object was encoded on 
the original lexical verb component. ${ }^{29}$ Structurally similar forms to Gidar can be found in Austronesian Mono and Tibeto-Burman Kinnauri.

(228) Gidar

wá-k̇̀-rg-á
FUT-2-hit-OBJ
'you (sg/pl) will hit him/her/it' (Frajzyngier 2008: 157)

(229) Mono [Solomon Islands] (230) Kinnauri [India]

$\begin{array}{ll}\boldsymbol{h a} \text {-na-nuhu-i} & \text { khya-ci-du-k} \\ \text { 1-FUT-dive-30BJ } & \text { see-2-AUX-1 } \\ \text { 'I will dive for it' } & \text { 'I see you' } \\ \text { (Ross 1982: 14) } & \text { (Sharma 1988: 140) }\end{array}$

Fused split/doubled formations are also not particularly common among the world's languages, African languages being no exception in this regard. A fused split/doubled formation does underlie the following complex verb form in the nearly extinct Kemantney language of Ethiopia, where subject is doubly marked, but other categories (e.g. tense/aspect) are marked only on the original auxiliary.

\footnotetext{
${ }^{29}$ Allen (1993: 39) analyses fused structures of this sort in Ewe but Nurse (2007a) on the other hand asserts that there are no synthetic forms in Ewe (the only affix is the verbal habitual), just cliticized forms, so Allen has wò-la-vó-é but Nurse (2007a) would $w \grave{o}=l a=v o ́=e ́$ for 'you will be afraid (of it)'. It really makes little difference per se as to what kind of morphophonology this reflects, as the distinction between these interpretations is morphotactic, not functional. Note also in this regard the caveat mentioned above about the different theoretical/analytic filters that operate to conform data to various preconceived notions of word types and the nature of the degrees of phonological integration or bondedness that are found in complex grammatical structures (e.g. the different word structure analyses of Bantu and other languages in the francographic and anglographic traditions).
} 
(231) a. Kemantney (Qemant)

intï was-y-am-y-äk
you hear-2-AUX-2-IMPF
'you have heard'

(Leyew 2003: 193) b. Kemantney (Qemant) ïntändew was-y-ïn-wan-y-äk $\boldsymbol{k}^{w-i ̈ n}$ you.PL hear-2-PL-AUX-2-IMPF-PL 'you (PL.) have heard' (Leyew 2003: 193)

Typologically similar formations to that in Kemantney are found in a range of a Eurasian languages such as the extinct Yeniseic language Yugh formerly spoken in northern central Siberia, the Dravidian language Pengo of India, the Kartvelian language Georgian from (former Soviet) Georgia and the isolate language Burushaski of Pakistan.

(232) Yugh

t-ku-g-di- $\chi \dot{t} p$

1-2-AUX-1-sell

'I sell you'

(Werner 1997: 138)

[Yeniseic; Siberia]
(233) Pengo

hur-t-ay-n-ay

see-PST-1-AUX-1

'I have seen'

(Steever 1988: 79)

[Dravidian; India]
(234) Burushaski

a-tú-ku-man-um-a

NEG- $d$-2-be.born-PST-2

'you weren't born'

(Berger 1998: 91)

[Isolate; Pakistan]
(235) a. Georgian [Kartvelian; Georgia]

mo-v-k'lu-l'-var
PV-1-kill-PRTCPL-1:AUX
'I have killed'

(Aronson 1982: 301) b. Georgian

$$
\begin{aligned}
& \boldsymbol{v}-\boldsymbol{u} \text { - } \boldsymbol{k} \text {-i-var } \\
& \text { 1-3-praise-PRF-1:AUX } \\
& \text { 'he praised me' } \\
& \text { (Aronson 1982: 272) }
\end{aligned}
$$

Fused or univerbated complex verb forms derived from AVCs of the split/doubled inflectional type can be found in other individual African languages as well. For example, the Kunama form below likely arose from a source construction with tense/aspect- and subject-marked on the auxiliary and a subject-marked lexical verb, in an original V AUX configuration. Thus, complex verb forms in languages often reflect rather straightforwardly their inflectional (and syntactic) pattern historically. This observation may help yield insight into the possible origins of such structures when they are 
encountered in languages that lack any or adequate comparative materials, or that represent isolate branches of a large phylum like Kunama within Nilo-Saharan. ${ }^{30}$

(236) Kunama

$$
\begin{aligned}
& \text { a'ba olle na- } \eta[a]-n a-i n a-k e \\
& \text { I there 1-eat-1-AUX-AOR } \\
& \text { 'I used to eat there' (Bender 1996: 45) }
\end{aligned}
$$

(237) Kunama: <*Subj-LV-Subj-AV-T ～<*Subj-LV Subj-AV-T....

Lastly, note that the LEX-headed pattern may also appear in fused or univerbated complex verb structures in various African languages, e.g. in S. Nilotic (Kalenjin) Nandi of Kenya (238).

(238) a. Nandi

$$
\begin{array}{ll}
\boldsymbol{m} \hat{\boldsymbol{a}}-a \text { :-kas } & \boldsymbol{m} \hat{\boldsymbol{a}}-\boldsymbol{a} \text { :-kás-é } \\
\text { FUT-1-hear } & \text { FUT-1-hear-ASP } \\
\text { 'I will hear it' } & \text { 'I will be listening' }
\end{array}
$$$$
\text { (Creider 1989: 111-112) }
$$

b. Nandi [S. Nilotic]

(239) Nandi: *AV SUBJ-LV-[ASP] > TA-SUBJ-LV[-ASP]

5.2 More on fused (univerbated) subject/TAM forms. It is clear that auxiliary verb constructions tend to undergo a diachronic process of prosodic/phonological integration commonly called univerbation or fusing. Some of these formations have been alluded to throughout sections 1, 2, 3 and 5.1. However, one pattern that occurs in (at least) three separate genetic/areal clusters among African languages, and one that is often not recognized as reflecting auxiliary structures per se, is a phenomenon called fused 'subject plus TAM/polarity auxiliary' forms by Anderson (2006). In these languages, there are what appear to be tense-marked pronouns, but which historically represent the fusing (or univerbation) of subject pronouns or agreement morphology with highly eroded auxiliary

\footnotetext{
${ }^{30}$ For more on fused structures from the split and split/doubled patterns, see Anderson (2006), Chapter 6.
} 
verbs. Such constructions are characteristic of various languages of the Macro-Sudan Belt, represented here by Mende (240), ${ }^{31}$ or unrelated to this, Cushitic Daasanech (241).

(240) a. Mende

b. Mende



(241) a. Dasenech (Daasanech)

yáá má-laalan

AUX:1 NEG-sing:PRS

'I do not sing' (Sasse 1976: 200)

Note that in the Chadic languages, these fused constructions may occur embedded within AUX-headed structures with Ø-marked lexical verb as in Hausa (242), in split/doubled AVCs as in Karekare (243), here with the pattern of doubled aspect marking and single subject marking that is highly marked for African languages, or indeed with dependentmarked lexical verbs as in Ngizim (244) in a classic AUX-headed structure.

(242) $\underline{\text { Hausa }}$

zán zóó

AUX:1 come

'I will come' (Heine 1993: 77)

${ }^{31}$ See also section 12 , where the formation is extrensively exemplified. 
(243) a. $\underline{\text { Karekare }}$

b. Karekare

$\begin{array}{lccl}\boldsymbol{n a ̀} & \text { tú-kòo } & \boldsymbol{n a ̀ a} & \text { tá-nà } \\ \mathbf{1 : P R F} & \text { eat-PRF } & \mathbf{1 : I M P F} & \text { eat-IMPF } \\ \text { no gloss } & \text { offered } & \text { (Schuh 1976: 5) }\end{array}$

(244) a. Ngizim

b. Ngizim

c. $\underline{\text { Ngizim }}$



According to Creissels (2005: 50-1; 55-9), forms showing what he calls the 'tense-person complex' are relatively common in West African languages, including Wolof.

Once such fused subject-plus-TAM-auxiliary forms exist in a language, they may, like any auxiliary structure or other functional element, be subjected to further prosodic/phonological integration with the lexical verbs with which they occur. Such formations have been called fused/fused constructions (Anderson 2006), and reflect various different original inflectional patterns. Thus, for example, a structure of this type from a fused/fused structure of the split(/doubled) inflectional type may be found in the Molo language of the Eastern Jebel family.

(245) a. Molo

j̀y tii:-bé

I PRS:1:go:1

'I go'

(Bender 1989: 166)

c. Molo

jy tà-sá
we PRS:PL-go:1PL
'we go'

(Bender 1989: 166) b. $\underline{\text { Molo }}$

$$
\begin{aligned}
& \text { in tá-bái } \\
& \text { you PRS:2:go:2/3 } \\
& \text { 'you go' }
\end{aligned}
$$

\section{d. Molo}

$$
\begin{aligned}
& \text { uu t’̀-só } \\
& \text { you(PL) PRS:PL-go:2PL } \\
& \text { 'you (PL) go' }
\end{aligned}
$$


Fused subject/auxiliary forms may also arise from AVCs of the doubled subject type. Here the auxiliary has fused with a subject marker itself, subsequently fused into one long complex verb form with the lexical verb. Such a development occured in the rise of the present progressive in the Surmic language Koegu, where the subject-marked lexical verb occurs in an infinitive form (246), and in the general present where the subject marked lexical verb rather occurs in an unmarked or Ø-marked form, or one in which the dependent morphology has eroded completely.

(246) a. Koegu

$$
\begin{array}{ll}
\text { a-am-iyaa } & \boldsymbol{a} \text {-am-en-iyaa } \\
\text { 1-eat-TA:1 } & \text { 1-eat-INF-TA:1 } \\
\text { 'I eat' } & \text { 'I'm eating' }
\end{array}
$$

(Hieda 1998: 365)

Cushitic languages make extensive use of this (see section 11) as do Hadza, Sandawe and other members of the Tanzanian Rift Valley (see section 10) linguistic area; see these sections for examples and further discussion.

As already exemplified above, there is considerable variation within not only genetic units but individual languages as well with respect to the inflectional pattern seen across different AVCs. Of course, one pattern may be dominant in a given language or genetic unit, and one might look to the differing origins of the constructions or the argument or functional properties of the grammaticalized elements concerned as first possible explanations for this type of variation. In the following sections I offer only representative samples of the range of auxiliary constructions found in four important African genetic units: (Narrow) Bantu (6), Chadic (7), Khoe (8), and Nilotic (9).

\section{6 (Narrow) Bantu}

One African family of languages where auxiliary verb constructions play and have played a major role in the verbal systems is (Narrow) Bantu (e.g. Nsuka Nkutsi 1986, Heine 1991, 1994). AVCs in Bantu languages generally appear with Aux V order, though a small number of languages show V Aux order (e.g., Tsotso or Mbugwe, see below). Indeed, most of the tense prefixes which occupy the so-called TA slot in the verb template in Bantu languages have arisen from a fusing of an original AVC reflecting an Aux V order. 
Most Bantu languages show AUX-headed and/or split/doubled constructions, with other formations occurring only relatively infrequently. However, given the size and diversity of the Bantu languages, it is hardly surprising that some instantiation of every pattern and fused version thereof may be found in a given individual Bantu language when considering all of the Bantu languages collectively. For certain AVCs, the inflectional pattern differs with differing lexical verbs. For example, not infrequently in Bantu one finds a situation in which intransitive verbs appear to be in a doubled inflectional pattern while transitive verbs show split/doubled structure, with object encoded only on the lexical verb component with the same auxiliary, with the exponence of the object logically lacking with intransitive verbs. ${ }^{32}$ Thus, these might be properly considered doubled/split-doubled formations. LEX-headed AVCs and forms showing fused subject/TAM constructions are rare in Bantu, although so-called Wambo Bantu languages of southwestern Africa may have these structures.

6.1 AUX-headed AVCs in Bantu. AUX-headed formations in Bantu languages come in many formal subtypes. Some appear with an overtly dependent-marked lexical verb and some with a zero-marked form. As discussed above, Bantu verb structure is synthetic and complex, but in many Bantu languages the final position in the verbal complex (the lexical verb in an AVC) is a position that licenses a construction specific 'final vowel', the unmarked or default instantiation of which in Bantu languages is $-a$ outside of the northwesternmost area, where $\varnothing$ may also be found. Lexical verbs appearing in a bare stem form in an AUX-headed structure occur only in Bantu languages of that region, and not in all such languages. They do occur for example in A15 Akoose with the lexical verb appearing with the $a$ - infinitive prefix and in a $\varnothing$ form of the final vowel in the following emergent AVC deriving from a verb + complement structure:

(247) SUBJ-'AV' INF-LV-Ø

(248) A15 $\underline{\text { Akoose }}$

bebaád bé-booted medyé a-kab

II.women II-begin VI.food INF-share

'the women began to share the food' (Hedinger 2008: 162)

\footnotetext{
${ }^{32}$ This is of course also precisely the situation which triggers intransitive copy pronouns in Chadic languages; see 7 below.
} 
AUX-headed AVCs with the lexical verb appearing with only the final vowel $-a$ are found in a range of Bantu languages such Duala (A20), Kikongo (H10) or Herero (R30).

(249) $\{$ SUBJ-TA- $\}-A V$ LV- $a$

(250) a. A20 Duala

$a \quad m a ̀-y a ̆ \quad n a n g a$ wa'se' bá m-endé janda
he PRS-FUT.AUX lie:FV ground they PRS-FUT.AUX buy:FV
'he will lie down right now'
(Heine and Reh 1984: 132; Ittmann 1949: 93-95)

(251) H10 Kikongo

$$
\begin{aligned}
& \text { y-a-kala kanga }{ }^{33} \\
& \text { 1-PST-PROG bind:FV } \\
& \text { 'I was binding' (Heine and Reh 1984: 88) }
\end{aligned}
$$

(252) R30 타ero

$$
\begin{aligned}
& \text { ha-tu-ja } \quad \text { muna } \\
& \text { NEG-1PL-AUX } \quad \text { see:FV } \\
& \text { 'we have not yet seen' (Meinhof 1948: 114) }
\end{aligned}
$$

In the following form from A43 Basaa (253), the construction is said to reflect a Øinfinitive form (Nurse 2008: 29), but with the final vowel $-a$ :

(253) A43 Basaa

$$
\begin{aligned}
& \text { a-bi-mal \#\# (Ø)-tíl-a } \\
& \text { 3-PST } 2 \text {-finish } \quad \text { (INF)-write-FV } \\
& \text { 'he has finished writing, he has written' (Nurse 2008: 29) }
\end{aligned}
$$

${ }^{33}$ Also $y$-a-ka kanga with erosion of the progressive auxiliary. 
A lexical verb in an AUX-headed AVC with both the familiar Bantu infinitive prefix $k u$ (in various local realizations) and the verb stem in the $-a$ final vowel form is a common and frequent component of the grammar of many Bantu languages. Such a diverse array of Bantu languages as N44 Sena and P10 Ndendeule can be included in this group.

(254) $\{$ SUBJ-TA $\}-A V$ INF-LV:a/-a

(255) N44 $\underline{\text { Sena }}$

$\begin{array}{ll}\text { ndi-sa-funa } & k u \text {-dya } \\ \text { 1-TA-AUX } & \text { INF-eat:FV }\end{array}$

'I will eat, near/less certain' (Nurse 2008: 92)

(256) a. P10 Ndendeule

bi-tenda ku-memena

2:PRS-AUX INF-eat:FV

'do people really eat them?'

(Güldemann 2003: 340) b. P10 Ndendeule

mwe n'-tenda ku-pëta you:PL 2PL-AUX INF-pass:FV 'you still/do go through'

Formally identical AUX-headed constructions may be found in such Bantu languages as JE31c Bukusu, E42 [E10] EkeGusii, and D61 [J60] Kinyarwanda, where the familiar Bantu infinitive prefix $k u$ - has local realizations such as $x \hat{u}$ :- in JE31c Bukusu, $g u$ - in D61 [J60] Kinyarwanda and ko- in E42 [E10] EkeGusii.

(257) JE31c Bukusu

$$
\begin{aligned}
& \text { ba-li xû:-bón-a } \\
& \text { 3PL-AUX INF-see-FV } \\
& \text { 'they see' (Aksenova 1997: 17) }
\end{aligned}
$$

(258) D61/J60 Kinyarwanda

$$
\begin{array}{lll}
\begin{array}{l}
\text { abagabo } \\
\text { men }
\end{array} \quad \text { 3PL-AUX } & \text { gu-som-a } \\
\text { menfread-ASP } \\
\text { 'the men would have read' (Kimenyi 1980: 9) }
\end{array}
$$


(259) E42 [E10] [Eke]Gusii

ko-a-is-ire ko-many-a ékeGusii

2-TNS-AUX-ASP INF-know-FV ékeGusii

'you are going to learn EkeGusii language' (Aksenova 1997: 17)

Note that the common Bantu negative element -(i)si- appears to remain a free-standing auxiliary synchronically in older sources on G10 Kaguru, such as in Torrend (1891). This negative auxiliary is found in an AUX-headed AVC of this formal sub-type with the lexical verb in the $k u$ - prefix and - $a$ final vowel form:

(260) a. G10 Kaguru

$$
\begin{array}{ll}
n i-s i & k u \text {-langa } \\
\text { 1-NEG } & \text { INF-see:FV } \\
\text { 'I don't see' }
\end{array}
$$$$
\text { (Torrend 1891: 233) }
$$

b. G10 Kaguru

$$
\begin{aligned}
& \text { ch-isi } \quad k u \text {-langa } \\
& \text { 1PL-NEG INF-see:FV } \\
& \text { 'we don't see' }
\end{aligned}
$$

The infinitive-marked lexical verb may appear with a prefix that encodes an adpositional relation, e.g., accompaniment 'with' or location 'in' or 'at', with an auxiliary verb whose original meaning was 'be (located)' (see 4.1 above). This is the form found for example in N14 Mpoto:

(261) $\{$ SUBJ-TA $\}-A V$ LOC-INF-LV:a/- $a$

(262) a. N14 Mpoto

$$
\begin{aligned}
& t i-y i-l i \quad m u-k u-l a \\
& \text { 1PL-TA-AUX LOC-INF-eat:FV } \\
& \text { 'we're eating' }
\end{aligned}
$$

b. N14 Mpoto

$$
\begin{aligned}
& \text { ti-ka-yi-li mu-ku-la } \\
& \text { 1PL-PST } 2 \text {-TA-AUX LOC-INF-eat:FV } \\
& \text { 'we were eating }\left\{\mathrm{P}_{2}\right\} \text { ' }
\end{aligned}
$$


c. N14 Mpoto

$$
\begin{array}{ll}
t \text {-a-yi-li } & m u-k u \text {-la } \\
\text { 1 } \text { PL-PST }_{3} \text {-TA-AUX } & \text { LOC-INF-eat:FV } \\
\text { 'we were eating } & \left\{\mathrm{P}_{3}\right\}
\end{array}
$$

(Nurse 2008: 141) d. N14 $\underline{\text { Mpoto }}$

$$
\begin{aligned}
& t-a ́-y a-y i \quad m u-k u-l a \\
& \text { 1PL-FUT-TA-AUX LOC-INF-eat:FV } \\
& \text { 'we will be eating' }
\end{aligned}
$$

In B51 Duma on the other hand, the $m \hat{u}$ - locative prefix is found attached directly to the verb stem (in the $-a$ final vowel form). This may be the original formation or, perhaps more likely, it may be a secondary formation, eroded from a form like the Mpoto one above.

(263) $\{$ SUBJ-(TA) $\}-A V L O C-L V: a /-a$

(264) B51 Duma

$$
\begin{aligned}
& \text { a-lí mî-kéna } \\
& \text { 3-AUX LOC-dance:FV } \\
& \text { 'she is dancing' (Nurse 2008: 141) }
\end{aligned}
$$

As mentioned above, while most AVCs in Bantu languages are AUX V, in JE32b Tsotso the reverse order V AUX is found in at least one AUX-headed construction with the lexical verb in the infinitive $k u$ - form and with the final vowel in $-a$. This is thus identical to the forms in (254)-(260) only with the relative order of auxiliary and lexical verb reversed.

(265) INF-LV:a/- $a$ \{SUBJ-(TA) $\}-A V$

(266) JE32b Tsotso

$$
\begin{aligned}
& \text { kù-wé:lá ng!íná } \\
& \text { INF-be.sick:FV I.am } \\
& \text { 'I am sick' (Hardemann 1996: 165) }
\end{aligned}
$$

The auxiliary verbs 'be and 'sit' in combination together with an adposition $l$ ' meaning 'with' in a clitic, quasi-prefix form create in [R10] Umbundu, the AUX-headed 
progressive formations (268a) and past progressive (268b), respectively; see (10) and (160) for more examples.

(267) $\{$ SUBJ-(TA) $\}-A V$ PREP INF-LV:a/- $a$

(268) a. R10 Umbundu

$\begin{array}{ll}\text { tu-li l' oku-lya } & \text { wa-kala l' oku-papala } \\ \text { 1PL-AUX with INF-eat:FV } & \text { 3-AUX with INF-play:FV } \\ \text { 'we are eating' } & \text { 'he was playing' } \\ \text { (Heine and Reh 1984: 125; Valente 1964: 281) }\end{array}$

6.2 Doubled inflection in Bantu AVCs. Doubled inflection in AVCs is also widely attested among Bantu languages. Most commonly one finds doubled subject formations, with the lexical verb appearing in various construction-determined and language-specific forms. As with AUX-headed formations, the lexical verb appears in a zero-marked form only in northwestern Bantu, such as A15 Akoose:

(269) SUBJ-AV SUBJ-LV-Ø

(270) A15 $\underline{\text { Akoose }}$

$\begin{array}{llll}\text { bé-táygéné } & \text { bé-sébé } & \text { bé-hed } & \text { melâm } \\ \text { II-must.EXT.PRF } & \text { II-first } & \text { II-look.for } & \text { VI.whiskey }\end{array}$

'they must first look for whiskey' (Hedinger 2008: 152)

AVCs with the lexical verb in a subject-marked form with the final vowel $-a$ in a doubled subject configuration are attested across the Bantu family, including such diverse languages as A62 Yambasa (repeating (41) above), K40 Siluyana, M14 Lungu, P22 Mwera, S21 Venda, and [S30] Setswana.

$$
\{\text { SUBJ-(TA) }\}-A V \quad \text { SUBJ-LV: } a /-a
$$


(272) A62 Yambasa

a-lé a-núun-ə

3-AUX 3-watch-FV

'he is watching' (Nurse 2008: 141)

(273) K40 Siluyana

ba-nu ba-li ba-tenda

PL-person 3PL-AUX 3PL-work:FV

'the people are working' (Givón 1971: 148)

(274) M14 Lungu

$\begin{array}{ll}\text { tw-áá-shá } & t w \text {-áá-lim-a } \\ \text { 1PL-PST-AUX } & \text { 1PL-HORT-farm-FV }\end{array}$

'we'll soon be farming' (Nurse 2008: 163)

(275) P22 Mwera

tw-a:ci tu-Ø-um-a

1PL-AUX 1PL-[TA-]buy-FV

'we were about to buy' (Nurse 2008: 195)

(276) S21 Venda
ndo-vha ndo-vhona
1SG.PRF-AUX 1SG.PRF-see:FV
'I had seen' (Heine 1993: 38)

(277) S30 Setswana

ke-nê ke-rêka
1-AUX 1-buy:FV
'I was buying' (Cole 1955: 235) 
Doubled formations also occur in such Bantu languages as L30 Hemba, M14 Lungu, N21 Tumbuka, N44 Sena, F21 Sukuma and S21Venda with dependent marked lexical verbs in certain AVCs. The future construction seen in the Bantu language N21 Tumbuka reflects a structure with doubled subject marking and the modal dependent (or subjunctive) final vowel $-e$.

(278) SUBJ-AV SUBJ-LV-FV [SBJNCTV]

(279) N21 Tumbuka

$$
\begin{array}{ll}
t i-t i & t i-l u t-\boldsymbol{e} \\
\text { 1PL-AUX.FUT } & \text { 1 PL-go-FV } \\
\text { 'we will go' } & \text { (Nurse 2008: 299) }
\end{array}
$$

In N44 Sena, a related formation is seen, here the auxiliary augments the future encoded by $-n a$ - in an assertive or emphatic future (and actually represents a split/doubled inflectional pattern). Both the Sena form and the Tumbuka one reflect a future auxiliary derived from the verb 'say' $-t i$. This is what probably explains the modal dependent final vowel forms on the lexical verbs in these AVCs. ${ }^{34}$

(280) N44 $\underline{\text { Sena }}$

$$
\begin{aligned}
& n d i-n a-t i \quad n d i-d y-\boldsymbol{e} \\
& 1 \text {-FUT-AUX } 1 \text {-eat-FV } \\
& \text { 'I will eat, far more certain' (Nurse 2008: 92) }
\end{aligned}
$$

${ }^{34}$ Thanks to an anonymous referee for pointing this out to me. 
A different kind of dependent marked but doubly-subject inflected AVC is exemplified by the S21 Venda continuous formation, where the dependent marker occurs following the subject prefix on the lexical verb:

(281) SUBJ-AV SUBJ-DEP-LV: $a$

(282) S21 Venda (Niger-Congo, Bantu; South Africa, Zimbabwe)

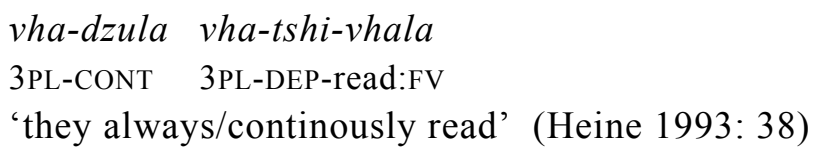

Doubled subject and future marking are found in S43 Siswati with the auxiliary -be when it means 'be about to' but not when it has progressive functions, when the future -tawuis found only on the auxiliary. Thus, the former construction shows a doubled pattern of inflection, the latter a split/doubled one.

(283) SUBJ-TA-AV SUBJ-TA-LV: $a \quad b e$ 'about to'

(284) S43 $\underline{\text { Siswati }}$

\begin{tabular}{|c|c|c|c|}
\hline ba-tawu-be & ba-tawu-cala & nakuvakala & kukhala \\
\hline 3PL-FUT-AUX & 3PL-FUT-start & when.to.beaudible & to.produce.sound \\
\hline
\end{tabular}

'they will be about to start when the whistle sounds' (Botne 1986: 307; Ziervogel and Mabuza 1976: 187)

(285) SUBJ-FUT-AV SUBJ-LV-a be PROG 
(286) S43 $\underline{\text { Siswati }}$
ba-hamba
$n a-b a-f i k a-k o$
bangani
3PL-FUT-AUX
3PL-travel
when-3PL-arrive-LOC
CLS2.PL:friends
bakhe
CLS2.PL:his
'they will be traveling when his friends arrive'
(Botne 1986: 312; Ziervogel and Mabuza 1976: 187)

Intra-language or dialect variation is not uncommonly found in Bantu languages. Torrend (1891) described forms in various Tonga varieties with the following four variants for the future. There are three variants with a $y a$ auxiliary element and one with a putative $*_{z a}$. The fourth form (287d) is structurally identical to the first one (287a) only with a different (?) auxiliary verb. Both likely reflect historical fusings of doubly-subject inflected forms, seen in (287b) This same auxiliary $-y a$ appears optionally within an AUX-headed structure with the lexical verb in the infinitive form $(287 \mathrm{c})$. Thus there is both variation between an AUX-headed and a doubled AVC and variation between degrees of univerbation in the AVCs as well.
(287) a. 'Tonga'
b. 'Tonga'
c. 'Tonga'
d. 'Tonga'
u-yoo-bona $\sim$ u-ya u-bona
3-FUT-see 3-FUT 3-see
u-ya ku-bona
u-zoo-bona
3-FUT INF-see
3-FUT-come
'he will see'

(Torrend 1891: 242)

In other words, there is four-way variability among future formations. Either the future marker appears as free-standing auxiliary in a bipartite AVC or in fused form. Further the future 'affix' appears as either-yoo- or -zoo-. Lastly, the synchronic bipartite AVC with $-y a$ is found either in an AUX-headed structure with the lexical verb in an infinitive form, or it is a doubled inflectional structure with the lexical verb appearing in the (fully) finite $-a$ form.

Lombard (1978: 327) offers examples of similar variation in Northern and Southern Tonga. Northern Tonga (288) has a straighforward AUX-headed pattern of the common 
Bantu type. The Southern Tonga form (289) may reflect a fusing of the tense element and the infinitive, or a fused doubled inflectional pattern, as above.

(288) $\underline{\text { N. Tonga }}$

u-na ku-langa

he-TNS INF-look

'he will look' (Lombard 1978: 327)

(289) $\underline{\text { S. Tonga }}$

u-noo-langa

he-TNS:INF-look

'he will look' (Lombard 1978: 327)

\begin{tabular}{lll}
\hline \hline SUBJ-AUX $<=$ FUT $>$ INF-LV- $a$ & ya & future \\
SUBJ-AUX $<=$ FUT $>$ SUBJ-LV- $a$ & ya & future \\
SUBJ-AUX $<=$ FUT $>$-LV- $a$ & yoo & future \\
SUBJ-AUX $<=$ FUT $>$-LV- $a$ & zoo & future $<*_{z} a[k] u-?$
\end{tabular}

Table 5: Tonga future variants

6.3 Split inflection in Bantu AVCs. True split formations are quite marked within the Bantu context. One possible split formation in Bantu may be seen in the following Northern Sotho form. Lombard (1978) argues for a derivation of this from *bá tlá go e tlifa, that is, a split form with an infinitive marked lexical verb. Subject appears with the auxiliary and object with the lexical verb.

(290) Northern Sotho

$$
\begin{aligned}
& \text { bá[-]tló e[-]tlífa ?? < *bá tlá go e tlífa } \\
& \text { they-FUT it-bring * they come INF it bring } \\
& \text { 'they will bring it (Lombard 1978: 319) }
\end{aligned}
$$


In Mbugwe an unusual situation for Bantu is seen in which the pattern with the common inflectional split between object-encoding with the lexical verb, but subject-encoded on the auxiliary is attested in a V AUX configuration. V AUX formations, although highly marked for Bantu, are a characteristic feature of the Tanzanian Rift Valley area, which includes Mbugwe (see section 10).

$$
\text { OBJ:LV: } a /-a \text { SSUBJ-(TA) }\}-A V
$$

(292) Mbugwe

$$
\begin{aligned}
& \text { ora ko-kéndé wári } \\
& \text { 15:eat:FV1PL-PRS.ProG ugali } \\
& \text { 'we are eating food' (Mous 2004: 472; Kießling et al. 2008: 219) }
\end{aligned}
$$

\subsection{Split/Doubled inflectional patterns in Bantu AVCs}

Split/Doubled patterns are more common in Bantu than in the other genetic units of Africa as a whole. Split/Doubled AVCs are widespread and of numerous formal subtypes in the Bantu languages. In almost all of the sub-patterns of AVCs in Bantu showing split/doubled inflection, the doubled category is subject.

AVCs in Bantu languages are particularly rich in variations on the general theme of doubled subject encoding, but with split or doubled distribution of other inflectional categories. One common pattern shows split negation, but doubled subject. Typically, the negative appears on the lexical verb with doubly marked subject.

A pattern is found with split negation and doubled subject encoding in the following construction from Swahili, with the lexical verb appearing in a conegative form:

SUBJ-AV NEG-SUBJ-LV- $i_{\text {CONEG }}$

(294) Swahili

$$
\begin{aligned}
& \text { tu-li-kuwa ha-tu-fany-i } \\
& \text { 1PL-AUX-INF:AUX NEG-1PL-do-FV } \mathbf{C O N E G}_{\text {CON }} \\
& \text { 'we weren't doing anything' (Aksenova 1997: 21) }
\end{aligned}
$$


As just mentioned, the lexical verb appears in the negative dependent (or co-negative) form in Swahili with the final vowel $-i$. Similar formations are found, for example, with negative on the lexical verb and a negative dependent form of the lexical verb in a double-subject inflected AVC in Setswana, here represented by the use of the final vowel $-e$ which may simply be a (conegative) use of the subjunctive final vowel $-e$, or the reflex of the conegative element $-i$ of Swahili in Setswana. The motivation for the use of irrealis-type morphology with a negative in a construction like this is straightforward.

(295) SUBJ-AV NEG-SUBJ-LV- $e_{\text {SBNCTV/CONEG }}$

(296) Setswana (Bantu, Botswana)

$$
\begin{aligned}
& \boldsymbol{k} \boldsymbol{e} \text {-nê } \boldsymbol{k} \boldsymbol{e} \text {-sa-rêke } \\
& \text { 1-AUX 1-NEG-buy:FV } \mathrm{SBJNTV}_{\mathrm{S} \text { CONEG }} \\
& \text { 'I was not buying' (Cole 1955: 251) }
\end{aligned}
$$

The auxiliary -nê in the following SeTswana form (and the one above) appears to encode past tense in the negative past formation. Other auxiliaries, like - bo in Setswana show the same doubled-subject/split negative inflectional pattern, but with additional tense marking split on the auxiliary verb, i.e. in a pattern like that of (297).

(297) SUBJ-TA-AV NEG-SUBJ-LV- $e_{\text {SBNNCTV/CONEG }}$

(298) a. Setswana

$\boldsymbol{k e}$-nê $\quad \boldsymbol{k e}$-sa-itse

1-AUX 1-NEG-know:FV SBJNCTV/CONEG

'I did not know' (Setshedi 1974: 34)

b. Setswana

ba-(tla)-bo ba-sa-itse

3PL-(FUT)-AUX 3PL-NEG-know:FV SBNACTV/CONEG $_{\text {in }}$

'in a way they did not know (won't be knowing)'

(Setshedi 1974: 34) 
Setswana also shows a different split/doubled patterning with the negative -se-appearing in the TA slot of the auxiliary verb $-k a$, and with doubled subject marking. Note that the lexical verb appears in the $-a$ final vowel form in these Setswana AVCs.

(299) SUBJ-NEG-AV SUBJ-LV:a

(300) $\underline{\text { Setswana }}$
ba-na ba-se-ka ba-robala
PL-children 3PL-NEG-AUX 3PL-sleep:FV
'the children must not sleep' (Setshedi 1974: 42)

With negative $g a$ - in pre-initial position in the template, the auxiliary -aka shows yet another formal sub-type of, or permutation on, the same theme of double subject inflection but split negative marking in Setswana.

(301) NEG-SUBJ-AV SUBJ-LV:a

(302) a. Setswana

ga-ke-aka ka-rêka

NEG-1-AUX 1-buy

'I did not buy'

(Cole 1955: 250) b. Setswana

$$
\begin{aligned}
& \text { ga-o-aka wa-rêka } \\
& \text { NEG-2-AUX 2-buy } \\
& \text { 'you did not buy' }
\end{aligned}
$$

In Kinyarwanda the pre-initial nti- negative can appear alternatively on either the lexical verb or the auxiliary verb in the negative progressive, yielding the following two variants.

(303a) NEG-SUBJ-AV SUBJ-LV:a (same as (301))

(303b) SUBJ-AV NEG-SUBJ-LV:a 
(304) a. Kinyarwanda

nti-tu-riho du-kór-a
NEG-1PL-AUX 1PL-work-FV
'we are not working'
(Kimenyi 1979: 193)

b. Kinyarwanda

$$
\begin{array}{ll}
\text { tu-riho } & \boldsymbol{n t i ̂ - d u} \text {-kór-a } \\
\text { 1PL-AUX } & \text { NEG-1PL-work-FV } \\
\text { 'we are not working' }
\end{array}
$$

A different kind of split/doubled pattern involving tense and aspect marking is also attested in various Bantu languages. Tense occurs on the auxiliary alone in Hemba (see (96) above) and Nkore-Kiga (306).

\section{SUBJ-TA-AV SUBJ-LV: $a$}

(306) Nkore-Kiga

$$
\begin{array}{llll}
\text { Abahima } & \text { ba-ka-gab }(w) a & \text { ba-tamba embuzi } \\
\text { Bahima } & \text { 3PL-REM.PST-AUX:P } & \text { 3PL-sacrifice:FV goats } \\
\text { 'the Bahima used to sacrifice goats' (Taylor 1985: 157) }
\end{array}
$$

Note that the lexical verb appears in the $-a$ final vowel form in the above AVCs. In another set of Bantu languages one finds a pattern with nearly identical distribution to that of Hemba and Nkore-Kiga above with tense encoded only on the auxiliary, and subject doubly marked; however in these Bantu languages, the lexical verb appears in the modal dependent final vowel form in $-e$. These latter types of formations, with doubled subject encoding but tense on the auxiliary and an overtly dependent lexical verb, are particularly common in central and eastern Bantu languages such as M14 Lungu.

(307) SUBJ-TA-AV SUBJ-LV: $e_{\text {SBINCTV }}$

(308) M14 Lungu

$$
\begin{aligned}
& \text { tw-áá-shá tú-Ø-lím-e } \\
& \text { 1PL-PST-AUX 1PL-TA-farm-FV } V_{\text {SBINCTV }} \\
& \text { 'we'll soon farm' (Nurse 2008: 163) }
\end{aligned}
$$

In the case of N44 Sena and G20 Shambala, the etymology of the auxiliary verb is 'say' which originally took a complement in the subjunctive form. This constructionally 
dependent and determined form was carried over onto the lexical verb in the AVC when the sequence grammaticalized, in two rather different functions in these two Bantu languages: as an 'already' past in Shambala (310), and a definite remote future in Sena (see (280) above for the Sena example):

(309) SUBJ-TA-AV SUBJ-LV: $e_{\text {SBINCTV }}$ repeat of (319)

(310) G20 Shambala

$$
\begin{aligned}
& n i-z a h-t i \quad n i-k u n d-e \\
& \text { 1-TA-AUX 1-hope-SBJNCTV } \\
& \text { 'I already hoped (Aksenova 1997: 34) }
\end{aligned}
$$

E72 Giryama shows a different formal sub-type of this pattern with double subject marking as expected, tense encoded on the auxiliary verb. The lexical verb stands in the $a$ final vowel form but is marked as dependent by what may have originally functioned as a consecutive marker $-k a$-, now appearing to have taken on the role of a dependent marker in an AVC:

(311) SUBJ-TA-AV SUBJ-ka-LV:a

(312) E72 Giryama

$$
\begin{array}{ll}
f \text {-á-kala } & f u \text {-ka-gula } \\
\text { 1PL-PST-AUX:FV } & \text { 1PL-ka-buy:FV } \\
\text { 'we used to buy' } & \text { (Nurse 2008: 292) }
\end{array}
$$

Yet another pattern is found with a dependent marker in the position following the subject marker (cf. the doubly inflected Venda form above), whether it be the infinitive or another marker of dependency, doubled subject inflection and tense/aspect marking on the auxiliary alone. Such AVCs are characteristic of Bantu languages in Tanzania like F21 Sukuma, F24 Kimbu or standard Swahili (G42). In F21 Sukuma, the dependent marker is -lii - in the following formation:

(313) SUBJ-TA-AV SUBJ-DEP-LV: $a$ 
(314) F21 Sukuma

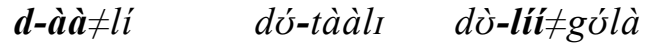

$$
\begin{aligned}
& \text { 1PL-PST-AUX 1PL-PRSTV 1PL-DEP-buy:FV } \\
& \text { 'we were still buying' (Nurse 2003: 91) }
\end{aligned}
$$

The $-k i$ - participle form may be used as a dependent marker on the lexical verb in a functionally similar split/doubled AVC in G42 Swahili:

$$
\text { (315) SUBJ-TA-AV SUBJ-PRTCPL-LV: } a
$$

(316) G42 $\underline{\text { Swahili }}$

$$
\begin{aligned}
& \boldsymbol{w a} \text {-li-kuwa wa-ki-temba} \\
& \text { 3PL.ANIM-PST-AUX 3PL.ANIM-PRTCPL-walk:FV } \\
& \text { 'they were walking' (Field Notes) }
\end{aligned}
$$

In other Bantu languages, tense is marked not on the auxililary, but rather on the lexical verb, with doubled subject inflection. Such a formation is found in J60/D61 Kinyarwanda and E10 Kuriya, with present and future tense, respectively encoded only on the lexical verb:

(317) SUBJ-AV SUBJ-TA-LV: $a$

(318) J60/D61 Kinyarwanda

$$
\begin{aligned}
& \boldsymbol{u} \text {-riho } \boldsymbol{u} \text {-ra-soma } \\
& \text { 2-AUX } \mathbf{2 - P R S - r e a d : F V ~} \\
& \text { 'you are reading' (Kimenyi 1979: 191) }
\end{aligned}
$$

(319) E10 Kuri[y]a

$$
\begin{aligned}
& \text { ni-yi n-ds-itaiki-a } \\
& \text { 1-AUX 1-FUT-continue-FV INDIC } \\
& \text { 'I will continue' (Aksenova 1997: 20) }
\end{aligned}
$$


A slight variation on this theme is seen in E71 Pokomo, where it is rather aspect, not tense that shows split inflection, restricted to the lexical verb alone in the following AVC (past tense being encoded by the auxiliary $-w a$ in this case presumably):

(320) E71 Pokomo

hu-wa hu-ki-cheza

1PL-AUX 1PL-SIT-play:FV

'we used to play' (Nurse 2008: 247)

Another permutation of this same pattern is found in M25 Bungu where subject is doubly marked, and aspect is restricted to the auxiliary verb.

$$
\text { SUBJ-AV-ASP SUBJ-TA-LV: } a
$$

(322) M25 Bungu

$$
\begin{array}{ll}
\boldsymbol{t u} \text {-li-sh- } a & \boldsymbol{t} \boldsymbol{u} \text {-Ø-bala } \\
\text { 1PL-AUX-PRSTV-FV } & \text { 1PL-go:FV } \\
\text { 'we're still going' } & \text { (Nurse 2008: 146) }
\end{array}
$$

In the following split/doubled AVCs found in L33 Luba and [P30] Makua-Maverone, tense is marked on the auxiliary and aspect of some sort on the lexical verb, while as always the doubled category is the subject.

(323) SUBJ-TNS-AV SUBJ-ASP-LV: $a$

(324) L33 Luba

$$
\begin{aligned}
& \text { w-aa-di } \quad u-k i-d y a \\
& \text { 3-PST-AUX } \quad 3 \text {-PRSTV-eat:FV } \\
& \text { 'he was still eating' (Nurse 2008: 146) }
\end{aligned}
$$


(325) P30 cluster [Makua]-(E)Maverone

$$
\begin{array}{lll}
\text { mu-lópwána } & \boldsymbol{a} \text {-n-iíra } & \multicolumn{1}{c}{\boldsymbol{a} \text {-voliwá-ká }} \\
\text { 1-man } & \text { 3SG-PRS-AUX } & \text { 3SG-PFV-starve:FV } \\
\text { 'the man is really starving' } & \text { (Kröger 2010: 170) }
\end{array}
$$

In the following conditional AVC from J20/E22 Haya, subject is doubly marked, tense is encoded on the auxiliary and tense-cum-mood on the auxiliary:

$$
\text { SUBJ-TM-AVSUBJ-TA }-\mathrm{i}-\mathrm{LV}: a
$$

(327) J20/E22 Haya



As exemplified in (101) above, a split/doubled AVC with aspect and tense appearing on the lexical verb but with subject doubly marked may be found in [P20] Ciyao. A different kind of split may be commonly found in various Bantu languages. In this pattern (328), subject is doubly marked, as is tense, but object appears only with the lexical verb. M54 Lamba is an example of a Bantu language possessing AVCs of this type; see (87).

$$
\text { SUBJ-TA-AV SUBJ-TA-OBJ-LV- } a_{\text {INDIC }}
$$

6.5 LEX-headed AVCs in Bantu. LEX-headed formations are very marked in Bantu. In certain instances, it is likely that the constructions represent eroded forms that originally reflected a split/doubled pattern. Thus, the future progressive in Sukuma which has doubled subject inflection $(332) /(68)$ is similar in shape to the future in Sukuma which is synchronically a LEX-headed formation (330)/(30). In other words, a dependent-marked auxiliary verb that appears in the modal dependent final vowel form appeared in the doubly-subject inflected progressive future (332) in what was the likely historical structural antecedent of the modern future in F21 Sukuma: *dv-Biiz-e dv-gřl-e [*1PL-


subject marking has been lost on the initial verb in the future in Sukuma, and this form thus rather reflects a LEX-headed construction (330) synchronically. 
(329) $\mathrm{AV}: e_{\text {SBNACTV }}$ sUBJ-LV- $e_{\text {SBNACTV }}$

(330) F21 Sukuma

$$
\begin{aligned}
& \check{I z} \boldsymbol{e} \quad d \mho-g \check{l}-\boldsymbol{e} \\
& \text { FUT:FV } V_{\mathrm{SBNCTV}} 1 \text { 1PL-buy-FV } \\
& \text { 'we will buy' (Nurse 2008: 299) }
\end{aligned}
$$

(331) SUBJ-AV- $e_{\text {SBJNCTV }}$ SUBJ-LV-a

(332) F21 Sukuma

$$
\begin{array}{ll}
d \mho-\text { Biiz-e } & d \mho-l_{\text {II-góla }} \\
\text { 1PL-AUX-FV } & \text { 1PL-TA-buy:FV } \\
\text { 'we'll be buying' } & \text { (Nurse 2008: 299) }
\end{array}
$$

As mentioned above one suspects that something like this kind of development might have occurred in the history of [G60] Kerewe. Here the future saa $<s a$ 'come' appears in a LEX-headed formation.

(333) AV SUBJ-LV:a

(334) G60 Kerewe

$$
\begin{aligned}
& \text { saa tu-gula } \\
& \text { FUT 1PL-buy:FV } \\
& \text { 'we will buy' (Kießling et al. 2008: 201) }
\end{aligned}
$$

This LEX-headed formation may well have derived from a doubled formation the type of which is exemplified by the second auxiliary verb $-v a$ in the complex future perfect AVC (336). 
(336) G60 Kerewe

$$
\begin{aligned}
& \text { saa tu-va tu-gus-ile } \\
& \text { FUT 1PL-AUX 1PL-buy-PRF } \\
& \text { 'we will have bought' (Kießling et al. 2008: 201) }
\end{aligned}
$$

Note that the auxiliary $-s a<$ 'come' also appears in an intentional/immediate future AVC in Kerewe as well (338) in the common Bantu AUX-headed configuration (lexical verb in the infinitive form plus final vowel $-a$ ).

$$
\text { SUBJ-AV INF-LV: } a
$$

(338) G60 Kerewe

$$
\begin{aligned}
& \text { tu-sa } \quad \boldsymbol{k} \boldsymbol{u} \text {-gula } \\
& \text { 1PL-AUX INF-buy:FV } \\
& \text { 'we are going to buy' (Kießling et al. 2008: 200) }
\end{aligned}
$$

It is not clear if the modal element anga in G23 Shambaa likewise comes from an eroded double subject formation as seems likely for both F21 Sukuma and G60 Kerewe. Perhaps it is noteworthy that such LEX-headed formations are common in G23 Shambaa's close sister variety, G23 Shambala. Note that synchronically this element anga may be alternatively incorporated into a larger verbal complex in the TA position in the verbal template in G23 Shambaa.

(339) a. G23 $\underline{\text { Shambaa }}$

$\begin{array}{ll}\text { anga } & \text { ti-za-dika } \\ \text { MOD } & \text { 1PL-AUX-cook:FV }\end{array}$

'we would have cooked'

(Nurse 2008: 251) b. G23 Shambaa

t-angá-dika

1PL-MOD-cook:FV

'we would have cooked'

6.6 Tense-marked pronouns or fused subject/auxiliary formations in Bantu. In addition to true split and LEX-headed formations, which, as I alluded to above, are rather rare among Bantu languages, so too are pronominals which represent fused TAM auxiliaries historically. Such formations are found across the languages of the MacroSudan Belt, which peripherally includes some northwestern Bantu languages, for 
example A71 Eton and 'Bantoid' languages (Watters 1989, Hedinger 1989, Watters and Leroy 1989). Note that such formations are found in related Benue-Congo languages and other groups more distantly related to Bantu (see section 12 for a discussion of these languages in the context of the areal characteristics of the languages of the MacroSudanic Belt).

In Eton clause-initial forms of the (historically) fused subject pronoun/auxiliary type are found with phonologically dependent 'infinitive' forms of the lexical verb.

(340) SubjProN:AV INF:LV

(341) a. A71 Eton

mèté ${ }^{\downarrow}$ bógbô vá

$1:$ PRS INF:sit:PNL here

'I sit down here' (Van de Velde 2008: 132)

b. A71 Eton

wèèy só idén

2:FUT INF:come when

'when will you come?' (Van de Velde 2008: 180)

In Wambo Bantu languages of Angola and Namibia, there are subject/auxiliary forms with a similar origin. Some of these appear as free-standing forms and are embedded in various inflectional sub-types of AVCs. Thus in R242 Eunda present and negative present first person 'pronouns' are found in an AUX-headed configuration:

(342) R242 Eunda (Wambo Bantu)

ándi lóngó itandí lóngo

PRS:1 work NEG:PRS: 1 work

'I work' 'I do not work' (Baucom 1972: 67)

(343) < AUX-1 work < NEG-AUX-1 work 
Mbalanhu has similar non-past and negative non-past first person 'pronouns' but used with a future tense marker ( $<$ 'go') to mark future and negative future, respectively. The future is similar to the present form in Eunda above, only using the future auxiliary between the 'tense-marked pronoun' and the verb.

(344) NPST:1 FUT LV < AUX-1 FUT LV

(345) Mbalanhu

ándi ká longó

NPST:1 FUT work

'I will work' (Fourie 1993: 24-25)

In the Mbalanhu negative future the lexical verb appears rather in the final vowel form in $-a$.

(346) NEG.NPST:1 FUT LV: $a<$ NEG-AUX-1 FUT LV: $a$

(347) $\underline{\text { Mbalanhu }}$

ihándi ká longá

NEG:NPST:1 FUT work: $a$

'I won't work' (Fourie 1993: 24-25)

In Ngandjera and Evale similar forms are found but used together with a phonologically dependent use of this $k a$ - future < 'go' in a fused auxiliary structure, with perhaps the now fused future being reanalyzed as a type of dependent marker? This is used together with the present tense (or non-past) 'pronoun'.

(348) PRS:1 AUX-LV: $a<$ NEG-AUX-1 AUX-LV: $a \quad<$ PV-AUX-1 AUX $<$ go $>$ work:FV

(349) Ngandjera

standi ka-lónga

PRS:1 AUX-work

'I am going to work; I shall work' (Baucom 1972: 68) 
(350) $<$ AUX-1 AUX $<\mathrm{g} o>$-work:FV

(351) Evale

andi ka-lónga

PRS:1 AUX-work

'I am going to work' (Baucom 1972: 68)

6.7 Fused/fused formations: More on complex verbs in Wambo Bantu. The final stage in this development is the reconstituting of larger fused complex verb forms that are typical of Bantu languages, as seen in Oshikwanyama, which has a perfect form also derived from split forms of the shape $<{ }^{*}$ NEG-TA<AUX-SUBJ[?-AUX?] LEX-PRF. As perfect was marked on the original lexical verb and the remaining inflectional categories on the former auxiliary, this Oshikwanyama formation represents a type of fused split structure.

(352) NEG-PST-1-work-PRF $<*$ NEG-AV-1 LV-FV PRF

(353) Oshikwanyama (Wambo Bantu)

inandi-lóngélé

1 :NEG:PST-work:PRF

'I have not worked' (Baucom 1972: 67)

Many Wambo Bantu varieties have fused/fused forms of this sort, including Mbandja, Kolonkadhi, and Kwambi.

(354) $<$ NEG-AV-1-LV-CONEG $<*$ NEG-AV-1 LV-CONEG

(355) Kwambi (Wambo Bantu)

ihándi-róngo-tsă

NEG:HAB: 1 -work-NEG

'I don't usually work' (Baucom 1972: 67)

$(356)<* N E G-A V-1 \mathrm{AV}_{<\mathrm{g}_{0}>} \mathrm{LV}: \mathrm{FV}$ 
(357) Kolonkadhi

itándi-ká-lojga

NEG:FUT:1-AUX-work

'I shall not work' (Baucom 1972: 68)

$(358)<*$ NEG-AV-1 AV $<\mathrm{g}_{0}>\mathrm{LV}: \mathrm{FV}$

(359) Mbandja

ihái-ká-loyga

NEG:FUT:1-AUX-work

'I shall not work' (Baucom 1972: 68)

6.8 On the AVC origins of synthetic TAM formations in Bantu. Tense prefixes in Bantu generally come from fused AVCs. These reflect both the dominant AUX-headed order characteristic of the family and the family-wide favoring of AUX-V order. These genetic/typological insights may also be used to help understand the origin of complex verb forms in individual Bantu languages. Bantu languages are rightly famous for their large complex verb forms. These complex forms typically represent the fusing of auxiliary verb structures. Sometimes all that is left of the construction is the auxiliary verb and the lexical verb stem. This is the case in the definite near future in -na- in N42 Sena and the present in $-n a$ - in G42 Swahili:

(360) *SUBJ-AV INF-LV $>{ }^{*}$ SUBJ-AV-INF-LV $>$ SUBJ-TA $<$ AV $>$ LV

(361) N44 Sena

ndi-na-dya

1-FUT-eat:FV

'I will eat, near/more certain' (Nurse 2008: 92) 
(362) G42 $\underline{\text { Swahili }}$
ni-na-taka
1-PRS-want
'I want' cf. -na 'have' (Field Notes)

Sometimes all that is left of an original AUX-headed structure in a given Bantu language is the infinitive marker, now itself having assumed the function of the original AVC. Such developments probably independently underly the formation of the present form in $-k u$ - in G11 Gogo and the future form in $-k u$ - in H42 Hungu.

(363) *SUBJ-AV INF-LV $>{ }^{*}$ SUBJ-AV-INF-LV $>$ SUBJ-TA $_{<\mathbb{N F}>}-\mathrm{LV}$

(364) G11 Gogo

$n i-k u$-gulá

1-GENERAL.PRS-buy:FV

'I buy' (Nurse 2008: 209)

(365) H42 Hungu
tu-ku-sumba
1 PL-FUT-buy:FV
'we will buy' (Nurse 2008: 209)

Because fused fuller structures are also found in other Bantu languages, it is easy to see how such forms would erode over time or in rapid speech. A fused AUX-headed AVC with an infinitive marked lexical verb may be found in the following Chichewa form:

(366) *SUBJ-TA-AV INF-LV > SUBJ-TA-AV-INF-LV 
(367) $\underline{\text { Chichewa }}$
ndi-na-li-ku-gona
pamene mu-na-ndi-ona
1-REM.PST-AUX-INF-sleep:FV when
2PL-REM.PST-1-see:FV
'I was sleeping when you saw me'

(Bentley and Kulemeka 2001: 33)

Other fused forms can be seen in individual Bantu languages derived from an original 'be (located/at)' plus locative (+ infinitive) marked construction encoding the progressive. A form with both the locative and infinitive preserved, in addition to the nearly eroded auxiliary may be seen in the following complex verb form in D28 Holoholo:

$(368)<*$ SUBJ-AV LOC-INF-LV

(369) D28 $\underline{\text { Holoholo }}$

$$
w-i-m u ́-k u-k e b a
$$

3-AUX-LOC-INF-search:FV

'she is searching' (Nurse 2008: 209)

With the locative marker alone preserved, the progressive form in B73 Lyaa reflects a univerbation of an original'be' + locative formation.

(370) *SUBJ(-TA)-AV LOC-INF-LV > > SUBJ(-TA)-AV-LOC-LV

(371) a. B73 Lyaa

bisí di-li-mu-sála

we 1PL-AUX-LOC:at-work:FV

'we are working' (Nurse 2008: 250)

b. B73 Lyaa

$$
\begin{aligned}
& \text { me } \quad n \text {-a-bá-mu-sála } \\
& \text { I } \quad \text { 1-PST-AUX-LOC:at-work:FV } \\
& \text { 'I was working' (Nurse 2008: 250) }
\end{aligned}
$$


The reader may have noticed that all the above complex verb forms derived from fused AVCs from across the Bantu languages reflect lexical verbs in the $-a$ final vowel form and this is typical of such complex verb forms in Bantu derived from AUX-headed AVCs. Fused AVCs with a verb in the dependent modal final vowel form in $-e$ are uncommon but may be found in such forms as the far future in JE31c Bukusu. Such a fact may suggest that this future derived from an eroded doubly inflected formation in Bukusu, not an AUX-headed formation which anomalously has the lexical verb in this modal dependent $-e$ final vowel form.

(372) SUBJ-TA-LV- $e_{\text {SBINCTV }}<$ ?*SUBJ-AV SUBJ-LV- $e_{\text {SBINCTV }}$

(373) JE31c/E31 Bukusu

$x u-x a-x u l-e$
1 PL-FUT-buy-FV
'we will buy $\left\{\mathrm{F}_{2}\right\}$ ' (Nurse 2008: 243)

The formation of just the future alone in Bantu could constitute the subject of a monograph in itself. Far and away the most common verb to get grammaticalized as a future in Bantu languages is the verb 'come', which has entered into grammaticalization paths in different Bantu languages at different stages (as it has in many African languages, see 4.1 above). Indeed, a wide range of patterns and variants are attested when looking at the full spectrum of future AVCs across the languages of the Bantu family. The crastinal future in Kinyarwanda is encoded by a fused version of what was probably historically the same structure, an AUX-headed formation using the verb come.

(374) SUBJ-TA-LV: $a \quad<$ ?*SUBJ-AV [INF-]LV: $a$

(375) J60/D61 Kinyarwanda

a-za-kora

1-FUT-work:FV

'he will work (after today)' (Botne 1990: 190; Hurel 1911)

A cognate looking fused formation preserving the infinitive marker is found in Zulu (377). 
(376) SUBJ-TA-INF:LV: $a \quad<$ ?*SUBJ-AV INF-LV: $a$

(377) $\underline{\text { Zulu }}$

ygi-za-ukuthanda

1-FUT-INF:love:FV

'I will love' (Meinhof 1948: 114)

The future form itself that gave rise to these bound future prefixes probably arose from a structure of 'come' plus an original infinitival complement clause. The putative original structure is in fact found in Kinyarwanda in the near future tense, which remains an AUXheaded AVC structure with an infinitive-marked lexical verb:

(378) J60/D61 Kinyarwanda

a-za gu-kora

1-FUT INF-work:FV

'he will work (later today)' (Botne 1990: 190; Hurel 1911)

$\underline{\text { Kinyarwanda }}$

SUBJ-AUX $<=$ FUT $>$ INF-LV- $a \quad z a$ hodiernal future

SUBJ-AUX $<=$ FUT $>$-LV- $a \quad$ crastinal future

$\underline{\text { Konde }}$

SUBJ-AUX $<=$ FUT $>$ INF-LV- $a$ sa future

$\underline{\text { Zulu }}$

SUBJ-AUX $<=$ FUT $>-L V-a \quad z a$ future

Table 6: Future < 'come' in Kinyarwanda, Makonde and Zulu

Nurse (2008: 254) describes a fused split AVC in F23 Sumbwa with the final vowel position on the original lexical verb encoding the perfect. Nurse has argued convincingly 
that the final vowel slot originally encoded aspectual or modal/aspectual semantics in Proto-Bantu. The F23 Sumbwa hesternal past is a fused AUX-headed form with the final vowel $-a$.

(379) SUBJ-TA-LV: $a \quad<$ ?*SUBJ-AV INF-LV: $a$

(380) F23 $\underline{\text { Sumbwa }}$

$$
\begin{aligned}
& \text { tw-a:la:-gol-a } \\
& \text { 1PL-TA-buy-FV } \\
& \text { 'we bought }\left\{\mathrm{P}_{2}\right\} \text { ' Nurse (2008: 255) }
\end{aligned}
$$

The past perfect form in the language on the other hand is a fused split form with the perfect suffix -ile in the final vowel slot of the lexical verb.

(381) SUBJ-TA-LV-ile $e_{\mathrm{PRF}}<*$ SUBJ-AV LV-ile $e_{\mathrm{PRF}}$

(382) F23 Sumbwa

$$
\begin{aligned}
& \text { tw-a:la:-gol-ile } \\
& \text { 1PL-TA-buy-FV } \\
& \text { 'we had bought' Nurse (2008: 255) }
\end{aligned}
$$

M63 Ila shows similar fused split forms where perfect was marked on the original lexical verb element and subject and tense on the original auxiliary.

$$
\text { SUBJ-TA-TA-LV-ile } e_{\mathrm{PRF}}
$$

$$
<*_{\text {SUBJ-TA-AV LV-ile }}
$$

(384) a. M63 $\underline{\text { la }}$

$$
\text { b. M63 Ila }
$$

$$
\begin{aligned}
& \text { tw-aká-ákú-p-ele } \\
& \text { 1PL-TA-ANT-give-PRF } \\
& \text { 'we have given }\left\{\mathrm{P}_{2}\right\} \text { ', }
\end{aligned}
$$$$
\text { tw-a-ákú-p-ele }
$$$$
\text { 1PL-TA-ANT-give-PRF }
$$$$
\text { 'we have given }\left\{\mathrm{P}_{1}\right\} \text { ' }
$$ 
c. M63 Ila

$$
\begin{aligned}
& \text { tu-la-aku-p-elé } \\
& \text { 1PL-FUT-ANT-give-PRF } \\
& \text { 'we will have given' (Nurse 2008: 158) }
\end{aligned}
$$

Fused doubled formations may not appear per se in Bantu (but see the Tonga alternations described above for one possible example of just such a structure). In fast speech however they are probably common with AVCs showing doubled inflection in many Bantu languages.

Unsurprisingly, just as LEX-headed formations are rare in Bantu languages, so too are fused complex verb forms derived from such structures. One possible exception is the use of the negative and some TAM markers that appear in the pre-initial position in a range of Bantu languages. Negative markers appearing in this position may derive from original auxiliary structures in S52 Tsongo or S62 Tonga.

$$
\text { NEG-SUBJ-LV- } i_{<\mathrm{CONEG}>}
$$$$
<? * \text { NEG/AV SUBJ-LV- } i_{<\mathrm{CONEG}}>
$$$$
<? ? * \text { SUBJ-NEG/AV SUBJ-LV- } i_{<\mathrm{CONEG}>}
$$

(386) S53 Tsongo

$$
\begin{aligned}
& a-h i-d y-i \quad \text { buswa } \\
& \text { NEG-1PL-eat-FV } V_{\text {CONEG }} \text { porridge } \\
& \text { 'we don't eat porridge' (Nurse 2008: 269) }
\end{aligned}
$$

(387) S62 Tonga

$$
\begin{aligned}
& \text { kha-hi-hoj-i } \\
& \text { NEG-1PL-eat-FV }{ }_{\text {CONEG }} \\
& \text { 'we don't eat' (Nurse 2008: 269) }
\end{aligned}
$$

The future in G52 Ndamba which derives from daghaya 'want' is a clear example of a fused LEX-headed formation in a complex verb form (note the modal dependent final vowel).

$$
\begin{aligned}
\text { (388) TA-SUBJ-LV- } i_{<\mathrm{DEP}>} & <? * \mathrm{AV} \quad \text { SUBJ-LV- } i_{<\mathrm{DEP}>} \\
& <? ?^{*} \mathrm{SUBJ}-\mathrm{AV} \quad \text { SUBJ-LV- } i_{<\mathrm{DEP}>}
\end{aligned}
$$


(389) G52 Ndamba

da-tu-telek-i

FUT-1PL-cook-FV:DEP

'we will cook' (Nurse 2008: 299)

Similar to the development of the future prefix $d a$ - in G52 Ndamba, a fused LEX-headed formation is probably what underlies the future formation in Shambala as well. Like the form above, the lexical verb in this fused AVC appears in a modal dependent form.

$$
\begin{aligned}
\text { (390) TA-SUBJ-LV- }-e_{\text {SBNNCTV }} & <? * A V \quad \text { SUBJ-LV- } e_{\text {SBINCTV }} \\
& <? ? * \text { SUBJ-AV } \quad \text { SUBJ-LV- } e_{\text {SB,NCTV }}
\end{aligned}
$$

(391) Shambala

$n \grave{e}-n i ́-d i k$-è

FUT-1-cook-SBJNCTV

'I will cook' (Mfwumba Besha 1989: 66)

Similar to the argument put forth with repsect to Bukusu above, that the lexical verb is in the modal dependent form in -e in Shambala might suggest that the form in question derives from an eroded doubly inflected form originally. Consider now the following form from P22 Mwera. The near future complex has the form of what appears to be a fused LEX-headed formation similar to the Shambala and Ndamba ones above.

(392) P22 Mwera

ci-tu-um-e

AUX-1PL-buy-FV SBJNCTV $_{\text {. }}$

'we will, are about to buy (today, tomorrow)' (Nurse 2008: 195)

Like Shambala and Bukusu, the modal dependent form of the final vowel in the verb form suggests it may derive from a doubly inflected form of the type presented above. AUX-headed formations in Mwera typically have the final vowel $-a$, as do fused forms derived from them (393), as indeed do certain of the doubly inflected AVCs in this language (394): 
(393) $\underline{\text { Mwera }}$

$\begin{array}{ll}\text { tw-a:ci-um-a} & t u-c i-u m-a \\ \text { 1PL-TA-buy-FV } & 1 \text { PL-TA-buy-FV } \\ \text { 'we bought two days ago' } & \text { 'we bought (recently)' }\end{array}$

(Nurse 2008: 195)

(394) $\underline{\text { Mwera }}$

$$
\begin{aligned}
& t w-a: c i \text { tu- } \varnothing-u m-a \\
& \text { 1PL-AUX 1PL-TA-buy-FV } \\
& \text { 'we were about to buy' (Nurse 2008: 195) }
\end{aligned}
$$

The only example of a quasi-fused split/doubled pattern that I have in my data set from Bantu is the fast speech form of the following Xhosa AVC. One suspects that similar quasi-fused formations are found in rapid speech of many if not most Bantu languages.

(395) Xhosa (Bantu; South Africa)

$$
\begin{array}{lll}
n d-a-n d i-t h e t h-i l e & n d-a-y e & n d i-t h e t h-i l e \\
\text { 1SG-PLUP-1SG-speak-PRF } & \text { 1SG-PLUP-AUX 1SG-speak-PRF } \\
\text { 'I had spoken (long ago)' } & \text { 'I had spoken (long ago)' }
\end{array}
$$

(Heine 1993: 108)

6.10 Summary of inflectional patterns in Bantu AVCs. Bantu languages have highly developed verb systems that exhibit an enormous range of variation, both in terms of degrees of synthesis seen in the verbal systems, as well as the sheer number of verbal constructions that have been grammaticalized repeatedly throughout a couple of millennia of development across the vast expanse of Bantu languages. To be sure familiar AUX-headed formations are common, with lexical verbs showing construction-dependent forms expressed both prefixally through infinitive, participial, or subordinate morphology, and suffixally through the use of the so-called final vowel position in the Bantu verb template. Doubled inflectional patterns, often with subject doubly expressed but lexical verbs in a dependent-marked form, are also highly characteristic of Bantu. Perhaps most characteristic of the family is the use of split/doubled inflectional patterns, where the doubled category is largely subject. Common splits include object-encoding 
being restricted to lexical verbs, but negative marking shows many complicated subpatterns across the various Bantu languages. True split and LEX-headed AVCs are quite uncommon in Bantu, as are fused subject/auxiliary forms or TAM/polarity pronouns. Finally, many complex verb forms in contemporary Bantu languages derived from the fusing of AVCs that were primarily of the AUX-headed type.

\begin{tabular}{ll}
\hline \hline AH & Akoose; Duala; Bassa; Duma; Ekegusii; Kaguru; Kinyarwanda; \\
& Mpoto; Sena; Kikongo; Herero; Bukusu; Nedndeule; Umbundu; Tsotso \\
& (V AUX); Mbugwe (V AUX) \\
2x & Akoose; Duala; Yambasa; Siluyana; Hemba; Sukuma; Lungu; \\
& Tumbuka; Mwera; Venda; Setswana; Siswati; Sena; Kirundi; \\
& Shambala; Tonga; "Babungo" \\
split & Swahili; N. Sotho \\
S/2 & Nkore-Kiga; Haya; Lamba; Shambala; Swahili; Ciyao; Kuriya; \\
& Pokomo; Luba; Lungu; Sena; Makua-Maverone; Setswana; \\
& Kinyarwanda; Hemba; Kimbu; Ejagham \\
LH & Sukuma; Shambaa; Kerewe \\
f S/TAM/P & Eton; Jarawa; Ngandjera; Eunda; Mbalanhu; Evale \\
fAH & Lyaa; Holoholo; Gogo; Swahili; Hungu; Bukusu; Kinyarwanda; \\
& Chichewa; Sena; Zulu; Makonde \\
f2x & ?Tonga \\
f-split & Sumbwa; Ila \\
fS/2 & ?Xhosa in rapid speech \\
fLH & Mwera; Tsongo; Ndamba; Tonga; Shambala \\
f/fS/TAM/P & Makonde; Evale; Mbandja; Kolonkadhi; Eunda; Ngandjera; \\
& Oshikwanyama
\end{tabular}

Table 7: Patterns of inflection in AVCs in representative Bantu languages 


\section{Chadic}

In this section, I offer a brief overview of the types of AVCs that are found in the languages of the Chadic family. Chadic languages are considered by Güldemann (2008) to form a peripheral member of the Macro-Sudanic Belt linguistic area (see section 12), and certain characteristics of the AVCs of Chadic languages support this position. Chadic languages are of course traditionally considered to be part of the Afroasiatic phylum as well.

7.1 AUX-Headed formations in Chadic. Chadic languages do not use AUX-headed formations as frequently as one might expect given how common auxiliary verb constructions are in these languages. That is not to say that AUX-headed AVCs are not attested in Chadic languages, since that is far from the case. In the Nigerian Chadic language Kwami, the number of the subject is encoded in the auxiliary, while lexical verbs appear in a variety of non-finite, nominalized, or subordinate forms, determined by the specific AVC they are embedded within, as for example the 'verbal noun' form in the following AUX-headed potential AVC.

(396) AV:SUBJ:TA LV<VN>

(397) Kwami [Chadic; Nigeria]

yìn dùmángò mècè

they AUX:PL:PST travel:VN

'could they travel?' (Leger 1994: 251)

Sayanci of Nigeria shows a similar construction to the formation in Kwami with a nominalized form of the lexical verb and subject prefixes on the auxiliary verb in the progressive.

(398) SUBJ-AV LV-VN 
(399) a. Sayanci

m-yìgá nál-gánì
1-AUX build-VN
'I am building'
(Schneeberg 1971: 95) b. Sayanci

$$
\begin{aligned}
& \text { m-yìgá gàm-gànì } \\
& \text { 1-AUX put-VN } \\
& \text { 'I am putting' }
\end{aligned}
$$

In Pero, the auxiliary -ikka encoding progressive licenses a lexical verb in an AUXheaded construction in either a bare-stem (or Ø-marked) form for active verbs or with the stative suffix for statives:

(400) SUBJ-AV LV[-STAT]

(401) a. Pero (W. Chadic)

nì-íkka tùkk-áanì
1-PROG hide-STAT
'I am hiding'

(Frajzyngier 1989: 103) b. $\underline{\text { Pero }}$

$$
\begin{aligned}
& \text { ni-ikka có mín(a) } \\
& \text { 1-PROG drink beer } \\
& \text { 'I am drinking beer' } \\
& \text { (Frajzyngier 1989: 104) }
\end{aligned}
$$

An AVC reflecting a familiar AUX-headed pattern may be found in Hausa. The subject is encoded via a suffix and the lexical verb appears in a structurally determined form, either a Ø-marked or phonologically dependent form (if the verb stem is monosyllabic), e.g., with auxiliaries $z a$ FUT, kan HAB, or a morphologically dependent form in $-y a$, e.g., with the auxiliaries $n a$ PROG and $b a$ PROG.NEG. Note that this dependent form of the lexical verb has nothing to do with whether the auxiliary verb inflects prefixally $(-k a n,-n a)$ or suffixally ( $z a-, b a-)$ in Hausa.
(402) $z a-$
AV-SUBJ
LV $[<$ phonologically.DEP $>]$
(403) ba-
AV-SUBJ
LV-DEP
(404) -kan SUBJ-AV
LV $[<$ phonologically.DEP $>]$
(405) -na SUBJ-AV
LV-DEP 
(406) Hausa (Chadic, Nigeria)

$z a ́-n \quad z o ́ o ́$

AUX-1 come

'I will come' (Heine 1993: 77)

(407) $\underline{\text { Hausa }}$

$z a-t a \quad$ tafi

FUT-3F go

'she will go'

(Schachter 1985: 42)
(408) $\underline{\text { Hausa }}$

$$
\begin{aligned}
& \text { ta-kan tafi } \\
& \text { 3F-HAB go } \\
& \text { 'she goes' }
\end{aligned}
$$

(409) $\underline{\text { Hausa }}$

ta-na tafi-ya

3F-PROG go-DEP

'she is going'

(Schachter 1985: 42)
(410) $\underline{\text { Hausa }}$

ba-ta tafi-ya

PROG:NEG-3F go-DEP

'she isn't going'

7.2 Doubled inflection in Chadic AVCs. Doubled inflection per se is also not common in Chadic languages. What is common is the use of intransitive copy or recapitulative 'pronouns' (Frajzyngier 1977) that give rise to structures that seem like double subject marking (see 7.3 below). However, true doubled subject formations are found in at least the Biu-Mandara Chadic language Muyang of Cameroon.

(411) SUBJ-AV SUBJ-LV

(412) Muyang



'he's about to eat something' (Smith 2010: 103)

7.3 Intransitive copy pronouns in Chadic AVCs. Chadic languages share, along with certain other genetic units of Nigeria and Cameroon (and of the Macro-Sudan Belt), a characteristic process of pronoun or pronominal agreement marker copying or what has 
been called an intransitive copy pronoun or a recapitulative pronoun. One language where this process is particularly robust is the Biu-Mandara Chadic language Gidar of the Nigeria/Cameroon/Chad border region. The process operates much as the name 'intransitive copy' suggests, that is, an agreement marker-in what is often an object slotpleonastically refers to the subject of the intransitive verb, thus marked on a lexical verb in an otherwise AUX-headed looking structure:

SUBJ-AV LV <INTRANS $>$-SUBJ Vs. SUBJ-AV LV $_{<\text {TRANS }>}$-OBJ

(414) a. Gidar



IMP-leaveASSC where 2-FUT leave-2 all

'leave by wherever you want to leave' (Frajzyngier 2008: 64)

b. Gidar

á-nná sá-w á jáabè

FUT-1 be-1 PREP Djabe

'I will be in Djabe'

(Frajzyngier 2008: 141) c. Gidar

wásá-n á jáabè

FUT:3 be-3M PREP Djabe

'he will be in Djabe'

d. Gidar

sá jáabè nà-dà zá-wà

from Djabe 1-DEP.PROG come-1

'I just came from Djabe' (Frajzyngier 2008: 143)

Note that this intransitive copy pattern has many formal realizations in Gidar, and the verb may be proceeded by a complementizer and an infinitive marker with feminine singular subjects in the negative capabilitive AVC (416), but lacking the infinitive with first singular subjects (418).

(415) $\mathrm{SUBJ}_{<\mathrm{F} . \mathrm{SG}>}-\mathrm{AV} \quad \mathrm{INF}-\mathrm{LV}-\mathrm{SUBJ}_{<\mathrm{F} . \mathrm{SG}}>$ 
(416) Gidar

$$
\begin{aligned}
& \text { tà-bàp ná o-zzà-t } \quad b a ̀ \\
& \text { 3F-able COMP INF-come-3F NEG } \\
& \text { 'she cannot come' (Frajzyngier 2008: 434) }
\end{aligned}
$$

(417) SUBJ $_{<1 S G>}-A V L V-S U B J_{<1 S G>}$

(418) Gidar

$$
\begin{aligned}
& \text { nذ̀-6àp ná zá-w } 6 a ̀ \\
& \text { 1-able COMP come-1 NEG } \\
& \text { 'I cannot come' (Frajzyngier 2008: 434) }
\end{aligned}
$$

7.4 Split inflection in Chadic AVCs. In a reflection of the cross-linguistically most common split pattern seen in AUX V languages, there are constructions in Gidar in which subject is encoded on the auxiliary verb and object on the lexical verb:

(419) AV-SUBJ LV-OBJ

(420) a. Gidar

$w \grave{a}-n \quad p l a ́-n$ wàtì $n \grave{a}-w$ sù-kó

FUT-1 leave-3M cow GEN-1 DAT-2

'I will leave my cow for you' (Frajzyngier 2008: 72)

b. Gidar

$$
\begin{aligned}
& \text { mà wín tà-t ázgál-nì } \\
& \text { mother child PROG-F feed-3M } \\
& \text { 'the mother is feeding the baby' (Frajzyngier 2008: 154) }
\end{aligned}
$$


c. Gidar

in $t a \grave{a}-t$

d. Gidar

úlà-n

1 PROG-COP.F

'I see him' see-3M

e. Gidar

(Frajzyngier 2008: 160) [ìntàtúlànì]

\section{f. Gidar}

wá-nò mpòr-kó

FUT-1 chew-2

'I will eat you' (Frajzyngier 2008: 263)

Causative formations in Gidar work this same way, except that the subject is encoded on the lexical verb and the auxiliary encodes the object and the tense/aspect in an otherwise atypical V AUX configuration in Gidar.

(421) SUBJ-LV AV-OBJ-TA

(422) a. Gidar

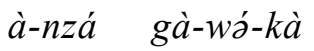

3M-run CAUS-1-PRF

'he made me run' (Frajzyngier 2008: 138)

b. Gidar

á nà-nzá gà-n gáwlá nkà

FUT 1-run CAUS-3M lad DEM

'I will make this lad run'

(Frajzyngier 2008: 171) 
c. $\underline{\text { Gidar }}$

$$
\begin{aligned}
& \text { nà-nzá gà-ná-k pársá nkà } \\
& \text { 1-run 1-CAUS-3M-PRF horse DEM } \\
& \text { 'I made this horse run' (Frajzyngier 2008: 171) }
\end{aligned}
$$

7.5 LEX-headed AVCs in Chadic. LEX-headed formations are marked and uncommon in Chadic languages but such formations are found in Gidar and Hdi. In the second person and third feminine singular with the future auxiliary wá in Gidar, the auxiliary is bare and there is a bizarre LEX-headed-cum-doubled formation where subject is doubly encoded on the lexical verb, most likely reflecting an instantiation of the intransitive copy pronoun.

(423) AV SUBJ-LV-SUBJ

(424) a. Gidar

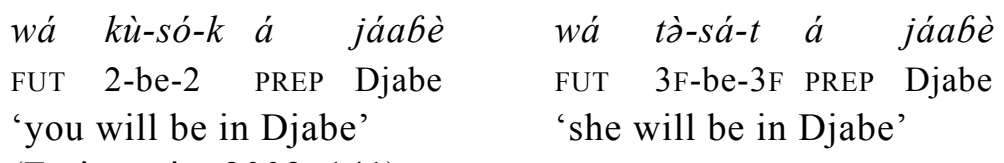
'you will be in Djabe' 'she will be in Djabe' (Frajzyngier 2008: 141)

The Gidar progressive in tà shows a similar distribution to the future, with a LEX-headed formation, subject and object both encoded on the lexical verb in the following AVC. ${ }^{35}$

(425) AV LV-OBJ-SUBJ

(426) Gidar

$$
\begin{aligned}
& \text { tà wlà-má-nì } \\
& \text { PROG see-1 PL-PL } \\
& \text { 'they see us' (Frajzyngier 2008: 247) }
\end{aligned}
$$

The other Chadic language with a LEX-headed AVC in my corpus is the nearby Hdi where the future in $d z a^{\prime} a ́$ appears in such a configuration:

\footnotetext{
${ }^{35}$ Note that gender shows a split inflectional distribution with this same auxiliary.
} 
(427) $\underline{\text { Hdi [Chadic; Cameroon, Nigeria] }}$

$$
\begin{aligned}
& \text { dzà'á gùy-éy-mú tá vghá màxtsím } \\
& \text { FUT meet-POT:OBJ-1PL OBJ body tomorrow } \\
& \text { 'will we meet tomorrow?' (Frajzyngier and Shay 2002: 197) }
\end{aligned}
$$

7.6 'Tensed pronouns' in Chadic. Tensed pronouns or fused subject auxiliary formswhich I call $\mathrm{S} / \mathrm{TAM} / \mathrm{P}$ morphs (for subject/tense-aspect-mood-polarity portmanteau morphs)-are well attested in Chadic languages, a fact which reflects their status as peripheral members of the Macro-Sudan Belt linguistic area where such formations are not uncommon (see 12.6 below). Thus such forms are found embedded within AUXheaded formations with Ø-marked lexical verbs in such West Chadic languages like various Gùrdùn varieties, Ader Hausa, and Angas, or the Biu-Mandara Chadic language Mbuko.

(428) SUBJ:AV LV

(429) a. Kùrukù Gùrdùn

àay wari

1. come

'I shall come'

(Haruna 2003: 14)

(430) a. Gayàr Gùrdùn

iĭy wari

1.FUT come

'I shall come'

(Haruna 2003: 14) b. Kùrukù Gùrdùn

taa wari

3.FUT come

'she shall come'

b. Gayàr Gùrdùn

tii wari

3.FUT come

'she shall come' 
(431) Ader Hausa

ani kay mà innà cf. Standard Hausa naà 2:POT

1:POT take to my.mother

'I will take them to my mother' (Caron 1989: 138)

(432) a. Angas

b. Angas

c. $\underline{\text { Angas }}$



(433) Mbuko
$n \bar{\imath} \quad z l \bar{a} m b \bar{a} l$
1.IMPF throw
'I am throwing' (Gravina 2001: 7)

The following fused subject/auxiliary form in Polci is found in a split inflectional configuration, with subject marked on the auxiliary and object on the lexical verb. A very similar formation is seen in the Biu-Mandara language Mofu-Gudur.

(434) SUBJ:AV LV-OBJ

(435) $\underline{\text { Polci }}$

Gărbà kan ndzay slo: wúde ka fŭ:-m

Garba COP couper viande ACC INJ 2:AOR dire-1

'Si Garba égorge une bête, dis-le moi' (Caron 2008: 153)

(436) Mofu-Gudur

fá tá-ka dáf

PROG.3 prepare-2.IO food

'she is preparing you food' (Pohlig 1992: 4) 
In the Biu-Mandara Chadic language Merey, tense-marked pronouns or fused subjectauxiliary formations are used in combination with tense-marking on the lexical verb in a kind of split/doubled configuration in the present tense:

(437) SUBJ:AV $V_{<P R S} \quad$ LV-PRS

(438) Merey

$\begin{array}{llll}\text { ne g-iye } & m a \quad \text {-iye } & n a \quad \text { zal-iye } & \text { mazal-iye } \\ \text { 1.PRS do-PRS } & \text { 3.PRS do-PRS } & \text { 1.PRS call-PRS } & \text { 3.PRS call-PRS } \\ \text { 'I do' } & \text { 'he does' } & \text { 'I call' } & \text { 'he calls' }\end{array}$

(Gravina 2007: 8)

In the past tense on the other hand, there is a curious difference between first person forms and those of the third person. The first person forms appear with a tense-marked pronoun (or fused subject auxiliary) with an unmarked lexical verb in a synchronically bi-partite AUX-headed construction similar to the Angas, Gurdun or Ader Hausa forms above (430-432). Third person forms on the other hand appear in a univerbated formation.

(439) SUBJ:AV $\mathrm{CPST}_{\mathrm{P}} \mathrm{LV}$

(440) a. Merey

b. Merey

c. Merey

d. Merey

$\begin{array}{llll}\text { nage } & \text { a-ge } & \text { na zal } & \text { a-zal } \\ \text { 1.PST do } & \text { 3.PST-do } & \text { 1.PST call } & \text { 3.PST-call } \\ \text { 'I did' } & \text { 'he did' } & \text { 'I called' } & \text { 'he called' } \\ \text { (Gravina 2007: 8) } & & \end{array}$

In Dott (also known as Zodi), the lexical verb encodes plurality of various sorts but combines with a tense-encoding pronoun:

(441) SUBJ:AV $V_{<\mathrm{TAM}>} \quad \mathrm{LV}[-\mathrm{PL}]$ 
(442) a. Dott/Zodi

man t ti-ni gálba

1PL.FUT eat-PL victory

'we will win' (Caron 2002: 164)

b. Dott/Zodi

$$
\begin{array}{lll}
m a \quad \text { labát-ni } \quad \dot{u} \quad \text { lootí } \\
\text { 1PL.AOR migrate-PL } & \text { GEN far } \\
\text { 'we came from afar' } & \text { (Caron 2002: 164) }
\end{array}
$$

Of all the Chadic languages in my corpus, the most developed system of such tensemarked pronouns or fused subject/auxiliary forms can be found in Guus (Sigidi) as described by Caron (2001), where ten different sets of these forms are attested.

\begin{tabular}{|c|c|c|c|c|c|c|c|}
\hline 1 & $\begin{array}{cc}\mathrm{AOR} & \mathrm{S} \\
m a & \end{array}$ & $\begin{array}{c}\text { SBJNCTV } \\
m \partial\end{array}$ & $\begin{array}{l}\text { IMM.PST } \\
\text { maa }\end{array}$ & $\begin{array}{l}\text { PFV } \\
\text { map }\end{array}$ & $\begin{array}{l}\text { REC.PST } \\
\text { mam }+H\end{array}$ & $\begin{array}{l}\text { IRR } \\
\text { más }\end{array}$ & $\begin{array}{l}\text { REM.PST } \\
m a ́ s a ̂ n\end{array}$ \\
\hline 2 & $k a$ & $k \partial$ & $k a a$ & kap & $k a m+H$ & kás & kásân \\
\hline 3 & $t \int a$ & $t \int i$ & $t \int a a$ & t $\int a p$ & $t \int a m+H$ & $t \int i s$ & $t \int i ́ s \hat{\partial} n$ \\
\hline $1 \mathrm{pl}$ & $-m a ̀ ?$ & ? mò & màà & màp & màm $+H$ & $m \grave{s}$ & $m \partial ̀ s \hat{n} n$ \\
\hline $2 \mathrm{pl}$ & -kà? & $k \grave{~}$ & 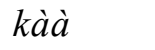 & $k \grave{a} p$ & $k \grave{a} m+H$ & $k \grave{s}$ & kàsân \\
\hline PL & $t \int \grave{a}$ & $t / \hat{\imath}$ & $t \int \grave{a} a ̀$ & $t \int \hat{a} p$ & $t$ tàm $+H$ & $t \int \hat{\imath} S$ & t/îsân \\
\hline
\end{tabular}

(443) SUBJ-AV $\mathrm{C}_{<\mathrm{TAM}>} \mathrm{LV}$

(444) a. Guus (Sigidi)

(Caron 2001: 8-9) 
b. Guus (Sigidi)

\begin{tabular}{|c|c|c|c|}
\hline & FUT & HAB & IPFV \\
\hline 1 & $m ə+H$ & $m ə k a \sim m a k$ & $m ə k \hat{a} p+H$ \\
\hline 2 & $k a+H$ & $k ə k a \sim k a k$ & $k a k a p+H$ \\
\hline 3 & $t f i+H$ & $t \int \partial k a \sim t \int a k$ & tfikap $+H$ \\
\hline $1 \mathrm{pl}$ & $m \grave{\partial}+H$ &  & màkàp + \\
\hline $2 \mathrm{pl}$ & $k \grave{\partial}+H$ & $k ə k a ̀ \sim k a ̀ k$ & $k \grave{k} k \grave{p} p+H$ \\
\hline $3 \mathrm{PL}$ & $t / \hat{\imath}+H$ & $t \int \partial k \grave{a} \sim t \int \grave{a} k$ & $t$ tikà̀ $+H$ \\
\hline
\end{tabular}

(Caron 2001: 8-9)

(445) Guus (Sigidi)

'n ka duu karáytfí máfi
if 2.IRR beat dog $\quad 3$. FUT die
'if you beat the dog, it will die' (Caron 2001: 11)

7.7 Other fused formations in Chadic. The perfect form in Gidar is a clear example of fused double subject form, derived from a V-AUX structure. As these are found with intransitive stems, it is of course possible if not likely that these do not actually reflect doubled subject formations per se, but rather fused versions of the intransitive copy pronoun formations mentioned above.

(446) SUBJ-LV-SUBJ-TAM <?*SUBJ-LV SUBJ-AV

$$
\text { or }<\text { ? }^{*} \text { SUBJ-LV-SUBJ }<\text { ICP }>\text { AV (see (439) above) }
$$

(447) a. Gidar

b. Gidar

à-nzá-n-kà

3M-run-3M-PRF

'he ran'

(Frajzyngier 2008: 138) tò-nzá-t-kà

3 F-run-3F-PRF

'she ran' 


\section{c. Gidar}

$$
\begin{aligned}
& n \grave{\partial}-s a ́-w-k a ̀ a \\
& \text { 1-stay-1-PRF } \\
& \text { 'I sat down' } \\
& \text { (Frajzyngier 2008: 142) }
\end{aligned}
$$

For some speakers, the future in Chadic Gidar has fused, reflecting subject on the original auxiliary and object on the original lexical verb part of the AVC; this thus constitutes a fused split formation with transitives. An example of this was given in (228) above.

Finally, in the Biu-Mandara Chadic language Mbuko of Cameroon, perfect and anterior forms are complex verb forms derived from a fusing of a tense-marked pronoun or fused subject-auxiliary form with the lexical verb univerbated into a larger complex (449). Compare these with the progressive form in Mbuko which remains a synchronically bi-partite AVC, given in (443) above:

(448) SUBJ:AV $V_{<\text {TAM }}-L V: /-T A M \quad<*$ SUBJ:AV $V_{<\text {TAM }} L V: /-T A M$

(449) a. $\underline{\text { Mbuko }}$

nò-zlàmbál

1PRF/ANT-throw:ANT

'I threw'

(Gravina 2001: 7) b. Mbuko

nə-zlāmbāl-ák

1PRF/ANT-throw-PRF

I have thrown' 


$\begin{array}{ll}\text { AH } & \text { Kwami; Sayanci; Pero; Hausa } \\ \text { 2x } & \text { Gidar; Gurdun; Muyang } \\ \text { split } & \text { Gidar } \\ \text { LH } & \text { Gidar } \\ \text { S/TAM/P } & \text { Gurduy; Polci; Ader Hausa, Angas, Mbuko, Merey, Mofu-Gudur } \\ \text { fAH } & \text { Pero } \\ \text { f2x } & \text { Gidar (V-AUX) } \\ \text { f-split } & \text { Gidar } \\ \text { f/fS/TAM/P } & \text { Merey (3.PST); Mbuko (PRF/ANT) } \\ \text { ICP } & \text { Gidar; Pero }\end{array}$

Table 8: Patterns of inflection in AVCs in selected Chadic languages

\section{Khoe}

In this section I present a brief overview of AVCs in Khoe languages. Like most languages of Africa, AUX-headed formations predominate in Khoe languages, which show almost no other types of AVCs in my corpus. Note that the linear phrasal syntactic order of AVCs is usually V AUX in Khoe languages.

8.1 AUX-headed AVCs in Khoe. A typical AUX-headed configuration for Khoe languages can be seen in the perfect in Naro, where the lexical verb precedes the auxiliary and appears in the dependent 'junctural' form.

(450) LV-JNCT SUBJ AV

(451) Naro (Khoisan, Central; Botswana)
キ'ú.á dá $h \bar{a}$
kháó sấN.a.hã́
eat-JNCT I PRF
you geruht.JNCT.PRF
'I have eaten'
'ihr habt geruht'

(Heine 1986: 15-16) 
The perfect form may also optionally appear in a fused (perhaps rapid speech) form in Naro as well (see 8.3 below).

Two AUX-headed formations are found in the Khoe language \|Ani marking prospective tense/aspect (one using an auxiliary meaning 'do' another 'want'); these both appear with a lexical verb in the - $\mid x \grave{\varepsilon}$ dependent form.

(452) LV-INTAV-I/II-TA

(453) a. $\| \underline{\text { Ani }}$

$$
\begin{aligned}
& \text { tá-khòè ||ga-khòè ||'ó-|xغ̀ hìn-à-tà } \\
& \text { old-person FEM-person die-INT PROSP-II-PST }
\end{aligned}
$$

b. $\| \underline{\text { Ani }}$

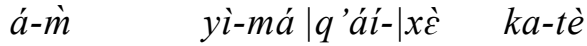

$$
\begin{aligned}
& \text { DEM-M:SG tree-M:SG fall-INT PROSP-PRS } \\
& \text { 'that tree is about to fall' (Heine 1999: 21) }
\end{aligned}
$$

Modern Khwe makes extensive use of V AUX auxiliary structures in a range of functions, e.g., progressive/present, terminative. The lexical verb in such formations appears in one of two or three construction-specific dependent or converb forms (e.g., $k \grave{o},-n a ́)$.

$$
\text { LV-CV AV-I/II-TA }
$$

(455) $\underline{\text { Modern Khwe }}$

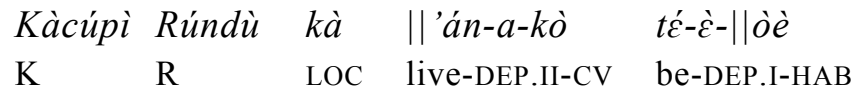

'Kacupi lives in Rundu' (Killian-Hatz 2008: 50) 


\section{Modern Khwe}

xà-má $\quad \tilde{u}-a ́-k \grave{o} \quad x e ́ r i-n a-x u-a-h \tilde{a}$

DEM-3M hunt-DEP.II-CV end-DEP.II-COMPL-II-PST.I

'he finished hunting' (Killian-Hatz 2008: 312)

(456) LV-DEP AV-I/II-TA

(457) Modern Khwe

xà-má thám̀ à igàrá-ná té-غ̀-tè

DEM-3M letter $\mathrm{O}$ write-DEP.II stay-DEP.I-PRS

'he is writing a letter' (Killian-Hatz 2008: 305)

8.2 LEX-headed AVCs in Khoe? The only example I have of a LEX-headed formation among Khoe languages is possibly the durative in !Ora, seen in the following examples:

$$
\text { LV NEG-SUBJ AV or LV-NEG SUBJ AV }
$$

(459) a. !Ora (Khoe-Khoe)

b. !Ora (Khoe-Khoe)

$\begin{array}{lll}\text { \#2an tama-r ha } & \text { mu-tama da hã } \\ \text { know NEG-1 DUR } & \text { see-NEG 1PL DUR } \\ \text { 'ich wieß nicht' } & \text { 'wir haben nicht gesehen' }\end{array}$

(Vossen 1997: 190)

8.3 Fused AUX-headed formations in Khoe TAM marking. Most if not all Khoe varieties make extensive use of fused AVCs in their TAM systems. The auxiliary $-h a /-$ hà̃?-hà encoding perfect (Kua, ||Ani) or past (Buga-/Anda) is found in fused structures throughout the Khoe languages. Note the retention of the dependent marker on the original lexical verb part of the AVC in the complex fused verb forms.

(460) LV-JNCT-TA <?*LV-JNCTAV 
(461) Kua

tá kứ.á.ha

I go.JNCT.PRF

'I went' (Heine 1986: 18)

(462) //Ani (C. Khoisan; Botswana)

tí hì̀-á-hà

I work-JNCT-PRF

'I have worked' (Heine 1986: 18)

(463) Buga-/Anda (Kxoe)
(tí) Pá-ná-hà-bé
I know-JNCT-PST-NEG
'ich weiß (es) nicht' (Vossen 1997)

A selection of such forms that likely derive mainly from fused AVCs in a Khoe language can be seen in the following set from modern Khwe (464) from Killian-Hatz (2008).

(464) Modern Khwe

\begin{tabular}{|c|c|c|}
\hline -tè PRS & $<t \varepsilon ́$ & 'stand, stay' \\
\hline 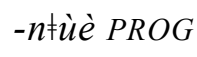 & $<n \neq \tilde{u} \sim n \neq \dot{u}$ & 'sit down' \\
\hline$-\| \grave{O}[\grave{e}] H A B$ & $<\| o^{\prime} e ́$ & 'lie, sleep' \\
\hline$-g \grave{e ̀ ~ F U T ~}$ & $<k o e ́$ & go towards \\
\hline -tà NR.PST & $<\operatorname{tàn}$ & 'stand up' \\
\hline
\end{tabular}

(Killian-Hatz 2008: 98-103)

8.4 Summary. Khoe languages are characterized by an almost exclusive use of AUXheaded auxiliary formations. The one example of a LEX-headed formation that I have may well be a reduced form of a typical AUX-headed formation in Khoe with the familyspecific order of Verb Auxiliary that distinguish these languages both from the Bantu languages as well the Ju and Tuu family languages of southern Africa. The development of numerous tense/aspect/mood suffixes out of former AUX-headed AVCs of the V-AUX configuration further typifies Khoe verbal systems. 
AH Khwe; Naro; \#Ani

LH !Ora

fAH Khwe; Buga-/Anda, ||Ani, Cara, Naro, Kua

Table 9: Patterns of inflection in AVCs in Khoe languages

\section{Nilotic}

The Nilotic languages of Eastern Africa present a heterogeneous profile of auxiliary verb constructions from an inflectional perspective. Within Nilotic, the specific profiles exhibited differ somewhat across the recognized sub-groups of this family, so I will repeatedly make reference to Eastern Nilotic, Western Nilotic and Southern Nilotic languages in that order throughout the presentation below. The Nilotic languages according to this taxonomy in my corpus are listed in (465).

(465) Nilotic Languages represented in my AVC corpus

\begin{tabular}{|c|c|c|}
\hline$\underline{\text { Eastern Nilotic }}$ & $\underline{\text { Western Nilotic }}$ & $\underline{\text { Southern Nilotic }}$ \\
\hline Bari & Acholi & Nandi \\
\hline Lotuko & Anywa & Datooga (see section 10 below) \\
\hline Maasai & {$[\mathrm{A}]$ Teso } & \\
\hline Turkana & Dho-Alur & \\
\hline & Dholuo & \\
\hline & Dinka & \\
\hline & Karimojong & \\
\hline & Lango & \\
\hline
\end{tabular}

9.1 AUX-headed AVCs in Nilotic. As in most African language families the AUXheaded pattern is common in the Eastern and Western subgroups of Nilotic. Nilotic languages always show AUX V order. The lexical verb may appear in an AUX-headed construction in a Ø-marked form as in East Nilotic Bari (467), or in a tonally-marked infinitive form in the prospective in West Nilotic Lango (469). 
(466) SUBJ:TA-AV LV

(467) a. Bari

$$
\begin{aligned}
& \text { nan a-jo/a-je kon } \\
& \text { I 1.PST-PLUP do } \\
& \text { 'I had done it' (Heine and Reh 1984: 127; Spagnolo 1933: 105) }
\end{aligned}
$$

b. Bari

$$
\begin{aligned}
& \text { nán } \begin{array}{l}
a-j e ́ \\
\text { I }
\end{array} \quad \text { 1.PST-AUX cut } \\
& \text { 'I have finished cutting (it)' (Tucker and Bryan 1966: 482) }
\end{aligned}
$$

(468) SUBJ-AV LV:INF

(469) Lango

$$
\begin{aligned}
& \text { míto } \quad \text { cغ̀m } \\
& \text { 3:AUX:HAB eat:INF } \\
& \text { 'he's about to eat' }
\end{aligned}
$$

Some AUX-headed formations may be marked by affixally realized dependent forms in Nilotic languages as well. This includes the following AVCs in the West Nilotic languages Lango and Dholuo or the East Nilotic language Lotuko.

(470) SUBJ-AV LV-INF

(471) Lango

$$
\begin{aligned}
& \text { à-bédò lwòyyò lócé } \\
& \text { 1-AUX:PRF call:INF man } \\
& \text { 'I kept on calling the man' (Noonan 1992: 140) }
\end{aligned}
$$


(472) Dholuo

wá-dhi nyiédho

1PL-AUX milk:INF

'we're going to milk' (Tucker/Creider 1994: 467)

(473) $\underline{\text { Lotuko }}$

a-ttu nI letcn

1-FUT I go:INF

'I'll leave immediately'

(Heine and Reh 1984: 132; Muratori 1938: 161ff.)

This basic AUX-headed pattern is found in East Nilotic Maasai, but here with the infinitive prefix $a$-.

(474) SUBJ-AV INF-LV

(475) $\underline{\text { Maasai }}$

$$
\begin{array}{lr}
\text { E-igil } \quad \text { a-ran } & \text { aa-igil-a } \text { a-ar } \\
\text { 3-AUX } \quad \text { INF-sing } & \text { 3>1-AUX-PRFINF-beat } \\
\text { 's/he will sing again' } & \text { 's/he beat me again' } \\
\text { (Tucker and Mpaayei 1955: } 99 ; \text { Hamaya 1993: 5) }
\end{array}
$$

According to data in Hamaya (1993), there appear to be four classes of AVCs in Maasai. Two are classic AUX-headed configurations: class-I is in (475) above with a 'simple infinitive' (Hamaya 1993). Class-II on the other hand take lexical verbs in the so-called subjunctive infinitive form.

(476) SUBJ-AV INF-LV-INF 
(477) $\underline{\text { Maasai }}$

\section{$\dot{i}$-ndim ata-ran-a \\ 2-AUX INF:SBJNCTV-sing-SBJNCTV \\ 'can you sing' (Tucker and Mpaayei 1955: 99; Hamaya 1993: 6)}

Class-III takes clausal subject inflection in the form of a dummy third person singular marking, while the lexical verb is marked for logical subject. This is thus a LEX-headed formation deriving from an original split inflectional construction.

\section{3-AV SUBJ-LV}

(479) $\underline{\text { Maasai }}$

$$
\begin{aligned}
& \varepsilon \text {-ton } \quad \text {-itrrag } \\
& \text { 3-AUX 1-lie.down } \\
& \text { 'I am still lying down' } \\
& \text { (Tucker and Mpaayei 1955: 101; Hamaya 1993: 7) }
\end{aligned}
$$

Class-IV is like this but the subject marking is preceded by the conjunctive prefix $n$-, i.e., it is overtly marked as non-finite:

(480) 3-AV CNJ-SUBJ-LV

(481) Maasai

$$
\begin{aligned}
& \text { E-nor } \quad n \text {-a-lo } \\
& \text { 3-Aux CONJ-1-go } \\
& \text { 'I ought to go' } \\
& \text { (Tucker and Mpaayei 1955: 101; Hamaya 1993: 7) }
\end{aligned}
$$

Western Nilotic Anywa AVCs appear in an AUX V order as is ubiquitous in Nilotic. Some Anywa AVCs are AUX-headed inflectionally, with subject encoded on the auxiliary and the lexical verb appearing in a so-called 'infinite complement' form (Reh 1996: 264, 267). 
(483) a. Anywa

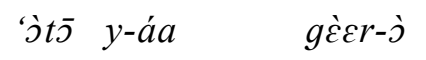

house PRF:AUX-1 build-INF

'I have built a/the house'

(Reh 1996: 267) b. Anywa

$$
\begin{aligned}
& \text { 'òt } \quad p \bar{v} \mho t \text { kàr-á } g \grave{\varepsilon} \varepsilon r-\grave{~} \\
& \text { house still AUX:NEG.PST-1 build-INF } \\
& \text { 'I have not yet built a/the house' }
\end{aligned}
$$

c. Anywa

$$
\begin{array}{lll}
\text { wèelō } & d \text {-áa } & \text { góor-ó } \\
\text { letter } & \text { AUX:DEONT-1 } & \text { write-INF } \\
\text { 'I should write a letter' } & \text { (Reh 1996: 267) }
\end{array}
$$

Other AVCs appear with the lexical verb in the verbal noun form in Anywa in a different AUX-headed configuration.

(484) $\mathrm{AV}$-SUBJ LV<VN>

(485) $\underline{\text { Anywa }}$

$$
\begin{aligned}
& \text { wā-críggó } \quad k \bar{l} \quad m \dot{\varepsilon} \varepsilon ́ \eta \\
& \text { 1PL.EXCL-AUX OBLQ dance:VN } \\
& \text { 'we started to dance' (Reh 1996: 266) }
\end{aligned}
$$

9.2 Doubled inflection in Nilotic AVCs. Doubled inflection is also found in AVCs in Turkana and Ateso and also in Lango, which Dimmendaal (2001b: 105) calls a Western Niloticized Teso-Turkana language. For example, the following AVC in Turkana is of this structure. As discussed above, Nilotic languages with doubled inflection generally show a dependent form of the subject marker on the lexical verb.

(486) SUBJ-AV SUBJ ¿DEP $>-\mathrm{LV}$ 
(487) a. Turkana (E. Nilotic, Nilo-Saharan, Kenya)

kì-pon-ì ato-mat-à

1PL-go-A 1PL.CONSEC-drink-PL

'we shall drink' (Dimmendaal 1983: 136)

b. Turkana

$$
\begin{array}{lll}
\grave{a}-\text {-ròko 'ay⿰y' } & a-y e-\grave{i} \\
\text { 1-still I } & 1-\text { be-A } \\
\text { 'I am still there' } & \text { (Dimmendaal 1983: 138) }
\end{array}
$$

As already exemplified above in (202), Eastern Nilotic (A)Teso represents a paradigm example of this Nilotic type of doubled subject pattern, with the subject marker on the lexical verb being of the optative/subjunctive or modally dependent type:

(488) SUBJ-AV SUBJ <SBNCTV>-LV $_{\text {- }}$

(489) a. [A]Teso

e-roko ke-buno

3-NEG 3SBJNCTV-come

'he has not yet come'

(Heine and Reh 1984: 105; Hilders and Lawrance 1956: 46)

b. [A]Teso

$a-b u$ ko-duk

2-PST 2SBJNCTV-build

'you built'

(Heine and Reh 1984: 185; Hilders and Lawrance 1956: 29-30)

Subject NPs may come between the sentence-initial auxiliary and the lexical verb in (A)Teso doubly-inflected AVCs: 
(490) [A]Teso

$$
\begin{aligned}
& \text { a-bu etelepat ko-lot ore bian } \\
& \text { he-AUX.PST boy 3SBJNCTV-go home yesterday } \\
& \text { 'the boy went home yesterday' } \\
& \text { (Heine and Reh 1984: 185; Hilders and Lawrance 1956) }
\end{aligned}
$$

In the Western Nilotic language Lango, a true doubled formation is attested. Here the lexical verb receives the same kind of inflection as the auxiliary and is not marked as overtly dependent as in Turkana or (A)Teso.

(491) SUBJ-AV[:TA] SUBJ-LV:TA

(492) Lango

$$
\begin{aligned}
& \text { án à-wót-ó à-lơb-j̀ dákô } \\
& \text { I 1-AUX-PRF 1-follow-PRF woman } \\
& \text { 'I followed the woman' (Noonan 1992: 211) }
\end{aligned}
$$

9.3 Split inflection in Nilotic AVCs. Split inflection per se is highly marked in Nilotic. The only secure example of this type of pattern I have in my corpus from a Nilotic language is the negative split pattern seen in the Western Nilotic languge Dhó-Alúr. In this split formation in Dhó-Alúr, there is AUX V order-as all AVCs in Nilotic languages are-with subject marking on the capabilitive auxiliary but negative marked on the lexical verb in the following construction:

(493) SUBJ-AV LV-NEG

(494) a. Dhó-Alúr

$$
\begin{array}{ll}
\text { é-cópó bì-ò̀gó } & \text { ibí-còpò cidh-òngó } \\
\text { 3-CAP:3 come-NEG } & \text { 2-CAP:2 go-NEG } \\
\text { 'he cannot come' } & \text { 'you cannot go' } \\
\text { (Knappert 1963: 126) } &
\end{array}
$$


9.4 Split/doubled inflection in Nilotic AVCs. Split/doubled inflection is also not overly common in my corpus of Nilotic AVCs, although one language, Lango, has two separate split doubled patterns. In one Lango AVC, there is a Bantu-like formation with double subject marking, but object encoded on the auxiliary:

(495) SUBJ-AV-TA SUBJ-LV-TA-OBJ

(496) Lango

màc dòy ò-tyèk-ò ò-nèk-ò-gí

fire then 3:AUX:PRF 3:kill:PRF:3PL.OBJ

'and so the fire killed them'

(Noonan 1992: 298)

Lango has another split doubled pattern with the negative auxiliary -pe and some other auxiliaries like bin in (498a) that rather show a split/doubled pattern with the encoding of perfect limited to the lexical verb, but subject being doubly marked. This is another Bantu-esque structure in this Nilotic language.

SUBJ-AV SUBJ-LV-TA

(498) a. Lango

án àbín àkwálò gwènò

I 1:AUX 1:steal:PRF chicken

'I did steal the chicken' (Noonan 1992: 139)

b. Lango

$$
\begin{array}{lcc}
\text { án } & \grave{a} \text {-pé } & \text { à-wótò Kàmpálà } \\
\text { I } & 1 \text { 1-NEG } & \text { 1-go:PRF Kampala } \\
\text { 'I didn't go to Kampala' (Noonan 1992: 142) }
\end{array}
$$




$$
\begin{aligned}
& \text { c. Lango } \\
& \text { án à-pe à-cámò réc } \\
& \text { I 1-NEG 1-eat:PRF fish } \\
& \text { 'I didn't eat the fish' (Noonan 1992: 143) }
\end{aligned}
$$

9.5 LEX-headed AVCs in Nilotic. Unlike most genetic units of Africa, LEX-headed formations are relatively common in Nilotic languages. A tonally inflected LEX-headed form is found in the Karimojong negative past construction.

(499) $\mathrm{AV}_{:<\text {TAM/POL }>} \quad$ SUBJ-LV

(500) Karimojong

$$
\begin{array}{lrl}
p a ́ & a ́-d \supset \eta i & a^{e} \grave{j} y \\
\text { NEG.PST } & \text { 1-pinch } & \text { 1SG } \\
\text { 'I did not pinch' } & \text { (Dryer 2009: 333; Novelli 1985: 442) }
\end{array}
$$

In a fused form, LEX-headed AVCs are found in Kalenjin (Southern Nilotic) languages like Nandi, where lexical verb and auxiliary have become univerbated into a complex verbal form.

(501) TA-SUBJ-LV-(é) < *AV SUBJ-LV(-é)

(502) a. Nandi

$m \hat{a}-a:-k a s$

FUT-1-hear

'I will hear it'

(Creider 1989: 112) b. Nandi

$$
m \hat{a}-a:-k a ́ s-\dot{e}
$$

FUT-1-hear-ASP

'I will be listening' 
(503) Nandi

tà-a:-kás-é

AUX-1-listen-ASP

'I'm still listening' (Creider and Tapsubei Creider 1989: 111)

(504) Nandi

$k a ́-t a ̂-a:-k a ́ s-e ́$

PST-AUX-1-listen-ASP

'I have just listened' (Creider and Tapsubei Creider 1989: 112)

A similar form is seen in the negative non-past form in Karimojong as well; compare this with the still synchronically bi-partite LEX-headed AVC in the negative past in Karimojong (506).

(505) NEG.TA-SUBJ-LV <*NEG.AV SUBJ-LV

(506) Karimojong

$$
n-\dot{a}-d \supset \eta i \quad a^{e} \grave{j} \eta
$$

NEG.NPST-1-pinch $1 \mathrm{SG}$

'I am not pinching' (Dryer 2009: 333; Novelli 1985: 442)

In one common type of LEX-headed formation in the synchronic grammars of Nilotic languages there is transparent internal structure historically, with so-called 'clausal subject' marking, in which a bi-clausal structure has been reanalyzed in the guise of a LEX-headed AVC. This type of formation is used with a lexical verb encoding the logical subject of the sentence. Examples of this were given for Maasai in $(479,481)$. Other AVCs of this type can be found in such Nilotic languages as Turkana (508), Acholi (510, repeating 208), and Lango (512).

(507) $\mathrm{AV}_{<* 3-[\mathrm{TA}]-\mathrm{AV}>} \quad$ SUBJ-TA-LV 
(508) a. Turkana

è-ìtem-o-kin-ò i-yoy 'i-los-ì-o t’̀kj̀na'

3-AUX-EPIPAT-DAT-VB you 2-go-ASP-VB now

'you must go now' (Dimmendaal 1983: 162)

b. Turkana

$\grave{\varepsilon}-\grave{a}-p \jmath t \grave{o} \quad t \jmath-t \jmath-k-a$

3-PST-AUX 3-dead-PL-PL

'then they died' (Dimmendaal 1983: 175)

(509) $\mathrm{AV}_{<* 3-\mathrm{AV}-\mathrm{TA}>} \quad$ SUBJ-LV

(510) $\underline{\text { Acholi }}$

$$
\begin{aligned}
& \text { in omyero i-cam mot } \\
& \text { you should } 2 \text {-eat } \quad \text { slowly } \\
& \text { 'you should eat slowly' (Heine 1993: 41) } \\
& \text { [omyero }<*^{*} \text { o-myero } 3 \text {-be.suitable/fit.PRF] }
\end{aligned}
$$

Note that the second Lango form below shows also tense/aspect marking and objectencoding on the lexical verb.

(511) $\mathrm{AV}_{<* 3-[\mathrm{TA}]-\mathrm{AV}>} \quad$ SUBJ-LV[-TA-OBJ]

(512) a. Lango

ònwòyò lócà àcèm

3:AUX:PRF man 3:eat:PROG

'a man was eating'

(Noonan 1992: 138) b. Lango

án ònwòyò àbwôté

I 3:AUX:PRF 1:deceive:PRF:3

'I had deceived him'

9.6 Tensed pronouns in Nilotic. Among the simplest of fused subject/TAM auxiliary formations is one found in the Nilotic language Dinka. In this language the order is AUX $\mathrm{V}$ as is typical of Nilotic languages, but the auxiliary encodes TAM and referent 
properties. Note in this regard the following two examples, both with a first person element fused into the auxiliary.

(513) AV:SUBJ/OBJLV

(514) a. Dinka

yin acaa kony apci
you INDIC:PST:1OBJ help very
'you have helped me very much'
(Hieda 1991: 102-103; Nebel 1948: 21) b. Dinka

wamuth aca tip your.brother INDIC:PST: 1 see 'I saw your brother

In one example (514a), this element refers to the logical subject and in the other, the object. The lexical verb in both cases appears in a Ø-marked form. This auxiliary element is thus embedded within an AUX-headed structure in Dinka. Otherwise Nilotic languages in my corpus do not used such subject/TAM/polarity pronouns.

9.7 More on fused AVC forms in Nilotic. Variation in cognate constructions may be seen in Lango and Acholi, two closely related Western Nilotic languages (indeed these are in many respects basically dialects of a single language). In Lango, the element is a synchronic bi-partite AVC with a full form of the auxiliary identical to its lexical verb source. In Acholi on the other hand, univerbation has occurred and the auxiliary has been reduced to its first syllable. In other words, Lango has an AUX-headed future AVC and Acholi a fused future form derived from it. In both instances, the auxiliary encodes future tense, and derives from a motion lexical verb meaning 'go' or 'come'.
(515)
SUBJ-AV LV:INF
SUBJ-TA-LV[IN
$[:$ INF] $<*$ SUBJ-AV LV:INF

(517) $\underline{\text { Lango }}$

ana-bino cammo
I 1-FUT eat:INF
'I will eat'
(518) $\underline{\text { Acholi }}$

$$
\begin{aligned}
& \text { an a-bi-camo } \\
& \text { I 1-FUT-eat } \\
& \text { 'I will eat' }
\end{aligned}
$$

(Heine and Reh 1984: 92; Bavin 1983: 151)

Dhó-Alúr shows a fused double subject formation in the past progressive (521), which contrasts with the fused AUX-headed structure of the present progressive (522) note also 
the tonal difference between the two forms. As alluded to previously, tonologically encoded features in verb 'morphology' are common in Nilotic languages.

(519)

$$
\begin{aligned}
& \text { SUBJ-TA-LV-INDEP } \\
& <* \text { SUBJ-AV LV-INDEP }
\end{aligned}
$$

(521) Dhó-Alúr

$$
\begin{aligned}
& \text { á-bè-lwó } \eta-o \\
& \text { 1-PRS.PROG-call-INDEP } \\
& \text { 'I am calling' } \\
& \text { (Knappert 1963: 111) }
\end{aligned}
$$

$$
\begin{aligned}
& \text { (520) SUBJ-TA-SUBJ-LV-INDEP } \\
& <* \text { SUBJ-AV SUBJ-LV-INDEP }
\end{aligned}
$$

(522) Dhó-Alúr

$$
\begin{aligned}
& \text { á-bé[d]-á-lwóy-ò } \\
& \text { 1-PST.PROG-1-call-INDEP } \\
& \text { 'I was calling' }
\end{aligned}
$$

$\begin{array}{ll}\text { AH } & \text { Bari; Turkana; Maasai; Lotuko; Lango; Dholuo; Anywa } \\ 2 \mathrm{x}+\text { DEP } & \text { Turkana; (A)Teso } \\ 2 \mathrm{x} & \text { Lango } \\ \text { split } & \text { Dho-Alur } \\ \mathrm{S} / 2 & \text { Lango } \\ \text { LH } & \text { Maasai; Turkana; Acholi; Lango; Karimojong } \\ \text { S/TAM/P } & \text { Dinka? } \\ \text { fAH } & \text { Acholi } \\ \text { f2x } & \text { Dho-Alur; (+Datooga) } \\ \text { fLH } & \text { Nandi; Karimojong; (+Datooga) }\end{array}$

Table 10: Patterns of inflection in AVCs in Nilotic languages

9.8 Summary. Nilotic languages are characterized by the relatively common use of LEXheaded AVCs and fused structures that derive from these. AUX-headed structures are not uncommon, nor are doubled inflectional patterns. Complex fused verb forms deriving from these are relatively restricted, though attested, e.g., fused AUX-headed forms are found in Acholi and fused doubled ones in Dho-Alur. Split/Doubled formations are highly marked for Nilotic, occuring only in two different guises in my corpus in Lango. 
Within Nilotic, there are distinct genetic profiles for each of the three recognized subgroups of Nilotic, viz. Eastern, Western, and Southern. Southern Nilotic is more synthetic than the other two groups; in addition to fused doubled formations in Datooga (which is covered in section 10 below in the discussion of the languages of the Tanzanian Rift Valley), fused LEX-headed future formations are found in both Southern Nilotic Nandi and Datooga. Only Karimojong has reduced uninflected auxiliaries in a LEXheaded configuration among Western and Eastern Nilotic languages. Other languages of these two groups make use of reanalyzed auxiliaries with third singular 'clausal' subject marking now functioning auxiliaries in LEX-headed AVCs, e.g., in Acholi or Turkana. Among Western Nilotic languages, only Lango and Dho-Alur has doubled subject formations (and complex verb forms derived form these). ${ }^{36}$ The Lango doubled subject inflection differs from those of the Eastern Nilotic languages in that the latter use modal dependent subject markers on the lexical verbs in doubly inflected AVCs, not simple copies of the subject inflection as is attested in Lango. A breakdown of the patterns of inflection by sub-group within Nilotic is offered in Table 11 .

\begin{tabular}{llll}
\hline \hline Eastern Nilotic & \multirow{2}{*}{ Aux V } & $2 \mathrm{x}^{+\mathrm{DEP}}$ & Maasai, Turkana, Teso \\
& & $\mathrm{AH}$ & Bari, Lotuko, Masai, Turkana \\
& & LH & Maasai, Turkana \\
Western Nilotic & Aux V & AH & Dholuo, Lango, Anywa \\
& & $2 \mathrm{x}$ & Lango \\
& & $\mathrm{fAH}$ & Acholi \\
& & split & Dho-Alur \\
& & $\mathrm{S} / 2$ & Lango \\
& & $\mathrm{S} / \mathrm{TAM} / \mathrm{P}$ & Dinka \\
& & LH & Acholi; Lango; Karimojong \\
Southern Nilotic & Aux V & $\mathrm{fLH}$ & Karimojong \\
& & f2x & Nandi; Datooga \\
& & Datooga
\end{tabular}

Table 11: Eastern, Western and Southern Nilotic AVCs

\footnotetext{
${ }^{36}$ Note that Lango's status as Western Nilotic language has in fact been questioned by some researchers, e.g., Dimmendaal (2001: 105) who considers Lango not to be West Nilotic proper but rather a West Niloticized Teso-Turkana language.
} 
There is hardly one mind about the nature or significance of the apparent distribution of linguistic characteristics among African languages of different regions, nor about the best way to interpret the areal dynamics that are/have been/may be/might have been at play, and thus the interpretation of the linguistic geography of various features across the languages of the African continent.

In the following section, I briefly examine the distribution of patterns of inflection in auxiliary verb constructions among the languages of various regions, linguistic areas or convergence zones of Africa, offering some thoughts, where appropriate, on preliminary areal profiles of the AVCs of the languages of these regions. These areas include three detailed in recent work in African comparative linguistics and linguistic geography (Heine and Nurse (eds.) 2008), the Tanzanian Rift Valley (section 10), 'Ethiopia' (section 11), and the Macro-Sudan Belt (section 12). As alluded to in Güldemann (2008), the area to the north of the Macro-Sudan Belt is occupied by a spread zone (in the Nichols (1992) sense) called here 'Sahara', which is examined in section 13. Each of these areas are best construed as spread zones. Underlying each of these spread zones, or, on occasion, contiguous to them, there are also linguistic residual zones (fragmentation zones) or micro-pockets that constitute refuges of linguistic diversity. A residual or fragmentation zone may stand out from the surrounding spread zones in the areal patterning of certain linguistic features. One such residual zone is occupied by languages representing the many families of the Nuba Hills region, discussed in section 14.

\section{Tanzanian Rift Valley}

The languages of the Tanzanian Rift Valley constitute a spread zone of probably relatively shallow time depth. Within this spread zone, languages of the S. Cushitic, S. Nilotic, and Bantu families have interacted with Sandawe and Hadza, the latter two of which represent the traces of the southernmost extension of a residual or fragmentation zone that stretch from the modern Ethiopia-Sudan border region through a strip in the highland parts of Uganda and Kenya to Tanzania, where various remnant families generally attributed to Nilo-Saharan like Gumuz, Shabo, Kuliak or Jebel languages may be found. ${ }^{37}$ In the northern regions, this fragmentation zone has been overlain by the

\footnotetext{
${ }^{37}$ There is thus a belt of Eastern Africa stretching from Tanzania to central Sudan where pockets of diverse linguistic group are found, whose languages exhibit different profiles. These relics of perhaps once more widespread diversity include Hadza, Sandawe, Kuliak
} 
Ethiopian spread zone (see section 11 below), in the middle by a northeastern part of the Narrow Bantu spread zone (see section 6 above) and the Nilotic expansion zone (see 9 above), and in the southern area by the Tanzanian Rift Valley spread zone.

10.1 AuX-headed AVCs in the Tanzanian Rift Valley. One of the characteristic features of the Tanzanian Rift Valley, is the relative paucity of AUX-headed formations that typify languages of the area. As is typical in a V AUX language, AUX-headed formations when found appear with the lexical verb in some kind dependent 'converb' or 'participle' form (called here the 'construct case') followed by an inflected auxiliary, as in the following Iraqw form.

\section{LV-CONSTR AV-SUBJ}

(524) Iraqw

$$
\begin{aligned}
& \text { makay } i \quad \text { ma'á wahúngw ay-á }
\end{aligned}
$$

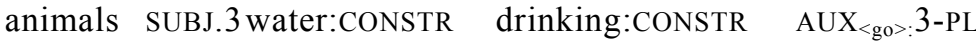

$$
\begin{aligned}
& \text { 'the animals will drink water' (Kießling et al. 2008: 219) }
\end{aligned}
$$

In Hadza, the negative element 'akwe-functions like an auxiliary verb in an AUX-headed configuration, here also incorporating subject markers that are themselves probably historically fused subject/TAM-auxiliary/polarity forms (see 10.6 below). This negative auxiliary may appear in AUX-headed formations in the AUX V order that is common in Hadza, with a following Ø-marked lexical verb.

(525) AV-SUBJ LV

languages, Koman languages (+ Gumuz), Surmic languages, Eastern Jebel languages, Shabo, Ongota, and the languages of the Nuba Hills. All of these genetic units are represented in the database and appear in appropriate sections throughout (e.g. Sandawe and Hadza in this section and those of the Nuba Hills in section 14), but the remainder are not explicitly discussed here per se as a whole. In the middle region the remnant genetic unit par excellence is Kuliak of Uganda. Data from the Kuliak languages Soo (Tepes), Ik and Nyang'i are mentioned sporadically throughout previous sections where relevant. 
(526) $\underline{\text { Hadza }}$

$$
\begin{array}{ll}
\text { 'akwe-ne'e haka } \\
\text { NEG-1.FUT/COND go } \\
\text { 'I wouldn't go' (Sands to appear-a: 6) }
\end{array}
$$

10.2 Doubled subject inflection in AVCs in the Tanzanian Rift Valley. Doubled subject formations among the languages of the Tanzanian Rift Valley are found in Cushitic Alagwa, with subject on both the auxiliary and the lexical verb. Note the AUX $\mathrm{V}$ order in Alagwa that may reflect Bantu influence in this language.

(527) AV-SUBJ LV-SUBJ

(528) Alagwa

l-aa leesá tsaahh-at raa'amu-w-ós k-od

OPT-S1/2 at.firstunderstand-2 song-M-3SG.POSS ANIM.M-D

'you first have to understand his song' (Kießling 2007: 191)

South Nilotic Datooga shows a Nilotic-type formation with doubled subject marking with the second subject marker appearing on the lexical verb in the modally dependent subjunctive form.

(529) (SUBJ)-AV-SUBJ $\quad$ SUBJ $_{\angle \text { SBNCTV }}-\mathrm{LV}$

(530) Datooga
qáa-mớrs-cí
dá-lâc
fùáandá
qùuwâayda
[DECL:?]1SG-can-1SG 1SG:SBJNCTV-cut string:CONSTR bow
'I can cut the bow-string' (Kießling et al. 2008: 213)

Hadza also makes use of what I have called fused/fused formations in a doubled configuration in the following negative AVCs. In both, the lexical verb appears in the fused first singular present/future form, while the the auxiliary verb appears with the fused subject/auxiliary form appropriate to the meaning of the larger construction (e.g., future or past). 
(531) AV-SUBJ LV-SUBJ

(532) a. $\underline{\text { Hadza }}$

'akwe-ne baha-ta hako kazi

NEG-1.FUT finish-1.FUT/PRS this work

'I am not finishing this work' (Sands to appear-a: 6)

b. Hadza

'akwa-na baha-ta hako kazi

NEG-1.PST finish-1.FUT/PRS this work

'I have not finished this work' (Sands to appear-a: 6)

10.3 Split inflection in Tanzanian Rift Valley AVCs. Split inflectional patterns of various sorts are found in auxiliary verb constructions in the languages of the Tanzanian Rift Valley. A highly marked pattern is found in S. Cushitic languages like Iraqw and Burunge, where object is encoded on the auxiliary and subject on the lexical verb. Note also the AUX V order in these constructions that is atypical of Central, Eastern and Northern Cushitic languages.

(533) OBJ-AV LV:PL-SUBJ

(534) $\underline{\text { Iraqw }}$

Paténtfupa a-na hats'maamíis

I bottle OBJ:3:F.SG-PST fill:PL:1SG.PRF

'I filled the bottles' (Kießling et al. 2008: 207)

The Bantu language Mbugwe shows the more typical reverse situation with subject encoded on the auxiliary and object on the lexical verb, with the same order of realization in the linear syntax of argument encoding elements as in the Cushitic languages above. However, the order of elements in the phrase is the opposite, and this Bantu language shows the highly un-Bantu order of V AUX in this AVC. Although given in (292), I offer this example from Mbugwe again in (536). 
(535) OBJ-LV SUBJ-AV

(536) $\underline{\text { Mbugwe }}$

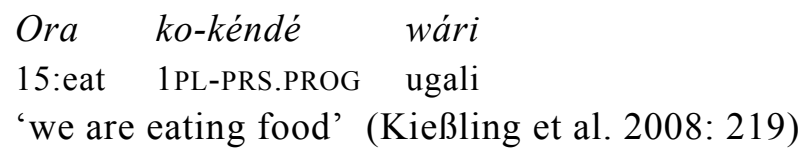

Hadza sentences are characterized by the use of a[n often] clause-initial consecutive or narrative auxiliary particle that encodes the subject and often the tense/aspect/mood of the clause. This is frequently the only means of encoding the properties of arguments functioning as subjects, with object properties encoded by suffixes in the lexical verb. This thus reflects a kind of split inflectional pattern in a characteristically Hadza configuration.

(537) AV:TA:SUBJ LV-OBJ

(538) a. Hadza

$\begin{aligned} & \text { yame lutl'u-ta yame } \\ & \text { NAR.PST.3FPL collect-3FSG.OBJ NAR.PST.3FPL }\end{aligned}$
eat-DISTR-3FPL?
$\begin{aligned} & \text { ma-mako-ma } \\ & \text { EMPH-boil-3MSG.OBL }\end{aligned}$
'they collected it up and boiled it up to eat'
(Sands to appear-a: 2)

b. $\underline{\text { Hadza }}$

\begin{tabular}{|c|c|c|c|}
\hline kaka & wech'e-ya & kaka & hama-sa \\
\hline NAR.PST.3MSG & lack-3MSG.OBJ & NAR.PST.3MSG & sit-3FSG.O \\
\hline
\end{tabular}

(Sands to appear-a: 3) 
10.4 Split/Doubled inflectional patterns in the Tanzanian Rift Valley. Unsurprisingly, Bantu languages of the Tanzanian Rift Valley linguistic area show splitdoubled inflectional patterns of various types in AVCs, as these particular configurations are family-wide characteristics of Bantu. Subject is doubly marked in the following forms in Nyaturu with aspect (540) or negative (542) marked on the lexical verb-both characteristic Bantu patterns (see section 6.4 above).

SUBJ-AV SUBJ-ASP-LV: $a$

(540) Nyaturu

ní náa a-kí u-qv-righisya

SUBORDINATE FAR.PST 3-PRSTV 3-PROG-speak

'while she was still speaking...'

(Nurse 2000a: 523; Kießling et al. 2008: 198)

(541) SUBJ-AV SUBJ-NEG-LV

(542) Nyaturu

ni I-kír njololo í-na-konkva

SUBORDINATE 9-PRSTV cock 9-NEG-crow

'when the cock has not yet crowed...'

(Nurse 2000a: 523; Kießling et al. 2008: 198; Olson 1964)

In Sukuma, the lexical verb appears in a dependent form in some doubly subject marked AVCs marked by the prefix -lii, and tense is encoded on the auxiliary.

(543) SUBJ-TA-AV [SUBJ-TA-AV] SUBJ-DEP-LV: $a$

(544) Sukuma

d-aa-lí d-áá-biiza dv-líi-gúla

1PL-PST-AUX 1PL-PST-AUX 1 PL-DEP-buy:FV

'we were just buying...' (Kießling et al. 2008: 201) 
Kimbu shows a similar pattern, with aspect encoded on the auxiliary, doubled subject marking and a dependent marked lexical verb, here using the familiar Bantu infinitive prefix.

(545) SUBJ-TA-AV SUBJ-INF-LV

(546) $\underline{\text { Kimbu }}$

$$
\begin{aligned}
& x \mho-x a \neq l_{I} \# \# \quad x \mho-x \mho \neq \text { gula } \\
& \text { 1PL-still-AUX } \quad \text { 1PL-INF-buy:FV } \\
& \text { 'we are still buying' (Nurse 2003: 91) }
\end{aligned}
$$

In Cushitic Burunge, the original auxiliary has eroded to zero in the following formation, leaving only inflectional morphology of the following structure, a highly-reduced kind of split/doubled pattern:

(547) SUBJ-OBJ LV:PL-SUBJ

(548) Burunge

$$
\begin{array}{llll}
\text { dandiray } & h a-g i & \text { tu'aaq-an-a } & x a{ }^{\prime} i \\
\text { we } & \text { S1/2-O.3PL } & \text { cut.down:PL-1PL-IMPF } & \text { trees } \\
\text { 'we cut down trees' (Kießling et al. 2008: 207) }
\end{array}
$$

10.5 LEX-headed formations in the Tanzanian Rift Valley. Sandawe makes use of a LEX-headed completive formation that almost assuredly derived historically from a serial verb form (see Eaton 2003 for a different view). A final auxiliary element meaning 'finish' appears after the inflected auxiliary (here appearing in the connective form, marking it as part of a larger structure, originally at least).

$$
\text { LV-SUBJ:TA-CNNCTV AV }
$$


(550) $\underline{\text { Sandawe }}$

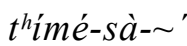
${ }^{\downarrow}$ tlèmsé
cook-3FSG.RLS.PGN-CNNCTV
finish
'she finished cooking' (Eaton 2003: ex. 7)

In the following two variant forms of the negative past progressive in Sandawe on the other hand, which differ as to whether they show AUX V (a) or V AUX (b) order, nevertheless have the same inflectional pattern: LEX-headed, with the auxiliary marked as 'dependent' by the connective marker.

\section{AV-CNNCTV LV-SUBJ:TA-NEG LV-SUBJ:TA-NEG AV-CNNCTV}

(552) a. Sandawe

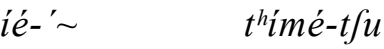

$$
\begin{aligned}
& \text { AUX-CNNCTV cook:3FSG.IRR.PGN-NEG } \\
& \text { 'she was not cooking' (Eaton 2003: ex. 16) } \\
& \text { nèmé-t ùu ié-' } \\
& \text { sweep:3FSG.IRR.PGN-NEG AUX-CNNCTV } \\
& \text { 'she was not sweeping' (Eaton 2003: ex. 17) }
\end{aligned}
$$

b. Sandawe

\subsection{Fused forms deriving from AVCs in languages of the Tanzanian Rift Valley.} The future in Datooga appears to be a fused LEX-headed formation, such as is found in its sister language Nandi. It may represent a development that is eroded from an originally doubly subject inflected form, later fused. The use of the subjunctive subject marker suggests that although probably deriving directly from a fusing of a LEX-headed formation this formation itself may well have originally derived from a doubly-inflected formation in pre-Datooga.

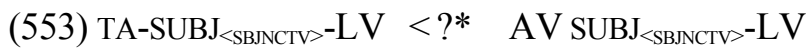

$$
\begin{aligned}
& <\text { ??* SUBJ-AV SUBJ }{ }_{<\text {SBNCTV }}-\mathrm{LV}
\end{aligned}
$$


(554) Datooga

gày-dá-lâc fùáandá qùuwâayda

FUT-1 SBJNCTV-cut string:CONSTR bow

'I will cut the bow string' (Kießling et al. 2008: 213)

Indeed fused forms with doubled subject are found in Datooga, but forms with the dáfirst singular subjunctive marker are otherwise primarily found in synchronically bipartite doubly subject inflected AVCs, not complex verb forms derived from fused AVCs. The perfect in Datooga is an example of one such fused double subject form.

TA-SUBJ-LV-SUBJ $<?^{*} A V-S U B J L V-S U B J$

(556) Gisamjanga Daatoga

$n-a ́ a-\eta \grave{u}-c i$

PRF-1SG-pierce-1SG

'I have pierced him (once)' (Kießling et al. 2008: 208)

(557) Datooga

n-áa-làj-ì fùáandá qùuwâayda

PRF-1-cut-1 string:CONSTR bow

'I have cut the bow string' (Kießling et al. 2008: 213)

Both Hadza and Sandawe reflect complex verb forms that appear to derive from earlier auxiliary structures with V-AUX order. Further, such auxiliaries themselves appear to encode subject properties simultaneously with TAM categories. Note that similar formations are common in Cushitic languages of the Ethiopia area (section 11). Examples of such fused/fused formations in Sandawe include the following:

$$
\text { LV(-TA)-SUBJ:TAM LV-SUBJ:TAM <?*LV(-TA) AV-SUBJ }
$$


(559) a. Sandawe

$t^{\text {himé-sà }}$

cook-3F.RLS

'she cooks/cooked'

(Eaton 2003) b. Sandawe

$$
\begin{aligned}
& \text { thimè- 's ̀̀ } \\
& \text { cook-FUT-3F.IRR } \\
& \text { 'she will cook' }
\end{aligned}
$$

While such formations appear to be an integral part of Hadza verbal structure, they appear to reflect a phrasal syntax of AVCs from an earlier stage of the language that differs from that which predominates today. Note that these elements are enclitic, or suffixed, to the object encoding lexical verb in contemporary Hadza. The simplest such formation is seen in the following Hadza forms:

(560) LV-SUBJ:TA $<? *$ LV AV:SUBJ

(561) $\underline{\text { Hadza }}$

$\begin{array}{lll}\text { puhlu-na'a } & \text { hi!'e-na'a } & \text { Amelika-na } \\ \text { arrive-1.PST } & \text { come.from-1.PST } & \text { America-LOC } \\ \text { 'I arrived here [coming] from America' (Sands to appear-b: 16) }\end{array}$

The lexical verb may also appear in a mood- or aspect-marked formation, to which the subject/TAM-encoding auxiliary encliticized or fused, as in the following structures:

(562) LV-TAM-SUBJ:TA $<$ ?*LV-TAM AV:SUBJ

(563) a. $\underline{\text { Hadza }}$

chi-ni-ne'e
run-NEC-1.FUT
'I must run' b. $\underline{\text { Hadza }}$

$$
\begin{aligned}
& d z a-n e-y a \\
& \text { come-NEC-3MSG.PRS } \\
& \text { 'he must come' }
\end{aligned}
$$


c. $\underline{\text { Hadza }}$

dza-ne-ya

come-INCH-3MSG.PRS

'he is coming, he is on his way'

(Sands to appear-b: 12)

Objects or obliques may also be encoded on the lexical verb preceding the incorporated subject-marked auxiliary in Hadza as well:

(564) LV-OBL/OBJ-SUBJ:TA <?*LV-OBL/OBJAV:SUBJ

(565) a. $\underline{\text { Hadza }}$

Boni-ko kwase-ta-kwa akwiti-ko

Bonny-F.SG hit-3FSG.OBJ-3FSG.PST woman-F.SG

Bonny hit the woman (Sands to appear-a: 1)

b. $\underline{\text { Hadza }}$

mu-musi-kwa-tita 'ono

EMPH-annoy-1SG.OBL-2SG.PRS I[MSG]

'you really annoy me' (Sands to appear-a: 3)

c. $\underline{\text { Hadza }}$

'ono tl'impi- 'a-na'a hich'i!

I[MSG] step.in-3MSG.OBJ-1.PST shit

'I stepped in shit!' (Sands to appear-a: 3)

10.7 Summary. The languages of the Tanzanian Rift Valley share numerous phonological and morphosyntactic features that establish this as a type of linguistic area in Africa (Kießling et al. 2008). From the perspective of the inflectional patterns and structure of AVCs among the languages of the region, no profile per se emerges. Many of the languages of the region reflect their genetic affiliation in the types of structures attested, although the exact realization may reflect strong areal tendencies (e.g. V AUX 
order in Mbugwe). Thus except for an unusual formation in Burunge, the Bantu languages of the area are the only ones where split/doubled patterns occur, while only South Nilotic Datooga shows fused LEX-headed formations, as well as modal dependent subject marking in doubly inflected forms that are typical of Nilotic, and only Iraqw has AUX-headed ones of the familiar type. Sandawe shows more of the areal profile in general, but both Sandawe and Hadza show significant divergence from areal norms in their auxiliary structures. The presence of fused complex verb forms incorporating fused subject-encoding auxiliaries that reflect an original V-AUX structure in both Sandawe and Hadza rather unite these two languages with some of the languages spoken further to the north in the Ethiopia area (see section 11).

$\begin{array}{ll}\text { AH } & \text { Iraqw } \\ 2 \mathrm{x} & \text { Alagwa; Datooga } \\ \text { split } & \text { Burunge; Hadza; Mbugwe } \\ \mathrm{S} / 2 & \text { Nyaturu; Sukuma; Kimbu; Burunge } \\ \text { LH } & \text { Sandawe } \\ \mathrm{f} 2 \mathrm{x} & \text { Datooga } \\ \mathrm{fLH} & \text { Datooga } \\ \mathrm{f} / \mathrm{fS} / \mathrm{TAM} / \mathrm{P} & \text { Sandawe; Hadza }\end{array}$

Table 12: Patterns of inflection in languages of the Tanzanian Rift Valley

\section{1 'Ethiopia'}

Perhaps the best-known linguistic area in Africa that I briefly overview here with respect to patterns of inflection in auxiliary verb constructions is 'Ethiopia', which includes in addition to the modern-day state of Ethiopia, the country of Eritrea and some adjacent parts of Sudan and Somalia. The stereotypic core of the languages of this region belong to several sub-groups of Afroasiatic (viz. Omotic (Bender 2000, 2003), Cushitic (Tucker 1967, Voigt 1985, 1987) and Ethiopic Semitic), which is one of the reasons people like Tosco (2000) have debunked the concept of the Ethiopian linguistic area. However, many features of this areal-cum-Afroasiatic profile are found in prossibly unrelated languages, such as the still unclassified Ongota (Fleming 2006), and definitively unrelated genetic units that are conventionally classified as branches of the 'NiloSaharan' language phylum, peripherally belong to this continuum as well, e.g., Nera 
(Thompson 1976a), Kunama (Tucker \& Bryan 1966, Thompson 1989, Bender 1996), Gumuz (Bender 1979, Uzar 1989) and Berta (Tiulzi et al. 1976).

With respect to AVCs, the most salient and obvious difference is the dominance of $\mathrm{V}$ AUX order in these languages of 'Ethiopia'. Other languages of the region, on the other hand, show AUX V order typically (see section 14 below). ${ }^{38}$

11.1 AUX-headed AVCs in languages of 'Ethiopia.' AUX-headed formations are somewhat common among the languages of 'Ethiopia'. A lexical verb in the infinitive form is found in the following future construction in Sese Gumuz (567) and in Maale (569):

(566) INF-LV AV:SUBJ:TA

(567) Sese Gumuz

kà gǐz ànjinééla ná ma-dok'w mec'a ḿPiirà

Next year time.this in INF-build house 1:FUT:AUX

'next year at this time I will build a house' (Uzar 1989: 379)

$$
\text { LV-INF AV-TA }
$$

(569) Maale

Piíni Púfk-itsi Park'-á-ne

3M.NOM drink-INF AUX-PFV-AFFRM:DECL

'he is starting to drink' (Amha 2001:125)

\footnotetext{
${ }^{38}$ As mentioned in section 14 below, Nubian and Rashad show V AUX dominant order, as do Ijoid languages, peripheral (or remnant) members of the Macro-Sudan Belt area, and Dogon either a peripheral/remnant member of the Macro-Sudan Belt or of the south/west part of 'Sahara' area, Sandawe and several other languages of the Tanzanian Rift Valley Area, and most of southern and central Saharan languages except Songhay, and as also do Khoe languages. A large AUX V area dominates the rest of Africa, in the far north, in the Nuba Hills and the residual zones of eastern Africa, in the Narrow Bantu spread zone and the southern 'Khoisan' residual zone, where the Ju and Tuu famlies as well as $\neq$ Hoan may be found also.
} 
Kunama has one class of verbs that appears in an adverbially dependent form in the present and past progressive forms (the other class appears with doubled subject marking):

(570) LV-DEP AV-SUBJ-TA

(571) a. Kunama

$$
\begin{array}{lll}
g a-n \quad g o-n a-n o & g a-n \quad g o-n a-k i \\
\text { go-DEP AUX-1-PRS } & \text { go-DEP AUX-1-AOR } \\
\text { 'I am going' } & \text { 'I was going' }
\end{array}
$$

(Tucker and Bryan 1966: 344)

Lexical verbs in AVCs in many languages of the Ethiopian area appear in a so-called converb or gerund form. Such languages include Cushitic Beja or the isolate Nera:

(572) LV-GER SUBJ-MOOD-AV

(573) Bedauye (Beja)

$$
\begin{aligned}
& d u: r-a: b \quad a-k a t-y e ́: k \\
& \text { visit-GER } \quad 1-C O N D-A U X_{<b e>} \\
& \text { 'If I had visited' (Tucker and Bryan 1966: 542) }
\end{aligned}
$$

(574) LV-GER AV-TA-SUBJ

(575) $\underline{\text { Nera }}$

$$
\begin{aligned}
& \text { kal-nu wa:l-n-ay-t-o} \\
& \text { eat-GER AUX-GER-AUX-PST-3 } \\
& \text { 'he was eating' (Thompson 1976a: 489) }
\end{aligned}
$$

In Ethio-Semitic Tigrinya and Cushitic Burji the dependent form of the lexical verb in the V AUX configuration is said to be in a 'conjunctive' non-finite form. 
(577) Burji [Cushitic, Afro-Asiatic; Ethiopia]
duk'as-ina ee gagar-i yeDa [gagareDa]
cold-FOC me catch-CONJ AUX:1 \{catch:AUX:1\}
'I have a cold' (Hudson 1976a: 264)

CONJ-LV AV:SUBJ

(579) Tigrinya

$\begin{array}{ll}\text { kabälla' 'əyyu } \\ \text { CONJ-eat } & \text { 3:AUX }\end{array}$

'he will eat' (Leslau 1968: 69)

In Alaaba on the other hand, the lexical verb appears in the absolutive form of the verbal noun in the following AUX-headed AVC:

(580) LV: $\mathrm{VN}_{<\mathrm{ABS}>} \quad \mathrm{AV}$-SUBJ:TA

(581) Alaaba

$$
\begin{aligned}
& \text { tées(u) Porroo?-ú Pataal-táant(i) } \\
& \text { now go-VN:ABS can-2SG:IMPF } \\
& \text { 'you can go now' (Schneider-Blum 2007: 269) }
\end{aligned}
$$

In Omotic Dizi (Maji), all non-final verbs in the string bear a marker of non-finite same subject marking. Only the final verb-the auxiliary-takes subject/tense marking. The use of same subject clause chaining morphology in AVCs in Dizi is quite marked for African languages, but is found in a small number of other languages. This was exemplified in (211)-(213) above.

Finally one language of the Ethiopian area reflects an AUX-headed structure that is akin to those seen in such forms as the perfect or passé composé in French. This is the Omotic language known as Bench[non] or Gimira. In this structure, the lexical verb appears in a participle form that encodes the gender/number of a (third person) subject, but not the person of the subject. Other inflectional categories are realized on the auxiliary. 
(583) a. Gimira (Benchnon)

$$
\begin{aligned}
& y i^{1} s i^{3} \quad \operatorname{han}^{3} k^{\prime} i^{5} \quad y i s^{4} k u^{2} e^{3} \\
& \text { he:SUBJ go.PST.PRTCPL:M AUX:PRS:3M } \\
& \text { 'he is going' (Breeze 1990: 31) }
\end{aligned}
$$

b. Gimira (Benchnon)

$$
w u^{1} \mathrm{sa}^{3} \quad \mathrm{han}^{3} \mathrm{k}^{\prime} a^{4} \quad y i \mathrm{~s}^{3} \mathrm{ten}^{2} \mathrm{e}^{3}
$$$$
\text { she:SUBJ go:PST.PRTCPL:F AUX:PST:3F }
$$$$
\text { 'she was going' (Breeze 1990: 31) }
$$

c. Gimira (Benchnon) [Omotic]

$$
\begin{aligned}
& t^{1} n a^{3} \quad h^{3} k^{3} n^{4} s a^{4} \quad y i s^{3} t u^{2} e^{3} \\
& \text { I } \quad \text { go:PRF.PRTCPL AUX:PST:1 } \\
& \text { 'I had gone' (Breeze 1990: 32) }
\end{aligned}
$$

While akin to structures found in languages like French, one might venture forth a different interpretation of these Gimira (Benchnon) constructions, and conclude that they are a special type of split-doubled pattern with subject gender.

Another language where it is unclear whether one is dealing with an AUX-headed structure like the English progressive, with the lexical verb appearing in constructiondependent and construction-determined non-finite form (like the -ing in the English progressive AVC in $<b e+\mathrm{LV}$-ing $>$ ), or a split structure where subject person and aspect are in a split distribution (on the auxiliary and lexical verb, respectively) is Ongota, an unclassified or isolate language that some consider to be a unique branch of Afroasiatic, others a divergent Cushitic language. 
(585) $\underline{\text { Ongota }}$

$$
\begin{aligned}
& \text { kaata č'ak-utto ka-Pida } \\
& \text { I } \quad \text { eat-PROG } 1 \text {-AUX } \\
& \text { 'I am eating' (Fleming 2006: 29) }
\end{aligned}
$$

11.2 Doubled inflection in AVCs in languages of 'Ethiopia.' Doubled inflectional patterns in AVCs are relatively marked in the Ethiopian linguistic area, limited to a small number of Cushitic languages. However, a rather straightforward doubled subject formation is seen in the following form from Harar Oromo.

(586) LV-SUBJ AV-SUBJ

(587) Harar Oromo (Cushitic)

$$
\begin{array}{ll}
\text { d'agay-ani } & \text { jir-an } \\
\text { hear-PL } & \text { AUX-PL }
\end{array}
$$

'they have heard' (Owens 1985: 74)

In its close sister language Oromo of Wellega, fused subject(-cum-TAM) forms are found in a range of constructions. Note that the formal realization of the subject markers differs on the two verbs in this Oromo of Wellega formation. This underscores the fact that doubled inflectional patterns deal with identity across the categories expressed, not the formal instantiations of the markers realizing these inflectional categories.

(588) LV-SUBJ:TA AV-SUBJ:TA

(589) Oromo of Wellega

k'ab-di tur-te

have-3F.PST AUX-3F.PST

'she had' (Gragg 1976: 185)

11.3 Split inflection in AVCs of 'Ethiopia.' Not all AVCs in Bench[non]/Gimira show the AUX-headed (or split) pattern described above and exemplified in (583). Negative AVCs in this language usually (but not always) consist of a negative marked lexical verb 
followed by a tense/subject inflected auxiliary-a split inflectional pattern familiar from other African languages with V AUX order.

(590) LV-NEG AV-TA:SUBJ

(591) Gimira (Benchnon)

$$
\begin{aligned}
& h a^{4} m a r^{4} g u^{2} \quad \check{s} i^{3} d u^{2} e^{3} \\
& \text { go:NEG.PRTPCL AUX:PST:3M } \\
& \text { 'he did not go' (Breeze 1990: 32) }
\end{aligned}
$$

Note that Daasanech, a Cushitic language that is spoken outside of the 'Ethiopia' linguistic area, shows a somewhat similar pattern, only reflecting the AUX V order that is characteristic of Kenyan languages. That tense is encoded tonally makes this properly a different kind of split than the one seen in Gimira/Bench[non] above.

(592) AV:SUBJ NEG-LV:TA

(593) Dasenech (Daasanech)

yáá ma-láálan

AUX:1 NEG-SING:PST

'I did not sing' (Sasse 1976: 200)

As exemplified originally in (80) above, in Cushitic Harar Oromo, something akin to the negative split in Daasanech is seen in which both negative and tense appear on the lexical verb and subject on the auxiliary; unlike Daasanech, the structure reflects the $\mathrm{V}$ AUX structure characteristic of languages of 'Ethiopia'. ${ }^{39}$

(594) NEG-LV:TA AV:SUBJ

\footnotetext{
${ }^{39}$ What I mean here is simply those languages that participate in this areal convergence zone, not all languages physically spoken within the borders of the region, as several conventionally classified as 'Nilo-Saharan', e.g. Surmic languages, do not show this order.
} 
(595) Harar Oromo (Cushitic)

$$
\begin{aligned}
& \text { xaléesá hin-déem-ne ture } \\
& \text { yesterday NEG-go-PST AUX:1 } \\
& \text { 'I didn't go yesterday' (Owens 1985: 74) }
\end{aligned}
$$

Yet another split pattern involving negation is seen in Omotic Dizi. Here the negative element functions as an auxiliary, but licenses a co-negative marker on the lexical verb. The auxiliary encodes subject but the lexical verb encodes tense.

(596) AV-SUBJ LV-TA-DEP CCONEG $>$

(597) a. Dizi (Maji)

$\begin{array}{ll}t a-n & k a t s e-d e-t i \\ \text { NEG-1 } & \text { cook-PRS-NEG }\end{array}$

'I'm not cooking' (Allan 1976b: 384)

b. Dizi (Maji)

$$
\begin{array}{ll}
t a-n & k^{\prime} e-k i-t i ̀ \\
\text { NEG-1 } & \text { work-PST-NEG }
\end{array}
$$

'I didn't work' (Allan 1976b: 387)

c. Dizi (Maji)

ta-nà $\quad k^{\prime} e-d e-t \grave{~}$

NEG-2 work-PRS-NEG

'you don't work' (Allan 1976b: 387)

d. Dizi (Maji)

ta-n k'é-e-ti

NEG-1 work-FUT-NEG

'I won't work' (Allan 1976b: 387) 
These formations thus differ from the Harar Oromo form by using a negative auxiliary and secondary co-negative on the lexical verb, and, moreover, the Dizi form reflects AUX V order rather than the order V AUX that is typical of the 'Ethiopian' linguistic area.

11.4 Split/Doubled inflectional patterns in languages of 'Ethiopia.' The nearly extinct Cushitic language Kemantney (Qemant) exhibits a range of different split doubled inflectional patterns. In the following pluperfect form, person and number of the subject is doubly expressed, and tense is limited to the auxiliary. Note that the lexical verb in this structure is overtly marked as syntactically dependent by the use of the gerund suffix (w) $\ddot{a}$.

LV-SUBJ-GER AV-SUBJ-TA

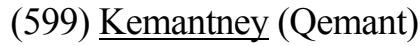

$$
\begin{aligned}
& \text { ïntändew } k \ddot{z} z-y-\ddot{n} n-w \ddot{a} \quad \text { sïmb-i-n- } \widehat{e^{w}} \\
& \text { you (PL) sell-2-PL-GER AUX-2-PL-PST } \\
& \text { 'you (PL) had sold' (Leyew 2003: 194) }
\end{aligned}
$$

The following construction in Kunama shows a slightly different pattern. Here subject is doubly marked, but tense is restricted to the lexical verb. Note that this Kunama structure shows AUX V order, not V AUX, and derives from an auxiliary verb whose lexical meaning was 'enter', thus this AVC likely derives from a serialized formation originally in pre-Kunama.

(600) SUBJ-AV SUBJ-LV-TA

(601) Kunama

$$
\begin{aligned}
& m \text {-ulu m-ibo-ke } \\
& \text { 2PL-AUX 2PL-plough-AOR } \\
& \text { 'you began ploughing' (Tucker and Bryan 1966: 344) }
\end{aligned}
$$

While the pluperfect in Oromo of Wellega shows a doubled inflectional pattern, the negative pluperfect on the other hand shows a split/doubled inflectional pattern, with negative on the lexical verb, but subject and tense doubly encoded. 
(602) NEG-LV-SUBJ:TA AV-SUBJ:TA

(603) Oromo of Wellega

hin-adeem-ee(n) ture

NEG-go-3M.PST AUX-3M.PST

'he had not gone' (Gragg 1976: 189)

11.5 LEX-headed AVCs in 'Ethiopia.' Unsurprisingly, LEX-headed formations are not overly common in the languages of Ethiopia but are attested in a small number of them. For example, in Hamer, an uninflecting auxiliary de/do may occur either before or after the lexical verb which bears aspectual marking.

(604) AV LV-ASP

(605) $\underline{\text { Hamer }}$

$\begin{array}{llll}s \wedge x \wedge & w o & d \partial & y \varepsilon ?-\varepsilon \\ \text { tomorrow } & \text { we } & \text { AUX } & \text { go-IMPF }\end{array}$

'tomorrow we are going' (Lydall 1976: 422)

(606) LV-ASP AV

(607) $\underline{\text { Hamer }}$

na ki ni?-a de

yesterday he come-PRF AUX

'he was coming/came yesterday' (Lydall 1976: 422)

Ethio-Semitic Inor has a structure in which an auxiliary originally inflected for a third singular (possibly 'clausal') subject has been reanalyzed as a clause final uninflecting past tense marker. Thus, it does not change for the subject person as would be typical of auxiliaries in Inor. Similar formations in Nilotic languages like Acholi or Turkana were presented in section 9 above 
(608) SUBJ-LV-ASPAV <*SUBJ-LV-ASP*AV:TA:3M

(609) $\underline{\text { Inor }}$

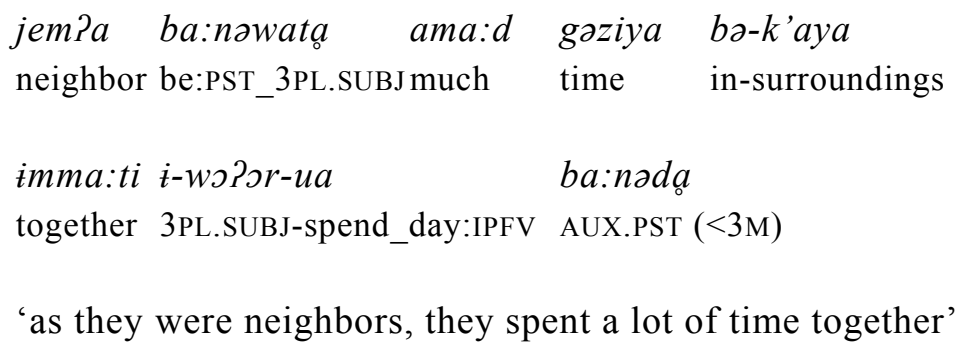
(Suter 2007: 203)

11.6 Complex verb forms derived from fused AVCs in 'Ethiopia.' Combined fused subject/auxiliary forms where the auxiliary element remains free-standing are not common in the 'Ethiopia' linguistic area. One future formation in Afar may show this. However, as is frequently the case in languages of the region with such structures, fully fused/fused (or cliticized) forms are also possible in Afar.

(610) LV-INF-TA:SUBJ <L-INF AV-TA:SUBJ

(611) $\underline{\text { Afar }}$

$$
\begin{aligned}
& \text { ha: 'd-e-tto } \sim \text { ha:'d-e li'to } \\
& \text { fly-INF-AUX: } \\
& \text { 'you will fly' (Bliese 1976: 147) }
\end{aligned}
$$

Fused doubled subject formations deriving from original doubly inflected auxiliary verb constructions are quite restricted in the languages of the region, but may be found in the speech of certain speakers of Ethio-Semitic Amharic.

(612) LV-SUBJ-AV-SUBJ $<$ ?*LV-SUBJ AV-SUBJ 
(613) a. Amharic

sämt-äh-all-äh

hear-2M-AUX-2M

'you (m) have heard'

(Leyew 2003: 194) b. Amharic

$s \ddot{a} m t-\ddot{a} \breve{s}-$ all- $\ddot{a} \breve{s}$

hear-2F-AUX-2F

'you (f) have heard' c. $\underline{\text { Amharic }}$

sämt-o-all-ä

hear-3M-AUX-3M

'he has heard'

As LEX-headed formations are uncommon in languages of 'Ethiopia', it is not a huge surprise that fused complex verb forms deriving from such constructions are likewise not common in languages of this region. However, just such a formation is at the heart of the future construction in various Gumuz varieties. While the exact element grammaticalized as a future is different across Sese Gumuz, Sai Gumuz, and Kokit Gumuz, the future serves as a proclitic or prefix to a subject-marked lexical verb. Note that this contrasts with the synthetic past form, which rather has a fused subject-marked auxiliary across all three Gumuz varieties, and probably ultimately derives from a fused split formation.

(614) TA-LV-SUBJ < ?*AV LV-SUBJ (615) TA:SUBJ-LV-TA < ?*AV-SUBJ LV-TA

(616) $\underline{\text { Sese Gumuz }}$

kəm-sara

FUT-eat:1[.FUT]

'I will eat'

(Bender 1979: 49)
(617) Sese Gumuz

bər-sa-ga

PST:1-eat-PST

'I ate'
(618) $\underline{\text { Sai Gumuz }}$

$m \partial-s a: n z-\varepsilon d a$

FUT-think-1[.FUT]

'I will think'

(Bender 1979: 49)
(619) Sai Gumuz

bar-le:-ga

PST:1-hoe-PST

'I hoed' 
(620) $\underline{\text { Kokit Gumuz }}$

de-sa:ra

FUT-eat:1[.FUT]

'I will eat'

(Bender 1979: 49)
(621) Kokit Gumuz

$d \varepsilon r-s \partial-b a$

IMPF: 1 -eat-IMPF

'I was eating'

In the Southern Omotic language Aari, an original post-verbal auxiliary in a LEX-headed construction appears enclitic to a lexical verb bearing markers of subject, TAM, and polarity. It is possible that the 'lexical' verb in these constructions themselves derive from fused AUX-headed formations, albeit now embedded within a larger LEX-headed formation.

LV:TA:SUBJ-AV < ?* LV:TA:SUBJAV

(623)

$\underline{\text { Aari }}$

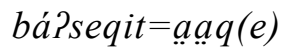

bring:PLUP: $1=\mathrm{AUX}$

'I had brought' (Hayward 1990: 476)

(624) LV:NEG:TA:SUBJ-AV < ?* LV:NEG:TA:SUBJ AV

(625) Aari

\section{ba?kit-ạq(e)}

bring:NEG:PLUP: $1=$ AUX

'I had not brought' (Hayward 1990: 476)

Split/doubled formations fused into large complex verbal forms are also attested among the languages of the 'Ethiopia' linguistic area. In the endangered Kemantney or Qemant subject is doubly marked, but aspect occurs on the auxiliary verb, not the lexical verb. According to Leyew (2003), these formations in Kemnatney may reflect Amharic influence (where only subject is doubly marked, see (605) above).

$$
\begin{aligned}
& \text { LV-SUBJ-AV-SUBJ-ASP-GEND/NUMB } \\
& <\text { ?* LV-SUBJ AV-SUBJ-ASP-GEND/NUMB }
\end{aligned}
$$


(627) a. Kemantney (Qemant)

intï was-y-am-y-äk

you hear-2-AUX-2-IMPF

'you have heard'

c. Kemantney (Qemant)

ni was-y-an- $\ddot{a}-t$

s/he hear-3-AUX-IMPF-F

'she has heard'

(Leyew 2003: 193) b. Kemantney (Qemant)

ïntändew was-y-ïn-wan-y-äk $k^{w}-\ddot{i n}$

you.PL hear-2-PL-AUX-2-IMPF-PL

'you (PL.) have heard'

As alluded to above, complex verb forms are found in various languages of the 'Ethiopia' linguistic area that incorporate already fused subject/auxiliary forms. Generally speaking these attach to unmarked verb stems, reflecting an original AUX-headed structure. Such formations are found in such languages as the isolate Berta:

LV-SUBJ:TA $<?^{*}$ LV AV:SUBJ

(629) a. Berta

b. Berta

Oin-ali

eat-1.PRF

'I have eaten'

(Tiulzi et al. 1976: 525)
Oin-ayo

eat-2.PRF

'you have eaten'

Cushitic languages of the region make particular use of such complex fused formations. Thus, formations of this type are attested in such diverse Cushitic languages as Gidole and Bilin.

(630) LV-neg:ta:subj<?*LV neg:AV:subj 
(631) a. Gidole (Cushitic)

am uk-hinam

NEG drink-PRS.NEG:1/3M

'I don't drink'

(Zaborskij 1975: 96) b. Gidole

amuk-híntam

NEG drink-PRS.NEG.2/3F

'you don't drink'

In Bilin, the formation appears to belong to the type of structure using a fused light verb whose lexical meaning is 'say'. Such formations are common across languages of 'Ethiopia' as well as the 'Sahara' (see sections 13 below and 4.1 above for more examples).

(632) LV-SUBJ:TA < ?* LV/say/:SUBJ:TA

(633) a. Bilin

wǔh -jăkw

shout-say:3M:PRS

'he shouts'

(Böhm 1983: 42) b. Bilin

wǔh -jäti

shout-say:3F:PRS

'she shouts'

Such formations are commonly found in Alaaba as well. The various first person TAM suffixes that derive from fused auxiliary structures bear little resemblance to each other, underscoring their origins from different auxiliary stems.

(634) LV-SUBJ:TAM $<$ ?* LV[-CV <SUBग $>]$ AV:SUBJ

(635) a. Alaaba

$$
\begin{aligned}
& \text { Pán(i) káapp'(a) wáal-l(i) mar-aamíit(i) } \\
& \text { 1SG:NOM DEM3SG:M:ABS go.to-CV1 go-1sG:PROG } \\
& \text { 'I am going away' (Schneider-Blum 2007: 249) }
\end{aligned}
$$


b. Alaaba

Pesáa t'iz-zho-Pékki'(i)

1SG:DAT become.sick-3SG:M:PRF-1SG.IRR

'I was sick' (Schneider-Blum 2009: 65) /-yo-/

c. Alaaba

Pán(i) t’iz-zhóom(i)

1SG:NOM become.sick-1SG:PRF

'I am sick' (Schneider-Blum 2009: 65) /-yóom-/ <be>

11.7 Summary. The languages of the 'Ethiopia' region show considerable diversity in the inflectional patterns of AVCs. AUX-headed formations are relatively frequent, as are complex verb forms derived from these. The lexical verb in the AUX-headed pattern appears in a construction-determined non-finite form labeled various things by different researchers, e.g., converbs, participles, verbal nouns, infinitives, etc. (see Amha and Dimmendaal 2006a). Of particular note among the languages of 'Ethiopia' is the presence of complex verb forms that derive from a double fusing of auxiliaries. First there is a subject-encoding auxiliary that appeared clause-finally in the characteristic V AUX order that typifies languages of the region. This fused subject and auxiliary form simultaneously encoded subject properties and TAM categories of various sorts. This in turn was later incorporated into a larger complex as a subject-TAM suffix in verb forms (these are represented as f/fS/TAM/P below, short for fused/fused-subject TAM/polarity formations). As mentioned above, in addition to the various languages of 'Ethiopia' (in particular Cushitic ones), such formations are commonly found in Hadza and Sandawe as well spoken to the south of this region. 


\begin{tabular}{ll}
\hline \hline AH & Sese Gumuz; Maale; Kunama; Burji; Nera; Tigrinya; Alaaba; Dizi \\
AH/split & Benchnon (Gimira)-subj.gender; Ongota \\
2x & Harar Oromo; Oromo of Wellega \\
split & Harar Oromo; Dizi; Benchnon (Gimira)-neg \\
S/2 & Kemantney (Qemant); Kunama; Oromo of Wellega \\
LH & Hamer; Inor \\
S/TAM/P & <Afar $>$ \\
fAH & ??? (Kunama; Nera; Bench) \\
f2x & Amharic \\
fS/2 & Kemantney (Qemant) \\
fLH & Sese Gumuz; Sai Gumuz; Kokit Gumuz; Aari \\
f/fS/TAM/P & $<$ Afar>; Alaaba; Bilin; Gidole; Kokit Gumuz; Sai, Sese Gumuz \\
& \\
Table 13: Patterns of inflection in languages of the 'Ethiopia' region
\end{tabular}

Note that while almost all of the data from the Cushitic languages above in 'Ethiopia' show V AUX structure or complex verb forms that were originally constructions showing V-AUX order, the Cushitic languages south of this area may reflect Nilotic or Bantu influence and rather exhibit AUX V order instead (cf. also the data from Burunge in section 10 above).

(636) Southern Cushitic

$\begin{array}{ll}\text { S'aamakko Dullay } & \text { Aux V } \\ \text { Dahalo } & \text { Aux V } \\ \text { Daasenech } & \text { Aux V }\end{array}$

Furthermore, except Nera, Kunama, some AVCs in Gumuz and certain fused structures underlying various complex verb forms in Berta, all mentioned above, the languages of the genetic units that are conventionally called Nilo-Saharan of the 'Ethiopia' region virtually all show AUX V order or AUX-V structure in complex fused structures. This includes languages belonging to Koman, the Jebel languages, Surmic languages and Shabo, as well as indeed even some constructions in Kunama, Berta, and Gumuz. Many other features of the AVCs in these languages show behavior that differs significantly from that of the languages of 'Ethiopia' presented here. A brief tabulation of these formations are offered in Table 14. 


$\begin{array}{ccl}\begin{array}{c}\text { Genetic Unit } \\ \text { Language }\end{array} & \text { Order } & \underline{\text { Patterns }} \\ \text { Jebel } & & \\ \text { Gaam } & \text { Aux V } & \text { fused/fused S/TAM/P + 2x } \\ \text { Aka } & \text { Aux V } & 2 \mathrm{x}+\text { DEP } \\ \text { Kelo } & \text { Aux V } & \text { fused/fused S/TAM/P + AH } \\ \text { Molo } & \text { Aux V } & \text { fused/fused S/TAM/P + 2x } \\ \text { Surmic } & & \\ \text { Koegu } & \text { V Aux! } & \text { f2x+DEP, AH } \\ \text { Baale } & \text { Aux V } & \text { LH } \\ \text { Majang } & \text { Aux V } & \text { fAH+CONEG } \\ \text { Murle } & \text { Aux V } & \text { AH } \sim 2 \mathrm{x} \\ \text { Mursi } & \text { Aux V } & \text { AH } \\ \text { Didinga } & \text { Aux V } & \text { AH } \sim 2 \mathrm{x} \\ \text { Tennet } & \text { Aux V } & \text { fAH, f2x, split+DEP, LH+DEP } \\ & & \end{array}$

Koman

$\begin{array}{lll}\text { Kwama } & \text { Aux V } & \text { fAH } \\ \text { Koma } & \text { Aux V } & \text { AH }+\varnothing \\ \text { Uduk } & \text { Aux V } & \text { AH }+ \text { dep, AH }+\varnothing\end{array}$

Shabo

Shabo

Aux V split

Table 14: AVCs in Nilo-Saharan languages in 'macro-Ethiopia'

Each genetic unit has a relatively straightforward profile across the languages of the region, e.g., AUX-headed and fused AUX-headed formations predominate among AVCs in the Koman languages, and fused subject/auxiliary formations in Eastern Jebel languages. Shabo appears to have a highly idiosyncratic but characteristic split pattern that merits further investigation in this enigmatic and nearly extinct language of Ethiopia. Finally, Surmic languages exhibit the greatest variation. Some show both AUX-headed and doubly inflected AVCs; Baale and Tennet also show LEX-headed formations, and Tennet one split formation as well. One language, Koegu, even has the V Aux order one expects of a language of 'Ethiopia', and thus may show other diagnostic characteristics of the languages of this area, and therefore properly belong to this areal grouping like Nera, 
Kunama, Berta and Gumuz similarly at least in part do. Resolving this issue in the history of Koegu is a topic that must remain an objective for future research.

\section{Macro-Sudan Belt}

In this section I briefly present data from the massive Macro-Sudan Belt linguistic area that runs west to east across the African continent from the Atlantic Ocean to the Ethiopian Plateau (Güldemann 2008: 152). This area is bounded by spread zones in the north ('Sahara', section 13), in the east (Macro-Ethiopia, section 11), in the south (Narrow Bantu section 6), and by the Nuba Hills residual zone (see section 14 below) in the northeast.

The core of the Macro-Sudan Belt [MSB] area consists of languages belonging to the following genetic units (Güldemann 2008's categories): Adamawa, Ubangian, non-Bantu Benue Congo, Bongo-Bagirmi, Moru-Mangbetu, Kwa, Kru, Gur, and Mande. In addition, Güldemann (2008) considers the following genetic units to be peripheral parts of the MSB linguistic area: Chadic (see section 7 above), Atlantic, Ijoid, Dogon and Songhay. ${ }^{40}$ For the purposes of the typology of auxiliary constructions advanced here, I deal mainly with the languages from the genetic units listed as core members of the area below, with occasional data from more peripheral members of the macro-area. To the list of genetic units adduced by Güldemann (2008), I also add the unclassified or isolated Laal to the core category and Bang[er]i Me to the peripheral group in this list here. On the other hand, in my discussion below I exclude what I call the marginal members of the area, viz. Ijoid, Dogon and Songhay languages. A full list of the languages from the Macro-Sudan Belt in my corpus and the genetic units I consider them to represent are listed in Table 15.

Table 15

$<$ CORE MEMBERS $>$

$\underline{\text { Genetic Unit }}$

$\underline{\text { Language(s) }}$

Bambukic $>$ Jen Burak

Bantoid, N

Mambiloid Mambila, Vute

${ }^{40}$ Dogon and Ijoid are particularly divergent here. Both have V AUX structure among other details. Dogon has certain features in common with languages of the 'Sahara' area and are treated in section 13 below accordingly. 
Bantoid S

$\begin{array}{ll}\text { East Beboid } & \text { Noni } \\ \text { West Beboid } & \text { Mundabli } \\ \text { Ekoid } & \text { Ejagham } \\ \text { Mbam-Nkam } & \text { Limbum } \\ \text { Ring >C } & \text { Kom } \\ \text { Grassfields } & \text { Yemba } \\ \text { Mamfe/Nyang } & \text { Kenyang } \\ \text { Mbam } & \text { Nomaande } \\ \text { Mbe } & \text { Mbe } \\ \text { Ndemli } & \text { Ndemli } \\ \text { Tikar } & \text { Tikar } \\ \text { Tiv } & \text { Tiv }\end{array}$

Cross River

Eleme, Gokana, Ibibio, Kana, KoHumono,

Lokaa, Mbembe, Obolo, Ogbronuagom

Jukunoid

Kuteb, Hone, Jibə, Wannu, Wapan-Wukari, Wap ${ }_{\sim}^{\text {ha }}$

Kainji

Amo, Duka Kahugu, ut-Ma'in

'Plateau'

Birom/Berom, (I)Rigwe, Izere/Afuzare/Zarek, Eloyi,

Gworok/Kagoro, Mada, Taro, Idũ, Eggon

Ukaan

Ukaan

Bendi

Bekwarra

Ghana-Togo Mtn

Avatime

Ka-Togo

Buem/Lelemi, Sele, Siwu

Leko-Nimbari

Na-Togo

Mbum-Day

Samba Leko, Zing Mumuye

Volta-Congo $>$ Ega

Doyayo, Karang, Lua/Niellim, Mbum

Volta-Niger

Gbe

Ega

Nupoid-Okoid-Idomoid

Idomoid

Anexo-Ewe, Ewe, Fongbe, Minagbe

Nupoid

Idoma

Òkó

Ebira/Igbirra, Gade, Nupe

Òkó [Oko/Ogori]

Yoruboid-Edoid-Akokoid-Igboid

Yoruboid

Yoruba

Edoid

Degema, Edo, Emai, Engenni, N. Ibie 
Igboid Echie, Ekpeye, Igbo, Izi, Onicha Igbo

Fali

'Gur'

Kru

Kwa

Ga-Dangme

Potou-Tano

Kulango

Senufic

E Mande

S Mande

CW Mande

SW Mande

Ubangi

Banda

Gbaya

Mba

Ngbaka

Ngbandi

Sere

Zande

Laal

Bongo-Bagirmi

Kresh

Lendu

Moru-Ma'di

Mangbetu

Mangbutu-Efe

Waja

Jen
Fali

Dagaare, Frafra, Kirma, Konkomba, Tyurama

Vata, Bété, Godie, Koyo, Neyo, Nyo, Kuwaa, Wobé,

Dewoin, Gbaeson Krahn, Tchien Krahn, Grebo, Krahn,

Bassa, Klao, Borobo, Tepo, Sapo

[A]Dangme, Ga

Akan, Anyi, Banda Nchumuru, Baule, Bejamso-Grubi

Nchumuru, Gehode, Genyanga, Krachi, Likpe, Nawuri,

Nkonya, Twi

Kulango, Lorhon

Nafaara, Supyire

Bobo-Fing, Bokobaru, Boko/Busa

Guro, Dan-Gweeta, Mano

Jalonke, Maninka, Bambara, Manding, Meeka, Banka

(Samogo), Jowulu

Mende, Kpelle

Linda

'Bozom, Gbaya 'Buli, Gbaya Kaka, Mbodomo

'Dongo, Ma, Mba

Baka, Mayogo, Mundu

Ngbandi, Yakoma

Ndogo

Zande, Barambu, Pambia

Laal

Bongo, Baka (BB), Kara, Fer, Yulu, Gula Sara, Gula

Méré, Sara, Morokodo, Mödö, Kabba, Gula Zura,

Mbay, Ngambay-Moundou

Kresh

Ngiti

Lugbara, Ma'di, Moru

Mangbetu, Meje

Lese, Mamvu

Dadiya, Awak

Burak 
$<$ PERIPHERAL MEMBERS $>$

$\underline{\text { Genetic Unit }}$

Bak

Senegambian

Cangin

Eastern N. Atlantic

Mel

Bijogo/Bijago

Bang[er]i-Me?

Chadic

West

East

Biu-Mandara
Language(s)

Dyola, Diola Fogny

Adamawa Fulani, Wolof

Ndut-Falor, Non

Pajade/Badiaranke

Kisi

Bijogo

Bang[er]i-Me
Ader Hausa, Angas, Bolanci, Burrum (Boghom), Chip, Dott, Daffo Ron, Gerka (Yiwom), Goemai, Guus/Sigidi, Hausa, Karekare, Kwami, Lele, Montol, Ngizim, Pero, Sayanci

Gurduy, Dera-Kanakuru, Mubi, ??Polci

Buduma, Gidar, Daba, Hdi, Mada, Malgwa, Mbuko, Merey, Mofu-Gudur, Moloko, Muyang, Vamé

$<$ MARGINAL MEMBERS $>$

Dogon

Ijoid

Songhay
Dogó sò, Donno So, Jamsay

Kolokuma Izon, Kalabari Ijo, bomo Ijo, Defaka

Koyra Chiini, Tasawaq, Tondi Songway Kiini

\section{Table 15: Languages of the Macro-Sudan Belt in my corpus}

One feature that languages of the Macro-Sudan Belt share in common is the dominance of AUX V order in AVCs. Furthermore, virtually all major sub-patterns of inflection in auxiliary verb constructions are attested in one language or another. However, the major areal trends show a distinctly different skewing. In particular, tense-marked pronouns or fused subject-auxiliary forms are a salient and noteworthy feature found in this area far more frequently than in other parts of Africa (or the rest of the world).

12.1 AUX-headed AVCs in the languages of the Macro-Sudan Belt. An AUX-headed pattern of a familiar type, with a dependent-marked lexical verb is seen in Barambu. 
(637) SUBJ-AV DEP-LV

(638) $\underline{\text { Barambu }}$
$\grave{a}$-íma $\quad t \varepsilon-d \grave{a}$
1.DEF-AUX DEP-come
'I have already come' (Tucker and Bryan 1966: 154)

The Bongo-Bagirmi languages are another core group of the MSB linguistic area. Numerous AUX-headed formations are found in these languages (and doubly inflected forms as well, see below). Morokodo (640) has a typical AUX-headed formation for this genetic unit with a subject marked auxiliary and the lexical verb in the infinitive form.

(639) SUBJ-AV INF-LV

(640) Morokodo

$$
\begin{array}{lll}
m \text {-édi } & k \grave{u} \text {-bu } & m o ̀ \\
\text { 1-AUX } & \text { INF-beat him }
\end{array}
$$

'I am beating him' (Tucker and Bryan 1966: 75)

Its sister language Gula Méré ((158), repeated here as (641)) shows a similar structure as well:

(641) Gula Méré

$$
\begin{aligned}
& \text { mó-ndó kūsá nj̀ } \\
& \text { 1-AUX INF:eat thing } \\
& \text { 'I am eating' (Nougayrol 1999: 137) }
\end{aligned}
$$

Similar AUX-headed formations with dependent-marked lexical verbs can be found in the negative progressive AVC with the negative auxiliary -bé in the isolate language Bangi$\mathrm{Me}$, where the lexical verb appears in the 'dependent' $n$-form.

(642) SUBJ-AV $n$-LV 
(643) $\underline{\text { Bangi Me }}$

$$
\begin{aligned}
& \grave{m} \text {-bé bòrèfì } n \text {-dya } \\
& \text { 1-NEG food } n \text {-eat } \\
& \text { 'I'm not eating food' (Blench 2007: 9) }
\end{aligned}
$$

This type of pattern is also the structure seen in the negative capabilitive AVC in Adamawa-Fulani, a Senegambian language, where the lexical verb appears rather in the suffixal infinitive form.

(644) SUBJ-AV:TA LV-INF

(645) Adamawa Fulani

$$
\begin{aligned}
& \text { mi-wáawataa joodaa-go } \\
& \text { 1-can:NEG.FUT sit:EMPH-INF } \\
& \text { 'I can't sit' (Stennes 1967: 214) }
\end{aligned}
$$

In the Central Delta Cross River language Ogbronuagom of Nigeria, also known as Bukuma, a more developed AUX-headed structure is encountered: the preverbal auxiliaries bear subject and tense proclitics and the lexical verbs appear in an infinitive form.

(646) SUBJ-TA/NEG-AVINF-LV

(647) a. Ogbronuagum (Bukuma)

$$
\begin{aligned}
& \text { n-dá-mó arílée ede } \\
& \text { 1-FUT-AUX to.eat food } \\
& \text { 'I must eat food' }
\end{aligned}
$$$$
\text { (Kari 2000: 38-39) }
$$

\section{b. Ogbronuagum (Bukuma)}

$$
\begin{aligned}
& \text { m-ḿ-mós arilée ede } \\
& \text { 1-FUT.NEG-AUX to.eat food } \\
& \text { 'I must not eat food' }
\end{aligned}
$$

In Bijogo, an isolate language (or a divergent member of the Atlantic stock), there are three sub-types of this same kind of AUX-headed AVC, with lexical verbs appearing in one of three construction-determined dependent forms (viz. $\eta{ }^{-}-, n$ - and $\operatorname{ta} n$-). 
(648) SUBJ-AV $\eta \supset$-LV[:ACCOMPLI]

(649) $\underline{\text { Bijogo }}$
$\eta \varepsilon-m \varepsilon g$
$\eta \supset-t a \varepsilon$
1S.ACC-avoir l'habitude $\eta \supset$-chasser:ACCOMPLI
'j'ai l'habitude de chasser' (Segerer 2002: 278)

(650) SUBJ-AV $n$-LV

(651) a. Bijogo

$$
\text { ne-te n-kpay }
$$

1-ETRE DEBOUT SV-tirer le vin du palme

'je suis en train de tirer le vin du palme'

\section{b. $\underline{\text { Bijogo }}$}

$$
\begin{array}{ll}
t u-r u & n-d o \\
\text { 1P.ACC-LEVER } & \text { SV-aller } \\
\text { 'préparons-nous à partir' } & \text { (Segerer 2002: 273) }
\end{array}
$$

(652) SUBJ-AV ta $n$-LV

(653) $\underline{\text { Bijogo }}$

$$
\begin{aligned}
& n i \text {-boj ta } n \text {-do } \\
& \text { 1s-POuvoIR de } \eta \text {-aller } \\
& \text { 'je peux partir' } \\
& \text { (Segerer 2002: } 274) / \mathrm{y} /=\text { homoorganic assimilation }
\end{aligned}
$$

As mentioned previously, some of the languages of the western part of the MSB area have AUX-headed AVCs with either an unmarked or Ø-marked lexical verb, e.g., Ewe (655) or appear with a phonologically-marked dependent verb form, as in the Igboid language Echie (657). 
(655) Ewe

$$
\begin{aligned}
& \text { mì-la-no kpó } \\
& \text { 2-FUT-AUX see } \\
& \text { 'you will see' (Allen 1993: 41) }
\end{aligned}
$$

(656) SUBJ-AV LV <PHON.DEP>

(657) Echie

$$
\grave{j}-d \grave{i}-\grave{I} \quad z \grave{a}: a \quad \text { ol̀̀ }
$$

3-AUX-NEG sweep:Ovs house

's/he did not sweep the house' (Ndimele 2003: 51)

'Dongo has a similar pattern to the Ewe form above. However in 'Dongo this construction may optionally also be univerbated within a fused complex verbal form (661):

(658) SUBJ-AV LV

(660) ‘ Dongo

i-mba ygàràgo mè

1PL-AUX child beat

'we had beaten the child'

(Tucker and Bryan 1966: 123)
(659) SUBJ- $a-\mathrm{AV}-\mathrm{LV}$

(661) ‘ Dongo

$$
\begin{aligned}
& n i ́-a-t i-m \dot{\varepsilon} \quad \text { ygaràgo } \\
& \text { 1PL-a-AUX-beat child } \\
& \text { 'we are beating the child' }
\end{aligned}
$$

In the Izi language of Nigeria, a similar construction is attested but this encodes only tense and aspect in the auxiliary, and historically derives from a serial verb construction. As in many West African languages, the tone associated with the auxiliary varies according to the specific TAM form in Izi.

(662) [SUBJ]AV-TA LV 
(663) a. Izi [Nigeria]

ó shì-wà tsúá 'nrí

she AUX-RSLT pound food

'she already pounded food'

(Bendor-Samuel 1968: 122) b. $\underline{\text { Izi }}$

ó tó 'shi-dú 'tsúá 'nrí

she NEG AUX-PST pound food

'she did not pound food'

In the Gbaya Ubangi language Mbodomo of Cameroon, a similar AUX-headed pattern is seen in which subject inflection is lacking, but the auxiliary takes suffixes that encode TAM categories.

(664) [SUBJ] AV-TALV

(665) Mbodomo (Gbaya-Ubangi; Cameroon)

ćlé dúy-ú wor mò Odile mà hò-à

$1 \mathrm{PL}$ AUX-PST talk something Odile SIM arrive-PST

'we were talking when Odile arrived' (Boyd 2003: 46)

Finally, Ewe has AUX-headed AVCs where the lexical verb appears in a constructiondetermined reduplicated form as well.

(666) SUBJ-AV REDPL-LV

(667) $\underline{\text { Ewe }}$

fifiá me-le ku-kú gé kpuie

now 1SG-be.AT:PRS REDPL-die PROSP shortly

'now I am about to die shortly' (Ameka 2006: 84)

12.2 Doubled inflection in AVCs in languages of the Macro-Sudan Belt. Doubled inflectional patterns are relatively common among languages of the MSB linguistic area. As alluded to above, Bongo-Bagirmi languages make extensive use of doubly inflected AVCs. A canonical instantiation of this pattern can be found in languages like Mbay and Gula Méré. 
(669) a. Mbay (C. Sudanic, Chad)

$\bar{m}$-ndi $\quad \bar{m}$-sá $y \stackrel{a}{a} a$

1 -AUX 1-eat food

'I am/was eating' (Keegan 1997: 69)

b. Mbay (C. Sudanic, Chad)

$k \grave{\partial}-n d \grave{l} \quad k \grave{\partial}-s \grave{a}-\bar{n} \quad y a ́ g a$

1PL-AUX 1PL-eat-PL food

'we are/were eating' (Keegan 1997: 69)

Note that the following form is a variant of the Gula Méré form given in (641) above, using the same auxililary and in the same function, only in a doubled inflectional pattern not an AUX-headed one (with an infinitive form of the lexical verb).

(670) Gula Méré $=($ repeat of 157)

$$
\begin{aligned}
& \text { má-ndá m-úsā nj̀ } \\
& \text { 1-AUX 1-eat thing } \\
& \text { 'I am eating' (Nougayrol 1999: 137) }
\end{aligned}
$$

The Bak language Dyola exhibits a similarly doubly subject-inflected construction in the following future formation.

(671) Dyola

$$
\begin{array}{lll}
\boldsymbol{u} \text {-ja } \quad \boldsymbol{u} \text {-waloa di } & e-k o l o-\eta \\
\text { 1PL-aux } & \text { 1PL-enter loc } & \text { PREP-well-the } \\
\text { 'we will enter the well' } & \text { (Marchese 1986: 111; Givón 1973) }
\end{array}
$$

Patterns involving a doubled category other than the subject are not at all common in languages of the MSB linguistic area, or really anywhere else in Africa. I offered an example of a doubled negative-marked form in Twi. This unusual pattern is found in its 
sister language Akan as well, where negative appears in a doubly inflected configuration, on both the auxiliary and the lexical verb.

(672) NEG-AV NEG-LV

(673) $\underline{\text { Akan }}$

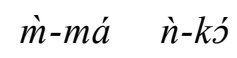

NEG-AUX NEG-go

'don’t go' (Osam 2004: 22)

Lastly, in (45) a form from Ma'di was exemplified with an unusual pattern where tonallymarked non-past (encoded by a floating low tone) appears with both the lexical verb and the auxiliary.

As pointed out by Nurse (2008) among others, the tradition of analysis of the researcher has a profound effect on whether a verb form in an African language gets interpreted as having bound or free-standing grammatical markers. Thus, the francophone/francographic tradition, and analyses inspired by such a tradition, particularly in certain parts of western and central Africa, generally interprets functional elements on the verb as free-standing particles, while anglophone/anglographic traditions might analyze the same data as a sequence of bound affixes or clitics. This said, a number of languages of the MSB area exhibit what appears to be doubled subject marking with unbound subject markers in a possibly 'pseudo-analytic' formation. Such a construction was offered by Prost (1964) in analyzing the Gur languages Kirma and Tyurama.

(674) SUBJ AV SUBJ LV

(675) Kirma

$$
\begin{aligned}
& \text { mi ta mi wo } \\
& 1 \text { AUX } 1 \text { eat } \\
& \text { 'I am eating' (Prost 1964: 56-59; Heine and Reh 1984: 117) }
\end{aligned}
$$


(676) Tyurama

$$
\begin{aligned}
& \text { me na me wu } \\
& \text { I AUX I eat } \\
& \text { 'I am eating' (Prost 1964: 103; 105; Heine and Reh 1984: 117) }
\end{aligned}
$$

A number of similar pseudo-analytic doubled subject forms of this type are found in the enigmatic unclassified language Laal of Chad.

(677) Laal

$$
\text { Pì cì Pì pùd kín }
$$

ils AUX ils terminer en se séparant

'ils meurent (tous)' (Boyeldieu 1982: 186)

The language of the actual original interpretation need not be French rather than English, just the influence of the analytic tradition. So, analyses offered for Nupoid Gade and Jalonke of the West Mande genetic unit similarly interpret the obviously doubly subjectinflected AVCs below as having doubled free-standing subject pronouns.

(678) a. SUBJ AV SUBJ LV $\quad$ b. SUBJ AV $\quad$ SUBJ $_{<\text {PHON.DEP> }} \mathrm{LV}$

(679) a. Gade

$m b \grave{a} \quad b a \quad n I \quad b a \quad g \varepsilon$ and 3PL AUX 3PL go 'and they happened to go' (Sterk 1994: 18) b. $\underline{\text { Gade }}$

baa cícì bàà sí gízè

3PL AUX 3PL.DEP buy yam

'they should still be buying yams'

Note that the Gade form shows a phonologically-marked dependent subject marker (tonally realized), despite being analyzed as within a quasi-analytic structure.

In Bantu A20 Duala and the Grassfields Bantu language Babungo of Cameroon, a doubled inflectional pattern appears in a phonologically/ prosodically less integrated form in a construction with a quasi-analytic but nevertheless doubly-marked subject. In Duala, the second subject marker is phonologically marked as dependent in (681), but not in Babungo (682). 
(680) SUBJ AV SUBJ LV

(681) a. Bantu A20 Duala

a mabé á nyj́ mao búnya té

he AUX:PRS he drink palmwine every day

'he drinks palmwine every day'

(Heine and Reh 1984: 118; Ittmann 1939: 96)

b. Duala

c. Duala

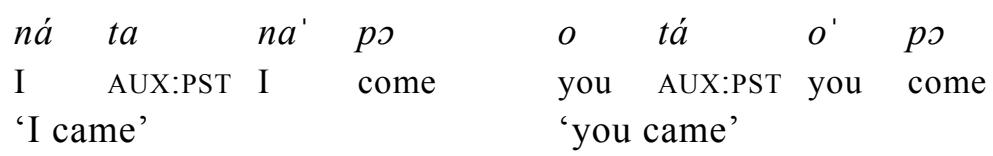

(Heine and Reh 1984: 118; Ittmann 1939: 97)

(682) Babungo [Grassfields Bantu, Niger-Congo; Cameroon]

ywá dù'tá $\eta w a ́ ~ k \hat{u}$
he already he die:PrF
'he has already died' (Schaub 1985: 219)

Jalonke shows a similar formation with unbound but doubled subject inflection in the following AVC, the second of which in some AVCs appears to be phonologically marked:

(683) Jalonke

$$
\begin{array}{llllll}
n & \text { an } & \text { tewi-xi } & \text { nde } & n & \text { jele } \\
1 \mathrm{SG} & 1 \mathrm{SG} & \text { do.deliberately-PRF INACT } & 1 \mathrm{SG} & \text { laugh } \\
\text { 'I laughed deliberately' (Lüpke 2009: } & 184)
\end{array}
$$

Variation with the same auxiliary showing an AUX-headed pattern or a doubled one is also not uncommon in languages of the MSB linguistic area. One such example from Gula Méré was offered above. Another example was given in (59) above from its BongoBagirmi sister language Ngambay-Moundou, where there is similar variation between a 
doubled inflectional pattern and an AUX-headed one with a nominalized lexical verb, but one that is also an overt syntactic dependent of a prepositional phrase. Likewise, in the Bak language Diola Fogny of Senegal and Gambia, the past progressive or imperfect is marked either by an AUX-headed formation with the lexical verb in an infinitive form or by doubly subject inflected AVC; see (58) for examples.

12.3 Split inflection in AVCs in languages of the Macro-Sudan Belt. Split inflection is attested among the languages of the MSB linguistic area in AVCs as well. The most common split pattern attested in languages of the MSB is the split where subject is encoded on the auxiliary verb and object on the lexical verb. Such a pattern is found for example in the Gbe language Ewe, and in Mbe, a S. Bantoid language.

(684) SUBJ-AV LV-OBJ

(685) Ewe

$$
\text { mì-le kpó-m }
$$

2PL-AUX see-1

'you see me' (Allen 1993: 39)

(686) $\underline{\text { Mbe }}$

$$
\begin{aligned}
& \text { ̀̀-rèkě } \quad \text { šék-àbó bèñèn } \\
& \text { 1-AUX:SFX sell-3PL things } \\
& \text { 'I will be selling them things' (Pohlig 1981: 30) }
\end{aligned}
$$

À propos to the discussion offered above on the influence of the tradition of metaanalysis that has a strong impact on the interpretation of linguistic phenomena, it would apppear that Laal shows a split inflectional pattern of this same 'pseudo-analytic' type.

(687) SUBJ AV LV-OBJ 
(688) Laal
màr.cē
bílá $\quad m \dot{t}$
bìlà ?ò̀ tê:
d'tg'tr
cultivateur(COMP) dire.que pour rien tu PROG tromper:1
'le cultivateur dit "certainement pas! tu es en train de me tromper'
(Boyeldieu 1982: 123)

As discussed previously and exemplified in (73), Ogonoid Kana (689) has a structure which appears to reflect such a pattern at first glance. The following two forms suggest that Kana might exhibit the object-with-lexical verb subject-with-auxiliary verb inflectional split that its sister language Eleme does (72).

(689) ana

$$
\begin{aligned}
& \grave{m} \text {-dààb } \quad \bar{a}-\bar{m} \grave{u} \varepsilon \\
& \text { 1-MOD:FACT 2-see } \\
& \text { 'I can see you' (Ikoro 1996) }
\end{aligned}
$$

However the following past capabilitive form suggests that these elements might rather be clitics ((691), repeating (75)), with the subject marker a clause-initial proclitic and the object marker a second-position proclitic (so it must attach to the word to the left or second verb in this sequence). This order reflects the areally typical S Aux [proN]O V order, that is especially common with pronominal objects (Gensler 1994, 1997, Güldemann and Gensler 2003; Childs 2005, Güldemann 2008) which typifies languages of the MSB.

(690) SUBJ-[A]V $\mathrm{V}_{1}$ PRON.OBJ-[A/L $] \mathrm{V}_{2} \quad\left[\mathrm{~L}_{\mathrm{V}} \mathrm{V}_{3} \ldots\right.$

(691) Kana

$$
\begin{aligned}
& \begin{array}{l}
m \text {-wèe } \\
\text { 1-PST }
\end{array} \quad \text { 2-MÓb } \quad \text { mùc̀ } \\
& \text { 'I was able to see you' (Ikoro 1996) }
\end{aligned}
$$

Note that Bijogo offers an example of a serial structure that is likely to be something like that which is at the origin of many instances of this split subject/object inflectional pattern. When a deictic motion serial verb like 'come' serializes in a nuclear serial 
structure with a transitive $V_{2}$, the first verb takes the subject marking governed by it, and the object is encoded by the lexical verb that subcategorizes for it. A reinterpretation of $\mathrm{V}_{1}$ as a functional element and thus as an auxiliary relatively straightforwardly would yield a split inflectional pattern of this subject/object type.

$$
\text { SVC: SUBJ-V } 1 \text { [sv]-OBJ-V } \mathrm{V}_{2}>\mathrm{V}_{1}>\mathrm{AV} \mathrm{V}_{2}>\mathrm{LV} \text { in AVC }
$$

(693) $\underline{\text { Bijogo }}$

$$
m \text {-ba-de } \quad n \text {-de-a ma-da n-na-jon }
$$

2S-IRR-finir SV-finir-VEN 2S.ACCOMPLI-venir SV-1s.OBJ-voir

'quand tu auras fini, viens me voir!' (Segerer 2002: 250)

Lastly, a different kind of split is seen in Doyayo, as exemplified in (83) above. Here tense is encoded on the lexical verb and object and subject properties on the auxiliary.

(694) AV-OBJ[-SUBJ] LV-TA

(695) Doyayo

$$
\begin{aligned}
& h i^{l} \quad g i^{2}-s-i^{l}-m i^{3}-g e^{3} \quad w \tilde{a} \tilde{a}-k o^{3} \\
& \text { they AUX-BEN-EP-1-3 catch-PROX } \\
& \text { 'they will be catching him for me' } \\
& \text { (Wiering and Wiering 1994: 75) }
\end{aligned}
$$

12.4 Split/Doubled inflection in languages of the Macro-Sudan Belt. Split/ Doubled inflectional patterns are found in various languages of the MSB, in particular the CrossRiver languages, but such formations overall are fairly marked for the languages of this region of Africa. In Ibibio and Ogbronuagom of Nigeria, negative is found on the auxiliary, while subject is doubly encoded on both the lexical verb and auxiliary verb component of the AVC.

(696) SUBJ-AV-NEG SUBJ-LV 
(697) Ibibio

Ùdèmé i-tóoñoké i-táñ ikộ ìté ábooñ

Udeme CNC-start:NEG CNC-talk word like chief

'Udeme has not started to talk like a chief' (Essien 1987: 154)

(698) SUBJ-TA/NEG-AV SUBJ-LV

(699) Ogbronuagum (Bukuma)

$$
\begin{array}{ll}
\text { oji-ne } & \text { oji-kile } \\
\text { 1PL:FUT.NEG-AUX } & \text { 1PL-do } \\
\text { 'we can't do it' } & \text { (Kari 2000: 41) }
\end{array}
$$

Cross-River (Ogonoid) Eleme shows systematic splits in certain paradigms between the behavior of second plural and third plural subjects.

(700) 2-AV LV-HAB-2PL

(701) Eleme

$$
\begin{aligned}
& \text { ró-bere } f \supset-a ́-i \quad \text { tfátfa:ma } \\
& \text { NEG.2-PRF plant-HAB-2PL beans } \\
& \text { 'you didn't used to plant beans' }
\end{aligned}
$$

(Bond 2006; Bond and Anderson 2003)

In the past habitual, habitual is marked on the lexical verb, while second plural subject is also found on the lexical verb but third plural subject on the auxiliary. 
(703) Eleme

àbà bere-ri fJ-غ̀nu

3PL PRF-3PL plant-something

'they used to plant something'

(Bond 2006; Bond and Anderson 2003)

In both instances the person but not number of the subject appears as a prefix on the auxiliary as well. Thus, in the third plural, a subject person/number vs. aspect split is attested (so properly this forms belongs in 12.3 above), while with second plural subject forms the split is rather subject person vs. aspect plus subject person+number in a kind of quasi-split/doubled pattern. For more on these and other similar forms in Eleme, see Bond (2010).

Mbay of Chad shows a split/doubled construction in the following future formation, where subject is doubly marked while object is found only on the lexical verb-a distribution that is a common one in split/doubled systems, and in Africa is particularly characteristic of Bantu languages (section 6).

(704) SUBJ-AV SUBJ-LV-OBJ

(705) Mbay (C. Sudanic, Chad)

$$
\begin{aligned}
& \bar{m}-\bar{a} \quad \bar{m}-e^{l} l-a ́ a \text { tàa lò-í } \\
& \text { 1-AUX 1-tell-3 words of-2 } \\
& \text { 'I'll tell him what you said' (Keegan 1997: 116) }
\end{aligned}
$$

Amo of the Kainji family is another language of the MSB linguistic area that presents a further example of an AVC with a split/doubled inflectional pattern of this same subject/object type:

(706) $\underline{\text { Amo }}$

$$
\begin{aligned}
& \text { fewe u-wasà } \grave{u} \text {-yenè- } i \\
& \text { you 2-AUX.HAB 2-see-1 } \\
& \text { 'you often see me' (Di Luzio 1972: 27) }
\end{aligned}
$$


Finally, the Òkó language of Nigeria has a different kind of split/doubled pattern where subject is doubly marked (as expected), but aspect is restricted to being expressed on the auxiliary in the following deontic modal formation:

(707) SUBJ-TA-AV SUBJ-LV

(708) Òkó

$$
\begin{aligned}
& b e-k \grave{e}-c a \quad b e-y o \\
& \text { 3PL-ASP-AUX 3PL-go } \\
& \text { 'they should leave' (Akerejola 2008: 177) }
\end{aligned}
$$

While Doyayo is analyzed as having unbound subject marking, it nevertheless shows a similar split/doubled inflectional pattern in the following AVCs, where subject is doubly marked and object restricted to the lexical verb.

(709) SUBJ AV SUBJ LV-OBJ

(710) Doyayo (Adamawa-Eastern, Cameroon)

$g \partial^{2} \quad h i^{3} \quad d a^{3} \quad h i^{3} \quad e^{4} l i^{4}-m s^{4}$

when 3PL REM 3PL call-2

'when they would call you' (Wiering and Wiering 1994: 220)

12.5 LEX-headed AVCs in languages of the Macro-Sudan Belt. True LEX-headed structures are quite rare in languages of the MSB linguistic area. One example of such a formation is found in the Bongo-Bagirmi language Mödö, where an unmarked future auxiliary is used with a subject-marked lexical verb (first exemplified in (28), repeated here as (712)).

(711) AV SUBJ-LV

(712) Mödö

tí mó-kj̀nyì yí

FUT 1-rescue you

'I will rescue you' (Persson and Persson 1991: 19) 
Interestingly is sister language Bongo shows a similar but non-cognate LEX-headed formation in its future, the future elements themselves however are not cognate. Another noteworthy difference is that the lexical verb encodes subject, but also appears in a dependent infinitive form. Thus morphosyntactically the lexical verb functions as the inflectional head, but syntactically it is the dependent of the phrasal head auxiliary. This further underscores my assertion in section 1 that morphosyntax (or inflection) and phrasal syntax are separate but often interconnected domains, at least with respect to AVCs, but more generally in any cross-linguistically defensible theory of the architecture of grammar.

(713) AV INF:LV-/=SUBJ

(714) a. Bongo

ma amai atäy
I FUT INF:see:1
'I shall see'

(Santandrea 1963: 65) b. Bongo

i amai ata $=m a$

you FUT INF:see=2

'you shall see'

One might assume that these LEX-headed structures at least sometimes derived from the erosion of a more inflected construction. This is certainly the case in the rise of the variant LEX-headed formations attested in Mbay. Here there is variation in the progressive AVC between a LEX-headed structure and doubled one, as alread mentioned above.

$$
\text { AV SUBJ-LV < SUBJ-AV SUBJ-LV }
$$

(716) a. Mbay

$$
\begin{aligned}
& \text { ndi } \bar{m} \text {-sá yáa < } \bar{m} \text {-ndi } \bar{m} \text {-sá yáa } \\
& \text { AUX 1-eat food 1-AUX 1-eat food } \\
& \text { 'I am/was eating' (Keegan 1997: 69) }
\end{aligned}
$$


b. Mbay

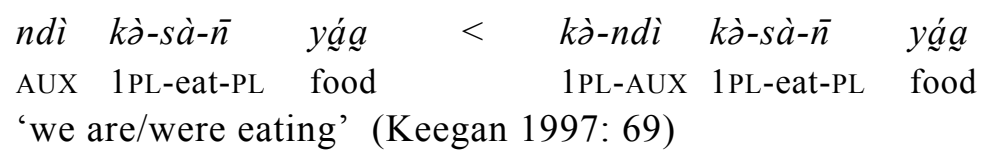

12.6 Tensed pronouns and fused subject/auxiliary formations. The fusing of a subject pronoun with a following TAM/polarity auxiliary is relatively wide-spread among the languages of the MSB. ${ }^{41}$ Indeed, such formations are a characteristic feature of the region, occuring only sporadically elsewhere in Africa. To be sure, genetic units that have languages both inside and outside of the MSB have languages with such tensemarked pronouns occuring in the languages in the area, but infrequently outside of the languages of the area (like some Bantu A-region subgroups, which pattern like Bantoid languages rather than the rest of Narrow Bantu in this regard (see 6 above). Tensemarked pronouns are found throughout the many genetic units of the MSB, including Northern and Southern Bantoid, Cross River and Ukaan, Jukunoid, Kainji and the many subgroups of Platoid, Gbe languages, the Volta-Congo isolate Ega, Waja languages, Gur languages, various subgroups of Ubangi, Chadic languages, Cangin and Senegambian Atlantic, Potou-Tano and Ga-Dangme Kwa languages, Bongo-Bagirmi, languages representing various genetic units of the Yoruboid-Edoid-Akokoid-Igboid and NupoidOkoid-Idomoid stocks of Nigeria, and Senufic languages to name just a random selection in my database.

A simple set of forms reflecting tense-marked pronouns of various types in an AUXheaded formation with a unmarked lexical verb can be seen in the Kulango-Lohorn language Kulango (718) or in the Southern Bantoid languages Tiv (719) or Ndemli (720).

(717) SUBJ:AV $\mathrm{CTAMP}_{<\mathrm{LV}}$

$\begin{array}{llll}\text { (718) a. Kulango } & \text { b. Kulango } & \text { c. Kulango } & \text { d. Kulango }\end{array}$

\begin{tabular}{|c|c|c|c|c|c|}
\hline dólì & $m i ́$ & dólì & $m i ́ I$ & dj̀lì & mádj̀lì \\
\hline PR & 1.SBJNCTV & sell & 1.PROG & sell & 1.HAB sell \\
\hline I have sold' & 'may I sell' & & 'I am s & lling' & 'I sell' \\
\hline
\end{tabular}

(Elders 2007: 193)

${ }^{41}$ See also Leger and Storch 1999, Ibriszimov and Segerer (eds. 2004), Vydrin (2006), Babaev (2010); also Frajzyngier (1982). 
(719) a. Tiv

b. Tiv

$\begin{array}{ll}\dot{m} \quad \text { Iva } & m e ́ ! v a \\ \text { 1.NFUT come } & \text { 1FUT come } \\ \text { 'I have come' } & \text { 'I will come' } \\ \text { (Arnott } 1967 / 1980: \text { TIV 4) }\end{array}$

(720) a. Ndemli

b. $\underline{\text { Ndemli }}$

$\begin{array}{ll}\text { mà tóm } & \text { mìgá } \quad \text { tóm } \\ \text { 1.PST send } & \text { 1.FUT NEG send } \\ \text { 'I sent' } & \text { 'I will not send' } \\ \text { (Ngoran 1999: 72) } & \text { (Ngoran 1999: 76) }\end{array}$

Naturally such formations are more typical of certain genetic units than others. Thus, 'tense-marked pronouns' are a family level characteristic of Kru languages, like Neyo, Klao or Wobé:

(721) SUBJ.PRON:TA LV[-ASP/DEP] < SUBJ-AV <TA>LV[-ASP/DEP]

(722) a. Neyo

$\bar{\jmath} b l \bar{l}-\varepsilon \dot{\varepsilon}$

he sing-IMPF

'he sings, can sing'

(Marchese 1982: 18) b. Neyo

j’j $\quad b l \bar{\imath}-\bar{\varepsilon}$

he:IMPF sing:IMPF

'he is singing'

(723) $\underline{\text { Klao }}[\mathrm{Kru}]$
$\bar{\jmath} \quad b l \bar{e}$
3:IMPF sing
'he is singing' (Marchese 1982: 3) 
(724) a. Wobé

$\tilde{e}^{2} \quad g y i^{32}$

1.PST come

'I have come' b. Wobé

$m a^{2} \quad g y i^{32}$

1.NPST come

'I am coming'

(Hofer and Link 1973/1980: WOB 3) c. Wobé

$m a^{2} \quad m u^{3}-\varepsilon^{3} \quad g y i^{32}-a^{2}$

1NPST FUT-INDIC come-INF 'I will come'

Tensed pronouns are also frequent in various sub-families of Plateau spoken in northeastern Nigeria. Such formations are characteristic of such languages as Central Plateau (I)Rigwe, Southeast Plateau Fyem, or Tarokoid languages like Tarok:

(725) SUBJ:AV $\mathrm{ATAM}_{<\mathrm{LV}}$

(726) a. Tarok

$$
\begin{aligned}
& n \quad \text { ya ù-yèn } \\
& \text { 1.PRF see CLS-child } \\
& \text { 'I have seen a child' or 'I see a child' (Sibomana 1981: 238) }
\end{aligned}
$$

b. Tarok

$$
\text { mi wá a-tí i-pin }
$$

1.IRR drink CLS-tea tomorrow

'I will drink tea tomorrow' (Sibomana 1981: 238)

(727) a. Rigwe

$\grave{a} \quad n i ́ \eta \quad \eta^{w} \grave{a} \quad \grave{n} t c \varepsilon \quad k \hat{s} z$ zòhù stú

3.IMPF me give money every day

'he gives me money every day'

(Blench 2009: 4) b. Rigwe

àá níy $\quad \eta w a \quad \grave{n t c \varepsilon}$ 3.PRF me give money 'he has given me money' 
(728) a. $\underline{\text { Fyem }}^{42}$

náá soo Gindirín

1.PRF go Gindiri

'I went to Gindiri'

(Nettle 1998a: 32) b. Fyem

in soo dirámméka

1.IMPF go farm.your.oBLQ

'I will go to your farm'

(Nettle 1998a: 35)

Western Plateau Idũ has an AUX-headed structure with tense-marked pronouns either with (future) or without (progressive) a copy pronoun in what looks like a quasi-doubled subject-marking construction.

(729) SUBJ:AV $V_{<\text {TAM }}$ LV (730) SUBJ:AV $V_{<\text {TAM }>}$ LV SUBJ.DEP

(731) Idũ



1.PROG/COMPL PROG beat dog

'I am beating the dog' (Blench 2010: 14)

(732) $\underline{\text { Idũ }}$

mi kwer tun jvwi

1.FUT/INCOMPL beat 1.DEP dog

'I will beat the dog' (Blench 2010: 15)

Mande languages also make use of such formations. The lexical verb in the following Kpelle form appears in a dependent locative form, licensed by the tensed pronoun; this is exactly the kind of construction that underscores the likely origin of such 'pronominal' forms in fused auxiliary structures.

(733) SUBJ.PRON.TA LOC-LV $<$ ?* SUBJ-AV $<$ TA $>$ LOC-LV

\footnotetext{
${ }^{42}$ Note that the first perfect form in Fyem náá is identical to the form in Hausa, and may be a loan element.
} 
(734) Kpelle

\author{
‘áa pâ-i \\ 3:AUX come-LOC \\ ' $\mathrm{s} / \mathrm{he}$ is coming' \\ (Heine and Reh 1984: 206; Welmers 1973: 315)
}

In Mende, on the other hand, like Kulango, Tarok or Tiv above, the lexical verb appears in a bare stem or Ø-marked form.

(735) a. $\underline{\text { Mende }}$

$\begin{array}{lc}n g-a a \quad \text { tewe } & n g-i \text { tewe } \\ \text { 1-NEG:PM cut } & \text { 1-AOR cut } \\ \text { 'I do not cut' } & \text { 'I cut' } \\ \text { (Heine and Reh 1984: 208; } & \text { Migeod 1908: 84) }\end{array}$

b. Mende

$$
\begin{aligned}
& n g-i \text { tewe } \\
& 1 \text {-AOR cut } \\
& \text { 'I cut' }
\end{aligned}
$$

In its distant sister language Guro, unusual portmanteau subject $>$ object pronouns of this type can be found:

(736) SUBJ.OBJ.PRON.TA.[NEG] LV:ASP < ??*SUBJ-OBJ-AV $V_{<\mathrm{TA} / \mathrm{NEG}}>$ LV-ASP

(737) a. Guro

$6 \bar{e}$

2SG $>3$ SG.IPFV wash-IPFV

'(you) wash him/her/it'

(Vydrine 2009: 239) 
(738) $\underline{\text { Kohumono }}$
B́́ fà
$1>2$.NPSTbite
'I bite you'
(Cook 1972/1980: 355) KOH 6

Atlantic languages can show structures of the broad fused subject/TAM type as well. Thus, Senegambian Wolof is renowned for its 'tense-marked pronouns' of this sort, as seen in the following examples:

(739) a. Wolof

nga dem

PST:2 go

'you went'

(Comrie 1985: 316) b. Wolof

mungi dyàng-al eleew yi tééré-ém PRS:3 read-APPL pupil the:PL book-his 'he is reading his book to the pupils'

The Cangin-Atlantic language cluster Ndut-Falor opposes a realis (or non-future) set of pronouns with an irrealis/future one. In some cases the lexical verb may be unmarked in an AUX-headed formation, as in the progressive (741), or in a modally dependent form in an AUX-headed construction as in the future (745), or it may rather appear in a TAMmarked form, as in the perfect form (744).

(740) SUBJ:PRON ${ }_{<R L S>} \quad$ AV LV

(741) Ndut-Falor

mi na ay

1RLS PROG come

'I am coming'

(Pichl 1973a/1980: NDU 4)

(742) SUBJ:PRON <RLS> $_{\text {LV:PRF }} \quad$ (743) SUBJ:PRON LFUT> $\quad$ LV:MOD 
(744) Ndut-Falor

miace

1.RLS come:PRF

'I have come'

(Pichl 1973a/1980: NDU 4)
(745) Ndut-Falor

$$
\begin{aligned}
& m a[y] \text { aye } \\
& \text { 1FUT come:MOD } \\
& \text { 'I will come' }
\end{aligned}
$$

Forms with unmarked lexical verbs used with a tensed pronoun in an AUX-headed formation contrasting with other AVCs with a marked lexical verb in a split inflectional configuration may be similarly found in the Senufic language Nafaara. Compare (747) with (749).

(746) SUBJ:PRON ${ }_{<\mathrm{TAM}>} \mathrm{LV}$
(747) a. Nafaara
b. Nafaara
ni pan
mepan
1.NFUT come
1.FUT come
'I have come'
'I will come'
(Jordan and Jordan 1975/1980: NAF 3)

(748) SUBJ:PRON ${ }_{<\text {TAM }}$ LV:ASP

(749) Nafaara
ni paan
1.NFUT come:IPFV/PROG
'I am coming'
(Jordan and Jordan 1975/1980: NAF 3)

Dadiya of the Waja family shows a similar range of constructions. The perfect pronouns are used with high-toned lexical verb (751), while the progressive AVC combines nonpast pronouns with a progressive-marked lexical verb (and reduplication with the stem 'eat') in a split configuration (753).

(750) SUBJ:PRON ${ }_{<\text {TAM }>}$ LV 
(751) a. Dadiya

$n \quad j a ́$
1.PRF eat.PRF
'I have eaten' b. Dadiya

ń já

2.PRF eat.PRF

'you have eaten'

(Jungraithmayr 1968/1969: 196)

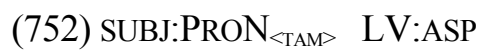

(753) a. Dadiya

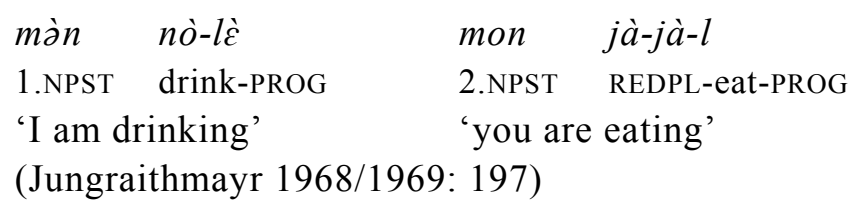

Structurally similar split formations can be found in Fali (Yc̃k GopRi) of Cameroon as well:

(754) a. Fali (Yẽk GopRi)

mìdikRàgé
1RLS come:PRF
'I have come' b. Fali (Y⿱̃⿻儿⿲二丶丶 GopRi)

c. Fali (Ỹ̃̃ GopRi)

(Ennulat 1973/1980: 229) FAL 3

The Gbaya Ubangi language 'Bozom has similar formations. Here lexical stems appear in one of two tone-marked aspectual forms, high-toned imperfective and low-toned perfective. These combine with realis (or non-future) and irrealis (future) sets of pronouns. The present and future forms combine these in simplex AVCs (756) while the perfect appears with an overtly dependent-marked lexical verb. Again, it is precisely these kinds of structures with a dependent lexical verb where it is most clear that these pronouns are in fact historically fused auxiliary forms.

(755) SUBJ:PRON ${ }_{<\mathrm{TAM}>}$ LV:ASP[:DEP] 
(756) a. 'Bozom

?à ré

3.RLS enter.IPFV

'he enters'

(Moñino 1995: 159) b. 'Bozom

$P \grave{a} \quad r \grave{e}-\dot{a}$

3.RLS enter.PRF-DEP

'he has entered' c. 'ㅇozom

márè

3.IRR enter.PRF

'he will enter'

To be sure, a range of split formations can be found in various languages of the MacroSudan Belt, where the auxiliary in the AVC takes the form of a tense-marked pronoun. Thus Ga of the Ga-Dangme genetic unit shows a split negative AVC (758) of this broad structural type.

(757) SUBJ:PRON $\mathrm{CTAM}_{<\mathrm{T}}$ LV-NEG

(758) $\underline{\mathrm{Ga}}$

$e^{\mid} \quad b a^{\prime}-\grave{y}$

3.FUT come-NEG

'he will not come' (Kropp-Dakubu 1988: 105)

Bagirmi of the Bongo-Bagirmi genetic unit has fused subject/auxiliary structures of the type under consideration here. That these pronouns incorporated auxiliaries historically in Bagirmi is shown by the fact that the lexical verb is in an infinitive form in the following AVCs, the definite and indefinite present forms. The vowel alternations seem like the subject-auxiliaries may themselves be being fused into larger verbal complexes, though this is not the analysis offered by Tucker and Bryan (1966).

$$
\text { SUBJ:PRON:TA }
$$

SUBJ-AV $\mathrm{CTA}_{<\mathrm{INF}-\mathrm{LV}}$

(760) a. Bagirmi

$\begin{array}{llll}m a ́ & k i-n j i . & m u ́ & k \grave{-} \text {-kó } \\ \text { 1.INDEF } & \text { INF-sit } & \text { 1.INDEF } & \text { INF-seize } \\ \text { 'I sit' } & & \text { 'I seize' }\end{array}$

(Tucker and Bryan 1966: 66) 
c. $\underline{\text { Bagirmi }}$

$m \ddot{a} \quad k \ddot{a}-s a$
1.INDEF INF-eat
'I am eating'
(Tucker and Bryan 1966: 74)

In Bagirmi, the so-called definite present exhibits a doubled subject inflectional pattern embedded within a construction showing subject marking fused with the auxiliary, as is also seen in the indefinite present form (where it is in an AUX-headed configuration with an infinitive marked lexical verb). That is, in the definite present, the subject and the original auxiliary have fused into a single word, which is followed by the subject-marked lexical verb in Bagirmi.

$$
\text { SUBJ.PRON.TA SUBJ-LV ASP }<?^{*} \text { SUBJ-AV } \mathrm{CTA}_{<\mathrm{T}}
$$

SUBJ-LV ASP

(762) Bagirmi

má. m-kó. gà

1.DEF 1-seize DEF

'I seize'

(Tucker and Bryan 1966: 66)

In the Kainji language Duka, the lexical verb appears in an unmarked (or Ø-marked) form in some AVCs (764) and in a overtly dependent-marked form in others (766). As etymologies are provided for some of these forms, the analysis of these tense-marked pronouns as original auxiliary verbs is secure (e.g., 764c and 766).

(763) SUBJ.PRON.TA

$\mathrm{LV}<*$ SUBJ $-\mathrm{AV}_{<\mathrm{TA}>}$ LV

(764) a. Duka

mân hé ò-kót á

I.FUT.NEG go to-bush NEG

'I won't go to the bush...' (Bendor-Samuel et al. 1973: 13) 
b. Duka

$m \varepsilon ́ \quad$ róà so á

I.IRR REM.FUT drink NEG

'I would not drink it' (Bendor-Samuel et al. 1973: 17)

c. Duka

maà he

I.FUT go

'I will go'

(Bendor-Samuel et al. 1973: 98) /*əm+rà/ > maà/màà future.1

(765) SUBJ.PRON.TA DEP-LV <*SUBJ-AV $V_{<T A>}$ DEP-LV

(766) a. Duka

\begin{tabular}{|c|c|c|c|c|c|c|}
\hline$m \varepsilon$ & àm-hà & $\sim$ & $m \varepsilon /$ & am ro & & àm-hà \\
\hline I.PROG & DEP-go & & I.PROG/ & I PROG & & DEP-go \\
\hline 'I am g & ing' & & 'I am go & ing' & or & 'I go' \\
\hline
\end{tabular}

Meje on the other hand shows fused subject/TAM auxiliary forms within a split/doubled structure, with tense marked on the lexical verb, and subject doubly encoded, once on the lexical verb and once on the tense-marked pronoun that itself derived from the fusing of an original auxiliary verb with a subject marker or pronoun.

(767) SUBJ.PRON SUBJ-LV-TA < SUBJ-AV SUBJ-LV-TA

(768) $\underline{\text { Meje }}$

má bhó ú méku-a

1:AUX already there 1:come-NPST

'I'm already (in the process of) coming' (McKee 1991: 167)

In the southeastern Plateau language Fyem an AVC with a tensed pronoun in a (split/)doubled inflectional pattern is found in the hodiernal past. 




(770) a. Fyem

inki náá wun-o

1.HOD 1.PRF see-2OBJ

'I saw you earlier today'

(Nettle 1998: 41) b. $\underline{\text { Fyem }}$

$$
\text { uki ti wun-uy }
$$

2.HOD 2.PRF see-1OBJ

'you saw me earlier today'

12.7 Complex verb forms derived from fused AVCs. Fused complex verb forms deriving from AUX-headed AVCs are frequently attested in the languages of the MSB. Again, there is some debate among specialists as to what exactly constitutes a fused or univerbated structure, and what remains synchronically bi-partite. Thus, under some analyses, Kwa languages show complex verb forms derived from fused AUX-headed structures, such as Standard Ewe, Akan, or Nkonya, while other researchers claim no fusing has occurred in such forms. As mentioned above, whether an obligatory index of a functional category is phonologically incorporated, 'cliticized' or independent has nothing to do with its status as an inflectional index.

(771) SUBJ-TA-LV <*?SUBJ-AV LV

(772) $\underline{\text { Standard Ewe }}$

$m-a ́-y i$

1 -FUT-go

'I will go'(Heine and Reh 1984: 131; Westermann 1907: 63)

(773) $\underline{\text { Akan }}$

j-bé-t’́ $\quad b i$

3-FUT-buy some

's/he will buy some' (Osam 2004: 7)

(774) SUBJ.TA-LV < SUBJ-AV LV 
(775) Nkonya [Guang, Kwa, Niger-Congo; Ghana]

$$
\begin{aligned}
& \text { nos-ho fos-ho mlec-ho bos-ho } \\
& \text { 1.FUT-buy 2.FUT-buy 2PL.FUT-buy 3PL.FUT-buy } \\
& \text { 'I'll buy' 'you will buy' 'you (pl) will buy' 'they will buy' } \\
& \text { (Reineke 1972: 51) }
\end{aligned}
$$

Another example of this type of fused AUX-headed structure yielding a complex verb form in a language of the MSB comes from the perfect form in the Amo (Timap) language of the Kainiji genetic unit as described by Di Luzio (1972).

(776) a. $\underline{\text { Amo }}$

$\grave{n-n a-s u ̀ ~}$
1-AUX.PRF-do
'I often did'
(Di Luzio 1972: 36) b. $\underline{\text { Amo }}$

$$
\begin{aligned}
& \grave{u} \text {-na-sù } \\
& \text { 2-AUX.PRF-do } \\
& \text { 'you often did' }
\end{aligned}
$$

This Kainji language has many interesting complex verb forms derived from fused AVCs that reflect different original inflectional patterns. Thus the habitual form in Amo represents a fused form with an original doubly subject inflected pattern.

(777) SUBJ-TA-SUBJ-LV <?*SUBJ-AV SUBJ-LV

(778) a. $\underline{\text { Amo }}$

$\dot{n}-s \grave{a}-n-s \hat{u}$

1-AUX.HAB-1-do

'I often do'

c. $\underline{\text { Amo }}$

$u$-wasà-ù-yenè

2-AUX.HAB-2-see

'you often see, saw'

(Di Luzio 1972: 36) b. $\underline{\text { Amo }}$

$u-s \grave{a}-u-s \hat{u}$

2-AUX.HAB-2-do

'you often do'

d. Amo

$i$-wasà-ì-dâ

3PL-AUX-3PL-come

'they often came, come' 
Indeed the only seemingly secure example of a fused split inflectional structure in a complex verb form in my corpus from languages of the MSB linguistic area also comes from Amo. Here the usual split pattern of the subject on the auxiliary and object on the lexical verb is fused into a large complex in the future form.

$$
\text { SUBJ-TA-LV-OBJ }<? * \text { SUBJ-AV LV-OBJ }
$$

(780) $\underline{\text { Amo }}$

$$
\begin{aligned}
& \grave{u} \text {-bà-yen-i } \\
& \text { 2-FUT-see-1 } \\
& \text { 'you will see me' (Di Luzio 1972: 27) }
\end{aligned}
$$

As mentioned above, fused subject/auxiliary 'tensed pronouns' are relatively common among languages of the MSB linguistic area. Further fusing of these forms with lexical or auxiliary verbs into complex verb forms is also found among languages of this region. Such fused/fused formations are found in a small number of languages like the MbaUbangi language Ma.

$$
\text { SUBJ.TA-AV INF-LV <*SUBJ-AV [SUBJ-]AV INF-LV }
$$

(782) $\underline{\mathrm{Ma}}$

$$
\begin{aligned}
& n \grave{a} \text {-zùlà } \quad k \hat{a} \text {-sùbù } \quad \text { noygbo } \\
& \text { 1.PST-AUX INF-eat:bù meat } \\
& \text { 'I was eating meat' (Tucker and Bryan 1966: 127) }
\end{aligned}
$$

However, it is of course possible that more such formations exist in the languages of the MSB, but have been differently interpreted in the analyses of these languages, due to the constraints of the analytical traditions from which various researchers come (e.g., the anglophone vs. the francophone traditions) that were mentioned in passing above.

As I said at the beginning of this section, languages of the Macro-Sudan Belt are predominantly AUX V. However, variation may be seen within a single construction in 
one and the same language, as is the case in Mamvu (a language of the Mangbutu-Efe genetic unit) in the following formation, where AUX V order alternates with V AUX: ${ }^{43}$

(783) a. Mamvu

b. $\underline{\text { Mamvu }}$

$\begin{array}{lll}\text { jbe } \quad \text { mu-taju } & \text { mu-taju } \quad \text { jbe } \\ \text { dance } \quad 1 \text {-AUX } & \text { 1-AUX dance } \\ \text { 'I was dancing' } & \text { 'I was dancing' } \\ \text { (Heine and Reh 1984: } & \text { 126; } & \text { Vorbichler 1971: 248-50) }\end{array}$

\begin{tabular}{ll}
\hline \hline AH & $\begin{array}{l}\text { Barambu; Morokodo; Gula Méré; Bangi Me; Adamawa Fulani; } \\
\text { Ogbronuagom; Bijogo; Ewe; Echie; 'Dongo; Izi; Mbodomo }\end{array}$ \\
AH $\sim 2 x$ & Ngambay-Moundou; Diola Fogny \\
$2 \mathrm{x}$ & Mbay; Gula Méré; Dyola; Bagirmi; Kana; Akan; Twi; Ma'di \\
"2x" & Kirma; Tyurama; Laal; Gade; Jalonke \\
split & Eleme; Ewe; Doyayo \\
"split”/LH & Laal \\
S/2 & Ibibio; Ogbronuagom; Eleme; Mbay; Doyayo; Amo; Òkó \\
LH & Mödö; Bongo; Mbay \\
S/TAM/P & Neyo; Klao; Kpelle; Guro; Mende; Wolof; Bagirmi; Duka; Meje; \\
& Ga; Fyem; 'Bozom; Fali; Dadiya; Nafaara; Ndut-Falor; Idũ; Tarok; \\
& Rigwe; KoHumono; Wobé; Kulango; Tiv; Ndemli \\
fAH & Ewe; Nkonya; Akan; 'Dongo; Amo \\
f2x & Amo \\
f-split & Amo \\
f/fS/TAM/P & Ma
\end{tabular}

Table 16: Inflection in selected languages of the Macro-Sudan Belt

12.8 Summary. Languages of the Macro-Sudan Belt are characterized by a predilection to AUX-headed or doubled inflectional patterns in AVCs. LEX-headed formations in the area are mainly limited to languages of the Bongo-Bagirmi family. Split/doubled

\footnotetext{
${ }^{43}$ Note that the tonal qualities of the lexical verbs varies with the position of the auxiliary in Mamvu.
} 
formations mainly occur in Cross-River languages and the Benue-Congo isolate Òkó which bear some close structural affinities with Bantu languages; the one exception is Mbay, although Bantu influence cannot be ruled out in this case either.

Different analytic traditions interpret word-structure in the languages of the MSB as either tending toward quasi-isolating (francophone tradition) or synthetic structures (anglophone tradition). Thus, many languages of the MSB are analyzed as showing doubled inflection but unbound 'agreement', pronouns or argument-encoding markers. Split patterns of this sort are also attested in languages of the MSB. Indeed, given these differing analytic traditions it is difficult to know whether the relative paucity of complex verb forms deriving from fused auxiliary structures is an artefact of these kinds of analyses or represent a valid typological observation for the languages of this linguistic area. One exception to this seeming relative lack of fused AVCs is the relative frequency with which fused subject-cum-auxiliary forms are found among the languages of the MSB attested in the guise of 'tense-marked pronouns' in representative languages from across the different component genetic units of the area.

\section{3 'Sahara' spread zone}

The area to the north of the Macro-Sudan Belt, the 'Sahara' region, encompasses several genetic units. Roughly speaking there appears to be a northern section, mainly where Berber languages, Arabic and N/W Nubian are found, and a southern and central area where languages belonging to the Saharan, Maban, Taman, Daju, Songhay, and Dogon families are spoken. The languages of the southern and central area tend to have V AUX order (except Songhay) while those of the northern region rather reflect AUX V order, so perhaps we are dealing with two separate spread zones here.

13.1 AUX-headed formations in languages of the 'Sahara.' AUX-headed formations are not overly common per se in languages of the 'Sahara' region, but light verb structures that have the form of AUX-headed AVCs are widely attested (as mentioned in Section 4.2 above in discussing the grammaticalized uses of 'say' in African languages). Some of the AUX-headed formations below may in fact be more properly speaking examples of this type of light verb structure. Typically the lexical verb in AUX-headed (quasi-light verb forms) appears in the stem form. Such is true in the Saharan language Beria/Zaghawa. 
(785) Beria/Zaghawa

$$
\begin{aligned}
& \text { sàì } \quad t \dot{\varepsilon}=\dot{I}^{\prime}-\zeta^{-} \bar{I} \\
& \text { taper } \quad 1 \text { PL.OBJ-AUX-3.SUBJ-AFFRM:IMPF } \\
& \text { 'il va nous taper' (Jacobi and Crass 2004: 66) }
\end{aligned}
$$

Maban languages of Chad show similar forms, as the following Aiki (Runga) and Maba forms exemplify:

(786) $\underline{\text { Aiki }}$ [Runga]

$$
\begin{array}{llll}
n d \grave{o} b o ́ & t i & j i ́ m & t-r a ́ y-t-\grave{\varepsilon} \\
\text { la viande } & \text { ANAPH } & \text { pourrir } & \text { 3-AUX-FUT-ASSRTV } \\
\text { 'la viande va pourrir' } & \text { (Nougayrol 1989: 65) }
\end{array}
$$

(787) Maba

$$
\begin{aligned}
& \text { j̀:-lì-gù súngó:-nú-gù mbòkód t-ír-ì } \\
& \text { wind-SG-DEF tree-DEF-ACC break 3SG-AUX-DECL } \\
& \text { 'the wind has destroyed the trees' (Dimmendaal 2010: 23) }
\end{aligned}
$$

13.2 Light verb formations in languages of the 'Sahara.' As mentioned above, a characteristic feature of the languages of the 'Sahara' region include relatively frequent use of light verbs 'say' or 'do' as an inflectional base with an uninflecting lexical element. Such constructions are formally identical to AUX-headed AVCs with an unmarked lexical verb. Languages exhibiting this type of formation among the languages of the 'Sahara' region include Tama, where both 'say' (789) and 'do' are used in this manner (790).

(788) Light Verb Constructions: 'LV' SUBJ.LightVerb-TA LightVerb = 'do', 'say' 
(789) Tama
ànáá-tá wút nú-クó
down-LOC fall 1SG:say-PRF
'I fell down to the ground'
(Dimmendaal 2009a: 314)

(790) Tama



'I opened the door for him/her' (Dimmendaal 2009a: 326)

Fur has a similar quasi-AUX headed light verb formation as well; in the following example the inflected light verb means 'do'.

(791) Fur

\begin{tabular}{|c|c|c|c|c|c|}
\hline $\begin{array}{l}n a ́ s I^{-} \eta \\
\text { CONT TR-PST:DUR }\end{array}$ & $\begin{array}{l}k-\varepsilon^{\prime} \varepsilon \dot{\varepsilon}-\eta \\
\text { PL-3SG-GEN }\end{array}$ & $\begin{array}{l}\text { léwa } \\
\text { goat.PL }\end{array}$ & $\begin{array}{l}n a \\
\text { and }\end{array}$ & $\begin{array}{l}\text { Puri-yá- `sí } \\
\text { sheep-PL-ACC }\end{array}$ & $\begin{array}{l}\text { duoy } \\
\text { herding }\end{array}$ \\
\hline$l \varepsilon-\check{\eta}$ & křlı & & & & \\
\hline
\end{tabular}

'he was continually herding his goats and sheep near the village' (Dimmendaal 2010: 22)

A similar formation is seen in the Maban language Aiki using 'do' as the light verb. This suggests the form offered above may well be another example of this quasi-AUX-headed light verb structure.

'LV': OBJ-SUBJ-LightVerb-ASSRTV 
(793) Aiki [Runga]

$$
\begin{aligned}
& \text { àndèi tèné cákám mbá-t-áry-̀̀ } \\
& \text { goat he to.sell 2-3-do-ASSRTV } \\
& \text { 'he sold you his goat' (Nougayrol 1989: 57) }
\end{aligned}
$$

Infinitive-marked lexical verb complements to emergent auxiliaries, that serve as input structures to the grammaticalization of AUX-headed formations, can be seen in such languages of the 'Sahara' region as Midob Nubian and Dar Daju Daju.

LV:INF

'AV':SUBJ.TA

(795) $\underline{\text { Midob }}$

áyélé sáaré kèllàwa

I now go:INF want:1SG.INDIC.CONT

'I want to go now' (Werner 1993: 58)

'AV'-TA REDPL:LV-INF

(797) Dar Daju Daju

sa wiE-e osos-ke ki sug-ne

3PL want-PRS go:REDPL-INF to market-CLS.SG.1

'they want to go to the market' (Aviles 2008: 52)

13.3 Other patterns of inflection in AVCs in languages of the 'Sahara.' Doubled inflection is mainly unattested among the languages of the 'Sahara'. True split inflection is likewise almost unknown among the languages of the region.

In this context it is somewhat bizarre that split/doubled forms are not overly uncommon in languages of the 'Sahara' region. Thus, Egyptian Arabic double marks subject, but aspect is expressed either non-concatenatively (perfective) or nonconcatenatively plus affixally (in the imperfective) in the following AVCs:

(798) AV:TA:SUBJ LV:TA:SUBJ 
(799) a. Egyptian Arabic

Sali kaan katab

Ali AUX:PST:3M write:PRF:3M

'Ali had written'

(Jelinek 1983: 26) b. Egyptian Arabic

Sali haykuun katab

Ali AUX:FUT:3M write:PRF:3M

'Ali will have written'

(800) AV:TA:SUBJ ASP:TA-LV:TA:SUBJ

(801) Egyptian Arabic

Sali kaan/haykuun biyiktib

Ali AUX:PST:3M/AUX:FUT:3M IMPF:write:3M

'Ali was/will be writing' (Jelinek 1983: 26)

Negative forms of these have the negative on the auxiliary verb alone, thus exhibiting a different kind of split/doubled pattern.

NEG-AV:TA:SUBJ-NEG

LV:TA:SUBJ

(803) a. Egyptian Arabic

Sali ma-kan-š katab

Ali NEG-AUX:PST:3M-NEG write:PRF:3M

'Ali had not written' (Jelinek 1983: 33)

b. Egyptian Arabic

Sali ma-haykun-š katab

Ali NEG-AUX:FUT:3M-NEG AUX:FUT:3M write:PRF:3M

'Ali won't have written' (Jelinek 1983: 33)

Masalit of the Maban family is another language of the 'Sahara' region that shows split doubled inflectional patterns in a number of AVCs. Subject is the doubly marked category as is usual in split/doubled patterns, but the lexical verb appears in a variety of 
non-finite, construction-dependent forms (including a Ø-marked stem form), with tense encoded on the auxiliary:

(804) SUBJ-LV[-DEP] SUBJ-AV

(805) a. Masalit

b. Masalit

g-oosiy-to $\quad g-\varepsilon$

2-know:BASE.II-PRTCPL 2-do

g-oosiy-ni $\quad g-\varepsilon$

'you try to know'

2-know:BASE.II-NR.FUT 2-do

'you are about to know'

c. Masalit

g-oosin $\quad g-\varepsilon$

2-know:BASE.II 2-do

'you do know already'

(Edgar 1989: 28)

(806) SUBJ-LV[-DEP] SUBJ-AV-TNS

(807) a. Masalit

b. Masalit

g-oosiy

$g-a y-\varepsilon$

2-know:BASE.II 2-go-PRS

g-oosiy-to

$n-i n d-\varepsilon$

'you are going to know'

(Edgar 1989: 23)

2-know.BASE.II-PRTCPL 2-want-PRS

'you want/need to know'

(Edgar 1989: 29)

c. Masalit

g-oos-o j-iy- $\varepsilon$

2-know-PRTCPL 2-be-PRS

'you knew' (Edgar 1989: 29)

(808) SUBJ-LV-NEG SUBJ-AV-TNS 
(809) $\underline{\text { Masalit }}$

$$
\begin{aligned}
& \text { g-oos-gede } \quad j \text {-iy- } \varepsilon \\
& \text { 2-know-NEG } \quad \text { 2-be-PRS } \\
& \text { 'you didn't know' (Edgar 1989: 29) }
\end{aligned}
$$

In the Saharan language Kanuri, lexical verbs appear in a converb or conjunctive form within various AVCs which encodes the subject of the verb. This appears with subjectand negative-marking in the following forms that therefore reflect a a special type of split/doubled inflectional pattern:

(810) AV:SUBJ:CONJ LV-Light.Verb:SUBJ:TA-NEG[:TA:SUBJ]

(811) a. Kanuri

$$
\text { ráksà rùwòj-înbâ }
$$

can:3:CONJ write:3:say-IMPF:NEG

'he cannot write' (Hutchison 1981: 323)

b. Kanuri

$$
\begin{aligned}
& \text { fàndákè lè-n-gânyí } \\
& \text { find:1:CONJ go-say-1:PRF.NEG } \\
& \text { 'I didn't get to go' (Hutchison 1981: 323) }
\end{aligned}
$$

LEX-headed constructions occur in languages of the 'Sahara' region more frequently than they do in many other regions of Africa. Two such languages include modern Dar Daju Daju and Ancient Egyptian:

(812) AV LV-TA

(813) Dar Daju Daju

$$
\begin{aligned}
& \text { naki idan-i awdin-ce } \\
& \text { I IRR hear-NPRS bird-CLS.SG.2 } \\
& \text { 'I will hear the bird' (Aviles 2008: 61) }
\end{aligned}
$$


(814) AV LV:TA SUBJ

(815) Ancient Egyptian

$j H \quad \underline{d} d \boldsymbol{t} \quad$ th $n \quad \underline{h r d w}$ tn

AUX parler:PROSP 2PL PREP enfant:PL 2PL

'parlez a vos fils!' (Oréal 2008: 169)

Berber languages make relatively frequent use of LEX-headed AVCs; included in this group are negative auxiliaries in some languages.

(816) AV SUBJ-LV:TA

(817) "Berber"

ur $\quad$ yə-kriz

NEG 3MSG-plough/NPRF

'he didn't [hasn't] plough[ed]' (Mettouchi 2009: 293)

In Tamashek, second position clitics (including object clitics) stack up on the otherwise uninflecting clause-initial auxiliary yielding what appears to be a split inflectional pattern but rather might be considered a pseudo-split LEX-headed one instead.

(818) $\mathrm{AV}=\mathrm{OBJ}$ LV:ASP-SUBJmimics AV-OBJ LV-SUBJ structure

(819) a. Tamashek

$a=t t=i n \quad$ itaw-cer

$\mathrm{FUT}=3 \mathrm{M} . \mathrm{OBJ}=\mathrm{CENTRIF}$ forget-1 SG.SUBJ

'I will forget him' (Heath 2005: 17)

b. Tamashek

kaelà $=t t \quad$ ale $-\gamma$

PST $=3$ M.OBJ have:PRF-1SG.SUBJ

'I used to have it' (Heath 2005: 585) 
13.4 Complex verb forms deriving from fused AVCs in the 'Sahara.' Fused AUXheaded formations are found in various languages of the 'Sahara' region, but fused light verb structures appear to be more common. Fused AUX-headed formations where the lexical verb retains its fused form traces of the dependent form inherited from the original AVC that underlies the complex verb form are found in Coptic.

(820) TA-SUBJ-LV:INF $<$ AV-SUBJ LV:INF

(821) Coptic

hah n-sop fa-k-aspadzo n-ta-tapro awo jə many of-occasion HAB-2M-kiss:INFPREP-POSS:1S-mouth CNJ COMP

fa-k-ankstk hijn-u-poj n-wot nmma-j n-ta-wfi

HAB-2M-sleep:INF on-INDEF-bed ATTR-single with-1s in-ART.F-night

titr-s

all-3F

'... you frequently kissed her on the mouth and that you used to sleep with her in a single bed all night'

(Kammerzell and Peust 2002: 312)

Fused light verb forms with the light verb 'say' are at the heart of many Saharan verb forms, e.g. in Zaghawa or Kanuri. This is a family-level feature of Saharan; for more details see Cyffer (1991).

(822) LV-SUBJ-LightVerb-TA $<$ LVSUBJ-LightVerb-TA

(823) Zaghawa

nว́:-gé-n-Í

see-3-LIGHT-TA

's/he sees' (Cyffer 1991: 80) 
(824) LV-SUBJ:TA:NEG < LVSUBJ:LightVerb:TA.NEG

(825) a. $\underline{\text { Kanuri }}$

bú-kánà
eat-1:PRF
'I have eaten'
(Hutchison 1981: 120)

b. Kanuri

$$
\begin{aligned}
& \text { bú-kànyi' } \\
& \text { eat-1:NEG:COMPL } \\
& \text { 'I have not eaten', }
\end{aligned}
$$

Fused doubled subject forms are found in the folllowing Coptic past form. The lexical verb in the original AVC, despite being inflected for subject, seems to have been in an infinitive form in pre-Coptic.

$$
\text { TA-SUBJ-LV:INF-SUBJ }<?^{*} \text { AV-SUBJ LV:INF-SUBJ }
$$

(827) Coptic

$$
\begin{array}{lll}
a-s-j o:-s & \text { gar } n a-j \quad n k j i \quad \text { ta-f:rə } & \text { jo } \\
\text { PST-3F-say:INF-3F } & \text { PRTCL for-1S PRTCL POSS:1S-daughter } & \text { COMP } \\
\text { 'my daughter told me that... } &
\end{array}
$$

(Kammerzell and Peust 2002: 312)

Tama on the other hand has fused light verb structures with doubled subject marking. As is typical of languages of the Sahara region (and 'Ethiopia' as well (section 11)), the light verb incorporated in this Tama form derives from 'say'.

(828) SUBJ-LV-SUBJ:LightVerb-TA < ?*SUBJ-LV SUBJ-LightVerb-TA

(829) Tama

$$
\begin{aligned}
& \text { nì-tín- }{ }^{\downarrow} \text { nú-yó } \\
& \text { 1SG-dream-1SG:say-PRF } \\
& \text { 'I dreamed' (Dimmendaal 2009a: } 314 \text { ) }
\end{aligned}
$$

A fused split structure may be found in the following complex verb form from Egyptian. Note that the lexical verb appeared in a semi-finite form, encoding object but nevertheless appearing in an infinitive form. 
(830) TA-SUBJ-LV:INF-OBJ $<$ ?*AV:SUBJ LV:INF:OBJ

(831) Egyptian

$j w: j-z>w-k \quad j w: j-j n-t-k \quad j w-k-w d>-t j$

FUT:1 S-protect:INF-2M FUT:1s-bring:INF-2M comp-2M-be.safe:STAT-2S

'he always says he would protect you, he would bring you back safe' (Kammerzell and Peust 2002: 309)

Masalit has a small number of complex verb forms that derive from fused AVCs that had a split/doubled inflectional pattern.

(832) SUBJ-LV-DEP-[NEG]-(SUBJ:)TA <?*SUBJ-LV-DEP-[NEG] SUBJ-AV

(833) a. $\underline{\text { Masalit }}$

b. Masalit

\begin{tabular}{|c|c|}
\hline g-oosiך-jenise & 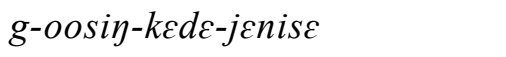 \\
\hline 2-know.BASE.II-(2:)PST.H & 2-know.BASE.II-NEG-(2:)PST.I \\
\hline $\begin{array}{l}\text { 'you used to know' } \\
\text { (Edgar 1989: 29) }\end{array}$ & $\begin{array}{l}\text { 'you didn't used to know' } \\
\text { (Edgar 1989: 29) }\end{array}$ \\
\hline
\end{tabular}

Fused subject/auxiliary forms that themselves are further fused into large complex verb forms are characteristic of several languages of the region. In Midob Nubian, the resulting forms often bear little resemblance to each other, cf. the 1.INDIC.PRF (835a) and the 1.INDIC.CONT (835b).

$$
\text { LV-SUBJ:TA }<\text { ?*LV SUBJ:TA } \quad<\text { ?*LV SUBJ:AV }{ }_{<\mathrm{TA}>}
$$

(835) a. Midob

$$
\begin{aligned}
& \text { áy àabéddí áar-hèm } \\
& \text { I bird[:INDEF] catch-1.INDIC.PRF } \\
& \text { 'I caught a bird' (Werner 1993: 67) }
\end{aligned}
$$


b. Midob

$$
\begin{aligned}
& \text { áy nèn àabédd áar-òwà } \\
& \text { I this bird } \quad \text { catch-1.INDIC.CONT } \\
& \text { 'I catch this bird' (Werner 1993: 67) }
\end{aligned}
$$

Dar Daju Daju shows a similar phenomena to that in the Nubian languages above, but here the markers are transparently related to each other.

$$
\text { LV-SUBJ:TA } \quad<\text { ? }^{*} \text { LV SUBJ:TA } \quad<\text { ? }^{*} \text { LV SUBJ-AV } \mathrm{CTA}_{<\mathrm{T}}
$$

(837) a. Dar Daju Daju

$\begin{array}{lll}\text { kona } & \text { or-cina } & \text { bor-ne } \\ \text { 1PL.INCL see-1PL.INCL.PROG } & \text { hyena-CLS.SG.1 }\end{array}$

'we see/are looking at a hyena' (Aviles 2008: 60)

b. Dar Daju Daju

ur-tina

drink-PST.ITER.1PL.INCL

'we drank repeatedly' (Aviles 2008: 58)

That this process has been active in the region is suggested by the presence of such forms in Later Egyptian sources, as in the following light verb example:

$$
\text { LightVerb-SUBJ.TA LV }
$$

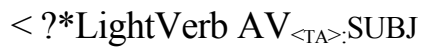

(839) Later Egyptian

$$
\begin{array}{ll}
i r j-i \quad s m t j \\
\text { do-1SG.PRF } & \text { examine } \\
\text { 'I examined (the documents) } & \text { (Cohen et al. 2002: 239) }
\end{array}
$$

13.5 Summary. The languages of the 'Sahara' region show a significant tendecy towards complex verb forms derived from the fusing of various types of constructions. Rather than auxiliary verbs, the default complex predicate structure in the languages of 
the 'Sahara' region is a light verb formation using a light verb meaning 'say' or 'do' (or both as in Tama). Fused formations incorporating light verbs are a family-wide feature of the Saharan family (Kanuri, Zaghawa). In addition to the overall relative frequency of fused formations in languages of this region, there is also a higher than typical incidence of LEX-headed formations among them. Synchronically bi-partite AVCs with either a doubled inflectional pattern or a split one are not attested in the languages of my corpus from this region, and even AUX-headed formations are rather uncommon, but perhaps surprisingly split/doubled AVCs are well attested.

$\begin{array}{ll}\text { AH } & \text { Aiki (Runga), Maba; Beria/Zaghawa } \\ \text { light verbs } & \text { Tama; Fur; Aiki; Later Egyptian } \\ \text { S/2 } & \text { Egyptian Arabic; Masalit; Kanuri } \\ \text { LH } & \text { Dar Daju Daju; Ancient Egyptian; Berber; Tamashek } \\ \text { fAH } & \text { Coptic } \\ \text { f-light } & \text { Zaghawa; Kanuri; Tama (=2x) } \\ \text { f2x } & \text { Coptic } \\ \text { f-split } & \text { Egyptian } \\ \text { fS/2 } & \text { Masalit } \\ \text { f/fS/TAM/P } & \text { Midob; Dar Daju Daju; Later Egyptian }\end{array}$

Table 17: AVC Inflection in selected languages of the 'Sahara' region

\section{Nuba Hills residual zone}

One area of extreme linguistic diversity in Africa is the Nuba Hills residual or fragmentation zone. A modest number of languages are found in this region which belong to a large number of different genetic units. I have data on nineteen languages of the area, belonging to ten genetic units. This set includes Daju (Shatt), Heiban (HeibanEbang, Tira, Otoro, Moro), Kado (Krongo, Katcha), Katla (Katla, Tima), Lafofa, Nyimang (Nyimang and Dinik), Rashad (Orig, Tumale, Tagoi, Rashad), Talodi (Masakin/Ngile, Talodi), Temein, and of course Nubian (Dilling and Ghulfan (Uncunwee)).

This diverse array of languages possess a staggeringly large set of inflectional patterns of AVCs and variation within and across their grammars. In terms of the relative linear 
order or phrasal syntax of auxiliary verbs and lexical verbs in AVCs, a small number of language groups in the Nuba Hills area show V AUX dominant order (Nubian, Rashad), and others show AUX V (e.g., Heiban, Talodi, Temein, or Shatt Daju). Fused structures or certain constructions that reflect the opposite order in a given language or genetic unit are also not infrequently found in Nuba Hills languages, e.g. V-AUX fused structure in the otherwise dominant AUX V Katla language (cf. Hadza in the discussion of Tanzanian Rift Valley (section 10 above) for another example of such a phemomenon).

14.1 AuX-headed formations in Nuba Hills languages. The familiar AUX-headed pattern of inflection of AVCs is widely attested in the languages of this region. Infinitive- (here locative-) marked lexical verbs in AUX-headed AVCs are found in the Kado language Krongo.

(840) SUBJ-AV INF:LOC-LV

(841) Krongo

$$
\begin{aligned}
& m \text {-ákká } \quad k \text {-áadìà } \\
& \text { 3F-FUT.AUX INF:LOC-come } \\
& \text { 'she will come' (Reh 1985: 188) }
\end{aligned}
$$

Note that the prohibitive formation in Krongo also represents an AVC of this structural type.

(842) $\mathrm{AV}_{<[\mathrm{PL}:] \mathrm{PHB}>} \mathrm{INF}:$ LOC-LV

(843) Krongo

$$
\begin{aligned}
& \text { òolú } \quad k \text {-áafàrà } \\
& \text { PL:PHB INF.LOC-cry } \\
& \text { ‘don't cry! (Reh 1985: 197) }
\end{aligned}
$$

Similar AUX-headed formations are attested in its sister language Katcha. Here the subject-marking is more complex appearing in a circumfix form, the suffix of which specifies the person of the subject.

(844) SUBJ $\mathrm{S}_{\mathrm{i}}-\mathrm{AV}-\mathrm{SUBJ}_{\mathrm{j}} \quad$ INF-LV 
(845) $\underline{\text { Katcha }}$
$n-a r-a a \quad \underline{t}-\supset \varepsilon$
1/2-FUT-1 INF-drink
'I shall drink' (Tucker and Bryan 1966: 309)

Heiban Kordofanian languages also show AUX-headed formations, although the auxiliary verb may encode either the person/number $\left(1^{\text {st }} / 2^{\text {nd }}\right.$ person forms $)$ or class/number features $\left(3^{\text {rd }}\right.$ person forms) of a subject in Heiban Kordfonanian languages like Otoro or Tira.

$$
\text { SUBJ.CLS-AV PREP INF:LV }
$$

(847) $\underline{\text { Otoro }}$

$$
\begin{array}{ll}
\text { yi gw-ujJ } & \text { gi Jidhira } \\
1 \text { CLSFR.SG-AUX.PST PREP INF:sleep:II } \\
\text { 'I was sleeping' (Stevenson 2009: 267) }
\end{array}
$$

(848) SUBJ-AV INF-LV

(849) Tira

$$
\begin{aligned}
& e-v e \quad d h ə-n d r a \\
& \text { 1-AUX.DEF INF-sleep:DEF } \\
& \text { 'I was/have been sleeping' (Stevenson 2009: 71) }
\end{aligned}
$$

Unmarked lexical verbs (or Ø-marked lexical verbs) are found in AUX-headed structures like the following AVC in Lafofa.

(850) SUBJ-AV LV 
(851) $\underline{\text { Lafofa }}$ ('Kordofanian')
i- $\underline{\text { de }} \quad \underline{\text { tia }}(\mathrm{i}) \mathrm{ko}$
1-AUX field hoe
'I hoe the field' (Tucker and Bryan 1966: 284)

In Nyimang, lexical verbs appear in one of two different construction-determined forms in quasi-AUX-headed AVCs marking progressive and future: ${ }^{44}$

(852) AV LV:DEP

(853) a. Nyimang

$\begin{array}{llll}k \varepsilon r \quad a \quad k w o n s & k a \quad \text { tam } \\ \text { woman VB.PRTCL meat AUX eat.INDEF } & \text { AUd } \\ \text { 'woman is eating meat' (Tucker and Bryan 1966: 251) }\end{array}$

b. Nyimang

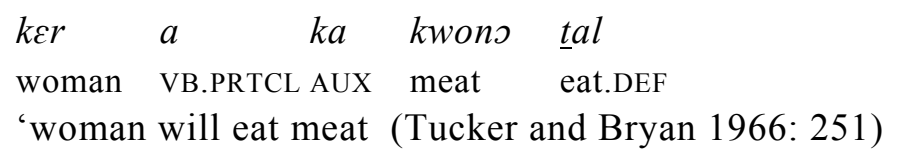

14.2 Doubled inflection in AVCs in languages of the Nuba Hills. Doubled subject inflection is common in the languages of the Nuba Hills region. Moro of the Heiban Kordofanian family shows the simplest system of doubled subject inflection in the negative past:

(854) SUBJ-AV SUBJ-LV

\footnotetext{
${ }^{44}$ In these examples the auxiliaries appear to be uninflected[-looking]; note that the exact nature of inflection in Nyimang remains relatively little investigated and the overall structure of the Nyimang verbal system is still obscure and poorly understood.
} 
(855) Moro

$$
\begin{array}{ll}
i \text {-gero } & i \text {-gaberta } \\
\text { 1-NEG.PST } & 1 \text {-have }
\end{array}
$$

'I didn't have' (Dryer 2009: 309; Black and Black 1971: 20)

Other members of the Heiban family may show only class marking, rather than person/number of the subject on both the lexical verb and the auxiliary verb. Such kinds of AVCs are found across the family, e.g. in Heiban or Otoro:

$$
\text { SUBJ.CLS-AV SUBJ.CLS-LV }
$$

(857) $\underline{\text { Heiban }}$

$$
\begin{array}{lll}
\text { nyi } & \text { gwa } & \text { gwithi } \\
1 & \text { CLSFR.SG:AUX } & \text { CLSFR.SG:go/come } \\
\text { 'I am going' or 'I am coming' (Stevenson 2009: 77) }
\end{array}
$$

(858) $\underline{\text { Otoro }}$

yi gwo gwu-dhiro

1 CLSFR.SG-AUX CLSFR.SG-sleep.I

'I am sleeping' (Stevenson 2009: 232)

(859) SUBJ.CLS-AV $\mathrm{\triangle NEG}_{\triangle}>$ SUBJ.CLS-LV CONEG

(860) Otoro

$$
\begin{aligned}
& \text { yigw-ate gwu-dhiro no } \\
& 1 \text { CLSFR.SG-NEG.AUX CLSFR.SG-sleep CONEG } \\
& \text { 'I do/did not sleep' (Stevenson 2009: 239) }
\end{aligned}
$$

Compare the following Otoro and Tira forms. Both reflect doubled inflectional patterns. In Otoro, class-marking is doubled in the negative auxiliary formation, while in the present progressive formation in its sister language Tira, both the class marker and the subject (pronoun) are doubly encoded. 
(861) Subj.ProN SUBJ.CLS-AV SUBJ.CLS-LV

(862) Otoro

$\begin{array}{llll}\text { anaya } & \text { l-ate } & \text { li-dhiro } & \text { no } \\ \text { we } & \text { CLSFR.PL-NEG.AUX } & \text { CLSFR.PL-sleep } & \text { CONEG }\end{array}$

'we do/did not sleep' (Stevenson 2009: 239)

(863) Subj[ProN] SUBJ.CLS-AV Subj.[ProN] SUBJ.CLS-LV

(864) Tira

nya l-ou nya l-etho

$1 \mathrm{PL}$ CLSFR.PL-AUX 1PL CLSFR.PL-Come:INDEF

'we are coming' (Stevenson 2009: 69)

Doubled subject marking with a dependent marked lexical verb is found in Temein:

(865) SUBJ-AV-FINSUBJ-LV:DEP

(866) a. Temein

ya-m-a ya-lam ntet isaatın

1-AUX-FIN 1-eat.DEP meat tomorrow

'I am going to eat meat tomorrow' (Tucker and Bryan 1966: 259)

b. Temein

$$
\begin{aligned}
& \text { kița-m-a kița-r-e kita-lam } \\
& \text { 2PL-AUX-FIN 2PL-AUX-FIN 2PL-eat.DEP } \\
& \text { 'you (PL) will eat' (Tucker and Bryan 1966: 259) }
\end{aligned}
$$

The system of doubled subject inflection is quite complex in Shatt Daju. Two different series of markers ( $k a$ - vs. $a$ - for first singular, respectively), predictably labelled definite and indefinite by Tucker and Bryan (1966), are used. All four logical combinations are attested, e.g. the AVC $-n j-+-e, 2 \mathrm{x}<a-, a->$ marks present progressive in Shatt Daju, the 
AVC $-n j-+-e, 2 \mathrm{x}<k a-, a->$ encodes past progressive, the AVC $-w u \eta, 2 \mathrm{x}<a-k a->$ marks future perfect the $\mathrm{AVC}-w u \eta, 2 \mathrm{x}<k a-k a->$ encodes irrealis:

(867) $\mathrm{SUBJ}_{\mathrm{a}}-\mathrm{AV}_{<n j>} \mathrm{SUBJ}_{\mathrm{a}}-\mathrm{LV}-e_{<\mathrm{DEP}>}$

(868) Shatt Daju

$$
\begin{array}{llll}
\text { agönay } & a-n j-u & a-s i-e & \text { iya } \\
\text { I } & 1 . \text { INDEF-AUX- } u & 1 . \text { INDEF-eat-e } & \text { meat } \\
\text { 'I am eating meat' (Tucker and Bryan 1966: 240) }
\end{array}
$$

(869) $\mathrm{SUBJ}_{\mathrm{b}}-\mathrm{AV}_{<n j>} \quad \mathrm{SUBJ}_{\mathrm{a}}-\mathrm{LV}-e_{<\mathrm{DEP}}>$

(870) Shatt Daju

$$
\begin{array}{llll}
\text { agönay } & k a-n j-u \quad a-s i-e \quad \text { iya } \\
\text { I } & \text { 1.DEF-AUX- } u & 1 . \text { INDEF-eat-e } & \text { meat } \\
\text { 'I was eating meat' } & \text { (Tucker and Bryan 1966: 240) }
\end{array}
$$

(871) $\mathrm{SUBJ}_{\mathrm{a}}-\mathrm{AV}_{<w u \eta\rangle} \quad \mathrm{SUBJ}_{\mathrm{b}}-\mathrm{LV}$

(872) Shatt Daju

$$
\begin{aligned}
& \text { agönay a-wuy ka-si } \\
& \text { I 1.INDEF-AUX 1.DEF-eat } \\
& \text { 'I shall have eaten meat' (Tucker and Bryan 1966: 240) }
\end{aligned}
$$

(873) $\mathrm{SUBJ}_{\mathrm{b}}-\mathrm{AV}_{<w u \eta\rangle} \quad \mathrm{SUBJ}_{\mathrm{b}}-\mathrm{LV}$

(874) Shatt Daju

$$
\begin{aligned}
& \text { Agönaך ka-wuך ka-si } \\
& \text { I 1.DEF-AUX 1.DEF-eat } \\
& \text { 'I should have eaten meat' (Tucker and Bryan 1966: 240) }
\end{aligned}
$$


14.3 Split inflectional patterns in AVCs in Nuba Hills languages. Split inflection is also not uncommon in languages of the Nuba Hills. Thus, in Lafofa, subject may appear on the auxiliary and aspect on the lexical verb in the following form:

$$
\text { SUBJ-AV LV-ASP }
$$

(876) Lafofa ('Kordofanian')

tia(i) $i-\underline{d e} \quad k w o-\underline{t a n}$

field 1-AUX hoe-ASP

'I hoed the field' (Tucker and Bryan 1966: 284)

The following Katcha formation reflects a similar type of split inflectional construction but with a dependent marked lexical verb. Subject is marked by the characteristic circumfix of Katcha, with perfective aspect encoded on the infinitive-marked lexical verb.

(877) SUBJ $_{\mathrm{i}}-\mathrm{AV}-\mathrm{SUBJ}_{\mathrm{j}} \quad$ INF-ASP-LV

(878) $\underline{\text { Katcha }}$

$$
\begin{array}{ll}
n \text { - } a s-a a & t-a g-\supset \varepsilon \\
\text { 1/2-COMPL-1 } & \text { INF-ASP-drink } \\
\text { 'I had drunk' } & \text { (Tucker and Bryan 1966: 309) }
\end{array}
$$

A characteristic feature of Rashad Kordofanian languages that set them apart from other languages of the Nuba Hills area is the presence of not only V AUX word order, but also the use of split inflection in the negative form of most AVCs. As mentioned above, such split-inflected forms are found in negative AVCs in Orig, Rashad, Tagoi and Tumale. This thus can be reconstructed as a feature of proto-Rashad.

$$
\text { NEG-LV SUBJ-AV }{ }_{<T A>}
$$


(880) a. Orig



(881) Rashad

yifas k-eye $\quad y$-en

I meat NEG-eat 1-AUX

'I am not eating meat' (Tucker and Bryan 1966: 297)

(882) Tagoi

$$
\begin{aligned}
& \text { yigIn nifi k-eyak y-en } \\
& \text { I meat NEG-eat 1-AUX } \\
& \text { 'I am not eating meat' (Tucker and Bryan 1966: 297) }
\end{aligned}
$$

(883) Tumale

$$
\begin{aligned}
& \text { ygi } \quad \text { k-alma } \quad \text {-en } \\
& \text { I } \quad \text { NEG-gather } 1 \text {-AUX } \\
& \text { 'I am not eating meat' (Tucker and Bryan 1966: 297) }
\end{aligned}
$$

14.4 Split/Doubled inflection in AVCs in languages of the Nuba Hills. Split/doubled inflection is uncommonly found in AVCs among the languages of the Nuba Hills. One such formation can however be found in Ebang. In Ebang (Heiban Kordofanian), the class of the subject is doubly-marked, but object appears on the lexical verb alone in the future AVC: 
(885) Ebang
yi-bupo kw.eleny abi $\quad$-aji $\quad \eta$-aji-l-wurejo
CNC-seek Lord but CNC-FUT CNC-2PL.OBJ-PL-return
'the Lord needs it and will return it to you'
(Schadeberg and Kossmann 2010: 95)

14.5 LEX-headed formations in languages of the Nuba Hills. LEX-headed formations are found in such languages of the Nuba Hills region as Temein of the Temein family:

(886) AV SUBJ-TA-LV-FIN

(887) Temein
nan $k \varepsilon \underline{n} \varepsilon$
$\eta \varepsilon-\underline{t} I-\underline{t} \underline{t} p-\varepsilon$
I PROG/HAB
1-PST-put-FIN
'I was going to put'
'I would have put'
(Tucker and Bryan 1966: 259)

Another example of a LEX-headed AVC can be seen in the future formation in Katla of the Katla family.

\section{AV SUBJ-LV}

(889) Katla
nyəy kari ny-a-bvk
I FUT 1-TV-drink
'I shall drink' (Tucker and Bryan 1966: 268)

14.6 Fused subject/auxiliary forms. Fused subject auxiliary forms are very marked among the languages of the Nuba Hills. In my database, only Dinik of the Nyimang genetic unit shows a formation with what appears to be a resumptive/agreement element, here found within something akin to an AUX-headed formation with a dependent marked lexical verb.

(890) SUBJ:AV $\mathrm{CTAM}_{<\mathrm{L}} \mathrm{LV}: \mathrm{DEP}$ 
(891) a. Dinik

$$
\begin{aligned}
& \text { ói kwòn kI tomòn } \\
& \text { I meat } 1: \text { IPFV eat:INDEF:DEP } \\
& \text { 'I am eating/eat meat' }
\end{aligned}
$$$$
\text { (Stevenson et al. 1992: 9) }
$$

b. $\underline{\text { Dinik }}$

$$
\begin{aligned}
& \text { ói kwòn ká tàlj̀ } \\
& \text { I meat } 1: \text { PFV eat:DEP } \\
& \text { 'I ate meat' }
\end{aligned}
$$

14.7 Complex verb derived from fused AVCs in Nuba Hills languages. Fused AUXheaded formations are also found in the languages of the Nuba Hills. In Dilling of the Nubian family, a fused AUX-headed structure deriving from a V-AUX construction is found in the future formation:

(892) LV-TA-SUBJ $<$ ?*LV AV-SUBJ

(893) Dilling Hill Nubian

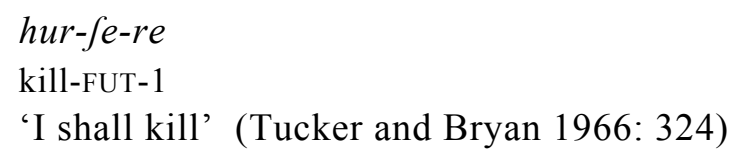

In combination with a co-negative element, a negative fused auxiliary structure is attested in Tima of the Katla family.

(894) NEG-SUBJ-LV $\quad \ldots=\mathrm{CONEG} \quad<?^{*} \quad \mathrm{AV}_{\mathrm{\triangle NEG}>}-\mathrm{SUBJLV} \ldots=\mathrm{CONEG}$

(895) a. Tima

\author{
$k \dot{t}-\grave{j}-k{ }^{\downarrow} l u ́ k$ kídì kábòh-রì̀ \\ NEG-1-eat $1 \mathrm{SG}$ meat-CONEG \\ 'I don't eat meat' (Dimmendaal 2009b: 343)
}


b. Tima

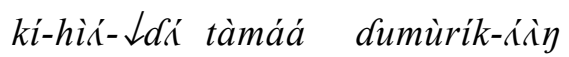

NEG-speak-1 language Tima-CONEG

'I don't speak Tima' (Dimmendaal 2009b: 346)

Fused double subject formations are also found in Tima. Such is the case in the progressive present and the negative past forms.

(896) $\mathrm{TA}-\mathrm{SUBJ}-L V-S U B J_{<\mathrm{DEP}>}<$ ?*AV-SUBJ LV-SUBJ $_{<\mathrm{DEP}>}$

(897) $\underline{\text { Tima }}$



PROG-1-buy-1 fish

'I am buying fish' (Dimmendaal 2009b: 339)

(898) NEG-SUBJ-LV-SUBJ $<$ DEP $>\ldots=$ CONEG

$<?^{*} \mathrm{AV}_{<\mathrm{NEG}, \mathrm{PST}>}-\mathrm{SUBJ} \mathrm{LV}-\mathrm{SUBJ} \mathrm{CDEP}_{<\mathrm{P}} \ldots=\mathrm{CONEG}$

(899) Tima

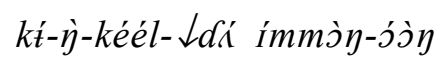

NEG-1-buy-1 fish-NEG

'I did not buy fish' (Dimmendaal 2009b: 345)

Complex verb forms derived from fused split/doubled constructions are attested in Tima and Otoro. In Tima, the object marker is encoded on the lexical verb as expected in split/doubled patterns of this sort.

(900) TA-SUBJ-LV-SUBJ $\mathrm{CDEP}-\mathrm{OBJ}<$ ? $^{*} \mathrm{AV}$-SUBJ $\quad$ LV-SUBJ $\mathrm{CDEP}_{<\mathrm{P}}-\mathrm{OBJ}$ 
(901) Tima



$$
\begin{aligned}
& \text { PROG-1-hit-1-2 PREP-firewood } \\
& \text { 'I will hit you with a piece of brushy firewood' }
\end{aligned}
$$

(Dimmendaal 2009b: 342)

In Otoro on the other hand, it appears to be the object (or perhaps it is the absolutive argument) that is doubly encoded in the following complex perfect form (903). This form appears to be highly anomalous within the areal typology of languages of the Nuba Hills

(902) ABS/OBJ-TA-ERG/SUBJ-ABS/OBJ-LV

$<$ ?* ABS/OBJ-AV ERG/SUBJ-ABS/OBJ-LV

(903) Otoro

$$
\begin{aligned}
& \text { ya } \quad l i-m-a-l-p i \\
& 2 \text { 3PL-PRF-2-3PL-hit } \\
& \text { 'you have hit them' (Stevenson 2009: 185) }
\end{aligned}
$$

The Rashad Kordofanian language Tumale has a complex verb form that appears to derive from a fused LEX-headed structure:

(904) SUBJ[:TA]-LV-TA <?*SUBJ[:TA]-LV AV

(905) Tumale

$$
\text { ya-lmak-ruyen }
$$

1.PRS-gather-FUT

'I shall gather' (Tucker and Bryan 1966: 296)

Fused formations in which fused subject/auxiliary forms have been incorporated are also attested in the languages of the region. Deriving from a V-AUX structure one finds complex verb forms of this type in Ghulfan/Uncunwee Nubian:

$$
\text { LV-SUBJ:TA }<\text { ?LV AV } \mathrm{LTA}_{<\mathrm{T}}: \mathrm{SUBJ}
$$


(907) a. Ghulfan (Uncunwee)

yě gīrjūlú-gi bīg-ع́ćrēe

I money:PL-ACC lose-PST:1SG

'I lost the money' (Dimmendaal 2010: 28)

b. Ghulfan (Uncunwee)

yě ànàbnáy bíjè kòtá-ní-ébé

I my.grandparent beer bring-APPL-PST.II:1SG

'I brought beer to [one of] my grandparents'

(Dimmendaal 2010: 28)

c. Ghulfan (Uncunwee)

yě à Jưk-kèrè

I you:ACC beat-FUT.1SG

'I will beat you' (Dimmendaal 2010: 28)

In Rashad on the other hand, these forms reflect the fusing of a construction with an original AUX-V order:

(908) SUBJ:TA-LV < ?*SUBJ:- $\mathrm{V}_{<\mathrm{TA}}>\mathrm{LV}$

(909) a. Rashad

b. $\underline{\text { Rashad }}$

c. $\underline{\text { Rashad }}$

d. $\underline{\text { Rashad }}$

\begin{tabular}{|c|c|c|c|}
\hline ya-tkan & $y \varepsilon-{ }^{\mid} t k a n$ & $y_{I}-k \partial r^{\mid \partial} k$ & $y \jmath-k o r^{\mid a} k$ \\
\hline .PRS & 1.PST-cook & 1.PRS-steal & 1.PST \\
\hline $\mathrm{coc}$ & 'I cooked' & 'I steal' & 'I stole' \\
\hline
\end{tabular}

(Tucker and Bryan 1966: 290-291)

The Talodi Kordofanian language Masakin (Ngile) has several other instantiations of this pattern, two deriving from a fusing of an original AUX-V structure (911a-911b) and one from a putative original V-AUX order (913).

(910) SUBJ:TA-LV <?*SUBJ:AV ${ }_{<\mathrm{TA}>} \mathrm{LV}$ 
(911) a. Masakin

b. Masakin

y-ome $\quad$ ya-yu $\quad$ jir

CLS-boy 3M.PROG-drink water

y-ome ka-yu $\quad$ jir

'the boy is drinking water'

CLS-boy 3M.PRS-drink water

(Tucker and Bryan 1966: 287)

(912)

LV-SUBJ:TA $<$ ? $^{*}$ LV SUBJ:AV ${ }_{<\mathrm{TA}}$

(913) Masakin

$\begin{array}{lll}y u \text { - } \underline{n} o & \text { y-ome } & \text { yir } \\ \text { drink-3M.PST } & \text { CLS-boy } & \text { water } \\ \text { 'the boy drank water' (Tucker and Bryan 1966: 287) }\end{array}$

14.8 Summary. The heterogeneous group of languages of the residual or fragmentation zone of central Sudan known as the Nuba Hills show a wide variety of inflectional patterns in their auxiliary structures. Unlike languages of the 'Sahara', Nuba Hills languages show a considerable range of AUX-headed, doubled and split inflectional patterns in AVCs. However, like a number of other areas in northeastern Africa, complex verb forms deriving from fused AVCs are common, in particular those in which the auxiliary components themselves consisted of forms deriving from the fusing of subject marking and original auxiliaries in what I call fused/fused formations. Note that this is particularly common in the languages of the Nuba Hills that show V Aux order, e.g. Nubian or Rashad Kordofanian, although they are not limited to languages of this type per se, as they are found in Masakin (Talodi Kordofanian) as well (though complex fused forms may be found in Masakin that appear to derive from a fused V-Aux structure of this type). 


\begin{tabular}{ll}
\hline \hline AH & Krongo; Katcha; Otoro; Tira; Lafofa; ?Nyimang \\
$2 \mathrm{x}$ & Moro; Heiban; Otoro; Tira; Temein; Shatt Daju \\
split & Orig; Rashad; Tagoi; Tumale; Lafofa \\
S/2 & Ebang \\
LH & Temein; Katla \\
fAH & Dilling; Tima \\
f2x & Tima \\
fS/2 & Tima; Otoro \\
f/fS/TAM/P & Tumale; Ghulfan (Uncunwee); Rashad; Masakin (Ngile)
\end{tabular}

Table 18: Patterns of inflection in languages of the Nuba Hills region

\section{Summary}

The use of two verbal elements in conventionalized functional matrices called here auxiliary verb constructions is widespread among the languages of Africa. In this presentation, I have discussed how the wide variety of complex predicate phenomena argue for careful distinctions among their syntactic, semantic, and morphosyntactic properties. While such constructions vary relatively minor ways syntactically and semantically across languages, there is considerable variation with respect to the formal patterns of encoding morphosyntactic or functional properties in AVCs. Such variation falls into five large macro-patterns. All patterns are attested within the structures of not only synchronically bipartite auxiliary formations, but also in fused complex synthetic verb forms that derive from each of these patterns when viewing the languages of Africa as a whole.

Why is there such great variation morphosyntactically in AVCs? The answer in part has to do with the heterogeneous constructional source pool that feeds the development of such formations. In particular, it is clear that not only do three broad constructional source types need to be reckoned as input for AVCs, viz., embedded structures, serialized structures, and clause-chained formations, but also sub-types within these broad categories. Each of these subtypes yields a fairly restricted set of target AVC structures. Thus, depending on its degree of finiteness (from fully non-finite to partially or largely finite) and the original valence features of its source verbal elements, an embedded structure may yield AUX-headed, doubled, or even split/doubled AVC structures, while 
nuclear serialized structures tend to yield LEX-headed or split inflectional systems, and core-serialized forms tend to develop into doubled and split-doubled formations.

Both split and split/doubled systems, at least when dealing with splits in encoding of argument properties, generally show a correlation with the valency of the original source elements, regardless of the construction type that they originate in: when transitive complements or $\mathrm{V}_{2}$ verbs are used with intransitive $\mathrm{V}_{1}$, split or split/doubled systems are often the result, while correspondence in valence between the two original verbs entering into the AVC more frequently yield AUX-headed or doubled inflectional structures.

Lastly, although there is considerable variation within and across recognized taxonomic or geographic groups of African languages, the languages of certain genetic units and linguistic areas show propensity to a sub-set of these patterns. Such examples include the relative frequency of split/doubled inflection in Bantu vs. other genetic units, a pattern with doubled-subject inflection with a modal dependent lexical verb in Nilotic, the predominance of fused AUX-headed formations in Khoe, LEX-headed formations and light verb constructions in languages of the 'Sahara' region or the fused subject-cumauxiliary forms functioning as tense-marked pronouns in languages of the Macro-Sudan Belt. 
Abbreviations Used:

\begin{tabular}{|c|c|c|c|}
\hline 1 & $1^{\text {st }}$ person & 15 & Class 15 \\
\hline $1 \mathrm{PL}$ & $1^{\text {st }}$ person plural & $1 \mathrm{~s}$ & $1^{\text {st }}$ person singular \\
\hline 2 & $2^{\text {nd }}$ person & $2 \mathrm{PL}$ & $2^{\text {nd }}$ person plural \\
\hline $2 x$ & Doubled Pattern & 3 & $3^{\text {rd }}$ person \\
\hline $3 \mathrm{M}$ & $3^{\text {rd }}$ person masculine & 3PL & $3^{\text {rd }}$ person plural \\
\hline $\mathrm{ACC}$ & Accusative & ACCOMPLI & Accomplished \\
\hline $\mathrm{ADV}$ & Adverbial & AFFRM & Affirmative \\
\hline $\mathrm{AH}$ & AUX-headed Pattern & ANAPH & Anaphoric \\
\hline ANIM & Animate & ANT & Anterior \\
\hline AOR & Aorist & APPL & Applicative \\
\hline ART & Article & ASP & Aspect \\
\hline ASSC & Associative & ASSRTV & Assertive \\
\hline ATTR & Attributive & AUGM & Augment \\
\hline AUX & Auxiliary & BEN & Benefactive \\
\hline CAP & Capabilitive & CAUS & Causative \\
\hline CENTRIF & Centrifugal & CLS & Class \\
\hline CLSFR & Classifier & COMPL & Completive \\
\hline $\mathrm{CNC}$ & Concord & CNNCTV & Connective \\
\hline COMP & Complementizer & COMPL & Completive \\
\hline COND & Conditional & CONEG & Conegative \\
\hline CONJ & Conjunctive & CONSEC & Consecutive \\
\hline CONSTR & Construct & CONT & Continuous \\
\hline $\mathrm{COP}$ & Copula & $\mathrm{CV}$ & Converb \\
\hline DAT & Dative & DECL & Declarative \\
\hline DEF & Definite & DEM & Demonstrative \\
\hline DEONT & Deontic & DEP & Dependent \\
\hline DER & Derivation[al] & DES & Desiderative \\
\hline DESCR & Descriptive & DISTR & Distributive \\
\hline DL & Dual & DO & Direct Object \\
\hline DUR & Durative & EMPH & Emphatic \\
\hline EPIPAT & Epipatetic & EPN & Epenthetic \\
\hline ERG & Ergative & EXCL & Exclusive \\
\hline EXPL & Expletive & EXT & Extension \\
\hline $\mathrm{F}[\mathrm{EM}]$ & Feminine & FACT & Fact[it]ive \\
\hline FIN & Finite & FOC & Focus \\
\hline FUT & Future & $\mathrm{FV}$ & Final Vowel \\
\hline
\end{tabular}




\begin{tabular}{|c|c|c|c|}
\hline GEN & Genitive & GER & Gerund \\
\hline HAB & Habitual & HOD & Hodiernal \\
\hline HORT & Hortative & I & Class-I active non-past \\
\hline I & Active non-past (Khwe) & II & Active past marker \\
\hline II & Class-II & ICP & Intransitive Copy Pronoun \\
\hline IMM & Immediate & IMP & Inactive \\
\hline $\mathrm{INCH}$ & Inchoative & INCL & Inclusive \\
\hline INCOMPL & Incompletive & INDIC & Indicative \\
\hline INDEF & Indefinite & INDEP & Independent \\
\hline $\mathrm{INF}$ & Infinitive & INJ & Injunctive \\
\hline INT & Intentional & IO & Indirect Object \\
\hline IPFV & Imperfective & IRR & Irrealis \\
\hline ITER & Iterative & JNCT & Junctural \\
\hline LIGHT & Light Verb & LNGTH & Length \\
\hline LOC & Locative & LOG & Logophoric Pronoun \\
\hline M & Masculine & MOD & Modal \\
\hline NPST & Non-Past & NAR & Narrative \\
\hline NEC & Necessative & NEG & Negative \\
\hline NFUT & Non-Future & NOM & Nominative \\
\hline NR & Near & OBJ & Object \\
\hline OBLQ & Oblique & $\mathrm{OM}$ & Object Marker \\
\hline OPT & Optative & OVs & Open Vowel Suffix \\
\hline $\mathrm{P}$ & Passive & PFX & Prefix \\
\hline PGN & Person Gender Number & PHB & Prohibitive \\
\hline PL & Plural & PLUP & Pluperfect \\
\hline PM & Predicate Marker & PNL & Positional \\
\hline POSS & Possessive & POT & Potential \\
\hline PP & Postposition & PREP & Preposition \\
\hline PREPRO & Prepronominal & PRF & Perfect \\
\hline PRFV & Perfective & PROG & Progressive \\
\hline PRON & Pronominal & PROSP & Prospective \\
\hline PROX & Proximate & PRS & Present \\
\hline PRSTV & Persistive & PRTCL & Particle \\
\hline PRTCPL & Participle & PST & Past \\
\hline PV & Preverb & $\mathrm{Q}$ & Question \\
\hline REC & Recent & REDPL & Reduplication \\
\hline
\end{tabular}




$\begin{array}{llll}\text { REL } & \text { Relative } & \text { REM } & \text { Remote } \\ \text { RLS } & \text { Realis } & \text { RSLT } & \text { Resultative } \\ \text { SAY } & \text { 'Say' as light verb } & \text { SBJNCTV } & \text { Subjunctive } \\ \text { SEQ } & \text { Sequential } & \text { SFX } & \text { Suffix } \\ \text { SG } & \text { Singular } & \text { SIM } & \text { Simultaneity } \\ \text { SIT } & \text { Situative } & \text { SM } & \text { Subject Marker } \\ \text { SS } & \text { Same Subject } & \text { STAT } & \text { Stative } \\ \text { SUBJ } & \text { Subject } & \text { SV } & \text { Serial Verb } \\ \text { TA } & \text { Tense/Aspect } & \text { TNS } & \text { Tense } \\ \text { TOP } & \text { Topic } & \text { TR } & \text { Transitive } \\ \text { TV } & \text { Thematic Vowel } & \text { VB } & \text { Verb } \\ \text { VENT } & \text { Ven[ti]tive } & \text { VI } & \text { Class-VI } \\ \text { VN } & \text { Verbal Noun } & \\ \text { AV } & \text { Auxiliary Verb } & & \\ \text { AVC } & \text { Auxiliary Verb Construction } & & \\ \text { CCC } & \text { Clause Chained Construction } & \\ \text { f/fS/TAM/P } & \text { Fused/fused Subject/TAM/Polarity morph formation } \\ \text { LH } & \text { LEX-headed Pattern } & & \\ \text { LV } & \text { Lexical Verb } & \\ \text { MSB } & \text { Macro-Sudan Belt } & \\ \text { (f)S/TAM/P } & \text { Fused Subject/TAM/Polarity } & \text { morph } & \\ \text { SVC } & \text { Serial Verb Construction } & \\ \text { VCC } & \text { Verb Complement Construct } & \\ & & \end{array}$

\section{References in Text and Corpus:}

Aaron, Uche. 1999. Tense and Aspect in Obolo Grammar and Discourse. Summer Institute of Linguistics and the University of Texas at Arlington Publications in Linguistics 128 Arlington: Summer Institute of Linguistics.

Abdel-Massih, Ernest T. 1968. Tamazight Verb Structure: A Generative Approach. Indiana University African Series 2. Bloomington, Indiana: Indiana University Press. 
Aboh, Enoch Oladé, Katharina Hartmann and Malte Zimmermann (eds.) 2007. Focus Strategies in African Languages. The Interaction of Focus and Grammar in NigerCongo and Afro-Asiatic. Trends in Linguistics Studies and Monographs 191. Berlin: Mouton de Gruyter.

Adounah, Gbandi. 2009. Description Phonologique et Grammaticale du Konkomba. Lomé/Rennes: Université Lomé/Rennes 2, Ph. D. dissertation.

Adwirah, Eleonore. 1989. Grammatik des Gworok (Kagoro). Frankfurt am Main: Peter Lang.

Agheyisi, Rebecca N. 1987. Verb serialization and lexical reanalysis: The case of compound verbs in Edo. In Odden, David (ed.) Current Approaches to African Linguistics 4, 1-11. Dordrecht: Foris Publications.

Agheyisi, Rebecca. 1991. The tense system of Edo. In Essien (ed.), 11-42.

Ahland, Colleen. 2010. Noun incorporation and predicate classifiers in Gumuz. Journal of African Languages and Linguistics 31: 159-203.

Aikhenvald, Aleksandra Y. 1999. Serial verb constructions and verb compounding: evidence from Tariana (North Arawak). Studies in Language 23: 479-508.

Aikhenvald, Aleksandra Y. 2006. Serial Verb Constructions in Typological Perspective. In Aikhenvald, A. and R. M. W. Dixon (eds.), 1-68.

Aikhenvald, Aleksandra Y. \& R. M. W. Dixon (eds.). 2006. Serial Verb Constructions. A Cross Linguistic Typology. Oxford: Oxford University Press.

Akerejola, Ernest S. 2008. Serial Verb Constructions in Òkó. South African Journal of African Languages 2008 (2): 172-186.

Aksenova, I. S. 1997. Kategorii vida, vremeni, i naklonenija v jazykax Bantu. [The categories of aspect, tense and mood in Bantu languages] Moscow: Nauka. 
Alexandre, Pierre. 1966. Système verbal et prédicatif $d u$ bulu. Paris: Libraire C. Klincksieck. [A74]

Allan, Edward Jay. 1976. Dizi (Maji). In Bender (ed.), 377-392.

Allan, Edward Jay. 1973/1980 (1977). Buem. In Kropp-Dakubu, M. E. (ed.) volume 1, 97-105.

Allan, Edward Jay. 1974/1980. Likpe. In Kropp-Dakubu, M. E. (ed.) volume 2, 6 pp.

Allen, Andrew S. 1993. Ewe verbs in derivation and periphrastic constructions. In Mufwene, Salikoko S. and Lioba Moshi (eds.) Topics in African Linguistics, 35-43. Amsterdam: Benjamins.

Allen, Christine. 1973/1980. Sele. In Kropp-Dakubu, M. E. (ed.) volume 2, 7 pp.

Alsina, Alex. 1999. Where's the mirror principle?. The Linguistic Review 16: 1-42.

Ameka, Felix K. 2005. Multiverb constructions on the West African littoral: microvariation and areal typology. Vulchanova, Mila and T. A. Åfarli (eds.) Grammar and Beyond: Essays in honour of Lars Hellan, 15-42. Oslo: Novus Press.

Ameka, Felix K. 2006a. Real descriptions: Reflections on native speaker and non-native speaker descriptions of a language. In Ameka et al. (eds.), 69-112.

Ameka, Felix K. 2006b. Ewe Serial Verb Constructions in their Grammatical Context. In Aikhenvald and Dixon (eds.), 124-143.

Ameka, Felix K. 2009. Likpe. In Dimmendaal (ed.), 239-279.

Ameka, Felix K., Alan Dench and Nicholas Evans (eds.) 2006. Catching Language: The Standing Challenge of Grammar Writing. Berlin: Mouton de Gruyter.

Amha, Azeb. 2001. The Maale Language. Leiden: Research School of Asian, African and Amerindian Studies Univesiteit Leiden.

Amha, Azeb. 2009. Wolaitta. In Dimmendaal (ed.), 355-384. 
Amha, Azeb and Gerrit J. Dimmendaal 2006a. Converbs in an African areal perspective. In Ameka et al. (eds.), 393-440.

Amha, Azeb and Gerrit J. Dimmendaal. 2006b. Verbal Compounding in Wolaitta. In Aikhenvald and Dixon (eds.), 319-337.

Amha, Azeb, Maarten Mous and Graziano Savà (eds.). 2007. Omotic and Cushitic Language Studies. Papers from the Fourth Cushitic Omotic Conference, Leiden, 1012 April 2003. Köln: Rüdiger Köppe Verlag.

Andersen, Torben. 1984. Aspect and word order in Moru. Journal of African Languages and Linguistics 6: 19-34.

Anderson, Gregory D. S. 1999. A typology of inflection in auxiliary verb constructions: contributions of minor language data. In Chicago Linguistic Society 35: Panel on Linguistic Diversity and Linguistic Theory, 1-15. Chicago: CLS.

Anderson, Gregory D. S. 2000. Split-inflection in auxiliary verb constructions. In Antrim, Nancy Mae, Grant Goodall, Martha Schulte-Nafeh, and Vida Samiian (eds.) Proceedings of the 28th Western Conference on Linguistics, 1999, 1-12. Fresno: California State University at Fresno.

Anderson, Gregory D. S. 2004. Auxiliary Verb Constructions in Altai-Sayan Turkic. Turcologica 51. Wiesbaden: Harrassowitz.

Anderson, Gregory D. S. 2006. Auxiliary Verb Constructions. Oxford: Oxford University Press.

Anderson, Gregory D. S. 2010. Perspectives on the global language extinction crisis: The Oklahoma and Eastern Siberia Language Hotspots. Revue Roumaine de Linguistique. LV (2): 129-42.

Anderson, Gregory D. S. In preparation. Language Extinction: Language Hotspots, Language Contact and Linguistic Diversity in the $21^{\text {st }}$ Century. Cambridge: Cambridge University Press. 
Anderson, Gregory D. S. and K. David Harrison. 1999. Tyvan. Languages of the World Materials 257. München: Lincom Europa.

Anderson, Gregory D. S. and K. David Harrison. 2006. Language Hotspots: Linking language extinction, biodiversity \& the human knowledge base. Living Tongues Institute for Endangered Languages. Occasional Papers Series, no. 01. http://www.livingtongues.org/docs/Hotspots whitepaper copy.pdf

Ansorge, Rainer. (ed.) 1994. Schlaglichter der Forschung. Zum 75 Jahrestag der Universität Hamburg. Berlin: Dietrich Reimer Verlag.

Arensen, Jonathan E. 1979. A grammar of the Murle language. Pibor, Sudan: SIL.

Arensen, Jonathan E. 1982. Murle grammar. Juba: College of Education/Institute of Regional Languages/SIL.

Armbruster, Carl. 1960. Dongolese Nubian: A Grammar. London: Cambridge University Press.

Arnold, T. 1981. La conjugasion composée en rwanda. Africana Linguistica 8: 23-64.

Arnott, D. W. 1967/1980. Tiv. In Kropp-Dakubu, M. E. (ed.) volume 2, 8 pp.

Arnott, D. W. 1968/1980 (1977). Fula. In Kropp-Dakubu, M. E. (ed.) volume 1, 233-244.

Arnott, D.W. 1958. The classification of verbs in Tiv. Bulletin of the School of Oriental and African Studies 21(1): 111-133.

Aroga Bessong, D. P. and Igor Mel'cuk. 1983. Un modele de la conjugasion bafia (à l'indicatif). Bulletin of the School of Oriental and African Studies 46 (3): 477-523.

Aronson, Howard I. 1982. Georgian: A Reading Grammar. Columbus, Ohio: Slavica.

Ashton, E. O. 1944. Swahili Grammar. London: Longmans. 
Aviles, Arthur. 2008. The Phonology and Morphology of the Dar Daju Daju Language. Grand Forks: University of North Dakota MA thesis.

Babaev, Kirill. 2010. Reconstructing Benue-Congo person marking II. Journal of Language Relationship/Voprosy Jazykovogo Rodstva 4: 1-45 .

Baker, Mark. 1985. The Mirror Principle and morphosyntactic explanation. Linguistic Inquiry 16 (3): 373-415.

Barnwell, Katherin nd/1980. Mbembe. In Kropp-Dakubu, M. E. (ed.) volume 2, 6 pp.

Batibo, Herman M. 2005. Future tense and aspect markings in Southern Bantu. In Voeltz (ed.), 1-12.

Baucom, Kenneth L. 1972. The Wambo Languages of South West Africa and Angola. Journal of African Languages 11 (2): 45-73.

Bavin, Edith L. 1983. Morphological and syntactic divergence in Lango and Acholi. In Voßen, Rainer and Marianne Bechhaus-Gerst (eds.) Nilotic Studies: Proceedings of the International Symposium on Languages and History of Nilotic Peoples, Köln January 4-6, 1982, Part 1, 147-68. Kölner Beiträge zur Afrikanistik 10.1 Berlin: Dietrich Reimer Verlag.

Bearth, Thomas. 1995. Nominal periphrasis and the origins of the predicative marker in Mande languages - an alternative view. Afrikanistische Arbeitspapiere 41: 89-117.

Bell, Alan 1978. Language samples. In Joseph H. Greenberg et al. (eds.) Universals of Human Language, vol. iv, 123-56. Stanford, California: Stanford University Press.

Bender, M. Lionel. 1979. Gumuz. A sketch of Grammar and Lexicon. Afrika und Übersee 62 (1): 38-69.

Bender, M. Lionel. 1989. The Eastern Jebel Languages. In Bender (ed.), 151-180.

Bender, M. Lionel. 1991. Sub-Classification of Nilo-Saharan. In Bender (ed.), 1-35. 
Bender, M. Lionel 1996. Kunama. Languages of the World/Materials 59. Munich: LINCOM.

Bender, M. Lionel. 2000. Comparative Morphology of the Omotic Languages. München: Lincom.

Bender, M. Lionel. 2003. NE Africa: a case study in genetic and areal linguistics. Annual Publication in African Linguistics 1: 21-45.

Bender, M. Lionel (ed.). 1976. Non-Semitic Languages of Ethiopia. East Lansing, Michigan: African Studies Center.

Bender, M. Lionel (ed.). 1989. Topics in Nilo-Saharan Linguistics. Nilo-Saharan Linguistic Analyses and Documentation 3. Hamburg: Helmut Buske Verlag.

Bender, M. Lionel. 1991. (ed.) Proceedings of the Fourth Nilo-Saharan Linguistics Colloquium. Nilo-Saharan Linguistic Analyses and Documentation Vol. 7. Hamburg: Helmut Buske Verlag.

Bendor-Samuel, John T. 1968. Verb clusters in Izi. Journal of African Languages 5 (2): 119-28.

Bendor-Samuel, John, Donna Skitch and Esther Cressman. 1973. Duka Sentence, Clause and Phrase. Studies in Nigerian Languages 3. Zaria: Institute of Linguistics and Centre for the Study of Nigerian Languages, Abdullahi Bayero College, Ahmadu Bello University, Kano.

Bennie, W. G. 1953. A Grammar of Xhosa for the Xhosa Speaking. Cape Province, South Africa: Lovedale Press.

Bentley, Delia and Thórhallur Eythórsson 2004. Auxiliary selection and the semantics of unaccusativity. Lingua 114: 447-471.

Bentley, Mayrene. and A. Kulemeka. 2001. Chichewa. Languages of the World/Materials 345. Munich: Lincom. 
Berger, Herrmann. 1998. Die Burushaski-Sprache von Hunza und Nager. 3 vols. Wiesbaden: Harrassowitz.

Berger, P. 1938. Die mit -ile gebildeten Perfektstämme in den Bantusprachen. Zeitschrift für Eingeborene Sprachen 28: 81-286.

Besha, Ruth Mfumbwa. 1989. A Study of Tense and Aspect in Shambala. Language and Dialect Studies in East Africa 10. Berlin: Reimer.

Beuchat, P. D. 1966. The Verb in Zulu. Johannesburg: Witwatersrand University Press.

Beyer, Klaus. 2009. Double negation-marking. A case of contact-induced grammaticalization in West Africa. In Cyffer et al. (eds.), 205-221.

Bisang, Walter. 1995. Verb serialization and converbs: differences and similarities. In König, Ekkehard and Martin Haspelmath (eds.) Converbs in Cross-linguistic Perspective, 137-88. Berlin: Mouton de Gruyter.

Bisang, Walter. 2001. Finite vs. non-finite languages. In Haspelmath, Martin et al. (eds.) Language Typology and Language Universals: An International Handbook, vol. ii, 1400-1413. Berlin: de Gruyter.

Black, K and K. Black 1971. The Moro Language. Grammar and Dictionary. Linguistic Monograph Series 6. Khartoum: Sudan Research Unit, Faculty of Arts.

Blackings, Mairi and Nigel Fabb. 2003. A Grammar of Ma'di. Mouton Grammar Library 32. Berlin: Mouton de Gruyter.

Blake, Barry J. 1994. Case. Cambridge: Cambridge University Press.

Blake, Barry J. 2001. Global trends in language. Linguistics 39(5): 1009-28.

Blansitt, Edward L. 1975. Progressive aspect. Stanford Working Papers on Language Universals 18: 1-34. 
Bleek, Dorothea, F. 1928-30. Bushman grammar: A grammatical sketch of the language of the |xam-ka-!k’e. Zeitschrift für Einbegorenen-Sprachen 19: 81-98; Zeitschrift für Einbegorenen-Sprachen 20: 161-174.

Blench, Roger M. 1993. New developments in the classification of Bantu languages and their historical implications. In Barreteau, D. and C. von Graffenried (eds.) Datation et chronologie dans le bassin du lac Tchad: séminaire de réseau Méga-Tchad, ORSTOM Bondy, 11 et 12 septembre 1989, 147-160. Colloques et séminaires. Paris: Office de la Recherche Scientifique et Technique d'Outre-Mer.

Blench, Roger M. 2006a. Mada Pronouns. Unpublished manuscript. Jos. http://www.rogerblench.info/Publications\%20opening\%20page.htm Accessed 2 November 2009

Blench, Roger M. 2006b. Mada Verbs. Unpublished manuscript. Jos. http://www.rogerblench.info/Publications\%20opening\%20page.htm Accessed 2 November 2009

Blench, Roger M. 2006c. Plural Verb Morphology in Eastern Berom. Unpublished manuscript.

Cambridge. http://www.rogerblench.info/Publications\%20opening\%20page.htm Accessed 2 November 2009

Blench, Roger M. and Gya Daniel 2009. Rigwe Pronouns. Irigwe Pronominal Systems. Unpublished manuscript. Jos/Cambridge. http://www.rogerblench.info/Publications\%20opening\%20page.htm Accessed 3 September 2010

Blench, Roger M. 2010. The Idũ language of Central Nigeria. Phonology, Wordlist, and Suggestions for Orthography Changes. Unpublished manuscript. Cambridge. http://www.rogerblench.info/Publications\%20opening\%20page.htm Accessed 19 November 2010

Bliese, Loren. 1976. Afar. In Bender (ed.), 133-65.

Bodomo, Adams B. 1997. The Structure of Dagaare. Stanford, Calif.: CSLI. 
Bodomo, Adams B. 1998. Serial verbs as complex predicates in Dagaare and Akan. In Maddieson, Ian and Thomas Hinnebusch (eds.) Trends in African Linguistics, vol. 2. Language History and Linguistic Description in Africa, 195-204. Trenton, New Jersey: Africa World Press.

Böhm, Gerhard. 1983. Der Bau des Prädikats in den Agau-Sprachen. Veröffentlichungen der Institute für Afrikanistik und Ägyptologie Nr. 25. Wien: Beiträge zur Afrikanistik, Band 18.

Bole-Richard, Remy. 1983. Ega, Esquisse de grammaire. In Hérault, Georges (ed.) Atlas des Langues Kwa, Tome 2, 359-401. Abidjan: ILA.

Bole-Richard, Remy. Ega Sketch Grammar. No date. http://www.spectrum.unibielefeld.de/langdoc/EGA/EgaSketchGrammar/L Ega dg.html

Accessed 3 September 2010.

Bond, Oliver and Gregory D. S. Anderson. 2003. Personal Inflection in Eleme in ArealTypological Perspective. Presented at WOCAL 4, New Brunswick, NJ, June, 2003.

Bond, Oliver and Gregory D. S. Anderson. 2005. Divergent structure in Ogonoid languages. In Cover, Rebecca T. and Yuni Kim (eds.) Berkeley Linguistics Society 31, 13-24. Berkeley: BLS.

Bond, Oliver. 2006. Eleme Verb Morphology. Manchester: University of Manchester, $\mathrm{Ph}$. D. Dissertation.

Bond, Oliver. 2010. Intra-paradigmatic variation in Eleme verbal agreement. Studies in Language 34 (1): 1-35.

Bot, D. M. L. 1998. Temps verbaux et aspects du Yasa. Afrikanistische Arbeitspapiere 53: 47-65.

Botne, Robert. 1986. The Temporal Role of Eastern Bantu -ba and -li. Studies in African Linguistics 17 (3): 303-317. 
Botne, Robert. 1990. The origins of the remote future formatives in Kinyarwanda, Kirundi and Giha (J61). Studies in African Linguistics 21 (2): 189-210.

Botne, Robert. 1993. Differentiating the auxiliaries - $t i$ and -wa in Tumbuka. Linguistique Africaine 10: 7-28.

Botne, Robert. 1999. Future and distal $-k a$-'s: Proto-Bantu or nascent form(s)? In Hombert and Hyman (eds.), 473-515.

Botne, Robert. 2003a. Lega Beya dialect. In Nurse, Derek and Gérard Phillipson (eds.) The Bantu Languages, 422-49. London: Routledge,.

Botne, Robert. 2003b. Dissociation in tense, realis, and location in Chindali verbs. Anthropological Linguistics 45 (4): 390-412.

Botne, Robert. 2006. Motion, Time, and Tense: On the grammaticization of come and go to future markers in Bantu. Studies in African Linguistics 35 (2): 127-188.

Bouquiaux, Luc 1970. La langue Birom (Nigeria septentrional) -phonologie, morphologie, syntaxe. Paris: Les Belles Lettres.

Boyd, Ginger. 2003. Tense and aspect in Mbodomo narrative discourse. Studies in African Linguistics 29 (1): 43-74.

Boyd, Raymond. (ed.) 1995. Le système verbal dans les langues oubangiennes. Lincom Studies in African Linguistics 7. München: Lincom Europa.

Boyd, Virginia Lee. 1997. A Phonology and Grammar of Mbodomo. SIL Cameroon.

Boyeldieu, Pascal. 1982. Deux études laal: Moyen-Chari, Tchad. Margurger Studien zur Afrika- und Asienkunde Serie A: Afrika Band 29. Berlin: Dietrich Reimer Verlag.

Boyeldieu, Pascal. 1985. La langue lua ("niellim"). (Groupe Boua-Moyen Chari, Tchad). Phonologie-Morphologie-Dérivation verbale. Descriptions des langues et monographes ethnolinguistiques 1. Cambridge/Paris: Cambridge University Press and Editions de la Maison des Sciences de l'Homme for SELAF. 
Boyeldieu, Pascal. 1987. Les langues fer (kara) et yulu du nord centrafricain: esquisses descriptives et lexiques. Paris: Libraire Orientaliste Paul Geuthner S. A.

Boyeldieu, Pascal. 1995. Le yakoma. In Boyd, Raymond (ed.) Le système verbal dans les langues oubanguiennes, 113-139. München/Newcastle: Lincom Europa.

Breeze, Mary J. 1990. A Sketch of the phonology and grammar of Gimira (Benchnon). In Hayward, Richard J. (ed.) Omotic Language Studies, 1-67. London: School of Oriental and African Studies.

Bril, Isabelle. 2004. Complex nuclei in Oceanic languages: contribution to an areal typology. In Bril, Isabelle and Françoise Ozanne-Rivierre (eds.) Complex Predicates in Oceanic Languages, 1-48. Berlin: Mouton de Gruyter.

Brisard, Frank and Michael Meeuwis. 2009. Present and Perfect in Bantu: The case of Lingála. Journal of African Languages and Linguistics 30: 21-43.

Brown, D. Richard. 1991. Information Focus in Kresh. In Bender (ed.), 325-345.

Browne, Gerald. M. 2002. Old Nubian Grammar. LW/M 330. München: Lincom.

Bryan, M. A. 1955. The verb in the Tama and Didinga language groups. In Lukas, Johannes (ed.) Afrikanistiche Studien, 312-332. Berlin: Akademie Verlag.

Buettner, C. G. 1886. Die Temporalformen in den Bantusprachen. Zeitschrift für Völkerpsychologie und Sprachwissenschaft 16: 76-117.

Burquest, Donald A. 1973. 1980 (1977). Angas. In Kropp-Dakubu, M. E. (ed.) volume 1, $35-43$.

Bybee, J. L. and Ö. Dahl. 1989. The creation of tense and aspect systems in the languages of the world. Studies in Language 13 (1): 51-103. 
Bybee, Joan L., William Pagliuca and Revere D. Perkins. 1991. On the assymetries in the affixation of grammatical material. In Croft, William, Keith Denning and Suzanne Kemmer (eds.) Studies in Typology and Diachrony for Joseph H. Greenberg, 1-42. Typological Studies in Language 20. Amsterdam: John Benjamins Publishing Company.

Bybee, Joan L. , Revere D. Perkins, and William Pagliuca 1994. The Evolution of Grammar. Tense, Aspect, and Modality in the Languages of the World. University of Chicago Press: Chicago.

Cadiou, Yves. 1985. Sur une problème de syntaxe: La relation verb-complément en Kinyarwanda. In Cadiou, Yves (ed.) Le Kinyarwanda: Études de morpho-syntaxe, 6583. Paris: Diffusion Peeters.

Calame-Griaule, Genevieve. 1974/1980. Dogó sò In Kropp-Dakubu, M. E. (ed.) volume 2, pp. 9pp.

Carlin, Eithne. 1993. The So language. Afrikanistische Monografien 2. Köln: Universität zu Köln.

Carlson, Robert. 1992. Narrative, subjunctive, and finiteness. Journal of African Languages and Linguistics 13: 59-85.

Carlson, Robert. 1994. A Grammar of Supyire. Berlin: Mouton de Gruyter.

Caron, Bernard. 1989. The verbal system of Ader Hausa. In Frajzyngier, Zygmunt (ed.) Current Progress in Chadic Linguistics, 131-69. Amsterdam Studies in the Theory and History of Linguistic Science 62 Amsterdam: John Benjamins.

Caron, Bernard 2001. Dott, aka Zodi, (Chadic, West-B, South Bauchi): grammatical notes and vocabulary. Afrika und Übersee 84: 1-60.

Caron, Bernard 2002. Guus, aka Sigidi (Chadic, West-B, South Bauchi): grammatical notes, vocabulary and text. Afrika und Übersee 85: 161-248. 
Caron, Bernard. 2008. La structure énonciative des subordonnées conditionnelles. In Caron, Bernard (ed.) Subordination, dépendance et parataxe dans les langues africaines, 145-158. SELAF No. 449. Louvain, Paris: Peeters.

Casali, Robert 1995. An overview of the Nawuri verbal system. Journal of West African Languages 15 (1): 63-86.

Cerulli, E. 1947. Three Berta Dialects in Western Ethiopia. Africa 17 (3): 157-69.

Chaphole, Solomon Rampasane. 1988. A study of the auxiliary verbs in Sesotho. Cape Town: University of Cape Town, Ph.D. dissertation.

Cherdyntseva, Aljona. 2002. Aspekto-temporal'naja sistema dan (dialekt gueta) [The tense-aspect system of Dan (Gwetta dialect)]. In Vydrin, V. F. and A. Ju. Zheltov (eds.) Juzhnye Mande: Lingvistika afrikanskikh ritmakh. Materialy peterburgskoj èkspeditsii v Kot d'Ivuar (K 50-letiju Konstantina Pozdnjakov), 125-53. SanktPetersburg: Evropejskij Dom.

Childs, G. Tucker 1995. A Grammar of Kisi. Berlin: Mouton de Gruyter.

Childs, G. Tucker. 2005. The S-Aux-O-V-Other Syntagm in Atlantic. Studies in African Linguistics 34 (1): 1-42.

Christaller, Johann G. 1875/1881. A Grammar of the Asante and Fante Language called Tshi (Chwee, Twi) Based on the Akuapem Dialect with Reference to the Other (Akan and Fante) Dialects. Basel: Basel Evangelical Missionary Society.

Clark, David. 1980 (1977). Ekpeye. In Kropp-Dakubu, M. E. (ed.) volume 1, 186-193.

Claudi, Ulrike. 1988. The development of tense/aspect marking in Kru languages (review article). Journal of African Languages and Linguistics 10: 53-77.

Cleal, Alizon M. 1973a. Gechode. In Kropp-Dakubu, M. E. (ed.) volume 1, 253-259.

Cleal, Alizon M. 1973b. Genyanga. In Kropp-Dakubu, M. E. (ed.) volume 1, 261-267. 
Cleal, Alizon M. 1973c/1980c. Krachi. In Kropp-Dakubu, M. E. (ed.) volume 1, 366378.

Cleal, Alizon M. 1973d/1980d. Nchumuru. In Kropp-Dakubu, M. E. (ed.) volume 2, 11 pp.

Cloarec-Heiss, France. 1986. Dynamique et équilibre d'une syntaxe: le banda-linda de Centrafrique. Descriptions de langues et monographies ethnolinguistiques, 2. Paris: SELAF.

Cohen David, Marie-Claude Simeone-Senelle and Martine Vanhove. 2002. The grammaticalization of 'say' and 'do': An areal phenomenon in East Africa. In Güldemann and von Roncador (eds.), 227-251.

Cole, Desmond T. 1955. An Introduction to Tswana Grammar. $6^{\text {th }}$ Edition. London: Longmans, Green \& Co.

Cole, Desmond T. 1959. Doke's classification of Bantu languages. African Studies 18 (4): 197-213.

Cole, Desmond T. 1961. Doke's classification of Bantu languages [revised]. In Doke, Clement M. and Desmond T. Cole (eds.) Contributions to the history of Bantu linguistics. Johannesburg: Witwatersrand University Press, 80-96.

Collins, Chris. 1998. Plurality in $¥$ Hoan. Working Paper No. 9. Khoisan Forum. Köln: University of Cologne.

Collins, Chris. 2001. The internal structure of the verb phrase in Ju|'hoan and łHoan. Cornell Working Papers in Linguistics 18: 1-27.

Collins, Chris. 2002. Multiple verb movement in łHoan. Linguistic Inquiry 33 (1): 1-29.

Comrie, Bernard. 1985. Causative verb formation and other verb-deriving morphology. In Shopen, Timothy (ed.) Language Typology and Syntactic Description, vol. iii: Grammatical Categories and the Lexicon, 309-48. Cambridge: Cambridge University Press. 
Cook, T. L. 1972/1980 (1977) Kohumono. In Kropp-Dakubu, M. E. (ed.) volume 1, 350356.

Cope, Anthony T. 1971. A consolidated classification of the Bantu languages. African Studies 30 (3/4): 213-236.

Crazzolara, Joseph Pasquale. 1960. A study of the Logbara (Ma'di) Language. London: Oxford University Press.

Creider, Chet. 1989. Syntax of the Nilotic Languages: Themes and Variations. Berlin: Dietrich Reimer Verlag.

Creider, Chet. and Jane Tapsubei Creider. 1989. A Grammar of Nandi. Hamburg: Helmut Buske.

Creissels, Denis. 1998a. Auxiliaires et auxiliarisation : l'exemple du tswana. Faits de Langues 11-12: 251-265.

Creissels, Denis. 1998b. Remarques sur l'auxiliarisation en tswana. Le gré des langues 13: 112-140.

Creissels, Denis. 2000. Grammaticalisation et hétérogénéité des paradigmes morphologiques : l'exemple des formes verbales négatives en tswana. In de Carvalho, P. \& L. Labrune (eds.), Travaux linguistiques du CERLICO 13: 13-30.

Creissels, Denis. 2002. Valence verbale et voix en tswana. Bulletin de la Société de Linguistique de Paris 97 (1): 371-426.

Creissels, Denis. 2003. L'emploi comme auxiliaire du verbe tswana re «dire». In Stéphane, Robert (ed.) Perspectives synchroniques sur la grammaticalisation, 162185. Louvain-Paris: Peeters.

Creissels, Denis. 2005. A typology of subject and object markers in African languages. In Voeltz (ed.), 43-70. 
Creissels, Denis, Gerrit J. Dimmendaal, Zygmunt Frajzyngier, and Christa König. 2008. Africa as a morhosyntactic area. In Heine, Bernd \& Derek Nurse (eds.) A Linguistic Geography of Africa, 86-150. Cambridge: Cambridge University Press.

Cristofaro, Sonia. 2006. The organization of reference grammars. In Ameka et al. (eds.), 137-170.

Crowley, Terry. 2002. Serial Verbs in Oceanic. Oxford: Oxford University Press.

Cyffer, Norbert, Erwin Ebermann and Georg Ziegelmeyer (eds.) 2009. Negation Patterns in West African Languages and Beyond. Typological Studies in Language 87. Amsterdam/Philadelphia: John Benjamins.

Cyffer, Norbert. 1978. Die Verbalstruktur im Kanuri. Afrika und Übersee 61: 94-111.

Cyffer, Norbert. 1991. The Zaghawa verb structure and its relation to other Saharan languages. In Bender (ed.), 79-90.

Dale, Desmond. 1972. Shona companion. Gwelo, Rhodesia: Mambo Press.

Dammann, Ernst. 1956. Das situative Formans ki in einigen Bantusprachen. Mitteilungen des Seminars für Orientalische Sprachen 4 (2): 424-34.

Dammann, Ernst. 1971. Vom Satz zum Wort in Bantusprachen. Folia Orientalia 13: 33 49.

Dammann, Ernst. 1978. Das Futurum in einigen Bantusprachen. Afrika und Übersee 61: 161-75.

David, Ngang 1999. Les pronoms en Karang (ALCAM 352). Ministère de la Recherche Scientifique et Technique. Yaoundé: SIL.

De Lancey, Scott. 1991. The origins of verb serialization in Modern Tibetan. Studies in Language 15: 1-23. 
Dempwolff, Otto. 1916. Die Sandawe. Linguistisches und ethnographisches Material aus Deutsch-Ostafrika. Abhandlungen des Hamburgischen Kolonialinstituts 34. Beiträge zur Völkerkunde, Kulturgeschichte und Sprachen 19. Hamburg: L. Friederichsen.

De Rop, Albert. 1963. Introduction à la linguistique bantoue congolaise. Brussels: Mimosa.

de Vries, James A. and Sandra A. de Vries. 1997. An overview of Kwerba verb morphology. In Pawley, Andrew (ed.) Papers in Papuan Linguistics no. 3, 1-35. Pacific Linguistics A-87. Canberra: Australian National University.

Di Luzio, Aldo. 1972. Preliminary description of the Amo language. Afrika und Übersee 56: 3-61.

Dickens, Patrick J. 2005. A Concise Grammar of Ju/'hoan. With a Ju/'hoan-English Glossary and a Subject Index. Research in Khoisan Studies vol. 17. Köln: Rüdiger Köppe Verlag.

Dickens, Patrick J. and Anthony Traill. 1977. Collective and Distributive in !Xõo. In Traill, Anthony (ed.) Khoisan Linguistic Studies 3, 132-144. Johnnesburg: University of the Witwatersrang, African Studies Institute.

Dimmendaal, Gerrit J. 1983. The Turkana Language. Dordrecht: Foris.

Dimmendaal, Gerrit J. 1998. A syntactic typology of the Surmic language family from an areal and historical-comparative point of view. In Dimmendaal and Last (eds.), 35-82.

Dimmendaal, Gerrit J. 2001a. Areal diffusion and genetic inheritance: An African perspective. In Aikhenvald, Aleksandra Y. and R. M. W. Dixon (eds.) Areal diffusion and genetic inheritance: Problems in Comparative Linguistics, 358-392. Oxford: Oxford University Press.

Dimmendaal, Gerrit J. 2001b. Language Shift and Morphological Convergence in the Nilotic Area. Sprache und Geschichte in Afrika 16/17: 83-124. 
Dimmendaal, G. 2008. Language ecology and linguistic diversity in Africa. Language and Linguistics Compass 2 (5): 840-858.

Dimmendaal, Gerrit. 2009a. Tama. In Dimmendaal (ed.), 305-329.

Dimmendaal, Gerrit. 2009b. Tima. In Dimmendaal (ed.), 331-353.

Dimmendaal, G. 2010. Differential Object Marking in Nilo-Saharan. Journal of African Languages and Linguistics 31: 13-46.

Dimmendaal, Gerrit (ed.) 2009. Coding Participant Marking. Construction types in twelve African languages. Amsterdam: Benjamins.

Dimmendaal, Gerrit J. and Marco Last (eds.). 1998. Surmic Languages and Cultures. Nilo-Saharan Linguistic Analyses and Documentation 13 Köln: Rüdiger Köppe Verlag.

Dixon, R. M. W. 2002. The eclectic morphology of Jarawara, and the status of word. In Dixon, R M. W. and Alexandra Y. Aikhenvald (eds.) Word. A Cross-Linguistic Typology, 125-152. Cambridge: Cambridge University Press.

Doke, Clement M. 1938. Textbook of Lamba Grammar. Johannesburg: Witwatersrand University Press.

Doke, Clement M. 1947. Textbook of Zulu Grammar, 3rd edn. London: Longmans, Green.

Dooley, Robert A. 1990. The positioning of non-pronominal clitics and particles. In Payne, Doris (ed.) Studies in Lowland South American Languages, 457-93. Austin: University of Texas Press.

Driberg, Jack H. 1931. The Didinga language. Mitteilungen des Seminars für Oreintalische Sprachen 34: 139-82.

Drolc, Ursula. 1992. On the perfect in Swahili. Afrikanistische Arbeitspapiere 29: 63-87. 
Dryer, Matthew S. 1989. Large linguistic areas and language sampling. Studies in Language 13: 257-92.

Dryer, Matthew S. 1992. The Greenbergian word order correlations. Language 68 (1): 81-138.

Dryer, Matthew S. 2009. Verb-object-negative order in central Africa. In Cyffer et al. (eds.), 307-362.

Ducos, Gisèle. 1974/1980. Pajade. In Kropp-Dakubu, M. E. (ed.) volume 2, 10 pp.

Dumestre, Gérard. 2003. Grammaire fondamentale du bambara. Paris: Editions Karthala.

Dunham, Margaret. 2004. On the verbal system in Langi, a Bantu language of Tanzania (F.33). Studies in African Linguistics 33 (2): 199-234.

Eaton, Helen. 2002. The Grammar of Focus in Sandawe. Reading: University of Reading, Ph. D. dissertation.

Eaton, Helen. 2003-ms. Focus as a key to the grammar of Sandawe. Unpublished manuscript. Paper presented at LOT3.

Eaton, Helen. 2010a. Information structure marking in Sandawe texts. In Fiedler and Schwarz (eds.), 1-34.

Eaton, Helen. 2010b. A Sandawe Grammar. SIL International.

Edgar, John. 1989. A Masalit Grammar. With notes on other languages of Darfur and Wadai. Berlin: Dietrich Reimer Verlag.

Ehret, Christopher. 1999. Subclassifying Bantu: the evidence of stem morpheme innovations. In Hombert and Hyman (eds.), 43-147.

Elderkin, Edward D. 1986. Diachronic inferences from basic sentence and noun structure in Central Khoisan and Sandawe. Sprache und Geschichte in Afrika 7 (2): 131-156. 
Elders, Stephan. 2004. Distributed predicative syntax in Doyayo: constituent order alternations and cliticisation. In Akinlabi, Akinbiyi and Oluseye Adesola (eds.) Proceedings of the $4^{\text {th }}$ WOCAL, 189-98. Cologne: Rüdiger Köppe Verlag.

Elders, Stephan. 2007. Complex Verb Morphology in Kulango (Gur): Similarities and Dissimilarities with Bantu. In Kula and Marten (eds.), 187-200.

Emanation, Michele. 1992. Chaga 'come' and 'go': metaphor and the development of tense-aspect. Studies in Language 16: 1-33.

Emenanjo, E. Nolue. 1985. Auxiliaries in Igbo Syntax: A Comparative Study. Bloomington: Indiana University Linguistics Club.

Emenanjo, E. Nolue. 1991. The tense system of Igbo. In Essien (ed.), 129-144.

Ennulat, Juergen. 1973/1980. Fali. In Kropp-Dakubu, M. E. (ed.) volume 1, 227-232.

Ėrman, Anna V. 2002. Sub"ektnye mestoimenija v dan-blovo I modal'no-aspektnotemporal'nye znachenija [Subject pronouns in Dan-Blowo and (their) modalaspectual-temporal meanings]. In V. F. Vydrin and A. Ju. Zheltov (eds.) Juzhnye Mande: Lingvistika afrikanskikh ritmakh. Materialy peterburgskoj èkspeditsii v Kot d'Ivuar (K 50-letiju Konstantina Pozdnjakov), 154-82. Sankt-Petersburg: Evropejskij Dom.

Ernst, Urs. 1995. Les formes verbales du kaks. Ministère de la Recherche Scientifique et Technique. Yaoundé: SIL.

Essegbey, James. 2004. Auxiliaries in serializing languages: On COME and GO in Sranan and Ewe. Lingua 114 (4): 473-494.

Essien, Okon E. 1987. The aspectual system of Ibibio. In Odden, David (ed.) Current Approaches to African Linguistics, Volume 4, 151-165. Dordrecht: Foris Publications.

Essien, Okon E. 1991. The tense system of Ibibio revisited. In Essien (ed.), 99-128.

Essien, Okon E. (ed.) 1991. The Tense Systems of Nigerian Languages and English. Afrikanistische Arbeitspapiere 27. Köln: Universität zu Köln. 
Fabre, Gwenaëlle. 2003. L'étude du Samba Leko, parler d'Allani. (Cameroun du Nord) familie Adamawa. Lincom Studies in African Linguistics 56. München: Lincom.

Fabre, Gwenaëlle. 2009. Sérialisation et hiérarchisation dans le système verbal du samba leko, langue adamawa du nord-cameroun. Journal of African Languages and Linguistics 30: 235-265.

Fiedler, Ines and Anne Schwarz (eds.). 2010. The Expression of Information Structure. A documentation of its diversity across Africa. Typological Studies in Language 91. Amsterdam/Philadelphia: John Benjamins.

Fiore, Lynne E. and Patricia M. Peck. 1973/1980. Limbum. In Kropp-Dakubu, M. E. (ed.) volume 2, $11 \mathrm{pp}$.

Fleisch, Axel. 2000. Lucazi Grammar: A Morphosemantic Approach. Köln: Rüdiger Köppe Verlag.

Fleming, Harold C. 1976. Gonga Kefa. In Bender (ed.), 351-76.

Fleming, Harold C. 1990. A grammatical sketch of Dime (Dim-Af) of the Lower Omo. In Hayward (ed.), 494-583.

Fleming, Harold C. 2006. Ongota: A Decisive Language in African Prehistory. Aethiopistische Forschungen 64. Wiesbaden: Harrassowitz Verlag.

Fleming, Harold C. , Aklilu Yilma, Ayyalew Mikitu, Richard Hayward, Yukio Miyakawi, Pavel Mikesh J. Michael Seelig. 1992. Ongota or Birale: a moribund language of Gemu-Gofa Ethiopia. Journal of Afroasiatic Linguistics 33: 181-225.

Foley, William A. and Mike Olson (1985). Clausehood and verb serialization. In Nichols, Johanna and Anthony C. Wooodbury (eds.) Grammar Inside and Outside the Clause: Some New Approaches to Theory from the Field, 17-60. Cambridge: Cambridge University Press.

Ford, Carolyn M. 1991. Notes on the phonology and grammar of Chaha-Gurage. Journal of Afroasiatic Linguistics 23: 231-96. 
Fortune, George. (1955) An Analytical Grammar of Shona. London: Longmans, Green \& Co.

Fourie, David J. 1993. Mbalanhu. Languages of the World/Materials 3. Munich: Lincom Europa.

Frajzyngier, Zygmunt. 1977. On the intransitive copy pronouns in Chadic. Studies in African Linguistics 7: 73-84.

Frajzyngier, Zygmunt. 1982. On the Form and Function of Pre-Pronominal Markers in Chadic. Bulletin of the School of Oriental and African Studies 45 (2): 323-342.

Frajzyngier, Zygmunt. 1989. A Grammar of Pero. Berlin: Dietrich Reimer.

Frajzyngier, Zygmunt 2001. A Grammar of Lele. Stanford Monographs in African Languages Stanford, California: Center for the Study of Language and Information.

Frajzyngier, Zygmunt. 2008. A Grammar of Gidar. Research in African Studies 13. Frankfurt: Peter Lang.

Frajzyngier, Zygmunt and Erin Shay. 2002. A Grammar of Hdi. Berlin: Mouton de Gruyter.

Friesen, Diane and Megan Mamalis. 2004. The Moloko Verb Phrase. Dallas, TX: SIL.

Gebre-Tsadik, Abebe. 1985. An overview of the structure of Sidamo verbs. Afrikanistische Arbeitspapiere 2: 64-81.

Gensler, Orin D. 1994. On reconstructing the syntagm "S Aux O V" to Proto-NigerCongo. In Moore, K. E. et al. (eds.) BLS 20, Special Session on African Historical Linguistics, 1-20. Berkeley, Calif: BLS.

Gensler, Orin D. 1997. Grammaticalization, typology, and Niger-Congo word order: Progress on a still unsolved problem. Journal of African Languages and Linguistics 18: 57-93. 
Gensler, Orin and Tom Güldemann 2003. S-AUX-O-V-OTHER in Africa: typological and areal perspective. Paper presented at World Congress of African Linguistics 4, Rutgers University, June 2003.

Gerhardt, Ludwig. 1984. More on the verbal system of Zarek (Northern Nigeria). Afrika und Übersee 67: 11-30.

Gerhardt, Ludwig. 2008. Bemerkungen zum Ayu (Südwest-Plateau, Nigeria). Afrika und Übersee 88 (1-2): 103-124.

Givón, Talmy. 1971. On the verbal origin of the Bantu verb suffixes. In Studies in African Linguistics 2 (2): 145-162.

Givón, Talmy. 1973. The time-axis phenomenon. Language 48: 890-925.

Givón, Talmy. 1975. Serial Verbs and Syntactic Change: Niger-Congo. In Li, Charles N. (ed.) Word Order and Word Order Change, 47-112. Austin: University of Texas Press.

Givón, Talmy. 1990. Syntax. A Functional-Typological Introduction. Vol. 2. Amsterdam: John Benjamins.

Givón, Talmy. 2009. Multiple routes to clause union: The diachrony of complex verb phrases. In Givón, Talmy and Masatoshi Shibatani (eds.) Syntactic Complexity, 81118. Amsterdam: John Benjamins.

Goldsmith, John. 1984. Bantu $-a-$ : the far past in the far past. Studies in African Linguistics Supplement 9: 123-34.

Good, Jeff. 2005. Reconstructing morpheme order in Bantu: The case of causativization and applicativization. Diachronica 22: 3-57.

Good, Jeff and Jesse Lovegren 2009. Reassessing Western Beboid. Presented at Bantu 3, Tervuren. March, 2009.

Gragg, Gene. 1976. Oromo of Wellega. In Bender (ed.), 166-195. 
Gravina, Richard. 2001. The Verb Phrase in Mbuko. SIL.

Gravina, Richard. 2007. The Verb Phrase in Merey. Ministère de la Recherche Scientifique et de l'Innovation. Yaoundé: SIL.

Green, M. M., and G. E. Igwe. 1963. A Descriptive Grammar of Igbo. Berlin: Akademie.

Grégoire Claire. 1979. Les voyelles finales alternantes dans la conjugaison affirmative des langues bantoues centrales. Journal of African Languages and Linguistics 1: 141172 .

Grieve, Jerry A. 1973. Kilba. In Kropp-Dakubu, M. E. (ed.) volume 1, pp. 326-334.

Gruber, Jeffrey S. 1978. Plural predicates in 拉ã. In Traill, Anthony (ed.) Bushmen and Hottentot Language Studies, 1-50. Johannesburg: University of Witwatersrand African Studies Institute.

Guarisma, Gladys. 1978. Etudes Vouté (Langue bantoïde du Cameroun). Bibliotheque de la SELAF 66-67. Paris: SELAF.

Güldemann, Tom. 1996. Verbalmorphologie und Nebenprädikationen im Bantu: Eine Studie zur funktional motivierten Genese eines konjugationalen Subsystems. BochumEssener Beiträge zur Sprachwandelforschung 27. Bochum: Universitätsverlag Dr. N. Brockmeyer.

Güldemann, Tom. 1998. The relation between imperfective and simultaneous taxis in Bantu: late stages of grammaticalization. In Fiedler, Ines, Catherine Griefenow-Mewis and Brigitte Reineke (eds.), Afrikanische Sprachen im Brennpunkt der Forschung: Linguistische Beiträge zum 12. Afrikanistentag Berlin, 3.-6. Oktober 1996, 157-177. Köln: Rüdiger Köppe.

Güldemann, Tom. 1999. The genesis of verbal negation in Bantu and its dependency on functional features of clause types. In Hombert and Hyman (eds.), 545-587.

Güldemann, Tom. 2002. When 'say' is not say: The functional versatility of the Bantu quotative marker $t i$ with special reference to Shona. In Güldemann and von Roncador (eds.), 253-87. 
Güldemann, Tom. 2003. Present progressive vis-à-vis predication focus in Bantu: a verbal category between semantics and pragmatics. Studies in Language 27 (2): 323360 .

Güldemann, Tom. 2005. Complex predicates based on generic auxiliaries as an areal feature in Northeast Africa. In Voeltz (ed.), 131-154.

Güldemann, Tom. 2007. Preverbal objects and information structure in Benue-Congo. In Aboh et al. (eds.), 83-111.

Güldemann, Tom. 2008. The Macro-Sudan belt: towards identifying a linguistic area in northern sub-Saharan Africa. In Heine and Nurse (eds.), 151-185.

Güldemann, Tom. 2010a. The relation between focus and theticity in the Tuu family. In Fiedler, Ines and Anne Schwarz (eds.), 69-93.

Güldemann, Tom. 2010b. Proto-Bantu and Proto-Niger-Congo: Macro-areal typology and linguistic reconstruction. To appear in König, Christa and Osamu Hieda (eds), International Symposium of the Center of Corpus-Based Linguistics and Language Education (CbLLE). Amsterdam \& Philadelphia: John Benjamins. Preprint version, $32 \mathrm{pp}$.

Güldemann, Tom and Rainer Vossen. 2000. Khoisan. In Heine, Bernd and Derek Nurse (eds.) African Languages: An Introduction. Cambridge: Cambridge University Press, 99-122.

Güldemann, Tom and Manfred von Roncador (eds.). 2002. Reported Discourse: A meeting ground for different linguistic domains. Typological Studies in Language 52. Amsterdam: John Benjamins.

Guma, Samson Mbizo. 1971. An Outline Structure of Southern Sotho. Pietermaritzburg: Shuter \& Shooter.

Guthrie, Malcolm. 1948. The classification of the Bantu languages. London: Oxford University Press. 
Guthrie, Malcolm. 1967/71. Comparative Bantu: an introduction to the comparative linguistics and prehistory of the Bantu languages. 4 vols. Letchworth, UK and Brookfield, VT: Gregg International.

Gutt, Ernst-August. 1997. Concise grammar of Silt'e. In Gutt, Ernst-August H. M. and H. Mohammed. Silt'e-Amharic-English Dictionary (with a concise grammar by ErnstAugust Gutt), 895-957. Addis Ababa: Addis Ababa University Press.

Haas, Mary. 1977. From auxiliary verb phrase to inflectional suffix. In Li, Charles N. (ed.) Mechanisms of Syntactic Change, 525-537. Austin: University of Texas Press.

Hagege, Claude. 1970. La langue Mbum de Nganha (Cameroun). Paris: SELAF. 2 volumes.

Hamaya, Mitsuyo. 1993. Maasai auxiliaries and infinitival constructions. Eugene: University of Oregon, MA thesis.

Hantgan, Abbie E. 2008-ms. A Grammar of Bangime. Dogon Languages of Mali. Bloomington, Indiana University Manuscript.

Hardemann, Pascale. 1996. Grammaticalisation de la structure Infinitif + Verbe conjugué $_{\text {dans }}$ quelques langues bantoues. Studies in African Linguistics 25 (2): 155-69.

Harries, Lyndon 1940. An outline of Mawiha grammar. African Studies 14: 91-146; 410-33.

Harris, Alice and Lyle Campbell. 1995. Historical Syntax in Crosslinguistic Perspective. Cambridge: Cambridge University Press.

Harris, Martin and Paolo Ramat, (eds.) 1987. Historical Development of Auxiliaries. Berlin: Mouton de Gruyter.

Harro, Gretchen and Nancy Haynes. 1991. Grammar Sketch of Yemba (Bamileke Dschang). Yaoundé: SIL.

Haruna, Andrew. 2003. A Grammatical Outline of Gùrdùy/Gùrùntùm (Southern Bauchi, Nigeria). Köln: Rüdiger Köppe Verlag. 
Hayward, Richard J. 1989. Comparative notes on the language of the S'aamakko. Journal of Afroasiatic Linguistics 21: 1-53.

Hayward, Richard J. 1990. Notes on the Aari Language. In Hayward, (ed.), 425-93.

Hayward, Richard J. (ed.). 1990. Omotic Language Studies. London: School of Oriental and African Studies.

Heath, Jeffrey. 1999. A Grammar of Koyra Chiini: The Songhay of Timbuktu. Berlin: Mouton de Gruyter.

Heath, Jeffrey. 2005a. Tondi Songway Kiini (Songhay, Mali). Reference Grammar and TSK-English-French Dictionary. Stanford Monographs in African Languages. Stanford, California: CSLI.

Heath, Jeffrey. 2005b. A Grammar of Tamashek (Tuareg of Mali). Mouton Grammar Library 35. Berlin: Mouton de Gruyter.

Heath, Jeffrey. 2008. A Grammar of Jamsay. Mouton Grammar Library 45. Berlin: Mouton de Gruyter.

Hedinger, Robert. 1985. The verb in Akoose. Studies in African Linguistics 16 (1): 1-55.

Hedinger, Robert. 1989. Northern Bantoid. In Bendor-Samuel, John (ed.) The Niger Congo Languages, 421-430. Arlington, Texas: SIL.

Hedinger, Robert. 2008. A Grammar of Akoose: A Northwest Bantu Language. Arlington, Texas: SIL International Publications.

Heine, Bernd. 1974/5. Tepes und Nyang'i: zwei ostafrikanische Restsprachen. Afrika und Übersee 58 (3/4): 263-300.

Heine, Bernd. 1976a. Ik-Eine ostafrikanische Restsprache. Afrika und Übersee 59 (1): 31-56. 
Heine, Bernd. 1976b. The Kuliak languages of Eastern Uganda. Nairobi : East African Publishing House.

Heine, Bernd. 1986. Bemerkungen zur Entwicklung der Verbaljunkturen im Kxoe und anderen Zentralkhoisan-Sprachen. In Rainer Vossen and Klaus Keuthmann (eds.) Contemporary Studies on Khoisan, 9-21. Hamburg: Helmut Buske.

Heine, Bernd. 1991. Auxiliaries in African Languages: The Lingala case. Berkeley Linguistic Society 17. Berkeley, California: BLS

Heine, Bernd. 1993. Auxiliaries. Cognitive Forces and Grammaticalization. New York: Oxford University Press.

Heine, Bernd. 1994. On the genesis of aspect in African languages: the Proximative. $B L S$ 20 Special Session on Historical Issues in African Linguistics, 35-46. Berkeley, California: BLS.

Heine, Bernd. 1999. The \|Ani: Grammatical notes and texts. Working Paper No. 11. Khoisan Forum. Köln: University of Köln.

Heine, Bernd, Ulrike Claudi and Friederike Hünnemeyer. 1991. Grammaticalization: A Conceptual Framework. Chicago: University of Chicago Press.

Heine, Bernd and Tania Kuteva. 2002. World Lexicon of Grammaticalization. Cambridge: Cambridge University Press.

Heine, Bernd and Mechthild Reh 1984. Grammaticalization and Reanalysis in African Languages. Hamburg: Helmut Buske Verlag.

Heine, Bernd and Derek Nurse, (eds.). 2008. A Linguistic Geography of Africa. Cambridge: Cambridge University Press.

Hellwig, Birgit. 2006. Serial Verb Constructions in Goemai. In Aikhenvald and Dixon (eds.), 88-107.

Hewson, John, Derek Nurse, and H. R. T. Muzale 2000. Chronogenetic staging of tense in Ruhaya. Studies in African Linguistics 29 (2): 33-56. 
Hewson, John and Derek Nurse. 2001. Chronogenetic staging in the Swahili verbal system. In Drinka, Bridget and Derek Nurse (eds.) African Language and Culture in Historical Perspective: Essays in Memory of Edgar C. Polomé. Special Issue of General Linguistics 38: 75-108.

Hieda, Osamu. 1991. Word order and word order change in Western Nilotic. In Rottland and Omondi (eds.), 97-122.

Hieda, Osamu. 1992. A grammatical sketch of the Koegu language. Journal of Swahili and African Studies 3: 131-155.

Hieda, Osamu. 1998. A sketch of Koegu grammar: Towards reconstructing ProtoSoutheastern Surmic. In Dimmendaal and Last (eds.), 345-373.

Hilders, J. H. and J. C. D. Lawrance 1956. An Introduction to the Ateso Language. Kampala: The Eagle Press.

His Highness the Ologori of Ogori and Ben O. Elugbe. nd/1980a. Ogori. In KroppDakubu, M. E. (ed.) volume 2, 4 pp.

His Highness the Ologori of Ogori and Ben O. Elugbe. nd/1980b. Okpamberi. In KroppDakubu, M. E. (ed.) volume 2, 4 pp.

Hofer, Verena and Christa Link 1973/1980. Wobé. In Kropp-Dakubu, M. E. (ed.) volume 2.

Hombert, Jean-Marie and Larry M. Hyman (eds.). 1999. Bantu historical linguistics: theoretical and empirical perspectives. CSLI Lecture Notes 99. Stanford, California: Center for the Study of Language and Information (CSLI).

Houngues, Desire and John Hutchison. 1999. Tense-aspect and serialization in Mínà. In Kotey, P. F. A. (ed.) New Dimensions in African Linguistics and Languages, 189-202. Trenton, NJ: Africa World Press.

Horton, A. E. 1949. A Grammar of Luvale. Johannesburg: Witwatersrand University. 
Hudson, Grover. 1976a. Highland East Cushitic. In Bender (ed.), 232-77.

Hudson, Grover. 1976b. Beja. In Bender (ed.), 96-132.

Hudson, Richard. 1987. Zwicky on heads. Journal of Linguistics 23: 109-32.

Hurel, Eugène. 1911. Manuel de langue kinyarwanda. Mitteilungen des Seminars für Orientalische Sprachen 14: 1-159.

Hutchison, John. 1981. The Kanuri Language: a reference grammar. Madison, Wisconsin: African Studies Program, University of Wisconsin.

Hyman, Larry M. 1981. Noni grammatical structure. Southern California Occasional Papers in Linguistics 9. Los Angeles: Department of Linguistics, University of Southern California.

Hyman, Larry M. 1985. Dependency relations in syntax: the mysterious case of the empty determiner in Aghem. Studies in African Linguistics, supplement 9: 151-6.

Hyman, Larry M. 1989. Accent in Bantu: An appraisal. Studies in Linguistic Sciences 19 (2): 115-134.

Hyman, Larry M. 1994. Conceptual issues in the comparative study of the Bantu verb stem. In Mufwene, Salikoko S. and Lioba Moshi (eds.) Topics in African Linguistics, 3-34. Amsterdam: Benjamins.

Hyman, Larry M. 2003. Suffix ordering in Bantu: A morphocentric approach. In Booij, Geert and Jaap van Marle (eds.) Yearbook of Morphology 2002, 245-281. Dordrecht: Kluwer.

Hyman, Larry M. 2007. Reconstructing the Proto-Bantu verbal unit: internal evidence. In Kula and Marten (eds.), 201-211.

Hyman, Larry M. 2010. Focus marking in Aghem. In Fiedler and Schwarz (eds.), 95-116.

Ibriszimow, Dymitr and G. Segerer (eds.) 2004. Système de marques personnelles en Afrique. Collection Afrique et langage 8. Louvain/Paris: Peeters. 
Iddah, Robert Komra. 1975/1980. Siwu. In Kropp-Dakubu, M. E. (ed.) volume 2, 6 pp.

Idiatov, Dmitry. 2000. Le sémantisme des marqueurs aspecto-temporels du bambara: une tentative analyse. Mandenkan 36: 1-58.

Ikoro, Suanu. 1996. The Kana Language. Leiden: Leiden University, Ph. D. Dissertation.

Innes, Gordon 1969. A Mende-English Dictionary. London: Cambridge University Press.

Ittmann, Johannes (with Carl Meinhof). 1939. Grammatik des Duala Kamerun. Zeitschrift für Eingeborenen-Sprachen 20 Berlin: Reimer/Hamburg: Friederichsen, de Gruyter.

Iwara, Alexander. U. 1991. The tense system of Lokaa. In Essien (ed.), 169-191.

Jakobi, Angelika. 1989. A Fur grammar: phonology, morphophonology and morphology. Nilo-Saharan Linguistic Analyses and Documentation 5. Hamburg: Helmut Buske Verlag.

Jakobi, Angelika and Joachim Crass (avec la collaboration de Bakhit Seby Abdoulaye). 2004. Grammaire du beria (langue saharienne). Avec un glossaire français-beria. Nilo- Saharan Studies 18. Köln: Rüdiger Köppe Verlag.

Jarrett, Keith A. 1981. The development of the Kanuri aspect system within Western Saharan. In Shadeberg, Thilo C. and M. Lionel Bender (eds.) Nilo-Saharan: Proceedings of the First Nilo-Saharan Linguistics Colloquium, Leiden, September 810, 1980, 201-15. Dordrecht: Foris.

Jelinek, Eloise. 1983. Person-subject marking in AUX in Egyptian Arabic. In Heny, Frank and Barry Richards (eds.) Linguistic Categories: Auxiliaries and Related Puzzles, vol. i: Categories, 21-46. Dordrecht: Reidel.

Jenewari, Charles E. W. 1983. Defaka, Ijo's closest relative. In Dihoff, Ivan R. (ed.) Current Approaches to African Linguistics, volume 1, 85-111. Dordrecht: Foris. 
Jones, Ross McCallum. 1998. The Boko/Busa Language Cluster. (Lincom Studies in African Linguistics 30) Munich: Lincom Europa.

Jordan, Dean and Carol Jordan 1975/1980. Nafaara. In Kropp-Dakubu, M. E. (ed.) volume 2, $6 \mathrm{pp}$.

Jungraithmayr, Herrmann. 1965. Materialien zur Kenntnis des Chip, Montol, Gerka und Burrum (Südplateau, Nordnigerien). Afrika und Übersee 48: 161-182.

Jungraithmayr, Herrmann. 1968/1969. The class languages of the Tangale-Waja district. Afrika und Übersee 52: 161-204.

Jungraithmayr, Herrmann. 1973. Notes on the Ishe dialect of Ukaan (Akoko, Western State, Nigeria). Africana Marburgensia 6 (1):39-57.

Jungraithmayr, Herrmann. 1987. Zur Suffixkonjugation im Osttschadischen. Afrika und Übersee 70: 49-60.

Kamba Muzenga, J.-G. 1981. Les formes négatives dans les langues bantoues. Tervuren: Musée Royal de l'Afrique Centrale.

Kamba Muzenga, J.-G. 2005. Le négatif du verbe être en bantou. In Bostoen, K. and J. Maniacky (eds.) Studies in African Comparative Linguistics with Special Focus on Bantu and Mande, 343-360. Tervuren: Musée Royal de l'Afrique Centrale.

Kammerzell, Frank and Carsten Peust. 2002. Reported speech in Egyptian: Forms, types and history. In Güldemann and von Roncador (eds.), 289-322.

Kari, Ethelbert E. 1997. Degema. Languages of the World/Materials 180 Munich: Lincom Europa.

Kari, Ethelbert E. 2000. Ogbronuagum (The Bukuma Language). Languages of the World/Materials 329. Munich: Lincom.

Kastenholz, Raimund. 1998. Mande Languages and Linguistics. Hamburg: Helmut Buske Verlag. 
Kastenholz, Raimund. 2002. "Samogo" language islands, and Mande-Senufo (Gur) interference phenomena. In Nicolai, Robert and Petr Zima (eds.) Lexical and Structural Diffusion. Interplay of Internal and External Factors of Language Development in the West African Sahel, 91-109. Nice: Publications de la Faculté des Lettres, Arts et Sciences humaines de Nice-Sophia Antipolis.

Kastenholz, Raimund. 2003. Auxiliaries, grammaticalization and word order in Mande. Journal of African Languages and Linguistics 24: 31-53.

Kawasha, Boniface. 2006. The structure of complement clauses in Lunda. Studies in African Linguistics 35 (1): 1-32.

Keegan, John 1997. A Reference Grammar of Mbay. Munich: Lincom Europa.

Kießling, Roland. 2002. Verbal plurality in Sandawe. Hamburger Afrikanistische Arbeitspapiere 1: 59-90.

Kießling, Roland. 2007. Alagwa functional sentence perspective and "incorporation". In Amha et al (eds.), 187-198.

Kießling, Roland, Maarten Mous, and Derek Nurse. 2008. The Tanzanian Rift Valley Area. In Heine and Nurse (eds.), 186-227.

Killian-Hatz, Christa. 1995. Das Baka. Grundzüge einer Grammatik aus der Grammatikalisierungsperspektive. Afrikanistische Monographien 6. Köln: Institut für Afrikanistik Universität zu Köln.

Killian-Hatz, Christa. 2006. Serial Verb Constructions in Khwe (Central-Khoisan). In Aikhenvald and Dixon (eds.), 108-123.

Killian-Hatz. Christa. 2008. A Grammar of Modern Khwe (Central Khoisan). Quellen zur Khoisan-Forschung Band 23. Köln: Rüdiger Köppe Verlag.

Killian-Hatz, Christa. 2009. Khwe. In Dimmendaal (ed.), 215-237.

Kim, Hae-Kyung, 2002?. Aspect, temps et modes en jowulu. 25 pp. Bamako: SIL Mali. 
Kimenyi, Alexandre. 1979. Double negation and negative shift in Kinyarwanda. Studies in African Linguistics 10 (2): 179-196.

Kimenyi, Alexandre. 1980. A Relational Grammar of Kinyarwanda. University of California Publications in Linguistics volume 91. Berkeley: University of California Press.

Kinnaird, William J. 2006. The Vamé Verbal System. Yaoundé: SIL.

Kisseberth, Charles W. 1984. Digo tonology. In Clements, George N. and John Goldsmith (eds.) Autosegmental Studies in Bantu Tone. Dordrecht: Foris Publications, 105-182.

Kiyomi, Setsuko and Stuart Davis. 1992. Verb Reduplication in Swati. African Languages and Cultures 5 (2): 113-124.

Knappert, Jan. 1963. The verb in Dhó-Alúr. Journal of African Languages 2 (2): 103-27.

Köhler, Oswin. 1962. Studien zum Genussystem und Verbalbau der zentralen KhoisanSprachen. Anthropos 57: 530-546.

Köhler, Oswin. 1981. La langue Kxoe. In Perrot, Jean. (ed.) Les langues dans le monde ancien et moderne, vol. I: Les langues de l'Afrique subsaharienne, 483-555. Paris: Centre National de la Recherche Scientifique.

Koné, D. 1984. Le verbe bambara: essai sur les propriétés syntaxiques et semantiques. Grenoble: Université des Langues et Lettres.

König, Christa. 2002. Kasus im Ik. Nilo-Saharan Linguistic Analyses and Documentation 17. Köln: Rüdiger Köppe Verlag.

König, Christa. 2009a. !Xun. In Dimmendaal (ed.), 23-53.

König, Christa. 2009b. Ik. In Dimmendaal (ed.), 141-172.

König, Christa and Bernd Heine. 2001. The !Xun of Ekoka. A demographic and linguistic report. Working Paper No. 21. Khoisan Forum. Köln: University of Cologne. 
Koops, R. and John Bendor-Samuel. 1974. The recapitulating pronouns in Kuteb. Journal of West African Languages 9 (1): 5-16.

Kotzé, Albert E. 2004. A diachronic approach to the explanation of problematic/unusual past tense forms in Lobedu and Northern Sotho. South African Journal of African Languages 2004 (1): 20-35.

Kouadio N'Guessan, Jeremie. 2000. Les séries verbales en baoulé: Questions de morphosyntaxe et de sémantique. In Studies in African Linguistics 29 (1): 75-90.

Kröger, Oliver. 2010. Discourse function of inverted passives in Makua-Maverone narratives. In Fiedler and Schwarz (eds.), 165-192.

Kropp Dakubu, M.E. (ed.). 1975-1980. West African Language Data Sheets. Volumes 12. Accra: West African Linguistic Society.

Kropp-Dakubu, M. E. (ed.). 1988. The Languages of Ghana. London: Kegan Paul International for the International African Institute.

Kula, Nancy C. and Lutz Marten (eds.). 2007. Bantu in Bloomsbury: Special Issue on Bantu linguistics. SOAS Working Papers in Linguistics 15. London: University of London.

Kuperus, J. 1982. The morphology of (Ba-)londo verb tenses. In Gladys Guarisma et al. (eds.) Le verbe bantou, 19-56. Paris: SELAF.

Kuteva, Tania. 2001. Auxiliation. Oxford: Oxford University Press.

Kutsch Lojenga, Constance. 1994. Ngiti. A Central-Sudanic Language of Zaire. NiloSaharan Linguistic Analyses and Documentation 9. Köln: Rüdiger Köppe Verlag.

Lafon, N. 1982. Brève presentation du système verbal et du fonctionnement d'un auxiliaire en shingazidja. In G. Guarisma et al. (eds.) Le verbe bantou, 151-77. Paris: SELAF. 
Lamberti, Marcello. 1986. Die Somali-Dialekte. Eine vergleichende Untersuchung mit 35 Karten und zahlreichen Tabellen. Kuschitische Sprachstudien Bd. 5. Hamburg: Helmut Buske Verlag.

Lamberti, Marcello and Roberto Sottile. 1997. The Wolaytta Language. Köln: Rüdiger Köppe Verlag.

Langacker, Ronald W. 1998. Cognitive grammar meets the Yuman auxiliary. In Hinton, Leanne and Pamela Munro (eds.) Studies in American Indian Languages: Description and Theory, 41-48. Berkeley: University of California Press.

Langdon, Margaret. 1978. Auxiliary verb constructions in Yuman. Journal of California Anthropology Papers in Linguistics, 93-130. Banning, California: Malki Museum.

Larochette, J. 1958. Grammaire des dialectes mangbetu et medje, suivie d'un manuel de conversation et d'un lexique. (Sciences de L'homme, 18.) Tervuren: Annales du Musée Royal du Congo Belge.

Leger, R. 1994. Eine Grammatik der Kwami-Sprache (Nordostnigeria). Westafrikanische Studien. Frankfürter Beiträge zur Sprach- und Kulturgeschichte Band 8. Köln: Rüdiger Köppe Verlag.

Leger, R and A. Storch. 1999. Zur Genese komplexer Verbalsysteme in einigen nordostnigerianischen Sprachen. Afrika und Übersee 82: 179-190.

Lepota, Biki. 2002. Exploring the 'conditional mood' in Northern Sotho. South African Journal of African Languages 2002 (2): 113-121.

Leroy, Jacqueline. 2007. Le Mankon. Langue bantoue des Grassfields (Province NordOuest du Cameroun). SELAF no. 437. Paris: Peeters.

Leslau, Wolf. 1968. The expression of the future in the Ethiopian languages. Journal of African Languages 7 (1): 68-72.

Leyew, Zelealem. 2003. The Kemantney Language. A Sociolinguistic and Grammatical Study of Language Replacement. Cushitic Language Studies 20. Köln: Rüdiger Köppe Verlag. 
Leyew, Zelealem. n.d. Gwama, a Little-known Endangered Language of Ethiopia: A sketch of its Grammar and Lexicon. 39pp. http://ldh.livingsources.org/2010/11/23/escidoc406288/

Accessed 23 Nov 2010.

Lienhard, Ruth. 1980. Le Verbe en Daba. SIL.

Lightfoot, David. 1979. Principles of Diachronic Syntax. Cambridge: Cambridge University Press.

Löhr, Doris. 2002. Die Sprache der Malgwa (Nárá Málgwa). Frankfurt: Peter Lang Verlag.

Lombard, Daan. 1978. A diachronic-tonological analysis of certain rank-shifted verbal structures in Northern Sotho. In Studies in African Linguistics 9 (3): 319-328.

Lord, Carol. 1993. Historical Change in Serial Verb Constructions. Typological Studies in Language 26. Amsterdam: John Benjamins.

Louw, J. A. 1963. $n$ Vergelykende Studie van die Defisiënte Verbum in die Ngunitale. Stellenbosch: University of Stellenbosch, D.Litt. thesis.

Louw, J. A. et al. 1967. A Handbook of the Zulu Language. Pretoria: Van Schaik.

Lukas, Johannes. 1933. Beiträge zur Kenntnis der Sprachen von Wadai (Mararēt, Maba). Journal de la Société des Africanistes 3 (1): 25-55.

Lukas, Johannes. 1939. Die Sprache der Buduma im Zentral Sudan. Auf Grund eigener Studien und des Nachlasses von Gustav Nachtigal. Leipzig: F. A. Brockhaus.

Lukas, Johannes. 1952. Verbalwurzel und Verbalaffixe in Maba. Afrika und Übersee 36: 93-98.

Lukas, Johannes. 1953. Die Sprache der Tubu in der zentralen Sahara. Deutsche Akademie der Wissenschaften zu Berlin Institüt für Orientforschung 14. Berlin: Akademie Verlag. 
Lukas, Johannes. 1970. Die Personalia und das primare Verb im Bolanci (Nordnigerien). Afrika und Übersee 54: 237-286.

Lukas, Johannes. 1971. Die Personalia und das primare Verb im Bolanci (Nordnigerien). Afrika und Übersee 55: 114-139.

Lukas, Johannes and A. Willms. 1961. Outline of the language of the Jarawa in northern Nigeria (Plateau Province). Afrika und Übersee 45: 1-66.

Lüpke, Friederike. 2009. Jalonke. In Dimmendaal (ed.), 173-214.

Lydall, Jean. 1976. Hamer. In Bender (ed.), 393-438.

Lyth, Richard E. 1971. The Murle language: Grammar and vocaulary. Linguistic Monograph Series 7. Khartoum: Sudan Research Unit (Faculty of Arts), University of Khartoum.

Mackay, Hugh. 1968/1980 (1977). Eloyi. In Kropp-Dakubu, M. E. (ed.) volume 1, pp. 194-207.

Maho, Jouni F. 2001. The Bantu area: (towards clearing up) a mess. Africa \& Asia: Göteborg working papers on Asian and African languages and literatures 1: 40-49.

Maho, Jouni F. 2003. A classification of the Bantu languages: an update of Guthrie's referential system. In Nurse, Derek \& Gérard Philippson (eds.) The Bantu Languages, 639-651. Routledge language family series. London and New York: Routledge.

Maho, Jouni F. 2007. The linear ordering of TAM/NEG markers in the Bantu languages. In Kula and Marten (eds.), 213-225.

Maho, Jouni F. 2008. Comparative TMA morphology in Niger-Congo: the case of persistive, and some other, markers in Bantu. In Josephson, Folke and Ingmar Söhrman (eds.) Interdependence of diachronic and synchronic analyses, 283-298. Studies in language companions series, v. 103. Amsterdam: John Benjamins.

Malete, E. N. 2003. The syntax and morphology of the negative morpheme /ha/ in Sesotho. South African Journal of African Languages 2003 (1): 26-36. 
Manessy, Gabriel. 1960. Tâches quotidiennes et travaux saisonniers en pays bwa. Dakar: Université de Dakar.

Manessy, Gabriel. 1983. Le bwamu et les langues voltaïques. Afrika und Übersee 66: 231-58.

Manfredi, Victor. 2005-ms. Tense Parameters and Serial Verbs. Pre-print version of paper submitted to Aboh, Enoch and James Essegbey (eds.) Studies in the Syntax of Kwa: a generative perspective. Amsterdam: John Benjamins.

Marchese, Lynell. 1982. Basic aspectual categories in Proto-Kru. Journal of West African Languages 12 (1): 3-23.

Marchese, Lynell. 1986. Tense/Aspect and the Development of Auxiliaries in Kru Languages. Summer Institute of Linguistics Publication 78. Arlington, Texas: SIL Publications.

Marchese, Lynell and Carol Gratrix. 1974/1980. Godie. In M. E. Kropp Dakubu (ed.), volume 1, 269-277.

Matseke, A. K. 1968. Setswana sa ka Metlha. Johannesburg: Better Books.

Mbuagbaw, Tanyi Eyang. 2008. The Standardisation and Modernisation of Kenyang. SIL Forum for Fieldwork 2008-001. SIL International.

McClelland, Clive W. III 2000. The Interrelations of Syntax, Narrative Structure, and Prosody in a Berber Language. Lewiston, NY: Mellen.

McKee, Robert G. 1991. "Here”, “There", "Yonder”, and beyond with Meje aspect. In Rottland and Omondi (eds.), 165-80.

McPherson, L. and M. Paster. 2009. Evidence for the Mirror Principle and Morphological Templates in Luganda Affix Ordering. In Ojo, A. and L. Moshi (eds.) Selected Proceedings of the 39th Annual Conference on African Linguistics, 56-66. Somerville, MA: Cascadilla Proceedings Project. 
Meeussen, Achille E. 1967. Bantu grammatical reconstructions. Africana Linguistica 61 (3): 79-121.

Meinhof, Carl. 1948. Grundzüge einer vergleichenden Grammatik der Bantusprachen. Zweite Völlig Umgearbeitete Auflage. Hamburg: Verlag von Eckardt \& Messtorff.

Mettouchi, Amina. 2009. The system of negation in Berber. In Cyffer et al (eds.), pp. 287-306.

Meyer, Ronny. 2005. Das Zay. Deskriptive Grammatik einer Ostguragesprache (Äthiosemitisch). Köln: Rüdiger Köppe Verlag.

Meyer, Ronny. 2006. Wolane. Descriptive Grammar of East Gurage language (Ethiosemitic). Köln: Rüdiger Köppe Verlag.

Meyer, Ronny. 2007. Non-verbal predication in East Gurage and Gunnän Gurage languages. In Joachim Crass and Ronny Meyer (eds.) Deictics, Copula and Focus in the Ethiopian Convergence Area, 177-194. Köln: Rüdiger Köppe Verlag.

Meyer-Bahlburg, Hilke. 1972. Studien zur Morphologie und Syntaxe der Musgu. Hamburg: Helmut Buske Verlag.

Miehe, Gudrun. 1992. Zur Herkunft von Tempus- und Aspekt-morphemen in Bantu. In Müller, Ernst and Anna-Maria Brandstetter (eds.) Forschungen in Zaire in memoriam Erika Sulzmann, 289-310. Münster/Hamburg: LIT.

Migeod, F. W. H. 1908. The Mende Language. London: Kegan Paul, Trench, Trübner.

Mithun, Marianne. 1999. The Languages of Native North America. Cambridge: Cambridge University Press.

Mkhatshwa, Simon Nyana Leon. 1991. Metaphorical extensions as a basis for grammaticalization. With special reference to Zulu auxiliary verbs. Pretoria: University of South Africa, MA Thesis.

Moñino, Yves. 1995. Le Proto-Gbaya. Essai de linguistique comparative sur vingt-etune langues d'Afrique centrale. Paris: Peeters. 
Moosally, Michelle 1998. Noun phrase coordination: Ndebele agreement patterns and cross-linguistic variation. Austin: University of Texas $\mathrm{Ph}$. D. dissertation.

Moser, Rosemarie. 2005. Grammaticalization chains of the verb kàre 'to give' in Kabba. In Voeltz (ed.), 277-301.

Mous, Maarten. 1993. A Grammar of Iraqw. Köln: Rüdiger Köppe Verlag.

Mous, Maarten. 2004. A Grammatical Sketch of Mbugwe. Bantu F34, Tanzania. Grammatical Analyses of African Languages 23. Köln: Rüdiger Köppe Verlag.

Mufwene, Salikoko S. 1991. On the status of auxiliary verbs in Gullah. Paper presented at Linguistic Society of America/Society for Pidgin and Creole Languages meeting, Chicago.

Mufwene, Salikoko S. 1978. A reconsideration of Lingala temporal inflections. Studies in African Linguistics 9 (1): 91-105.

Muratori, P. C. 1938. Gramatica lotuxo. Verona: Missioni Africane.

Musehane, N. M. 2007. The structure and semantic classification of compounds with a verbal complement. South African Journal of African Languages 2007 (4): 181-205.

Mutaka, Ngessimo M. 1994. The Lexical Tonology of Kinande. München: Lincom Europa.

Myers, Scott. 1998. AUX in Bantu morphology and phonology. In Hyman, Larry M. and Charles W. Kisseberth (eds.) Theoretical Aspects of Bantu Tone, 231-264. Stanford, California: CSLI.

Ndimele, Ozo-mekuri. 2003. A Concise Grammar and Lexicon of Echie. Aba: National Institute for Nigerian Languages.

Ndimele, Ozo-mekuri. 2009. Negation marking in Igbo. In Cyffer et al (eds.), 121-37. 
Nebel, P. A. 1948. Dinka Grammar (Rek-Malual Dialect) with Texts and Vocabulary. Museum Combonianum Verona: Missioni Africane.

Nettle, Daniel. 1998a. The Fyem Language of $N$. Nigeria. Languages of the World/Materials 136. München: Lincom.

Nettle, Daniel. 1998b. Materials from the Southeastern Plateau languages of Nigeria. Afrika und Übersee 81: 253-79.

Newman, John ed. 2002. The Linguistics of Sitting, Standing, Lying. Amsterdam: Benjamins.

Newman, Paul. 2000. The Hausa Language. An Encyclopedic Reference Grammar. New Haven and London: Yale University Press.

Ngoran Loveline Lenaka. 1999. A Sketch Outline of the Phonology of Ndemli. Yaoundé: University of Yaoundé, MA Thesis.

Nichols, Johanna. 1986. Head-marking and dependent-marking grammar. Language 62: 56-119.

Nichols, Johanna. 1992. Linguistic Diversity in Space and Time. Chicago: University of Chicago Press.

Nikolaeva, Irina. (ed.) 2007. Finiteness. Theoretical and Empirical Foundations. Oxford: Oxford University Press.

Noonan, Michael. 1992. A Grammar of Lango. Berlin: Mouton de Gruyter.

Nougayrol, Pierre. 1989. La langue des aiki dits rounga. Tchad, République Centrafricaine. esquisse descriptive et lexique. Paris: Libraire Orientaliste Paul Geuthner S. A.

Nougayrol, Pierre. 1999. Les parlers gula (République centrafricaine, Soudan, Tchad). Éléments de grammaire comparative et lexique. Paris; CNRS.

Novelli, Bruno. 1985. A Grammar of the Karimojong Language. Berlin: Dietrich Reimer Verlag. 
Nsuka Nkutsi, François. 1986. Formatifs et auxiliaires dans les langues bantoues: Quelques critères de détermination. Africana Linguistica 10: 339-64.

Nurse, Derek 1979a. Classification of the Chaga Dialects. Hamburg: Helmut Buske Verlag.

Nurse, Derek 1979b. Description of sample Bantu languages of Tanzania. African Languages/Langues Africaines 5: 1-150.

Nurse, Derek 2000a. Diachronic morphosyntactic change in Western Tanzania. In Voßen, Rainer et al. (eds.), "Mehr als nur Worte.."; afrikanistische Beiträge zum 65. Geburtstag von Franz Rottland, 517-534. Köln: Rüdiger Köppe Verlag.

Nurse, Derek. 2000b. Inheritance, contact, and change in two East African languages. Language Contact in Africa 4. Köln: Rüdiger Köppe Verlag.

Nurse Derek. 2003. Aspect and tense in Bantu languages. In Nurse, Derek and Gérard Philippson (eds.) The Bantu Languages, 90-102. London: Routledge.

Nurse Derek. 2007a. Did the Proto-Bantu verb have a synthetic or an analytic stucture?. In Kula and Marten (eds.), 239-256.

Nurse Derek. 2007b. The Emergence of Tense in Early Bantu. In Payne, Doris L. and Jaime Peña (eds.) Selected Proceedings of the 37th Annual Conference on African Linguistics, 164-179. Somerville, MA: Cascadilla Proceedings Project.

Nurse Derek. 2008. Tense and aspect in Bantu. Oxford: Oxford University Press.

Nurse, Derek and Gérard Philippson. 2006. Common tense-aspect markers in Bantu. Journal of African Languages and Linguistics 27 (2): 155-196.

Nurse, Derek and Franz Rottland. 1994. Sonjo: description, classification, history. Sprache und Geshichte in Africa 12/13 (1991/1992): 171-290.

O’Neil, Joesph. 1935. A Shona Grammar. London: Longmans, Green. 
Obilade, Tony. 1977. On the logical structure of the serial verb construction in Yoruba. Berkeley Linguistics Society 3: 386-93. Berkeley: BLS.

Odden, David. 1996. The Phonology and Morphology of Kimatuumbi. Oxford: Oxford University Press.

Okombo, Okoth. 1991. Valency in Dho-Luo. In Bender, M. Lionel. (ed.), 185-196.

Olson, Howard S. 1964. The Phonology and Morphology of Rimi. Hartford: Hartford Studies in Linguistics.

Oréal, Elsa. 2008. Les formes de la dépendance entre syntaxe et énonciation: la solution égyptienne. In Caron, Bernard (ed.) Subordination, dépendance et parataxe dans les langues africaines, 159-181. SELAF No. 449. Louvain, Paris: Peeters.

Orwin, Martin. 1995. Colloquial Somali: A Complete Language Course. London: Routledge.

Osam, E. Kweku. 2004. An introduction to the structure of Akan: its verbal and multiverbal systems. Legon, Ghana: Department of Linguistics.

Oumarou Yaro, Bourahima. 1993. Eléments de description du Zarma. Grenoble: University of Grenoble, Ph.D. dissertation.

Owens, Jonathan. 1985. A Grammar of Harar Oromo. Hamburg: Helmut Buske Verlag.

Paroz, R. A. 1946. Elements of S. Sotho. Basutoland: Morija Sesuto Book Depot.

Pasch, Helma. 1995. Kurzgrammatik des Ewe. Köln: Rüdiger Köppe Verlag.

Pawlak, Nina. 2001. Diachronic Typology of Locative Phrases in Chadic. Sprache und Geschichte in Afrika 16/17: 355-386.

Perkins, Revere D. 2001. Sampling procedures and statistical methods. In Haspelmath, Martin, Ekkehard König, Wulf Oesterreicher, and Wolfgang Raible (eds.), Language Typology and Linguistic Universals: An International Handbook, vol. i, 419-34. Berlin: de Gruyter. 
Perrin, Mona. 1973/1980. Mambila. In Kropp-Dakubu, M. E. (ed.) volume 2, 5 pp.

Person, Ingrid. 1973. Lorhon. In Kropp-Dakubu, M. E. (ed.) volume 2, 4 pp.

Persson, Andrew M. and Janet R. Persson. 1991. Mödö-English Dictionary with Grammar. Bilingual Dictionaries of Sudan no. 1. Nairobi: Summer Institute of Linguistics-Sudan.

Pichl, Walter J. 1973a/1980a. Ndut-Falor. In Kropp-Dakubu, M. E. (ed.) volume 2, 8 pp.

Pichl, Walter J. 1973b/1980b. Non. In Kropp-Dakubu, M. E. (ed.) volume 2, 5 pp.

Pichl, Walter J. 1973c/1980c. Wolof. In Kropp-Dakubu, M. E. (ed.) volume 2, 6 pp.

Plungian, Vladimir. 1995. Dogon. Munich: Lincom Europa.

Pohlig, James N. 1981. The Mbe Verb. A description of the verb system of Mbe, a language of the northern Cross River State, Nigeria. SIL.

Pohlig, James N. 1992. An Account of Mofu-Gudur Verb Infixes and Suffixes. Ministry of Scientific and Technical Research. Yaoundé: SIL.

Pretorius, W. J. 2006. The grammatical function, morphological status and hierarchical development of the Northern Sotho verb form ka. South African Journal of African Languages 2006 (1): 40-52.

Price, Norman. 1975/1980. Nchumuru. In Kropp-Dakubu, M. E. (ed.) volume 2, 11 pp.

Prost, André. 1964. Contribution à l'étude des langues voltaïques. (Mémoires de l'Institut Français d'Afrique Noire 70). Dakar: IFAN.

Prost, R. P. André (and R. P. M. Kervran). 1969. Les parlers dogons. I. Donno so. Dakar: Publications du Département de Linguistique Générale et Linguistique Africaine de la Faculté des Lettres et Sciences Humaines de l'Université Dakar. 
Prost, R. P. André. 1969. Les parlers dogons. II. Togo Kã. Documents Linguistiques 17. Dakar: Publications du Département de Linguistique Générale et Linguistique Africaine de la Faculté des Lettres et Sciences Humaines de l'Université Dakar.

Pyne, P. C. 1972/1980 (1977). Anyi. In Kropp-Dakubu, M. E. (ed.) volume 1, 45-55.

Randal, Scott. 1998. A grammatical sketch of Tennet. In Dimmendaal, and Last (eds.), 219-72.

Rassadin, V. I. 1994. Törcecen soot [Native Word]. Irkutsk: Vostochno-sibirskoe knizhnoe izdatel'stvo.

Redden, James E. 1979. A Descriptive Grammar of Ewondo. Occasional Papers in Linguistics 4. Carbondale: Department of Linguistics, Southern Illinois University.

Reh, Mechthild. 1985. Die Krongo-Sprache (nìnò mó-di). Beischreibung, Texte, Wörterverzeichnis. Kölner Beiträge zur Afrikanistik. 12. Band. Berlin: Dietrich Reimer Verlag.

Reh, Mechthild. 1996. Anywa Language: Description and Internal Reconstructions. Nilo-Saharan Linguistic Analyses and Documentation 11 Köln: Rüdiger Köppe Verlag.

Reineke, Brigitte. 1972. The Structure of the Nkonya Language. Leipzig: VEB Verlag Enzyklopädie.

Rijkhoff, Jan et al. 1993. A method of language sampling. Studies in Language 17: 169203.

Rijkhoff, Jan and Dik Bakker. 1998. Language sampling. Linguistic Typology 22-3: 263314.

Rilly, Claude. 2010. Le Méroïtique et sa familie linguistique. Afrique et Langage 14. SELAF 454. Paris: Peeters.

Roberts, Ian. 1985. Serial verbs and Government Binding theory. Studies in African Linguistics, Supplement 9: 262-8. 
Ross, Malcolm D. 1982. The development of the verb phrase in the Oceanic languages of the Bougainville region. In Halim, A. Lois Carrington, and Stephan A. Wurm (eds.) Papers from the Third International Conference on Austronesian Linguistics, vol. I: Currents in Oceanic, 1-57. Pacific Linguistics C-74. Canberra: Australian National University.

Rottland, Franz and Lucia A. Omondi (eds.) 1991. Proceedings of the Third NiloSaharan Linguistics Colloquium. Kisumu, Kenya August 4-9, 1986. Nilo-Saharan Linguistic Analyses and Documentation 6. Hamburg: Helmut Buske Verlag.

Rowland-Oke, Mary. 2003. Déscription systématique de la langue Obolo-Andoni. Langue du group Cross River. Paris: L'Harmattan.

Salffner, Sophie. 2009. Tone in the phonology, lexicon and grammar of Ikaan. London: University of London, Ph D dissertation.

Salffner, Sophie. 2010. Tense, aspect and manner encoding in Ikaan beyond verbal inflection. London. Unpublished manuscript.

Salone, Sukari. 1979. Typology of conditionals and conditionals in Haya. Studies in African Linguistics 10 (1): 65-80.

Samarin, William J. 1967. A Grammar of Sango. Janua Linguarum, Series Practica 38 The Hague: Mouton.

Sands, Bonny. 2009. Africa's Linguistic Diversity. Language and Linguistics Compass 3 (2): 559-580.

Sands, Bonny. To appear-a. Hadza Syntax. To appear in Vossen, Rainer (ed.) The Khoisan Languages. London: Curzon.

Sands, Bonny. To appear-b. Hadza Morphology. To appear in Vossen, Rainer (ed.) The Khoisan Languages. London: Curzon.

Santradrea, Stefano. 1961. Comparative Outline Grammar of Ndogo-Sere-Tagbu-BaiBviri. Bologna: Editrice Nigrizia. 
Santandrea, Stefano. 1963. A concise grammar outline of the Bongo language (Bahr el Ghazal Province, Sudan). Verona Museum Comboanium 14. Rome: Sodality of the St. Peter Claver.

Santandrea, Stefano. 1970. Brief Grammar Outlines of the Yulu and Kara Languages. Rome: Sodality of St. Peter Claver.

Sapir, J. David. 1973/1980. Diola. In M. E. Kropp Dakubu (ed.), volume 1, pp. 143-149

Sasse, Hans-Jürgen. 1976. Dasenech. In Bender (ed.), 196-221.

Savà, Graziano. 2005. A Grammar of Ts 'amakko. Köln: Rüdiger Köppe Verlag.

Savà, Graziano, and Mauro Tosco. 2000. A sketch of Ongota, a dying language of Southwest Ethiopia. Studies in African Linguistics 29 (1): 59-136.

Savà, Graziano and Mauro Tosco. 2003. The classification of Ongota. In Bender, M. Lionel, Gabor Takács, and David L. Appleyard (eds.) Selected comparative-historical Afrasian linguistic studies (In memory of Igor M. Diakonoff), 307-16. München, Germany: Lincom Europa.

Schachter, Paul. 1974. A non-transformational account of serial verbs. Studies in African Linguistics, supplement 5: 253-70.

Schachter, Paul. 1985. Parts-of-speech systems. In Shopen, Timothy (ed.) Language Typology and Syntactic Description, vol. i: Clause Structure, 3-61. Cambridge: Cambridge University Press.

Schadeberg, Thilo C. 1981a. A survey of Kordofanian. Vol. 1. The Heiban Group. Hamburg: Helmut Buske Verlag.

Schadeberg, Thilo C. 1981b. A survey of Kordofanian. Vol. 2. The Talodi Group. Hamburg: Helmut Buske Verlag.

Schadeberg, Thilo C. 1985. A small sketch of Ewe. Special Number of Afrikanistische Arbeitspapiere. Köln: Rüdiger Köppe. 
Schadeberg, Thilo C. 1990. A sketch of Umbundu. Grammatische Analysen afrikanischer Sprachen 1. Köln: Rüdiger Köppe.

Schadeberg, Thilo C. and Philip Elias. 1979. A Description of the Orig Language (Southern Kordofan) based on the notes of Fr. Carlo Muratori. België Archief voor Anthropolgie 26. Tervuren: Koninklijk Museum Voor Midden-Afrika.

Schadeberg, Thilo C. and Maarten Kossmann. 2010. Participant reference in the Ebang verbal complex (Heiban, Kordofanian). Journal of African Languages and Linguistics 31: 79-100.

Schaefer, Robert and Darius B. Asakiyah. 1975/1980. Frafra. In Kropp-Dakubu, M. E. (ed.) volume 2, 6 pp.

Schaefer, Ronald P. and Francis O. Egbokhare. 2007. A Dictionary of Emai: An Edoid Language of Niger. Including a Grammatical Sketch. Köln: Rüdiger Köppe Verlag.

Schaefer, Ronald P. and Francis O. Egbokhare 2008. A preliminary assessment of Emai posture verbs. Journal of African Languages and Linguistics 29: 215-235.

Schaefer, Ronald P. and Richard Masagbor. 1984. The forms of negation in North Ibie and their functions. Journal of West African Languages 14 (2): 27-42.

Schaub, Willy. 1985. Babungo. London: Croom Helm.

Schneeberg, Nan. 1971. Sayanci verb tonology. Journal of African Languages 10 (1): 87-100.

Schneider-Blum, Gertrud. 2007. A Grammar of Alaaba. Cushitic Language Studies Band 25. Köln: Rüdiger Köppe Verlag.

Schneider-Blum, Gertrud. 2009. Alaaba. In Dimmendaal (ed.), 55-95.

Scholz, Hans-Juergen. 1973/1980 (1977). Igbirra. In Kropp-Dakubu, M. E. (ed.) volume $1,279-285$. 
Schuh, Richard G. 1976. The Chadic verbal system and its Afroasiatic nature. Journal of Afroasiatic Linguistics 3 (1): 1-14.

Schultz, George. 1997. Kom Grammar Sketch. Part I. Ministry of Scientific and Technical Research. Yaoundé: SIL.

Schultze-Berndt, Eva. 2006. Taking a closer look at function verbs: Lexicon, grammar, or both?. In Ameka et al. (eds.), 359-391.

Segerer, Guillaume. 2002. La language Bijogo du Bubaque (Guinée Bissau). Collection Afrique et Langage 3. Peeters: Louvain-Paris.

Senft, Gunter. 2004. What do we really know about serial verb constructions in Austronesian and Papuan languages?. In Bril, Isabelle and Françoise Ozanne-Rivierre (eds.) Complex Predicates in Oceanic Languages, 49-64. Berlin: Mouton de Gruyter.

Senft, Gunther (ed.). 2008. Serial verb constructions in Austronesian and Papuan languages. Canberra: Australian National University.

Setshedi, J. E. 1974. The Auxiliary Verbs and the Deficient Verbs in Tswana. Pietersburg: University of the North, MA Thesis.

Seuren, Pieter. 1990. Serial Verb Constructions. In Joseph, Brian and Arnold Zwicky (eds.) When Verbs Collide, 14-33. Columbus, Ohio: Ohio State University Press.

Seyoum, Mulugeta. 2007. Some notes on reduplication in Dime. In Amha et al. (eds.), 59-68.

Sharma, D. D. 1988. A Descriptive Grammar of Kinnauri. Studies in Tibeto-Himalayan Languages 1. Delhi: Mittal.

Sharpe, M. R. L. 1980. Everyday Sesotho Grammar. Morija, Lesotho: Morija Sesuto Book Depot.

Shimizu, Kiyoshi. 1983. The Zing dialect of Mumuye. A Descriptive Grammar. With a Mumuye-English dictionary and an English-Mumuye index. Hamburg: Helmut Buske Verlag. 
Sibomana, Leo. 1981/82. Tarok III: Das Verbalsystem und der Satz. Afrika und Übersee 64 (2): 237-247.

Sibomana, Leo. 1985. A Phonological and Grammatical Outline of Eggon. Afrika und Übersee 68: 43-68.

Slattery, H. 1981. Auxiliary verbs in Zulu. Communication 10. Grahamstown, South Africa: Department of African Languages, Rhodes University.

Smith, N. V. 1967/1980. Nupe. In Kropp-Dakubu, M. E. (ed.) volume 2, 6 pp.

Smith, Rebecca Dow 2007. The Noun Class system of Ut-Ma'in, A West Kainji Language Of Nigeria. Grand Forks: University of North Dakota, M.A. Thesis.

Smith, Tony. 2002/2006. The Muyang Verb Phrase. Yaoundé: SIL Cameroon.

Smith, Tony and Richard Grevina. 2010. The Phonology of Two Central Chadic Languages. Arlington, Texas: SIL International.

Song, Jae Jung. 2001. Linguistic Typology: Morphology and Syntax. Longmans Linguistics Library Harlow: Pearson.

Spagnolo, Lorenzo M. 1933. Bari Grammar. Verona: Missioni Africane.

Stanford, Ronald. 1973/1980 (1977). Bekwarra. In Kropp-Dakubu, M. E. (ed.) volume 1, p. $81-86$.

Stanley, Carol. 1991. Description morpho-syntaxique da la langue tikar (parlée au Cameroun). Société International de Linguistique.

Stappers, Leo. 1964. Morfologie van het Songye. Annales Linguistiques 51 Tervuren: Musée Royal de l'Afrique Centrale.

Steever, Sandford. 1988. The Serial Verb Formation in the Dravidian Languages. Delhi: Motilal Barnarsidass. 
Stennes, Leslie H. 1967. A Reference Grammar of Adamawa Fulani. East Lansing, Michigan: Michigan State University African Studies Center.

Sterk, Jan P. 1994. Gade-English Dictionary including English-Gade Reference Dictionary and Summary of Gade Grammar. Sprache und Orientalität in Afrika 15. Berlin: Reimer.

Stevenson, Roland 1957a. A Survey of the Phonetics and Grammatical Structure of the Nuba Mountain Languages, with particular reference to Otoro, Katcha and Nyimang, part II. Afrika und Übersee 41 (1): 27-65

Stevenson, Roland 1957b. A Survey of the Phonetics and Grammatical Structure of the Nuba Mountain Languages, with particular reference to Otoro, Katcha and Nyimang, part III. Afrika und Übersee 41 (2): 117-53

Stevenson, Roland 1957c. A Survey of the Phonetics and Grammatical Structure of the Nuba Mountain Languages, with particular reference to Otoro, Katcha and Nyimang, part IV. Afrika und Übersee 41 (3): 171-96.

Stevenson, Roland C. 1969. Bagirmi Grammar. Khartoum: University of Khartoum.

Stevenson, Roland C. 2009. Tira and Otoro. Two Kordofanian Grammars by Roland C. Stevenson. Thilo C. Schadeberg, editor. Archiv Afrikanistischer Manuskripte Herausgegeben von Gudrun Miehe und Hilke Meyer-Bahlburg, Band VIII. Köln: Rüdiger Köppe Verlag.

Stevenson, Roland, Franz Rottland and Angelika Jakobi. 1992. The verb in Nyimang and Dinik. Afrikanistische Arbeitspapiere 32: 5-64.

Storch, Anne. 1999a. Zur Aspektmarkierung im Jukun. Afrikanistische Arbeitspapiere 58: 107-116.

Storch, Anne. 1999b. Das Hone und seine Stellung in Zentral-Jukunoid. Köln: Rüdiger Köppe.

Storch, Anne. 2009a. Hone. In Dimmendaal (ed.), 123-140. 
Storch, Anne. 2009b. Negation in Jukun. In Cyffer et al (eds.), 107-120

Suter, Rafael. 2007. Copula constructions and information structure in Inor. In Crass, Joachim and Ronny Meyer (eds.) Deictics, Copula and Focus in the Ethiopian Convergence Area, 195-212. Köln: Rüdiger Köppe Verlag.

Sweetser, Eve. 1988. Grammaticalization and semantic bleaching. Berkeley Linguistics Society 14: 389-405. Berkeley: BLS.

Taylor, Charles. 1985. Nkore-Kiga. London: Croom Helm.

Teferra, Anbessa. 1991. A Sketch of Shabo Grammar. In Bender (ed), 371-387.

Thomas, Elaine. 1978. A Grammatical Description of the Engenni Language. Arlington, Tex.: Summer Institute of Linguistics.

Thompson, E. David. 1976a. Nera. In Bender (ed.), 484-494.

Thompson, E. David. 1976b. The languages of Northern Eritrea. In Bender, (ed.), 597603.

Thompson, E. David. 1989. Kunama Verb Phrase. In Bender (ed.), 305-46.

Thwing, Rhonda and John R. Watters. 1987. Focus in Vute. Journal of African Languages and Linguistics 9: 95-121.

Thwing, Rhonda. 2006. Verb Extensions in Vute. SIL.

Timitimi, Albert Okponanabofa. 1973/1980 (1977). Izón. In Kropp-Dakubu, M. E. (ed.) volume 1, 300-309.

Timyan, Judith. 1975/1980. Baule. In Kropp-Dakubu, M. E. (ed.) volume 2.7 pp.

Torrend, J. 1891. A Comparative Grammar of the South African Bantu Languages. Comprising Those of Zanzibar, Mozambique, The Zambezi, Kafirland, Benguela, Angola, The Congo, The Ogowe, The Cameroons, The Lake Region, etc. London: Kegan, Paul, Trench, Trübner \& Co, Ltd. 
Tosco, Mauro. 1991. A Grammatical Sketch of Dahalo. Cushitic Language Studies 8. Hamburg: Helmut Buske Verlag.

Tosco, Mauro. 2000. Is there an Ethiopian language area? Anthropological Linguistics 42 (3): $329-65$.

Tosco, Mauro. 2010. Why contrast matters: Information structure in Gawwada. In Fiedler and Schwarz (eds.), 315-347.

Triulzi, Alessandro, A. A. Dafallah and M. Lionel Bender. 1976. Berta. In Bender (ed.), 513-532.

Tröbs, Holger. 2009. Sprachtypologie, TAM-Systeme und historische Syntaxe im Manding (West-Mande). Mande Languages and Linguistics 8. Köln: Rüdiger Köppe Verlag.

Tucker, Archibald N. 1967. Fringe Cushitic: An Experiment in Typological Comparison. Bulletin of the School of Oriental and African Studies 30 (3): 655-80.

Tucker, Archibald N. 1994. A Grammar of Kenya Luo Dholuo. Chet A. Creider (ed.). Nilo-Saharan Linguistic Analyses and Documentation 8 Köln: Rüdiger Köppe Verlag.

Tucker, Archibald N. and M. A. Bryan 1966. Linguistic Analyses: The Non-Bantu Languages of North-Eastern Africa. London: Oxford University Press.

Tucker, Archibald N., with P. E. Hackett 1959. Le Groupe linguistique Zande. Annales du Musée Royale du Congo Belge 8.22. Tervuren: Musée Royale du Congo Belge.

Tucker, Archibald N. and J. Tompo ole Mpaayei. 1955. A Maasai Grammar. London: Longmans Green.

Turton, D. J. and M. Lionel Bender 1976. Mursi. In Bender (ed.), 533-61.

Unseth, Peter. 1989 Sketch of Majang Syntax. In Bender (ed.), 97-128.

Unseth, Peter. 1991. Reduplication in Majang. In Rottland and Omondi (eds.), 239-62. 
Uzar, Henning. 1989. Studies in Gumuz: Sese phonology and TMA system. In Bender (ed.), 347-83.

Valente, Jose Francisco. 1964. Gramática umbundu. Lisbon: Junta de Investigações do Ultamar.

van de Kamenade, Martin. 1954. Essai de grammaire et vocabulaire de la langue Sandawe. Micro-Bibliotheca Anthropos 9: 1-118.

Van de Velde, Mark L. O. 2008. Grammar of Eton. Mouton Grammar Library 46. Berline: Mouton de Gruyter.

van Valin, Robert, and Randy La Polla 2000. Syntax. Cambridge: Cambridge University Press.

Vandame, Charles. 1963. Le Ngambay-Moundou. Phonologie, grammaire et textes. (Mémoires de l'Institut Français d'Afrique Noire 69). Dakar: IFAN.

Vanhove, Martine. 2004. 'Dire' et finalité en bedja: Un cas de grammaticalisation. Journal of African Languages and Linguistics 25: 149-169.

Vanhove, Martine 2007. The independent personal pronouns in Beja: synchronic functions and diachronic perspective. In Amha et al. (eds.), 231-243.

Vincent, Nigel. 1982. The development of the auxiliaries habere and esse in Romance. In Vincent, Nigel and Martin Harris (eds.) Studies in the Romance Verb, 71-96. London: Croom Helm.

Voeltz, F. K. Erhard. 1980. The etymology of the Bantu perfect. In Bouquiaux, Luc (ed.) L'expansion bantoue, Viviers France, 4-16 avril 1977, vol. ii, 487-92. Paris: Société d'Études Linguistiques et Anthropologiques de France.

Voeltz, F. K. Erhard (ed.). 2005. Studies in African linguistic typology. Typological Studies in Language 64. Amsterdam: John Benjamins.

Voigt, Rainer. 1985. Die beiden Präfixkonjugation des Ostkuschitischen. Afrika und Übersee 68: 87-104. 
Voigt, Rainer. 1987. The two prefix conjugations in East Cushitic, East Semitic and Chadic. Bulletin of the School of Oriental and African Studies 50: 330-345.

Vorbichler, Anton. 1971. Die Sprache der Maтvu. Africanistische Forschungen 5. Glückstadt: Augustin.

Vossen, Rainer. 1997. Die Khoe-Sprachen. Ein Beitrag zur Erforschung der Sprachgeschichte Afrikas. Köln: Rüdiger Köppe.

Vydrin, Valentin F. 2006. Lichnye mestoimenija v juzhnykh jazykakh mande [Personal pronouns in South Mande languages]. Trudy instituta lingvisticheskh issledovanij. Tom 2, chast' 2, 327-413. Sankt-Petersburg: Nauka.

Vydrine, Valentin F. 2009. Negation in Southern Mande. In Cyffer et al (eds.) 223-260.

Wagner, Donna. 1985. Objects in Gokana. Studies in African Linguistics supplement 9: 304-8.

Wald, Benji. 1997. The $\varnothing$ tense marker in the decline of the Swahili auxiliary focus system. Afrikanistische Arbeitspapiere 51: 55-82.

Watters, John R. 1981. A phonology and morphology of Ejagham, with a note on dialect variation. Los Angeles: University of California, Los Angeles, Ph. D. dissertation.

Watters, John R. 1989. Bantoid Overview. In Bendor-Samuel, John (ed.) The Niger Congo Languages, 401-420. Arlington, Texas: SIL.

Watters, John R. 2000. Syntax. In Heine, Bernd and Derek Nurse (eds.) African Languages: An Introduction, 194-230. Cambridge: Cambridge University Press.

Watters, John R. and Jacqueline Leroy. 1989. Southern Bantoid. In Bendor-Samuel, John (ed.) The Niger Congo Languages, 431-449. Arlington, Texas: SIL.

Welmers, William E. 1973. African Language Structures. Berkeley: University of California Press.

Werner, Heinrich K. 1997. Das Jugische (Sym-Ketische). Wiesbaden: Harrassowitz. 
Werner, Roland. 1993. Tìdn-Áal: A Study of Midob (Darfur-Nubian). Berlin: Dietrich Reimer Verlag.

Westermann, Dietrich 1907. Grammatik der Ewe-Sprache. Berlin: Dietrich Reimer Verlag.

Westermann, Dietrich 1911. Die Sudansprachen: eine sprachvergleichende Studie. Abhandlungen des Hamburgischen Kolonialinstituts 3. Hamburg: L. Friedrichsen.

Westermann, Dietrich and Margaret A. Bryan. 1952. Languages of West Africa. Handbook of African Languages Part II. London/New York/Toronto: Oxford University Press for International African Institute.

Whiteley, W. H. 1966. A Study of Yao Sentences. Oxford: Clarendon Press.

Wiering Elisabeth. and Martinus Wiering 1994. The Doyayo Language. Selected Studies. Arlington, Texas: SIL.

Wilkendorf, Patricia 2001. Sketch Grammar of Nomaándé: Sections 1-4. SIL.

Will, Hans-Georg. 1998. The Me'en verb system. In Dimmendaal and Last (eds.), 437458.

Williamson, Kay. 1965. A Grammar of the Kolokuma Dialect of Ijo. Cambridge: Cambridge University Press. In association with The West African Languages Survey and the Institute of African Studies, Ibadan.

Williamson, Kay. 1991. The tense system of Izon. In Essien (ed.), 145-167.

Woldemariam, Hirut. 2009. Haro. In Dimmendaal (ed.), 97-122.

Wolff, H. Ekkehard and Ousseina Alidou 2001. On the non-linear ancestry of Tawassaq (Niger). Sprache und Geschichte in Afrika 16/17: 523-574. 
Wolff, H. Ekkehard \& Hilke Meyer-Bahlburg 1979. Morphologie und Semantik der erweiteren Verbalstämme in der Sprache der Afuzare (Zarek). Afrika und Übersee 62: $1-32$.

Yigezu, Moges and Gerrit J. Dimmendaal 1998. Notes on Baale. In Dimmendaal and Last (eds.), 273-317.

Zaborski, Andrzej. 1975. The Verb in Cushitic. Studies in Hamito-Semitic I. Cracow: Nakładem Uniwersytetu Jagiellońskiego.

Ziervogel, D. 1952. A Grammar of Swazi. Johannesburg: Witwatersrand University.

Ziervogel, D. 1959. A Grammar of Northern Transvaal Ndebele. Pretoria; Van Schaik.

Ziervogel D. and R. S. Dau. 1961. Handbook of the Venda Language. Pretoria: University of South Africa.

Ziervogel D. and E. J. Mabuza. 1976. A Grammar of the Swati Language (Siswati). Pretoria: J. L. van Schaik Ltd.

Zimmermann, Wolfgang, and Paavo Hasheela. 1998. Oshikwanyama Grammar. Windhoek: Gamsberg Macmillan.

Zwicky, Arnold. 1985. Heads. Journal of Linguistics 21: 1-30.

Zwicky, Arnold. 1990. What are we talking about when we talk about serial verbs?. In Joseph, Brian and Arnold Zwicky (eds.) When Verbs Collide, 1-13. Columbus, Ohio: Ohio State University Press.

Zwicky, Arnold. 1993. Heads, bases, and functors. In Corbett, Greville, Norman M. Fraser, and Scott McGlashan (eds.) Heads in Grammatical Theory, 292-315. Cambridge: Cambridge University Press.

Zylharz, E. 1926. Das Verbum in Kondjara. Anthropos 21: 244-263. revised p. 550. 


\section{Appendices}

Appendix-1a: List of languages with sources consulted

\section{Language}

!Ora

!Xõo Lone Tree

!Xun

//Ani

$\neq$ Hoan

‡Ungkue

|Xam

Aari

Acholi

Adamawa Fulani

Ader Hausa

Afar

Afuzare, see Izere

Aghem

Aiki [Runga]

Aka

Akan

Akoose

Akwa

Alaaba

Alagwa

Amharic

Amo

Anexo-Ewe

Angas

Anyi

Anywa

(A)Teso

Avatime

Awak

Ayu

\section{Sources}

Vossen 1997

Güldemann 2005/2010a, Dickens/Traill 1977, Collins 1998

König \& Heine 2001, König 2009a

Heine 1986, 1999, Güldemann \& Vossen 2000

Gruber 1978, Collins 1998, Collins 2001, 2002

Güldemann 2005

Bleek 1928-30

Hayward 1990

Bavin 1983, Heine \& Reh 1984, Heine 1993

Stennes 1967

Caron 1989

Bliese 1976, Cohen et al. 2002

Hyman 1985, 2010

Nougayrol 1989

Bender 1993

Osam 2004, Bodomo 1998

Hedinger 1985, 2008

Aksenova 1997

Schneider-Blum 2007, 2009

Kießling 2007

Leyew 2003

Di Luzio 1972

Heine \& Reh 1984

Burquest 1973/1980

Pyne 1972/1980

Reh 1996

Hilders \& Lawrance 1956, Heine \& Reh 1984

Westermann and Bryan 1952

Jungraithmayr 1968/1969

Gerhardt 2008 


\begin{tabular}{ll} 
Baale & Yigezu \& Dimmendaal 1998 \\
Babungo & Schaub 1985 \\
Bafia & Aroga Bessong \& Mel'chuk 1983 \\
Bagirmi & Tucker \& Bryan 1966, Stevenson 1969 \\
Baka & Killian-Hatz 1995 \\
Baka & Tucker \& Bryan 1966 \\
Balondo & Kuperus 1982 \\
Bambara & Tröbs 2009, Koné 1984, Kastenholz 1998, Idiatov 2000 \\
Bamileke see Yemba & \\
(Dschang) & \\
Banda Nchumuru & Cleal 1973d/1980; Price 1975/1980 \\
Baygi Me & Blench 2007; Hantgan 2008-ms \\
Banka (Samogo) & Kastenholz 2003 \\
Barambu & Tucker \& Bryan 1966 \\
Bari & Spagnolo 1933, Tucker \& Bryan 1966, Heine \& Reh 1984 \\
Basaa & Nurse 2008 \\
Bassa & Marchese 1986 \\
Baule & Kouadio N'Guessan 2000, Timyan 1975/1980 \\
Beja & Hudson 1976b, Vanhove 2004, 2007, Tucker \& Bryan 1966 \\
Bejamso-Grubi NchumuruCleal 1973d/1980; Price 1975/1980 \\
Bekwarra & Stanford 1973/1980 \\
Bemba & Nurse 2008 \\
'Berber' & Mettouchi 2009, McClelland 2000 \\
Berom/Birom & Bouquiaux 1970; Blench 2006c \\
Berta & Tiulzi et al. 1976, Cerulli 1947 \\
Bété & Marchese 1986 \\
Beya Lega & Botne 2003a \\
Bijogo & Segerer 2002 \\
Bilin & Böhm 1993 \\
Bobo-Fing & Heine \& Reh 1984 \\
Boko/Busa & Jones 1998 \\
Bokobaru & Jones 1998 \\
Bolanci & Lukas 1970, 1971 \\
Bongo & Santandrea 1963, Tucker \& Bryan 1966 \\
Borobo & Claudi 1988 \\
'Bozom & \\
Buamu & \\
& Manessy 1960, 1983 \\
\hline &
\end{tabular}


Buduma

Buem/Lelemi

Buga-/Anda

Bukusu

Bulu

Bungu

Burak

Burji

Burrum (Boghom)

Bushoong

6omo Ijo

C. B. K

C. B. L

Cara

Chaha Gurage

Chichewa

Chip

Ciyao

Coptic $^{\dagger}$

Daba

Dabarro Somali

Dadiya

Daffo Ron

Dagaare

Dahalo

Dangme

Dan Blowo

Dan-Gweeta

Dar Daju Daju

Dasenech

Datooga

Defaka

Degema

Dera-Kanakuru

Dewoin
Lukas 1939, Pawlak 2001

Allan 1973/1980

Vossen 1997

Aksenova 1997, Nurse 2008

Alexandre 1966

Nurse 2008

Jungraithmayr 1968/1969

Hudson 1976a

Jungraithmayr 1965

Nurse 2008

Williamson 1991

de Rop 1963

de Rop 1963

Vossen 1997

Ford 1991

Bentley and Kulemeka 2001

Jungraithmayr 1965

Whiteley 1966, Botne 1986

Cohen et al. 2002

Lienhard 1980

Heine \& Reh 1984

Jungraithmayr 1968/1969

Schuh 1976

Bodomo 1997, 1998

Tosco 1991

Kropp-Dakubu 1988

Vydrine 2009, Ėrman 2002

Vydrine 2009, Cherndytseva 2002

Aviles 2008

Sasse 1976

Kießling et al. 2008

Jenewari 1983

Kari 1997

Zaborskiij 1975

Marchese 1982, Marchese 1986 
Dho-Alur

Dholuo

Didinga

Dilling

Dime (Dim-Af)

Dinik (Afitti)

Dinka

Diola

Diola-Fogny

Dizi (Maji)

'Dogon'

Dogó sò

Dongolese

Donno So

Dott/Zodi

Doyayo

Duala

Duka

Duma

Dyola

Dzalamo

'Dongo

Ebang/Heiban

Ebira/Igbirra

Echie

Edo

Ega

Eggon

Egyptian Arabic

Egyptian $^{\dagger}$

Ejagham

EkeGusii

Ekpeye

Eleme

Eloyi

Emai

Engenni
Knappert 1963

Okombo 1991

Bryan 1955, Tucker \& Bryan 1966, Driberg 1931

Tucker \& Bryan 1966

Fleming 1990, Seyoum 2007

Stevenson et al. 1992

Nebel 1948, Hieda 1991

Sapir 1973/1980

Heine 1993

Allen 1976b

Plungian 1995

Calame-Griaule 1974/1980

Armbruster 1960, Cohen et al. 2002

Prost 1969(a)

Caron 2002

Wiering \& Wiering 1994

Ittmann 1939; Heine \& Reh 1984

Bendor-Samuel et al. 1973

Nurse 2008

Givón 1973, Marchese 1986

Meinhof 1948

Tucker \& Bryan 1966

Schadeberg \& Kossmann 2010

Scholz 1973/1980

Ndimele 2003

Agheyisi 1991, 1987

Bole-Richard nd, Bole-Richard 1983

Sibomana 1985

Jelinek 1983

Oréal 2008, Kammerzell \& Peust 2002

Watters 1981, Watters 2000

Aksenova 1997, Nurse 2008

Clark nd/1980

Bond 2006, 2010; field notes; Bond \& Anderson 2003, 2005

Mackay 1968/1980

Schaefer \& Egbokhare 2007, 2008

Thomas 1978, Lord 1993 
Eton

van de Velde 2008

Eunda

Baucom 1972

Evale

Baucom 1972

Schadeberg 1985, Allen 1993, Pasch 1995, Ameka 2006a, Ameka

Ewe 2006b,Westermann 1907, 1911, Heine \& Reh 1984

Ewondo

Fadicca (Nobiin)

Aksenova 1997, Nurse 2008, Güldemann 2007, Redden 1979

Fali

Tucker \& Bryan 1966

Fer

Ennulat 1973/1980

Fongbe

Boyeldieu 1987

Frafra

Fula

Manfredi 2005-ms

Schaefer \& Asakiyah 1975/1980

Fur

Arnott 1968/1980

Fyem

Tucker \& Bryan 1966, Jakobi 1989, Dimmendaal 2010

$\mathrm{Ga}$

Gaam

Gade

Nettle 1998a, 1998b

Kropp-Dakubu 1988

Bender 1989

Gawwada Dullay

Sterk 1994

Gbaeson Krahn

Tosco 2010

Gbaya 'Buli

Marchese 1986

Gbaya Kaka

Moñino 1995

Tucker \& Bryan 1966

Gehode

Cleal 1973a

Genyanga

Cleal 1973b

Gerka (Yiwom)

Jungraithmayr 1965

Ghulfan

Dimmendaal 2010

Gidar

Gidole

Frajzyngier 2008

Gik[u]yu

Zaborskij 1975

Gimira (Benchnon)

Nurse 2008

Giryama

Breeze 1990

Nurse 2008

Godie

Marchese and Gratrix 1974/1980, Marchese 1986

Goemai

Hellwig 2006

Gogo

Nurse 2008

Gokana

Wagner 1985, Roberts 1985, Dryer 2009

Gonga (Kefa/Kafa)

Fleming 1976 
Grebo

Gula Méré

Gula Sara

Gula Zura

Gumuz

Gùrdùn

Guro

Guus/Sigidi

Gwama

Gworok/Kagoro

Haddiya

Hadza

Hamer

Harar Oromo

Haro

Hausa

Haya

Hdi

Heiban

Hemba

Herero

Holoholo

Hune

Hung'an

Hungu

Ibibio

Idũ

Igbo

Ik

Ila

Inor

Iraqw

Izere

Izi

Jalonke

Jamsay

Jibo
Marchese 1986

Nougayrol 1999

Nougayrol 1999

Nougayrol 1999

Bender 1979, Ahland 2010

Haruna 2003

Vydrine 2009

Caron 2001

Leyew no date

Adwiraah 1989

Hudson 1976a

Sands to appear-a, Sands to appear-b

Lydall 1976

Owens 1985

Woldemariam 2009

Newman 2000, Heine \& Reh 1984, Schachter 1985

Salone 1979, Nurse 2008

Frajzyngier \& Shay 2002

Stevenson 2009, Schadeberg 1981a

Aksenova 1997, Nurse 2008

Meinhof 1948

Nurse 2008

Storch 2009a, Storch 1999a 1999b

Nurse 2008

Nurse 2008

Essien 1987, 1991

Blench 2010

Ndimele 2009, Green \& Igwe 1963, Emenanjo 1991, 1985

Heine 1976a, 1976b, König 2002, König 2009b

Nurse 2008

Suter 2007

Mous 1993

Lukas \& Willms 1961, Wolff \& Meyer-Bahlburg 1979, Gerhardt 1984

Bendor-Samuel 1968

Lüpke 2009

Heath 2008

Storch 1999a, 1999b 
Jiddu Somali

$\mathrm{Jo}$ [wulu]

Ju/'hoan

Kabba

Kafima

Kaguru

Kahugu

Kako

Kalabari Ijo

Kamba

Kambaata

Kana

Kanuri

Kara

Karang

Karekare

Karimojong

Katcha

Katla

Kelo

Kemantney

KenyanPidgin Swahili

Kenyang

Kerewe

Khoe/Khwe/Kxoe

Kikongo

Kilba

(Ki)Matumbi

Kimbu

Kinyarwanda

Kirma

Kirundi

Kisi

Kituba
Heine \& Reh 1984

Kim 2002?

Dickens 2005, Güldemann and Vossen 2000, Collins 2001

Moser 2005

Baucom 1972

Torrend 1891

Westermann and Bryan 1952

Ernst 1995

Jenewari 1983

Nurse 2008

Hudson 1976a

Ikoro 1996

Cyffer 1978, Hutchison 1981, Jarrett 1981

Santandrea 1970

Ngang David 1999

Lukas 1970-71, Schuh 1976

Novelli 1985, Dryer 2009

Tucker \& Bryan 1966, Stevenson 1957a, 1957b, 1957c

Tucker \& Bryan 1966; Dryer 2009

Bender 1993

Leyew 2003

Heine and Reh 1984

Mbuagbaw 2008

Kießling et al. 2008

Köhler 1962, 1981, Vossen 1997, Heine \& Reh 1984, Killian-Hatz 2006, 2008, 2009

Heine \& Reh 1984, Nurse 2008

Grieve 1973/1980

Nurse 2008, Odden 1996

Nurse 2003

Kimenyi 1979, Kimenyi 1980, Hurel 1911, Botne 1986, Aksenova 1997, Nurse 2008, Cadiou 1985

Prost 1964; Heine \& Reh 1984

Botne 1986

Childs 1995

Heine \& Reh 1984 
Klao

Koegu

Kohumono

Kolokuma Ijo/Izon

Kolonkadhi

Kom

Koma

Konde

Kondjara Fur

Konkomba

Koyo

Koyra Chiini

Kpelle

Krachi

Krahn

Kresh

Krongo

Kua

Kulango

Kunama

Kuri(y)a

Kuteb

Kuwaa

Kwama

Kwambi

Kwami

Laadi

Laal

Lafofa

Lamba

Langi

Lango

Later Egyptian ${ }^{\dagger}$

Lele

Lese

Likpe

Limbum
Marchese 1982, Marchese 1986

Hieda 1998, 1992

Cook 1972/1980

Williamson 1965, Timitimi 1973/1980, Williamson 1991

Baucom 1972

Schultz 1997

Tucker \& Bryan 1966, Dryer 2009

Meinhof 1948

Zylharz 1926

Adouna 2009

Marchese 1982, Marchese 1986

Heath 1999

Welmers 1973, Heine \& Reh 1984

Cleal 1973c

Marchese 1986

Tucker \& Bryan 1966, Brown 1991

Reh 1985

Heine 1986

Elders 2007

Tucker \& Bryan 1966, Thompson 1976b, Bender 1996

Aksenova 1997

Koops and Bendor-Samuel 1974, Storch 2009b

Marchese 1986

Leyew no date

Baucom 1972

Leger 1994

Aksenova 1997

Boyeldieu 1982

Tucker \& Bryan 1966

Doke 1938, Botne 1986

Nurse 2008

Bavin 1983, Heine \& Reh 1984, Noonan 1992

Cohen et al. 2002

Frajzyngier 2001

Tucker \& Bryan 1966

Allan 1974/1980, Ameka 2005, 2009

Fiore and Peck 1973/1980 
Linda

Lingala

Lobedu

Lokaa

Lorhon

Lotuko

Lua/Niellim

Luba

Lucazi

Luganda

Lugbara

Luguru

Lunda

Lungu

Luvale

Lyaa

Ma

Maale

Maasai

Maba

Mabiha

Mada

Ma'di

Majang

Makonde

Makua-Maverone

Malgwa

Mambila

Mamvu

Manding

Mangbetu

Maninka

Mankon

Mano

Masakin (Ngile)

Masalit
Claorec-Heiss 1986, Watters 2000

Mufwene 1978, Heine 1991, Brisard and Meeuwis 2009

Kotzé 2004

Iwara 1991

Person 1973/1980

Muratori 1938, Heine \& Reh 1984

Boyeldieu 1985

Nurse 2008

Fleisch 2000, Nurse 2008

Botne 1986, Aksenova 1997

Tucker \& Bryan 1966, Crazzolara 1960

Nurse 1979b, Botne 1990

Kawasha 2006

Nurse 2008

Horton 1949

Aksenova 1997, Nurse 2008

Tucker \& Bryan 1966, Dryer 2009

Amha 2001

Tucker \& Mpaayei 1955, Dimmendaal 1983, Hamaya 1993

Dimmendaal 2010, Lukas 1933, 1952

Harries 1940, Botne 1999

Blench 2006a, 2006b

Tucker \& Bryan 1966, Blackings \& Fabb 2003

Unseth 1989, 1991

Meinhof 1948

Kröger 2010

Löhr 2002, Dryer 2009

Perrin 1973/1980, Heine \& Reh 1984

Tucker \& Bryan 1966, Vorbichler 1971, Heine \& Reh 1984

Tröbs 2009, Dumestre 2003, Kastenholz 1998

Larochette 1958, Tucker \& Bryan 1966

Heine \& Reh 1984

Leroy 2007

Vydrine 2009

Tucker \& Bryan 1966

Edgar 1989 


\begin{tabular}{ll} 
Mayogo & Tucker \& Bryan 1966 \\
Mba & Tucker \& Bryan 1966 \\
Mbalanhu & Fourie 1993 \\
Mbandja & Baucom 1972 \\
Mbay & Keegan 1997 \\
Mbe & Pohlig 1981 \\
Mbembe & Barnwell nd/1980 \\
Mbodomo & Boyd 1997, Boyd 2003 \\
Mbugwe & Mous 2004 \\
Mbuko & Gravina 2001 \\
Mbum & Hagège 1970 \\
Me'en & Will 1998 \\
Meeka & Beyer 2009, Kastenholz 2002 \\
Meje & Larochette 1958, Mckee 1991 \\
Mende & Migeod 1908, Innes 1969, Heine \& Reh 1984 \\
Merey & Gravina 2007 \\
Midob & Werner 1993 \\
Mínà & Houngues \& Hutchison 1999 \\
Minagbe & Manfredi 2005-ms \\
Mödö & Persson and Persson 1991 \\
Mofu-Gudur & Pohlig 1992 \\
Molo & Bender 1993 \\
Moloko & Friesen and Mamalis 2004 \\
Montol & Jungraithmayr 1965 \\
Moro & Black \& Black 1971; Dryer 2009 \\
Morokodo & Tucker \& Bryan 1966 \\
Moru & Tucker \& Bryan 1966 \\
Mpoto & Nurse 2008 \\
Mubi & Jungraithmayr 1987 \\
Mudung Somali & Heine \& Reh 1984 \\
Muher & Meyer 2007 \\
Mundabli & Good and Lovegren 2009 \\
Mundu & Tucker \& Bryan 1966 \\
Murle & Tucker \& Bryan 1966, Lyth 1971, Arensen 1979, 1982 \\
Mursi & Turton \& Bender 1976 \\
Musgu & \\
Muyang & Meyer-Bahlburg 1972 \\
\hline & \\
\hline
\end{tabular}


Mwera

$\mathrm{N}$ Tonga

N. Sotho

$\mathrm{N} \mid \mathrm{uu}$

Nafaara

Nama

Nande

Nandi

Naro

Nawuri

Ndamba

Ndebele

Ndemli

Ndendeule

Ndogo

Ndut-Falor

Nera

Neyo

Ngambay-Moundou

Ngandjera

Ngbandi

Ngiti

Ngizim

Nkonya

Nkore-Kiga

Nomaande

Non

Noni

North Ibie

Ntandu

Nupe

Nyakyusa

Nyimang

Nymawezi

Nyo
Nurse 2008

Torrend 1891, Lombard 1978

Lombard 1978, Lepota 2002, Kotzé 2004, Pretorius 2006, Nurse 2008

Collins 2004, Güldemann 2010

Jordan and Jordan 1975/1980

Vossen 1997

Nurse 2008

Creider 1989, Creider \& Tapsubei Creider 1989

Heine 1986

Casali 1995

Nurse 2008

Ziervogel 1959, Moosally 1998

Ngoran 1999

Güldemann 2003

Santandrea 1961

Pichl 1973a/1980

Thompson 1976a

Marchese 1982, Marchese 1986

Vandame 1963, Heine \& Reh 1984

Baucom 1972

Tucker \& Bryan 1966

Kutsch Lojenga 1994

Schuh 1976

Reineke 1972

Taylor 1985

Wilkendorff 2001

Pichl 1973b/1980

Hyman 1981

Schaefer and Masagbor 1984

Aksenova 1997

Smith 1967/1980

Aksenova 1997

Stevenson et al. 1992, Tucker \& Bryan 1966, Stevenson 1957a, 1957b, $1957 \mathrm{c}$

Nurse 2008

Marchese 1986 
Obolo (Andoni) Aaron 1999, Rowland-Oke 2003

Ogbronuagom (Bukuma) Kari 2000

Òkó /Ogori

Okpamberi

Akerejola 2008, HH Ologori of Ogori/Elugbe nd/1980a

-heri

Old Nubian ${ }^{\dagger}$

HH Ologori of Ogori/Elugbe nd/1980b

Ongota

Onicha Igbo

Browne 2002

Orig

Fleming et al. 1992-93, Fleming 2006, Savà \& Tosco 2000, 2003

Ndimele 2009

Oromo of Wellega

Schadeberg \& Elias 1979

Oshikwanyama

Gragg 1976

Zimmermann \& Hesheela 1998

Otoro

Stevenson 2009, Stevenson 1957a, 1957b, 1957c

Pajade (Badiaranke)

Ducos 1974/1980

Pambia

Tucker \& Bryan 1966

Pare

Nurse 1979a, Botne 1990

Pero

Frajzyngier 1989

Pimbwe

Nurse 2008

Pokomo

Nurse 2008

Polci

Caron 2008

pre-Swahili

Heine \& Reh 1984

Proto-Kru

Marchese 1986

Punu

Hadermann 1996

Rashad

Tucker \& Bryan 1966

(I)Rigwe

Blench and Gya Daniel 2009

Ruri

Nurse 2008

S Tonga

Lombard 1978

S'aamakko Dullay

Hayward 1989, Savà 2005

Sai Gumuz

Bender 1979

Samba Leko

Fabre 2003, 2009

Eaton 2010a, 2010b, Eaton 2003, Kießling 2002, Elderkin 1986, van de

Sandawe

Kamenade 1954, Dempwolff 1916

Sango

Samarin 1967, Heine \& Reh 1984

Sapo

Marchese 1986

Sara

Tucker \& Bryan 1966

Sayanci

Schneeberg 1971

Sele

Allen 1973/1980

Sena

Nurse 2008 
Sese Gumuz

Sesotho

Setswana

Shabo

Shambaa

Shambala

Shatt

Shona

Sidamo

Sil'te

Siluyana

Siswati

Siwu

So

Somali

Songye

Sonjo

Strandberg |Xam

Sukuma(-Kiiya)

Sumbwa

Supyire

Swahili

Swazi (see Siswati)

Tagoi

Talodi

Tama

Tamashek

Tamazight

Tarok

Tasawaq

Tchien Krahn

Temein

Tennet

Tepo
Uzar 1989, Bender 1979

Guma 1971, Paroz 1946, Malete 2003

Sharpe 1980, Cole 1955, Setshedi 1974, Matseke 1968, Chaphole 1988,

Creissels 1998a, 1998b, 2000, 2002, 2003

Teferra 1991

Nurse 2008

Aksenova 1997, Mfwumba Beshe 1989

Tucker \& Bryan 1966

Fortune 1955, Dale 1972, Güldemann 2002, Nurse 2008, O’Neil 1935

Hudson 1976a, Gebre-Tsadik 1985

Meyer 2007, Gutt 1997

Givón 1971

Ziervogel and Mabuza 1976, Botne 1986, Kiyomi \& Davis 1992

Komra Iddah 1975/1980

Carlin 1993, Heine 1974/1975, Heine 1976b, Heine \& Reh 1984

Orwin 1995, Heine \& Reh 1984, Lamberti 1986

Nurse 2008, Stappers 1964

Nurse and Rottland 1994

Güldemann 2010a

Nurse 2008; Kiesling et al. 2008

Nurse 2008

Carlson 1994

Givón 1971, Aksenova 1997, field notes

Ziervogel 1952

Tucker \& Bryan 1966

Tucker \& Bryan 1966, Schadeberg 1981b

Bryan 1955, Dimmendaal 2009a

Heath 2005b

Abdel-Massih 1968

Sibomana 1981

Wolff and Alidou 2001

Marchese 1986

Tucker \& Bryan 1966

Dimmendaal 1998, Randal 1998

Marchese 1986 
Tigrinya

Tikar

Tima

Tira

Tiv

Togbo

Tondi Songway Kiini

Tonga

Tsongo

Tsotso

Tubu (Tedaga)

Tumale

Tumbuka

Turkana

Twi

Tyurama

Uduk

Ukaan

Umbundu

ut-Ma'in

Vamé

Vata

Venda

Vute

W. !Xoon

Wannu

Wapan/Wukari

Wap ${ }_{\stackrel{\text { ha }}{\mathrm{a}}}$

Wobé

Wolaitta

Wolane

Wolof

Xhosa

Yakoma

Yambasa
Leslau 1968, Blansitt 1975, Heine \& Reh 1984

Stanley 1991

Dimmendaal 2009b

Stevenson 2009

Arnott 1958, 1967/1980

Tucker \& Bryan 1966

Heath 2005a

Torrend 1891, Nurse 2008

Nurse 2008

Hardemann 1996

Lukas 1953

Tucker \& Bryan 1966

Nurse 2008, Botne 1993

Dimmendaal 1983

Lord 1993, Christaller 1875/1881

Prost 1964; Heine \& Reh 1984

Tucker \& Bryan 1966

Sallfner 2009, 2010, Jungraithmayr 1973

Valente 1964; Heine \& Reh 1984, Schadeberg 1990

Smith 2007

Kinnaird 2006

Marchese 1986

Heine 1993, Nurse 2008, Ziervogel \& Dau 1961, Musehane 2007

Guarisma 1978, Thwing 2006 Güldemann 2007, Thwing \& Watters 1987

Güldemann 2010a

Storch 1999

Storch 1999, Storch 2009b

Storch 1999

Hofer and Link 1973/1980, Marchese 1986

Amha \& Dimmendaal 2006b, Amha 2009, Lamberti \& Sottile 1997

Meyer 2006

Pichl 1973/1980c, Comrie 1985

Torrend 1891, Meinhof 1948, Heine 1993, Bennie 1953

Boyeldieu 1995

Nurse 2008 
Yao ?=Ciyao?

Torrend 1891

Yasa

Bot 1998

Yemba (Dschang)

Harro and Haynes 1991

Yoruba

Obidale 1977, Lord 1993

Yulu

Santandrea 1970, Boyeldieu 1987

Zaghawa/Beria

Cyffer 1991, Jakobi and Crass 2004, Dimmendaal 2010

Zande

Boyd 1995, Tucker 1959, Heine \& Reh 1984, Tucker \& Bryan 1966

Zarek, see Izere

Zarma

Creissels et al. 2008, Oumarou Yaro 1993

Zay

Meyer 2005

Zing Mumuye

Shimizu 1983

Meinhof 1948, Slattery 1981, Beuchat 1966, Doke 1947, Mkatshwa

Zulu 1991, Louw 1963, Louw et al. 1967

Appendix-1b: List of languages by country

\section{Language}

!Ora

!Xõo Lone Tree

!Xun

//Ani

\#Hoan

¥Ungkue

|Xam

Aari

Acholi

Adamawa Fulani

Ader Hausa

Afar

Afuzare, see Izere

Aghem

Aiki [Runga]

Aka

Akan

\section{Country/Countries Primarily Spoken}

South Africa

[Botswana, Namibia]

Angola, Namibia, Botswana

South Africa, Botswana

Namibia, Botswana, Angola

South Africa

South Africa

Ethiopia

Uganda, South Sudan

Cameroon, Chad, Nigeria, Sudan

Nigeria

Eritrea, Ethiopia, Djibouti

Nigeria

Cameroon

Chad, Central African Republic

Sudan

Ghana 


\begin{tabular}{ll} 
Akoose & Cameroon \\
Akwa & Congo \\
Alaaba & Ethiopia \\
Alagwa & Tanzania \\
Amharic & Ethiopia \\
Amo & Nigeria \\
Anexo-Ewe & Ghana, (Togo) \\
Angas & Nigeria \\
Anyi & Ghana, Côte d'Ivoire \\
Anywa & Sudan, Ethiopia \\
(A)Teso & Uganda, Kenya \\
Avatime & Ghana \\
Awak & Nigeria \\
Ayu & Nigeria \\
Baale & Ethiopia \\
Babungo & Cameroon \\
Bafia & Cameroon \\
Bagirmi & Chad \\
Baka & Cameroon, Gabon \\
Baka & South Sudan, Democratic Republic of Congo \\
Balondo & Cameroon \\
Bambara & Mali, Burkina Faso, Gambia, Guinea, Mauritania, Senegal \\
Bamileke see Yemba & Nigeria \\
(Dschang) & Ghana \\
Banda Nchumuru & Mali \\
Bangi Me & Mali \\
Banka (Samogo) & Democratic Republic of Congo \\
Barambu & South Sudan, Uganda, Democratic Republic of Congo \\
Bari & Cameroon \\
Basaa & Liberia, Sierra Leone \\
Bassa & Corte d'Ivoire \\
Baule & Sudan, Eritrea \\
Beja & Ghana \\
Bejamso-Grubi Nchumuru Africa \\
Bekwarra & Nigeria \\
Bemba & 'Berber' \\
\hline
\end{tabular}


Berom/Birom

Berta

Bété

Beya Lega

Bijogo

Bilin

Bobo-Fing

Boko/Busa

Bokobaru

Bolanci

Bongo

Borobo

'Bozom

Buamu

Buduma

Buem/Lelemi

Buga-/Anda

Bukusu

Bulu

Bungu

Burak

Burji

Burrum (Boghom)

Bushoong

6oms Ijo

C. B. K

C. B. L

Cara

Chaha Gurage

Chichewa

Chip

Ciyao

Coptic $^{\dagger}$

Daba

Dabarro Somali
Nigeria

Ethiopia, Sudan

Cote d'Ivoire

Democratic Republic of Congo

Guinea-Bissau

Eritrea

Burkina Faso, Mali

Nigeria, Benin

Nigeria, Benin

Nigeria

South Sudan

Liberia, Cote d'Ivoire

Central African Republic

Burkina Faso, Mali

Chad, Cameroon, Nigeria

Ghana

Botswana, Angola

Kenya

Cameroon

Tanzania

Nigeria

Ethiopia, Kenya

Nigeria

Democratic Republic of Congo

Nigeria

Congo

Congo

Botswana

Ethiopia

Malawi, Mozambique

Nigeria

Tanzania, Malawi, Mozambique

Egypt

Cameroon, Nigeria

Somalia 
Dadiya

Daffo Ron

Dagaare

Dahalo

Dangme

Dan Blowo

Dan-Gweeta

Dar Daju Daju

Dasenech

Datooga

Defaka

Degema

Dera-Kanakuru

Dewoin

Dho-Alur

Dholuo

Didinga

Dilling

Dime (Dim-Af)

Dinik (Afitti)

Dinka

Diola

Diola-Fogny

Dizi (Maji)

'Dogon'

Dogó sò

Dongolese

Donno So

Dott/Zodi

Doyayo

Duala

Duka

Duma

Dyola

Dzalamo

'Dongo

Ebang/Heiban
Nigeria

Nigeria

Ghana, Burkina Faso

Kenya

Ghana

Côte d'Ivoire

Côte d'Ivoire, Liberia, Guinea

Chad

Kenya

Tanzania

Nigeria

Nigeria

Nigeria

Liberia

Uganda, Democratic Republic of Congo

Kenya

Sudan

South Sudan

Ethiopia

Sudan

South Sudan

Gambia, Guinea-Bissau

Gambia, Senegal

Ethiopia

Mali

Mali, Burkina Faso

Sudan, Egypt

Mali

Nigeria

Cameroon

Cameroon

Nigeria

Gabon

Senegal, Gambia

Tanzania

Democratic Republic of Congo

Sudan 
Ebira/Igbirra

Nigeria

Echie

Nigeria

Edo

Nigeria

Ega

Côte d'Ivoire

Eggon

Nigeria

Egyptian Arabic

Egypt

Egyptian $^{\dagger}$

Egypt

Ejagham

EkeGusii

Nigeria, Cameroon

Kenya

Ekpeye

Eleme

Eloyi

Emai

Engenni

Eton

Eunda

Evale

Ewe

Ewondo

Fadicca (Nobiin)

Fali

Fer

Nigeria

Nigeria

Nigeria

Nigeria

Nigeria

Cameroon

Namibia

Angola

Ghana, Togo

Cameroon

Sudan

Nigeria

Central African Republic

Fongbe

Benin, Togo

Frafra

Burkina Faso, Ghana

Fula

West/Central Africa

Fur

Sudan, Chad

Fyem

Ga

Gaam

Gade

Gawwada Dullay

Gbaeson Krahn

Gbaya 'Buli

Gbaya Kaka

Gehode

Nigeria

Ghana

Sudan, Ethiopia

Nigeria

Ethiopia

Liberia

Central African Republic

Cameroon, Central African Republic, Congo

Ghana 
Genyanga

Gerka (Yiwom)

Ghulfan

Gidar

Gidole

Gik[u]yu

Gimira (Benchnon)

Giryama

Godie

Goemai

Gogo

Gokana

Gonga (Kefa/Kafa)

Grebo

Gula Méré

Gula Sara

Gula Zura

Gumuz

Gùrdùn

Guro

Guus/Sigidi

Gwama

Gworok/Kagoro

Haddiya

Hadza

Hamer

Harar Oromo

Haro

Hausa

Haya

Hdi

Heiban

Hemba

Herero

Holoholo

Hõne

Hung'an
Ghana, Togo

Nigeria

Sudan

Cameroon, Chad

Ethiopia

Kenya

Ethiopia

Kenya

Côte d'Ivoire

Nigeria

Tanzania

Nigeria

Ethiopia

Liberia, Cote d'Ivoire

Central African Republic

Central African Republic

Central African Republic

Ethiopia, Sudan

Nigeria

Côte d'Ivoire

Nigeria

Ethiopia, Sudan

Nigeria

Ethiopia

Tanzania

Ethiopia

Ethiopia

Ethiopia

Nigeria, Niger

Tanzania

Nigeria, Cameroon

Sudan

Democratic Republic of Congo

Namibia

Democratic Republic of Congo

Nigeria

Democratic Republic of Congo 
Hungu

Ibibio

Idũ

Igbo

Ik

Ila

Inor

Iraqw

Izere

Izi

Jalonke

Jamsay

Jibə

Jiddu Somali

Jo[wulu]

Ju/'hoan

Kabba

Kafima

Kaguru

Kahugu

Kako

Kalabari Ijo

Kamba

Kambaata

Kana

Kanuri

Kara

Karang

Karekare

Karimojong

Katcha

Katla

Kelo

Kemantney

Kenyan Pidgin Swahili
Democratic Republic of Congo

Nigeria

Nigeria

Nigeria

Uganda

Zambia

Ethiopia

Tanzania

Nigeria

Nigeria

Guinea, Mali, Senegal, Sierra Leone

Mali

Nigeria

Somalia

Mali

Botswana, Namibia, Angola

Central African Republic, Chad

Angola

Tanzania

Nigeria

Cameroon

Nigeria

Kenya

Ethiopia

Nigeria

Nigeria, Niger, Chad, Cameroon, Sudan

Central African Republic, Sudan

Cameroon

Nigeria

Uganda

Sudan

Sudan

Sudan

Ethiopia

Kenya 


\begin{tabular}{|c|c|}
\hline Kenyang & Cameroon \\
\hline Kerewe & Tanzania \\
\hline Khoe/Khwe/Kxoe & Namibia, Botswana, Angola \\
\hline Kikongo & Congo, Democratic Republic of Congo, Angola \\
\hline Kilba & Nigeria \\
\hline (Ki)Matumbi & Tanzania \\
\hline Kimbu & Tanzania \\
\hline Kinyarwanda & Rwanda \\
\hline Kirma & Burkina Faso, Cote d'Ivoire \\
\hline Kirundi & Burundi \\
\hline Kisi & Sierra Leone, Liberia \\
\hline Kituba & Congo, Democratic Republic of Congo \\
\hline Klao & Liberia, Sierra Leone \\
\hline Koegu & Ethiopia \\
\hline Kohumono & Nigeria \\
\hline Kolokuma Ijo/Izon & Nigeria \\
\hline Kolonkadhi & Namibia \\
\hline Kom & Cameroon \\
\hline Koma & Sudan, Ethiopia \\
\hline Konde & Tanzania, Mozambique \\
\hline Kondjara Fur & Sudan \\
\hline Konkomba & Ghana, Togo \\
\hline Koyo & Cote d'Ivoire \\
\hline Koyra Chiini & Mali \\
\hline Kpelle & Liberia \\
\hline Krachi & Ghana \\
\hline Krahn & Liberia, Cote d'Ivoire \\
\hline Kresh & South Sudan \\
\hline Krongo & Sudan \\
\hline Kua & Botswana, Zimbabwe \\
\hline Kulango & Côte d'Ivoire, Ghana \\
\hline Kunama & Eritrea, Sudan \\
\hline Kuri(y)a & Tanzania, Kenya \\
\hline Kuteb & Nigeria, Cameroon \\
\hline Kuwaa & Liberia \\
\hline Kwama & Ethiopia \\
\hline Kwambi & Namibia \\
\hline
\end{tabular}


Kwami

Laadi

Laal

Lafofa

Lamba

Langi

Lango

Later Egyptian $^{\dagger}$

Lele

Lese

Likpe

Limbum

Linda

Lingala

Lobedu

Lokaa

Lorhon

Lotuko

Lua/Niellim

Luba

Lucazi

Luganda

Lugbara

Luguru

Lunda

Lungu

Luvale

Lyaa

$\mathrm{Ma}$

Maale

Maasai

Maba

Mabiha

Mada

Ma'di

Majang
Nigeria

Democratic Republic of Congo, Congo

Chad

Sudan

Zambia, Democratic Republic of Congo

Tanzania

Uganda, South Sudan

Egypt

Chad

Democratic Republic of Congo

Ghana

Cameroon, Nigeria

Central African Republic

Democratic Republic of Congo, Congo

South Africa

Nigeria

Cote d'Ivoire, Burkina Faso

South Sudan

Chad

Democratic Republic of Congo

Angola, Zambia

Uganda, Tanzania

Uganda, Democratic Republic of Congo

Tanzania

Zambia, Angola, Democratic Republic of Congo

Tanzania

Angola, Zambia

?Congo, Gabon?

Democratic Republic of Congo

Ethiopia

Kenya, Tanzania

Chad

Mozambique, Tanzania

Nigeria

Uganda, South Sudan

Ethiopia 
Makonde

Makua-Maverone

Malgwa

Mambila

Mamvu

Manding

Mangbetu

Maninka

Mankon

Mano

Masakin (Ngile)

Masalit

Mayogo

Mba

Mbalanhu

Mbandja

Mbay

Mbe

Mbembe

Mbodomo

Mbugwe

Mbuko

Mbum

Me'en

Meeka

Meje

Mende

Merey

Midob

Mínà

Minagbe

Mödö

Mofu-Gudur

Molo

Moloko

Montol

Moro
Mozambique

Mozambique

Cameroon

Cameroon, Nigeria,

Democratic Republic of Congo (+Uganda?)

Senegal, Gambia, Guinea-Bissau

Democratic Republic of Congo

Guinea, Mali, Sierra Leone

Cameroon

Liberia, Guinea

Sudan

Sudan, Chad

Democratic Republic of Congo

Democratic Republic of Congo

Namibia

Angola, Namibia

Chad

Nigeria

Nigeria

Cameroon

Tanzania

Cameroon

Cameroon, Central African Republic

Ethiopia

Burkina Faso

Democratic Republic of Congo, Uganda

Sierra Leone, Liberia

Cameroon

Sudan

Cameroon

Benin, Togo

South Sudan

Cameroon

Sudan

Cameroon

Nigeria

Sudan 
Morokodo

Moru

Mpoto

Mubi

Mudung Somali

Muher

Mundabli

Mundu

Murle

Mursi

Musgu

Muyang

Mwera

N Tonga

N. Sotho

$\mathrm{N} \mid \mathrm{uu}$

Nafaara

Nama

Nande

Nandi

Naro

Nawuri

Ndamba

Ndebele

Ndemli

Ndendeule

Ndogo

Ndut-Falor

Nera

Neyo

Ngambay-Moundou

Ngandjera

Ngbandi

Ngiti

Ngizim
South Sudan

South Sudan

Tanzania

Chad, Sudan?

Somalia

Ethiopia

Cameroon

South Sudan

South Sudan, Ethiopia

South Sudan, Ethiopia

Cameroon, Chad

Cameroon

Tanzania

Zambia, Malawi

South Africa

South Africa

Ghana, Côte d'Ivoire

Namibia, S. Africa, Botswana

Democratic Republic of Congo

Kenya

Botswana

Ghana

Tanzania

Zimbabwe/South Africa

Cameroon

Tanzania

South Sudan

Senegal

Eritrea

Cote d'Ivoire

Chad

Namibia, Angola

Democratic Republic of Congo, Central African Republic

Democratic Republic of Congo

Nigeria 
Nkonya

Nkore-Kiga

Nomaande

Non

Noni

North Ibie

Ntandu

Nupe

Nyakyusa

Nyimang

Nymawezi

Nyo

Obolo (Andoni)

Ogbronuagom (Bukuma)

Òkó /Ogori

Okpamberi

-heri

Old Nubian ${ }^{\dagger}$

Ongota

Onicha Igbo

Orig

Oromo of Wellega

Oshikwanyama

Otoro

Pajade (Badiaranke)

Pambia

Pare

Pero

Pimbwe

Pokomo

Polci

pre-Swahili

Proto-Kru

Punu

Rashad

(I)Rigwe

Ruri
Ghana

Uganda

Cameroon

Senegal

Cameroon

Nigeria

Democratic Republic of Congo

Nigeria

Tanzania, Malawi

Sudan

Tanzania

Cote d'Ivoire

Nigeria

Nigeria

Nigeria

Nigeria

Ancient Nubia ${ }^{\dagger}$

Ethiopia

Nigeria

Sudan

Ethiopia

Namibia, Angola

Sudan

Guinea, Guinea-Bissau, Senegal

Democratic Republic of Congo

Tanzania

Nigeria

Tanzania

Kenya

Nigeria

N/A

N/A

Congo

Sudan

Nigeria

Tanzania 
S Tonga

S'aamakko Dullay

Sai Gumuz

Samba Leko

Sandawe

Sango

Sapo

Sara

Sayanci

Sele

Sena

Sese Gumuz

Sesotho

Setswana

Shabo

Shambaa

Shambala

Shatt

Shona

Sidamo

Sil'te

Siluyana

Siswati

Siwu

So

Somali

Songye

Sonjo

Strandberg |Xam

Sukuma(-Kiiya)

Sumbwa

Supyire

Swahili

Swazi (see also Siswati)

Tagoi
Zambia

Ethiopia

Ethiopia

Cameroon, Nigeria

Tanzania

Central African Republic

Liberia

Chad

Nigeria

Ghana

Mozambique

Ethiopia, Sudan

Lesotho, South Africa

Botswana. South Africa,

Ethiopia

Tanzania

Tanzania

Sudan

Zimbabwe

Ethiopia

Ethiopia

Angola

Swaziland, South Africa

Ghana

Kenya, Uganda

Somalia +

Democratic Republic of Congo

Tanzania

South Africa

Tanzania

Tanzania

Mali, Cote d'Ivoire

Kenya, Tanzania +

Swaziland

Sudan 


\begin{tabular}{ll} 
Talodi & Sudan \\
Tama & Chad \\
Tamashek & Mali \\
Tamazight & Morocco \\
Tarok & Nigeria \\
Tasawaq & Niger \\
Tchien Krahn & Liberia \\
Temein & Sudan \\
Tennet & South Sudan \\
Tepo & Cote d'Ivoire \\
Tigrinya & Eritrea \\
Tikar & Cameroon \\
Tima & Sudan \\
Tira & Sudan \\
Tiv & Cameroon, Nigeria \\
Togbo & Democratic Republic of Congo \\
Tondi Songway Kiini & Mali \\
Tonga & S. Africa, Mozambique \\
Tsongo & S. Africa, Mozambique, Zimbabwe \\
Tsotso & Kenya \\
Tubu (Tedaga) & Chad, Nigeria \\
Tumale & Sudan \\
Tumbuka & Zambia, Malawi \\
Turkana & Kenya \\
Twi & Ghana \\
Tyurama & Burkina Faso, Cote d'Ivoire \\
Uduk & Ethiopia, Sudan \\
Ukaan & Nigeria \\
Umbundu & Angola \\
ut-Ma'in & Nigeria \\
Vamé & Cameroon \\
Vata & Cote d'Ivoire \\
Venda & South Africa, Zimbabwe \\
Vute & Cameroon, Nigeria \\
W. !Xoon & Nigeria \\
Wannu & \\
Wapan/Wukari & Nigeria \\
\hline & \\
\hline
\end{tabular}




$\begin{array}{ll}\text { Wapha }^{\text {ha }} & \text { Nigeria } \\ \text { Wobé } & \text { Côte d'Ivoire } \\ \text { Wolaitta } & \text { Ethiopia } \\ \text { Wolane } & \text { Ethiopia } \\ \text { Wolof } & \text { Senegal, Gambia, Mauritania, Mali } \\ \text { Xhosa } & \text { South Africa } \\ \text { Yakoma } & \text { Central African Republic } \\ \text { Yambasa } & \text { Cameroon } \\ \text { Yao ?=Ciyao? } & \text { Tanzania, Malawi, Mozambique } \\ \text { Yasa } & \text { Cameroon, Equatorial Guinea, Gabon } \\ \text { Yemba (Dschang) } & \text { Cameroon } \\ \text { Yoruba } & \text { Nigeria, Benin, Togo } \\ \text { Yulu } & \text { Central African Republic, South Sudan } \\ \text { Zaghawa/Beria } & \text { Sudan, Chad, Libya } \\ \text { Zande } & \text { Democratic Republic of Congo, South Sudan, Cameroon } \\ \text { Zarek, see Izere } & \text { Nigeria } \\ \text { Zarma } & \text { Niger } \\ \text { Zay } & \text { Ethiopia } \\ \text { Zing Mumuye } & \text { Nigeria } \\ \text { Zulu } & \text { South Africa }\end{array}$

Appendix-2: List of languages sorted by genetic unit with linear syntactic order and ISO 639-3 codes

$\begin{array}{llll}\text { Language } & \text { code } & \text { Order } & \text { Genetic Unit } \\ \text { Ayu } & \text { ayu } & \text { AUX V } & \text { Ayu Plateau } \\ \text { Diola-Fogny } & \text { dyo } & \text { AUX V } & \text { Bak } \\ \text { Dyola } & \text { dyu } & \text { AUX V } & \text { Bak } \\ \text { Diola } & \text { ?jol } & \text { AUX[-]V; } & \text { Bak } \\ & & \text { V-AUX } & \\ \text { Linda } & \text { liy } & \text { XV, AUX V } & \text { Banda Ubangi } \\ \text { Togbo } & \text { tor/tbm } & \text { AUX V } & \text { Banda Ubangi (tor)/Sere Ubangi (tbm) } \\ \text { C. B. K } & ? & \text { AUX V } & \text { Bantu }\end{array}$




\begin{tabular}{|c|c|c|c|}
\hline C. B. L & $?$ & AUX V & Bantu \\
\hline Balondo & bqz & AUX V & Bantu $>$ A10 \\
\hline Akoose & bss & AUX V & Bantu $>$ A15 \\
\hline Duala & dua & AUX V & Bantu $>$ A20 \\
\hline Basaa & bas & "AUX"V & Bantu $>$ A43 \\
\hline Bafia & $\mathrm{ksf}$ & AUX V & Bantu $>$ A50 \\
\hline Yambasa & yas & AUX V & Bantu $>$ A62 \\
\hline Eton & eto & AUX(-)V & Bantu $>$ A71 \\
\hline Ewondo & ewo & AUX V' & Bantu $>$ A72 \\
\hline Bulu & bum & AUX V & Bantu $>$ A74 \\
\hline Punu & puu & AUX V & Bantu $>$ B40 \\
\hline Duma & dma & AUX V & Bantu $>$ B51 \\
\hline Lyaa & iyx & AUX-V & Bantu $>$ B73c \\
\hline Akwa & akw & AUX V & Bantu $>$ C30 \\
\hline Lingala & $\operatorname{lin}$ & AUX V & Bantu $>\mathrm{C} 40$ \\
\hline Bushoong & buf & AUX-V & Bantu $>$ C83 \\
\hline Beya Lega & lea/lgm & AUX V & Bantu $>$ D25 \\
\hline Holoholo & hoo & AUX-V & Bantu $>$ D28 \\
\hline Nande & $\mathrm{nnb}$ & AUX-V & Bantu $>$ D42 \\
\hline Kuri(y)a & kuj & AUX V & Bantu $>$ E10 \\
\hline Sonjo & $\mathrm{SOZ}$ & AUX V & Bantu $>$ E10 \\
\hline EkeGusii & guz & AUX V & Bantu $>$ E10 or E42 \\
\hline Nkore-Kiga & nyn & AUX V & Bantu $>$ E13/J10 \\
\hline Ruri & kya & AUX V & Bantu $>$ E25[3] \\
\hline Gik[u]yu & kik & AUX-V & Bantu $>$ E51 \\
\hline Kamba & kam & AUX-V & Bantu $>$ E55 \\
\hline Pokomo & poj or pkb & AUX V & Bantu $>$ E71 \\
\hline Giryama & nyf & AUX V & Bantu $>$ E72 \\
\hline Sukuma(-Kiiya) & suk & AUX V & Bantu $>$ F21 \\
\hline Nymawezi & nym & AUX-V & Bantu $>$ F22 \\
\hline Sumbwa & suw & AUX-V & Bantu $>$ F23 \\
\hline Kimbu & kiv & AUX V & Bantu $>$ F24 \\
\hline Langi & lag & AUX-V & Bantu $>$ F33 \\
\hline Mbugwe & mgz & V AUX & Bantu $>$ F34 \\
\hline Kaguru & kki & AUX V & Bantu $>$ G10 \\
\hline
\end{tabular}




\begin{tabular}{|c|c|c|c|}
\hline Gogo & gog & AUX-V & Bantu $>$ G11 \\
\hline Shambala & $\mathrm{ksb}$ & AUX V & Bantu $>$ G20 \\
\hline Pare & asa & AUX V & Bantu $>$ G20 > G22 \\
\hline Shambaa & $\mathrm{ksb}$ & AUX V & Bantu $>$ G23 \\
\hline Dzalamo & zaj & AUX V & Bantu $>$ G30 \\
\hline Luguru & ruf & AUX V & Bantu $>$ G30 > G35 \\
\hline Swahili & swh & AUX V & Bantu $>$ G42 \\
\hline Ndamba & ndj & AUX V & Bantu $>$ G52 \\
\hline Kikongo & kng, kon & AUX V & Bantu $>\mathrm{H} 10$ \\
\hline Laadi & ldi & AUX V & Bantu $>\mathrm{H} 10>\mathrm{H} 16 \mathrm{f}$ \\
\hline Ntandu & kon & AUX V & Bantu $>\mathrm{H} 10>\mathrm{H} 16 \mathrm{~g}$ \\
\hline Hung'an & hum & AUX V & Bantu $>$ H42 \\
\hline Hungu & hum & AUX-V & Bantu $>\mathrm{H} 42$ \\
\hline Luganda & $\operatorname{lug}$ & AUX V & Bantu $>\mathrm{J} 10$ \\
\hline Haya & hay & AUX V & Bantu $>$ J20 or E22 \\
\hline Bukusu & bxk & AUX V & Bantu $>$ J30/JE31c \\
\hline Bukusu & bxk & AUX-V & Bantu $>$ J30/JE31c \\
\hline Tsotso & luy & V AUX & Bantu $>$ J30/JE32b \\
\hline Kirundi & run & AUX V & Bantu $>$ J60 \\
\hline Kinyarwanda & kin & AUX V & Bantu $>$ J60 or D61 \\
\hline Lucazi & lch & AUX-V & Bantu $>$ K13 \\
\hline Luvale & lue & AUX V & Bantu $>$ K20 \\
\hline Lunda & lun & AUX V & Bantu $>$ K30 \\
\hline Siluyana & lyn & AUX V & Bantu $>$ K40 \\
\hline Songye & sop & AUX V & Bantu $>$ L23 \\
\hline Hemba & hem & AUX V & Bantu $>$ L30 \\
\hline Luba & lua, lub & AUX V & Bantu $>$ L33 \\
\hline Pimbwe & piw & AUX V & Bantu $>$ M11 \\
\hline Lungu & mgr & AUX V & Bantu $>$ M14 \\
\hline Bungu & wun & AUX V & Bantu $>$ M25 \\
\hline Nyakyusa & nyy & AUX V & Bantu $>$ M30 \\
\hline Bemba & bem & AUX V & Bantu $>$ M42 \\
\hline Lamba & lam & AUX V & Bantu $>$ M50 \\
\hline N Tonga & toy & AUX V & Bantu $>$ M60 \\
\hline
\end{tabular}




\begin{tabular}{|c|c|c|c|}
\hline S Tonga & toi & AUX V & Bantu $>$ M60 \\
\hline Ila & ilb & AUX-V & Bantu $>$ M63 \\
\hline Mpoto & mpa & AUX V & Bantu $>$ N14 [N12] \\
\hline Tumbuka & tum & AUX V & Bantu $>$ N21 \\
\hline Chichewa & nya & AUX V & Bantu $>$ N30 \\
\hline Sena & seh & AUX V & Bantu $>$ N44 \\
\hline Ndendeule & dne & AUX V & Bantu $>$ P10 \\
\hline Kimatumbi & $\mathrm{mgw}$ & AUX V & Bantu $>$ P13 \\
\hline Ciyao & yao & AUX V & Bantu $>$ P20 \\
\hline Konde & kde & AUX V & Bantu $>$ P20 \\
\hline Yao ?=Ciyao? & yao & AUX V & Bantu $>$ P20 \\
\hline Mwera & mwe & AUX(-)V & Bantu $>$ P22 \\
\hline Makonde & kde & AUX-V & Bantu $>$ P23 \\
\hline Mabiha & kde & AUX V & Bantu $>$ P25 \\
\hline Makua-Maverone & xme & AUX V & Bantu $>$ P30 \\
\hline Umbundu & umb & AUX V & Bantu $>$ R10 \\
\hline Kwambi & kwm & AUX V & Bantu $>$ R20 \\
\hline Mbalanhu & $\operatorname{lnb}$ & AUX V & Bantu $>$ R20 \\
\hline Ngandjera & nne & AUX V & Bantu $>$ R20 \\
\hline Oshikwanyama & kua & AUX V & Bantu $>$ R20 \\
\hline Kafima & kua & AUX V & Bantu $>$ R211 \\
\hline Evale & kua & AUX V & Bantu $>$ R212 \\
\hline Mbandja & kua & AUX V & Bantu $>$ R213 \\
\hline Eunda & ndo, nne & AUX V & Bantu $>$ R242 \\
\hline Kolonkadhi & ndo, nne & AUX V & Bantu > R242 \\
\hline Herero & her & AUX V & Bantu $>$ R30 \\
\hline Shona & sna & AUX V & Bantu $>$ S10 \\
\hline Venda & ven & AUX V & Bantu $>$ S21 \\
\hline Setswana & tsn & AUX V & Bantu $>$ S31a \\
\hline N. Sotho & nso & AUX V & Bantu $>$ S32 \\
\hline Lobedu & nso & AUX V & Bantu $>$ S32b \\
\hline Sesotho & sot & AUX V & Bantu $>$ S33 \\
\hline Siswati & ssw & AUX V & Bantu $>$ S40 \\
\hline Xhosa & xho & AUX V & Bantu $>$ S40 \\
\hline
\end{tabular}

(V AUX?) 


\begin{tabular}{|c|c|c|c|}
\hline Zulu & zul & AUX V & Bantu $>$ S42 \\
\hline Ndebele & nde/nbl & AUX V & Bantu $>$ S44 \\
\hline Tsongo & tso & AUX-V & Bantu $>$ S53 \\
\hline Tonga & toh & AUX V & Bantu $>$ S62 \\
\hline Kako & $\mathrm{kkj}$ & AUX V & Bantu A43/ALCAM 440 \\
\hline Kerewe & ked & AUX V & Bantu G60/J20 \\
\hline Mundabli & boe & AUX V & Beboid, Western \\
\hline Noni & nhu & AUX V & Beboid, Eastern \\
\hline Bekwarra & bkv & AUX V & Bendi \\
\hline 'Berber’ & ber & AUX V & Berber \\
\hline Tamashek & taq & AUX V & Berber \\
\hline Tamazight & $\operatorname{tmz}$ & AUX V & Berber \\
\hline \multirow[t]{3}{*}{ Berom/Birom } & bom & AUX V & Beromic Plateau \\
\hline & wti & AUX-V & \\
\hline & & "AUX"V & \\
\hline Berta & & V-AUX & Berta \\
\hline Bijogo & bjg & AUX V & Bijago \\
\hline Daba & $\mathrm{dbq}$ & AUX V & Biu-Mandara Chadic \\
\hline \multirow[t]{2}{*}{ Gidar } & gid & AUX V & Biu-Mandara Chadic \\
\hline & & V-AUX & \\
\hline Hdi & xed & AUX V & Biu-Mandara Chadic \\
\hline \multirow[t]{2}{*}{ Kilba } & hbb & AUX V & Biu-Mandara Chadic \\
\hline & & V-AUX & \\
\hline Mbuko & $\mathrm{mqb}$ & AUX V & Biu-Mandara Chadic \\
\hline Merey & meq & AUX V & Biu-Mandara Chadic \\
\hline Mínà & hna & AUX V & Biu-Mandara Chadic \\
\hline Mofu-Gudur & mif & AUX V & Biu-Mandara Chadic \\
\hline Moloko & $\mathrm{mlw}$ & AUX V & Biu-Mandara Chadic \\
\hline Musgu & mug & AUX V & Biu-Mandara Chadic \\
\hline Muyang & muy & AUX V & Biu-Mandara Chadic \\
\hline Vamé & $\mathrm{mlr}$ & AUX V & Biu-Mandara Chadic \\
\hline Malgwa & $\mathrm{mfi}$ & V-AUX & Biu-Mandara Chadic \\
\hline Bagirmi & bmi & AUX V & Bongo-Bagirmi \\
\hline Bongo & bot & AUX V & Bongo-Bagirmi \\
\hline
\end{tabular}




\begin{tabular}{|c|c|c|c|}
\hline & & V AUX & \\
\hline Fer & kah & AUX V & Bongo-Bagirmi \\
\hline Gula Méré & $\mathrm{kcm}$ & AUX V & Bongo-Bagirmi \\
\hline Gula Sara & $\mathrm{kcm}$ & AUX V & Bongo-Bagirmi \\
\hline Gula Zura & $\mathrm{kcm}$ & AUX V & Bongo-Bagirmi \\
\hline Kabba & $\mathrm{ksp}$ & AUX V & Bongo-Bagirmi \\
\hline Kara & $\mathrm{kcm}$ & AUX V & Bongo-Bagirmi \\
\hline Mbay & myb & AUX V & Bongo-Bagirmi \\
\hline Mödö & bex & AUX V & Bongo-Bagirmi \\
\hline Morokodo & $\operatorname{mgc}$ & AUX V & Bongo-Bagirmi \\
\hline Ngambay-Moundou & $\mathrm{sba}$ & AUX V & Bongo-Bagirmi \\
\hline Sara & mwm & AUX V & Bongo-Bagirmi \\
\hline Yulu & yul & AUX V & Bongo-Bagirmi \\
\hline Baka & bdh & AUX V & Bongo-Bagirmi \\
\hline Ndut-Falor & ndv/fap & AUX V & Cangin \\
\hline Non & $\operatorname{snf}$ & AUX V & Cangin \\
\hline Izere/Afuzare/Zarek & fiz & AUX V & Central (South) Plateau \\
\hline Kemantney & ahg & V AUX & Central Cushitic \\
\hline Bilin & byn & V-AUX & Central Cushitic \\
\hline (I)Rigwe & iri & AUX V & Central Plateau \\
\hline Kituba* & mkw & AUX V & Creole \\
\hline Sango* & sag & V AUX & Creole \\
\hline Eleme & elm & AUX V & Cross River \\
\hline Ibibio & $\mathrm{ibb}$ & AUX V & Cross River \\
\hline Kohumono & bcs & AUX V & Cross River \\
\hline Lokaa & yaz & AUX V & Cross River \\
\hline Obolo (Andoni) & ann & AUX V & Cross River \\
\hline $\begin{array}{l}\text { Ogbronuagom } \\
\text { (Bukuma) }\end{array}$ & ogu & AUX V & Cross River \\
\hline Mbembe & $\mathrm{mfn}$ & $\begin{array}{l}\text { AUX-V } \\
\text { ?V-AUX }\end{array}$ & Cross River \\
\hline Gokana & gkn & AUX V & Cross River $>$ Ogonoid \\
\hline Kana & ogo & AUX V & Cross River $>$ Ogonoid \\
\hline Alagwa & wbj & AUX V & Cushitic \\
\hline Dar Daju Daju & djc & AUX V & Daju \\
\hline
\end{tabular}




\begin{tabular}{|c|c|c|c|}
\hline & & V-AUX & \\
\hline Shatt & shj & AUX V & Daju \\
\hline 'Dogon' & & V AUX & Dogon \\
\hline Jamsay & $\operatorname{djm}$ & V AUX & Dogon \\
\hline Donno So & dds & V[-]AUX & Dogon \\
\hline Gùrdùy & grd & AUX V & Eastern Chadic \\
\hline Polci & plj & AUX V & Eastern? Chadic \\
\hline Dera-Kanakuru & kna & AUX-V & Eastern Chadic \\
\hline Mubi & mub & V-AUX & Eastern Chadic \\
\hline & & AUX V & \\
\hline Dasenech & dsh & AUX V & Eastern Cushitic \\
\hline S'aamakko Dullay & tsb & AUX V & Eastern Cushitic \\
\hline Afar & aar & V AUX & Eastern Cushitic \\
\hline Alaaba & alw & V AUX & Eastern Cushitic \\
\hline Burji & bji & V AUX & Eastern Cushitic \\
\hline Dabarro Somali & $\mathrm{dbr}$ & V AUX & Eastern Cushitic \\
\hline Haddiya & hdy & V AUX & Eastern Cushitic \\
\hline Harar Oromo & hae & V AUX & Eastern Cushitic \\
\hline Jiddu Somali & jii & V AUX & Eastern Cushitic \\
\hline Mudung Somali & ?som & V AUX & Eastern Cushitic \\
\hline Oromo Wellega & gaz & V AUX & Eastern Cushitic \\
\hline Sidamo & sid & V AUX & Eastern Cushitic \\
\hline Somali & som & V AUX & Eastern Cushitic \\
\hline Gidole & gdl & V[-]AUX & Eastern Cushitic \\
\hline Gawwada Dullay & gwd & V-AUX & Eastern Cushitic \\
\hline Kambaata & $\mathrm{ktb}$ & V-AUX & Eastern Cushitic \\
\hline Amo & amo & AUX V & Eastern Kainji \\
\hline Bobo-Fing & bbo & AUX V & Eastern Mande \\
\hline Boko/Busa & bqc & AUX V & Eastern Mande \\
\hline Bokobaru & bus & AUX V & Eastern Mande \\
\hline (A)Teso & teo & AUX V & Eastern Nilotic \\
\hline Bari & bfa & AUX V & Eastern Nilotic \\
\hline Lotuko & lot & AUX V & Eastern Nilotic \\
\hline Maasai & mas & AUX V & Eastern Nilotic \\
\hline
\end{tabular}




\begin{tabular}{|c|c|c|c|}
\hline Turkana & tuv & AUX V & Eastern Nilotic \\
\hline Degema & deg & AUX V & Edoid [YEAI] \\
\hline Emai & ema & AUX V & Edoid [YEAI] \\
\hline North Ibie & atg & AUX V & Edoid [YEAI] \\
\hline \multirow[t]{2}{*}{ Okpamberi -heri } & opa & AUX V & Edoid [YEAI] \\
\hline & & V AUX & \\
\hline Edo & bin & AUX V/V AUX & Edoid [YEAI] \\
\hline Engenni & enn & V AUX & Edoid [YEAI] \\
\hline Ega & ega & AUX V & Ega Volta-Congo \\
\hline Egyptian $^{\dagger}$ & egy & AUX V & Egyptian-Coptic \\
\hline Later Egyptian $^{\dagger}$ & egy/egx & AUX V & Egyptian-Coptic \\
\hline Coptic $^{\dagger}$ & cop & AUX-V & Egyptian-Coptic \\
\hline \multirow[t]{2}{*}{ Ejagham } & etu & AUX V & Ekoid S. Bantoid \\
\hline & & AUX-V & \\
\hline Eloyi & afo & AUX V & Eloyi ?Plateau \\
\hline Fali & fli & AUX V & Fali \\
\hline \multirow[t]{3}{*}{ Fali } & fur/?fvr & AUX V & Fali \\
\hline & & V AUX & \\
\hline & & V-AUX & \\
\hline Fur & fvr & V LIGHT & Fur \\
\hline Kondjara & & AUX V & Fur \\
\hline Dangme & ada & AUX V & Ga-[A]Dangme \\
\hline $\mathrm{Ga}$ & gaa & AUX V & Ga-[A]Dangme \\
\hline 'Bozom & gbq & AUX V & Gbaya Ubangi \\
\hline Gbaya Kaka & $\mathrm{kkj}$ & AUX V & Gbaya Ubangi \\
\hline Mbodomo & mdo/gmm & V AUX & Gbaya Ubangi \\
\hline Gbaya 'Buli & gso & AUX V & Gbaya Ubangi \\
\hline Anexo-Ewe & ewe & AUX V & Gbe \\
\hline Fongbe & fon & AUX V & Gbe \\
\hline Minagbe & gej & V AUX, AUX V & Gbe \\
\hline Ewe & ewe & AUX V & Gbe \\
\hline Aghem & agq & AUX V & Grassfields S. Bantoid \\
\hline Babungo & bav & AUX V & Grassfields S. Bantoid \\
\hline Mankon & nge & AUX V & Grassfields S. Bantoid \\
\hline Yemba & $y b b$ & AUX V & Grassfield S. Bantoid \\
\hline
\end{tabular}




\begin{tabular}{|c|c|c|c|}
\hline Kom & bkm & AUX-V & Grassfields S. Bantoid $>$ C. Ring \\
\hline Gumuz & guk & AUX-V & Gumuz \\
\hline Kokit Gumuz & guk & AUX-V & Gumuz \\
\hline Sai Gumuz & guk & $\begin{array}{l}\text { V AUX } \\
\text { AUX V }\end{array}$ & Gumuz \\
\hline Sese Gumuz & guk & AUX V & Gumuz \\
\hline Ebang/Heiban & hbn & AUX V & Heiban Kordofanian \\
\hline Moro & mor & AUX V & Heiban Kordofanian \\
\hline Otoro & otr & AUX V & Heiban Kordofanian \\
\hline Tira & tic & AUX V & Heiban Kordofanian \\
\hline Ekpeye & ekp & AUX V & Igboid \\
\hline Echie & ibo & AUX V & Igboid [YEAI] \\
\hline Igbo & ibo & AUX V & Igboid [YEAI] \\
\hline Izi & izi & AUX-V & Igboid [YEAI] \\
\hline Onicha Igbo & ibo & V AUX & Igboid [YEAI] \\
\hline 6rms Ijo & $\mathrm{ijc}$ & V AUX & Ijoid \\
\hline Kalabari Ijo & ijn & $\begin{array}{l}\text { V[-]AUX } \\
\text { AUX V }\end{array}$ & Ijoid \\
\hline Kolokuma Ijo/Izon & $\mathrm{ijc}$ & V-AUX & Ijoid \\
\hline Defaka & afn & $\begin{array}{l}\text { AUX V } \\
\text { V-AUX }\end{array}$ & Ijoid \\
\hline Hadza & hts & $\begin{array}{l}\text { ?AUX } \\
\text { V-T/A } / \mathrm{A}\end{array}$ & Isolate \\
\hline Bangi Me & $\mathrm{dba}$ & AUX V & Isolate \\
\hline Aka & soh & AUX V & Jebel \\
\hline Gaam & tbi & AUX V & Jebel \\
\hline Kelo & xel & AUX V & Jebel \\
\hline Molo & zmo & AUX V & Jebel \\
\hline Burak & bys & AUX V & Jen [Waja-Jen] \\
\hline $\mathrm{Ju} /$ 'hoan & ktz & $\begin{array}{l}\text { AUX-V } \\
\text { AUX V }\end{array}$ & $\mathrm{Ju}$ \\
\hline !Xun & knw & $\begin{array}{l}\text { AUX V PRF } \\
\text { V AUX PROG }\end{array}$ & $\mathrm{Ju}$ \\
\hline$\neq$ fHoan & ktz & AUX V & Ju or Unclassified \\
\hline
\end{tabular}




\begin{tabular}{|c|c|c|c|}
\hline Hone & juh & $\begin{array}{l}\text { AUX V } \\
\text { AUX-V }\end{array}$ & Jukunoid \\
\hline Wapan/Wukari & juk & AUX[-]V & Jukunoid \\
\hline Hụne & juh & AUX-V & Jukunoid \\
\hline Jibə & jib/juo & AUX-V & Jukunoid \\
\hline Wannu & jub & AUX-V & Jukunoid \\
\hline Wap $\underset{\sim}{\mathrm{h}} \underset{\mathrm{a}}{ }$ & juw & V AUX & Jukunoid \\
\hline Kuteb & kub & AUX V & Jukunoid \\
\hline Krongo & kgo & AUX V & Kado \\
\hline Katcha & $\mathrm{xtc}$ & AUX V & Kado or Unclassified NS \\
\hline Duka & dud & AUX V & Kainji \\
\hline Kahugu & grh & AUX-V & Kainji $>$ Eastern \\
\hline Avatime & avn & AUX V & Ka-Togo Ghana-Togo Mountain \\
\hline //Ani & $\mathrm{hnh} / \mathrm{xuu}$ & V AUX & Khoe \\
\hline !Ora & kqz & V AUX & Khoe \\
\hline Buga-/Anda & $\mathrm{hnh} / \mathrm{xuu}$ & V AUX & Khoe \\
\hline Cara & shg & V AUX & Khoe \\
\hline Khoe & xuu & $\begin{array}{l}\text { V-AUX; } \\
\text { AUX V }\end{array}$ & Khoe \\
\hline Khwe & xuu & AUX V & Khoe \\
\hline Kua & tyu & AUX V & Khoe \\
\hline Nama & naq & V AUX & Khoe \\
\hline Naro & nhr & AUX V & Khoe \\
\hline Koma & xom & AUX V & Koman \\
\hline Uduk & udu & AUX-V & Koman \\
\hline Kwama & $\mathrm{kmq}$ & AUX V & Koman \\
\hline Kresh & $\mathrm{krs}$ & AUX V & Kresh-Aja \\
\hline Dewoin & dee & AUX V & Kru \\
\hline Vata & dic & AUX V & Kru \\
\hline Wobé & wob & AUX V & Kru \\
\hline Bété & bev, btg, bet & AUX V & $\mathrm{Kru}>\mathrm{E}$ \\
\hline Godie & god & $\begin{array}{l}\text { AUX V } \\
\text { V-AUX? }\end{array}$ & $\mathrm{Kru}>\mathrm{E}$ \\
\hline Koyo & god & AUX V & $\mathrm{Kru}>\mathrm{E}$ \\
\hline Neyo & ney & AUX V & $\mathrm{Kru}>\mathrm{E}$ \\
\hline
\end{tabular}




\begin{tabular}{llll} 
Nyo & ?ney & AUX V & Kru > Eastern \\
Kuwaa & blh & AUX V & Kru $>$ Kuwaa \\
Bassa & bza & AUX V & Kru > W \\
Klao & klu & AUX V & Kru > W \\
Krahn & krw & AUX V & Kru > W \\
Tchien Krahn & kqo & V AUX & Kru > W \\
Grebo & ?gry; grv; & AUX V & Kru > W \\
& gec; gbo; & & \\
Gbaeson Krahn & grj? & & \\
korobo & grv & AUX V & Kru > West \\
Sapo & krn & AUX V & Kru > Western \\
Tepo & ted & AUX V & Kru > Western \\
Kulango & kzc/nku & AUX V & Kulango-Lorhon \\
& & ?V-AUX & \\
Lorhon & lor & AUX V & Kulango-Lorhon \\
So & teu & V AUX, AUX V & Kuliak \\
Ik & ikx & V AUX & Kuliak \\
Kunama & kun & AUX V & Kunama \\
Lafofa & laf & AUX V & Lafofa \\
Samba Leko & ndi & AUX V & Leko-Nimbari \\
Zing Mumuye & mzm & AUX V & Leko-Nimbari \\
Ngiti & niy & V AUX & Lendu Central Sudanic \\
Aiki [Runga] & rou & V AUX & Maban \\
Maba & mde & V AUX & Maban \\
Masalit & mls & AUX V & Maban \\
Mambila & mzk; mcu & AUX V & Mambiloid N. Bantoid \\
Vute & vut & AUX V & Mambiloid N. Bantoid \\
Kenyang & ken & V-AUX & Mamfe/Nyang S. Bantoid \\
Bambara & bam & AUX V & Mande > [C]W \\
Mangbetu & mdj & AUX V & Mangbetu \\
Meje & mdj & AUX V & Mangbetu \\
Lese & les & V AUX/ & Mangbutu-Efe \\
& & AUX V & \\
\hline & &
\end{tabular}




\begin{tabular}{|c|c|c|c|}
\hline Mamvu & mdi & AUX V & Mangbutu-Efe \\
\hline Ma & $\mathrm{msj}$ & AUX V & Mba Ubangi \\
\hline $\mathrm{Mba}$ & $\mathrm{mfc}$ & AUX[-]V & Mba Ubangi \\
\hline 'Dongo & doo & AUX V & Mba Ubangi \\
\hline Nomaande & lem & AUX V & Mbam S. Bantoid \\
\hline Limbum & $\operatorname{lmp}$ & AUX V & Mbam-Nkam S. Bantoid \\
\hline Mbe & mfo & AUX V & Mbe S. Bantoid \\
\hline Doyayo & dow & AUX V & Mbum-Day \\
\hline Karang & kzr & AUX V & Mbum-Day \\
\hline Lua/Niellim & nie & AUX V & Mbum-Day \\
\hline Mbum & mdd & AUX V & Mbum-Day \\
\hline Kisi & kss & AUX[-]V & Mel \\
\hline Lugbara & $\operatorname{lgg}$ & AUX[-]V & Moru-Madi \\
\hline Moru & $\operatorname{mgd}$ & V AUX & Moru-Madi \\
\hline Moru & $\mathrm{mhi} / \mathrm{snm}$ & AUX[-]V & Moru-Madi \\
\hline Ma'di & $\mathrm{mhi} / \mathrm{snm}$ & AUX V & Moru-Madi \\
\hline Buem/Lelemi & lef & AUX V & Na-Togo Ghana-Togo Mountain \\
\hline \multirow[t]{2}{*}{ Siwu } & akp & AUX-V & Na-Togo Ghana-Togo Mountain \\
\hline & & AUX V & \\
\hline Sele & snw & AUX V & Na-Togo Ghana-Togo Mountain \\
\hline \multirow[t]{2}{*}{ Likpe } & lip & AUX V & Na-Togo Ghana-Togo Mountain or \\
\hline & & & Potou-Tano Kwa \\
\hline Ndemli & $\mathrm{nml}$ & V AUX & Ndemli S. Bantoid \\
\hline Nera & nrb & AUX V & Nera \\
\hline Baka & bkc & AUX V & Ngbaka Ubangi \\
\hline Mayogo & $\mathrm{mdm}$ & AUX V & Ngbaka Ubangi \\
\hline Mundu & muh & AUX V & Ngbaka Ubangi \\
\hline Ngbandi & $\mathrm{ngb} / \mathrm{nbw}$ & AUX V & Ngbandi Ubangi \\
\hline Yakoma & yky & V AUX & Ngbandi Ubangi \\
\hline Beja & bej & AUX V & North Cushitic \\
\hline Buamu & box & AUX V & Northern Gur \\
\hline Dagaare & dgi & AUX V & Northern Gur \\
\hline Frafra & gur & AUX V & Northern Gur \\
\hline Konkomba & xon & V AUX & Northern Gur \\
\hline Dizi (Maji) & $\operatorname{mdx}$ & V AUX & Northern Omotic \\
\hline
\end{tabular}




\begin{tabular}{|c|c|c|c|}
\hline Gimira (Benchnon) & bcq & V AUX & Northern Omotic \\
\hline Gonga (Kefa/Kafa) & $\mathrm{kbr}$ & V AUX & Northern Omotic \\
\hline Haro & kqy & V AUX & Northern Omotic \\
\hline Maale & mdy & V AUX & Northern Omotic \\
\hline Wolaitta & wal & AUX V & Northern Omotic \\
\hline Idũ & $\mathrm{ldb}$ & V AUX & NorthWestern Plateau \\
\hline Fadicca (Nobiin) & fia & $\begin{array}{l}\text { V(-)AUX } \\
\text { AUX V }\end{array}$ & Nubian \\
\hline Midob & mei & V-AUX & Nubian \\
\hline Dilling & dil & V-AUX & Nubian \\
\hline Dongolese & $\mathrm{kzh}$ & V-AUX & Nubian \\
\hline Ghulfan & ghl & V-AUX & Nubian \\
\hline Old Nubian $^{\dagger}$ & onw & AUX V & Nubian \\
\hline Ebira/Igbirra & igb & AUX V & Nupoid \\
\hline Gade & ged & AUX V & Nupoid \\
\hline Nupe & nup & $\begin{array}{l}\text { AUX V } \\
\text { V-AUX }\end{array}$ & Nupoid \\
\hline Nyimang & nyi & $\begin{array}{l}\text { AUX V } \\
\text { (but OV)! }\end{array}$ & Nyimang \\
\hline Dinik (Afitti) & aft & $\begin{array}{l}\text { AUX[-]V } \\
\text { AUX V } \\
\text { V AUX }\end{array}$ & Nyimang \\
\hline Òkó/Ogori & oks & AUX V & Okoid [NOI] \\
\hline $\begin{array}{l}\text { Kenyan Pidgin } \\
\text { Swahili }\end{array}$ & & AUX V & 'Pidgin' \\
\hline Baule & bci & AUX V & Potou-Tano Kwa \\
\hline Bejamso-Grubi & ncu & AUX V & Potou-Tano Kwa \\
\hline Nchumuru & & & \\
\hline Gehode & acd & AUX V & Potou-Tano Kwa \\
\hline Genyanga & ayg & AUX V & Potou-Tano Kwa \\
\hline Krachi & kye & AUX V & Potou-Tano Kwa \\
\hline Nawuri & naw & AUX V & Potou-Tano Kwa \\
\hline Nkonya & nko & AUX(-)V & Potou-Tano Kwa \\
\hline Akan & aka & AUX[-]V & Potou-Tano Kwa \\
\hline
\end{tabular}




\begin{tabular}{|c|c|c|c|}
\hline Anyi & any & AUX-V & Potou-Tano Kwa \\
\hline Banda Nchumuru & ncu & V AUX AUX V & Potou-Tano Kwa \\
\hline \multirow[t]{2}{*}{ Twi } & aka & V AUX & Potou-Tano Kwa \\
\hline & & AUX V & \\
\hline \multirow[t]{2}{*}{ Orig } & $\operatorname{tag}$ & V AUX & Rashad Kordofanian \\
\hline & & AUX-V & \\
\hline Rashad & ras & V AUX & Rashad Kordofanian \\
\hline \multirow[t]{2}{*}{ Tagoi } & tag & V AUX & Rashad Kordofanian \\
\hline & & AUX-V & \\
\hline \multirow[t]{2}{*}{ Tumale } & tag & AUX V & Rashad Kordofanian \\
\hline & & V-AUX & \\
\hline Kanuri & knc & V(-)AUX & Saharan \\
\hline \multirow[t]{2}{*}{ Zaghawa/Beria } & zag & V AUX & Saharan \\
\hline & & AUX V & \\
\hline Sandawe & sad & AUX V & Sandawe \\
\hline Fula & ful & AUX V & Senegambian \\
\hline Adamawa Fulani & fub & V AUX & Senegambian \\
\hline Pajade (Badiaranke) & pbp & AUX-V & Senegambian \\
\hline Pajade (Badiaranke) & pbp & AUX V & Senegambian \\
\hline Nafaara & $\mathrm{nfr}$ & AUX V & Senufic \\
\hline Supyire & spp & AUX V & Senufic \\
\hline Ndogo & $\mathrm{ndz}$ & AUX V & Sere Ubangi \\
\hline Koyra Chiini & khq & AUX V & Songhay \\
\hline Tasawaq & twq & AUX V & Songhay \\
\hline \multicolumn{2}{|c|}{ Tondi Songway Kiini son? } & AUX V & Songhay \\
\hline Zarma & dje & V AUX & Songhay \\
\hline Amharic & $\mathrm{amh}$ & V AUX & South Semitic \\
\hline Chaha Gurage & sgw & V AUX & South Semitic \\
\hline Inor & ior & V AUX & South Semitic \\
\hline Muher & sgw & V AUX & South Semitic \\
\hline Sil'te & stv & V AUX & South Semitic \\
\hline Tigrinya & tir & V AUX & South Semitic \\
\hline Wolane & wle & V AUX & South Semitic \\
\hline Zay & zwa & AUX V & South Semitic \\
\hline Gworok/Kagoro & $\mathrm{kcg}$ & AUX V & South-Central Plateau \\
\hline
\end{tabular}




$\begin{array}{llll}\text { Fyem } & \text { pym } & \text { AUX V } & \text { Southeast Plateau } \\ \text { Eggon } & \text { ego } & \text { AUX V } & \text { Southern [Eggonic] Plateau } \\ \text { Dahalo } & \text { dal } & \text { V AUX } & \text { Southern Cushitic } \\ \text { Iraqw } & \text { irk } & \text { AUX V } & \text { Southern Cushitic } \\ \text { Kirma } & \text { cme } & \text { AUX V } & \text { Southern Gur } \\ \text { Tyurama } & \text { tuz } & \text { V-AUX } & \text { Southern Gur } \\ \text { Doǵ́ s̀ } & \text { dts/dgs } & \text { AUX V } & \text { Southern Gur } \\ \text { Dan-Blowo } & \text { daf } & \text { AUX V } & \text { Southern Mande } \\ \text { Dan-Gweeta } & \text { daf } & \text { AUX V } & \text { Southern Mande } \\ \text { Guro } & \text { goa } & \text { AUX V } & \text { Southern Mande } \\ \text { Mano } & \text { mev } & \text { AUX V } & \text { Southern Mande } \\ \text { Datooga } & \text { tcc } & \text { AUX V } & \text { Southern Nilotic } \\ \text { Nandi } & \text { kln } & \text { V AUX } & \text { Southern Nilotic }>\text { (Kalenjin) } \\ \text { Aari } & \text { aiw } & \text { V[-]AUX } & \text { Southern Omotic } \\ \text { Dime (Dim-Af) } & \text { dim } & \text { AUX V } & \text { Southern Omotic } \\ \text { Hamer } & \text { amf } & \text { AUX V } & \text { Southern Omotic } \\ \text { Kpelle } & \text { xpe } & \text { AUX V } & \text { Southwestern Mande } \\ \text { Mende } & \text { men } & \text { AUX V } & \text { Southwestern Mande } \\ \text { Mada } & \text { mda } & \text { AUX V } & \text { Southwestern Plateau } \\ \text { Baale } & \text { koe } & \text { AUX V } & \text { Surmic } \\ \text { Didinga } & \text { did } & \text { AUX V } & \text { Surmic } \\ \text { Majang } & \text { mpe } & \text { AUX V } & \text { Surmic } \\ \text { Murle } & \text { mur } & \text { AUX V } & \text { Surmic } \\ \text { Mursi } & \text { muz } & \text { AUX V } & \text { Surmic } \\ \text { Tennet } & \text { tex } & \text { V AUX } & \text { Surmic } \\ \text { Koegu } & \text { xwg } & \text { V AUX } & \text { Surmic } \\ \text { Me'en } & \text { mym } & \text { AUX V } & \text { Surmic } \\ & & \text { AUX-V } & \\ \text { Masakin (Ngile) } & \text { jle } & \text { AUX V } & \text { Talodi Kordofanian } \\ \text { Talodi } & \text { tlo } & \text { X Light.vb } & \text { Talodi Kordofanian } \\ & & \text { AUX V } & \\ \text { Tama } & \text { tma } & \text { AUX V } & \text { Taman } \\ \text { Tarok } & \text { AUX V } & \text { Tarokoid Plateau } \\ \text { Temein } & & \text { Temein East Sudanic } \\ & \text { ter } & \end{array}$




$\begin{array}{llll}\text { Tikar } & \text { tik } & \text { AUX V } & \text { Tikar S. Bantoid } \\ \text { Katla } & & \text { V-AUX } & \\ \text { Tima } & \text { kcr } & \text { AUX V } & \text { Tima-Katla ('Kordofanian') } \\ \text { Tiv } & \text { tms } & \text { AUX V } & \text { Tima-Katla ('Kordofanian') } \\ \text { łUngkue } & \text { tiv } & \text { "AUX” V } & \text { Tivoid S. Bantoid } \\ \text { |Xam } & \text { ?xeg/xam } & \text { AUX V } & \text { Tuu (!Ui-Taa) } \\ \text { N|uu } & \text { xam } & \text { AUX V } & \text { Tuu (!Ui-Taa) } \\ \text { Strandberg |Xam } & \text { ngh } & \text { AUX V } & \text { Tuu (!Ui-Taa) } \\ \text { W. !Xoon } & \text { nmn } & \text { AUX V } & \text { Tuu (!Ui-Taa) } \\ \text { !Xõo Lone Tree } & \text { nmn } & \text { AUX V } & \text { Tuu (!Ui-Taa) } \\ \text { Ukaan } & \text { kcf } & \text { AUX V } & \text { Tuu (!Ui-Taa) } \\ \text { Laal } & \text { gdm } & \text { V AUX } & \text { Ukaan Benue-Congo } \\ & \text { bxe } & & \\ \text { Ongota } & & \text { AUX V! } & \text { Unclassified Afroasiatic } \\ & & \text { SOV } & \\ \text { Shabo } & \text { sbf } & \text { AUX V } & \text { Unclassified Nilo-Saharan } \\ \text { Awak } & \text { awo } & \text { AUX V } & \text { Waja [Waja-Jen] } \\ \text { Dadiya } & \text { dbd } & \text { AUX V } & \text { Waja [Waja-Jen] } \\ \text { Ader Hausa } & \text { hau } & \text { AUX V } & \text { West Chadic } \\ \text { Angas } & \text { anc } & \text { AUX V } & \text { West Chadic } \\ \text { Burrum (Boghom) } & \text { bux } & \text { AUX V } & \text { West Chadic } \\ \text { Chip } & \text { mjs } & \text { AUX V } & \text { West Chadic } \\ \text { Daffo Ron } & \text { cla } & \text { AUX V } & \text { West Chadic } \\ \text { Dott/Zodi } & \text { dot } & \text { AUX V } & \text { West Chadic } \\ \text { Gerka (Yiwom) } & \text { gek } & \text { AUX V } & \text { West Chadic } \\ \text { Goemai } & \text { ank } & \text { AUX V } & \text { West Chadic } \\ \text { Guus/Sigidi } & \text { say } & \text { AUX V } & \text { West Chadic } \\ \text { Hausa } & \text { hau } & \text { AUX V } & \text { West Chadic } \\ \text { Kwami } & \text { ksq } & \text { AUX V } & \text { West Chadic } \\ \text { Lele } & \text { lln } & \text { AUX V } & \text { West Chadic } \\ \text { Montol } & \text { mtl } & \text { AUX V } & \text { West Chadic } \\ \text { Ngizim } & \text { AUX V } & \text { West Chadic } \\ \text { Pero } & \text { AUX V V } & \text { West Chadic } \\ \text { Sayanci } & & \text { West Chadic } \\ & & \end{array}$




\begin{tabular}{|c|c|c|c|}
\hline \multirow{3}{*}{ Karekare } & \multirow{3}{*}{ kai } & \\
\hline & & V-AUX & West Chadic \\
\hline & & AUX/Lght V & \\
\hline Bolanci & bol & AUX V & West Chadic \\
\hline Egyptian Arabic & $\operatorname{arz}$ & AUX V & West Semitic \\
\hline ut-Ma' in & gel & AUX V & Western Kainji \\
\hline Jalonke & yal & AUX V & Western Mande \\
\hline Manding & mnk & AUX V & Western Mande \\
\hline Maninka & $\mathrm{mku} / \mathrm{msc}$ & AUX V & Western Mande \\
\hline Meeka & rkm & AUX V & Western Mande \\
\hline 'Dinka' & $\begin{array}{l}\text { dip, diw, } \\
\text { dib, dks, dik }\end{array}$ & AUX V & Western Nilotic \\
\hline Acholi & ach & AUX V & Western Nilotic \\
\hline Anywa & anu & AUX V & Western Nilotic \\
\hline Dho-Alur & alz & AUX V & Western Nilotic \\
\hline Dholuo & luo & AUX V & Western Nilotic \\
\hline Lango & laj & AUX-V & Western Nilotic \\
\hline Karimojong & $\mathrm{kdj}$ & AUX V & Western Nilotic \\
\hline Banka (Samogo) & bxw & AUX V & Western or Samogo Mande \\
\hline $\mathrm{Jo}[$ wulu] & jow & AUX V & Western or Samogo Mande \\
\hline & & V-AUX & \\
\hline Wolof & wol, wof & V AUX & Wolof \\
\hline Yoruba & yor & AUX V & Yoruboid [YEAI] \\
\hline Barambu & brm & AUX V & Zande Ubangi \\
\hline & & AUX-V & \\
\hline Zande & zne & AUX-V & Zande Ubangi \\
\hline Pambia & $\mathrm{pmb}$ & & Zande Ubangi \\
\hline
\end{tabular}


$\underline{\text { Key to Appendices } 3 \text { through 7: }}$

$\mathrm{AH}$

"AH"

AUX

$\mathrm{CO}$

CONEG

DEP

$\mathrm{f}$

f/f S/TAM/P

FOC

LH

"LH"

LV

NEG

n. o. p.

$\mathrm{O}$

pas

PHON

pseudo-

$\mathrm{S}$

S/TAM/P

SVC

$\mathrm{S} / 2$

$(\mathrm{S} /)_{2}$

$\mathrm{V}$

V2

$\sim$

$+$

$<$
AUX-Headed pattern

possibly analytic, possibly synthetic structure in AUX-headed configuration

Auxiliary Verb

Cognate Object

Conegative

Dependent

Fused pattern

Complex verb forms derived from fusing of fused

subject/TAM/Polarity

Focus

LEX-Headed pattern

possibly analytic, possibly synthetic structure in LEX-headed

configuration

Lexical Verb

Negative

Nominal origin of progressive

Object

Reinforcing element like French (quasi-conegative) pas that may become sole index of functional category

Phonologically (dependent)

pattern that mimics another pattern, e.g. due to behavior of

clitics or mismatch between phonological/morphological words

Subject

Fused subject/TAM/Polarity forms

Serial Verb Construction

Split/Doubled inflectional pattern

Split/Doubled [OBJ/SUBJ] pattern with transitive verbs, doubled inflectional pattern with intransitives

Verb

Second Verb in a sequence of verbs (e.g., in a serial verb

construction)

Alternates with

Pattern in addition to/in combination with another configuration derives historically from 
$>\quad$ develops into

1SG First person singular

$2 \mathrm{x} \quad$ Doubled Inflectional pattern

" $2 \mathrm{x}$ " possibly analytic, possibly synthetic structure in doubled configuration

$\varnothing \quad$ zero-morph (bare stem) of lexical verb or zero form of auxiliary

Appendix-3: Languages w/AUX-Headed AVCs and derived complex verbs

\begin{tabular}{|c|c|c|}
\hline Language & ISO 639-3 Code & Pattern \\
\hline fHoan & $\mathrm{Ktz}$ & “AH” \\
\hline Berta & Wti & ?+DEP; fused AH (+S/TAM/P) \\
\hline Meeka & Rkm & {$[\mathrm{AH}] \mathrm{S} / \mathrm{TAM} / \mathrm{P}[\mathrm{NEG}]$} \\
\hline Dar Daju Daju & $\mathrm{Djc}$ & $\{2 \mathrm{x} / \mathrm{AH} / \mathrm{split}\}\}$ \\
\hline !Xun & Knw & “AH” \\
\hline Bari & $\mathrm{Bfa}$ & "AH" \\
\hline Bejamso-Grubi Nchumuru & $\mathrm{Ncu}$ & “AH” \\
\hline Dangme & Ada & "AH" \\
\hline Emai & Ema & “AH” \\
\hline Fongbe & Fon & "AH" \\
\hline Gbaeson Krahn & Krw & "AH" \\
\hline Genyanga & Ayg & “AH” \\
\hline $\mathrm{Ju} /$ 'hoan & Ktz & "AH" \\
\hline Minagbe & Gej & “AH” \\
\hline Oko/Ogori & Oks & “AH” \\
\hline Strandberg |Xam & Xam & "AH" \\
\hline Tchien Krahn & Kqo & “AH” \\
\hline Vute & Vut & "AH" \\
\hline Wapan/Wukari & Juk & "AH" \\
\hline Baka & bkc & “AH" + DEP \\
\hline Kuwaa & blh & “AH” +DEP \\
\hline Mambila & mzk; mcu & "AH" +DEP \\
\hline
\end{tabular}




\begin{tabular}{|c|c|c|}
\hline Mbum & mdd & “AH” +DEP \\
\hline Ndogo & $\mathrm{ndz}$ & “AH” + DEP \\
\hline Samba Leko & ndi & “AH” +DEP \\
\hline !Xõo Lone Tree & $\mathrm{nmn}$ & “AH" $<$ SVC V 2 \\
\hline Tondi Songway Kiini & son? & “AH” $\pm \mathrm{DEP}$ \\
\hline Bobo-Fing & bbo & “AH” n.o.p. \\
\hline Banka (Samogo) & bxw & “AH” or split \\
\hline Konkomba & xon & “AH”/“"LH” \\
\hline Maninka & $\mathrm{mku} / \mathrm{msc}$ & "AH"; n.o.p. \\
\hline Tikar & tik & “AH”? \\
\hline Lorhon & lor & “AH"+DEP \\
\hline Lua/Niellim & nie & “AH”+DEP \\
\hline Yemba & ybb & “AH”+DEP \\
\hline fHoan & ktz & +fused V-AUX AH \\
\hline Kua & tyu & $2 \mathrm{x} \sim \mathrm{AH}$ \\
\hline Gula Méré & $\mathrm{kcm}$ & $2 \mathrm{x} \sim \mathrm{AH}+\mathrm{DEP}$ \\
\hline $\mathrm{Ik}$ & $\mathrm{ikx}$ & $2 \mathrm{x} / \mathrm{AH}$ \\
\hline !Ora & kqz & $\mathrm{AH}$ \\
\hline Zande & zne & $\mathrm{AH}$ \\
\hline 'Dinka' & dip, diw, dib, dks, dik & $\mathrm{AH}$ \\
\hline ‘Dongo & doo & $\mathrm{AH}$ \\
\hline Goms Ijo & ijc & $\mathrm{AH}$ \\
\hline Adamawa Fulani & fub & $\mathrm{AH}$ \\
\hline Afar & aar & $\mathrm{AH}$ \\
\hline Aiki [Runga] & rou & $\mathrm{AH}$ \\
\hline Akwa & akw & $\mathrm{AH}$ \\
\hline Anywa & anu & $\mathrm{AH}$ \\
\hline Babungo & bav & $\mathrm{AH}$ \\
\hline Bari & bfa & $\mathrm{AH}$ \\
\hline Basaa & bas & $\mathrm{AH}$ \\
\hline Bassa & bza & $\mathrm{AH}$ \\
\hline Bijogo & bjg & $\mathrm{AH}$ \\
\hline Bolanci & bol & $\mathrm{AH}$ \\
\hline Bukusu & bxk & $\mathrm{AH}$ \\
\hline C. B. K & $?$ & $\mathrm{AH}$ \\
\hline
\end{tabular}


Dabarro Somali

$\mathrm{dbr}$

$\mathrm{AH}$

Dadiya

$\mathrm{dbd}$

$\mathrm{AH}$

Dahalo

dal

$\mathrm{AH}$

Dholuo

luo

$\mathrm{AH}$

Dime (Dim-Af)

$\operatorname{dim}$

$\mathrm{AH}$

Donno So

dds

$\mathrm{AH}$

Doyayo

dow

$\mathrm{AH}$

Duala

dua

$\mathrm{AH}$

Duka

dud

$\mathrm{AH}$

Duma

dma

$\mathrm{AH}$

Dzalamo

zaj

$\mathrm{AH}$

Echie

ibo

$\mathrm{AH}$

EkeGusii

guz

$\mathrm{AH}$

Eleme

elm

$\mathrm{AH}$

Eton

eto

$\mathrm{AH}$

Evale

kua

$\mathrm{AH}$

Ewe

ewe

$\mathrm{AH}$

Ewondo

ewo

$\mathrm{AH}$

Fur

fur/?fvr

$\mathrm{AH}$

Godie

god

$\mathrm{AH}$

Godie

god

$\mathrm{AH}$

Gokana

gkn

$\mathrm{AH}$

Haddiya

hdy

$\mathrm{AH}$

Hadza

hts

$\mathrm{AH}$

Harar Oromo

hae

$\mathrm{AH}$

Hausa

hau

$\mathrm{AH}$

Herero

her

$\mathrm{AH}$

Hung'an

hum

$\mathrm{AH}$

Igbo

ibo

$\mathrm{AH}$

Ik

ikx

$\mathrm{AH}$

Izi

izi

$\mathrm{AH}$

$\mathrm{Ju} /$ 'hoan

ktz

$\mathrm{AH}$

Kabba

ksp

$\mathrm{AH}$

Kaguru

kki

$\mathrm{AH}$ 
Kako

Kalabari Ijo

Kana

Kara

Kenyan Pidgin Swahili

Kenyang

Kerewe

Khwe/Khoe

Kikongo

Kinyarwanda

Kituba

Kolokuma Ijo

Kom

Konde

Kwami

Laadi

Lango

Later Egyptian $^{\dagger}$

Lingala

Lotuko

Maba

Mamvu

Manding

Mba

Mbe

Mbodomo

Mbodomo

Mende

Mödö

Mpoto

Mudung Somali

Mursi

Naro

Ndendeule

Ndut-Falor kkj

ijn

ogo

$\mathrm{kcm}$

ken

ked

xuU

kng, kon

kin

mkw

ijc

bkm

kde

$\mathrm{ksq}$

ldi

laj

egy or egx

lin

lot

mde

mdi

mnk

$\mathrm{mfc}$

mfo

mdo

gmm

men

bex

mpa

?som

muz

nhr

dne

ndv/fap
$\mathrm{AH}$

$\mathrm{AH}$

$\mathrm{AH}$

$\mathrm{AH}$

$\mathrm{AH}$

$\mathrm{AH}$

AH

AH

$\mathrm{AH}$

$\mathrm{AH}$

$\mathrm{AH}$

$\mathrm{AH}$

$\mathrm{AH}$

$\mathrm{AH}$

$\mathrm{AH}$

$\mathrm{AH}$

$\mathrm{AH}$

$\mathrm{AH}$

$\mathrm{AH}$

$\mathrm{AH}$

$\mathrm{AH}$

$\mathrm{AH}$

$\mathrm{AH}$

$\mathrm{AH}$

$\mathrm{AH}$

AH

AH

$\mathrm{AH}$

AH

$\mathrm{AH}$

$\mathrm{AH}$

$\mathrm{AH}$

$\mathrm{AH}$

AH

$\mathrm{AH}$ 


\begin{tabular}{|c|c|c|}
\hline Nkonya & nko & $\mathrm{AH}$ \\
\hline Noni & nhu & $\mathrm{AH}$ \\
\hline North Ibie & atg & $\mathrm{AH}$ \\
\hline Nyakyusa & nyy & $\mathrm{AH}$ \\
\hline Òkó & oks & $\mathrm{AH}$ \\
\hline Oromo of Wellega & gaz & $\mathrm{AH}$ \\
\hline Pero & pip & $\mathrm{AH}$ \\
\hline S'aamakko Dullay & tsb & $\mathrm{AH}$ \\
\hline \multirow[t]{2}{*}{ Sayanci } & say & $\mathrm{AH}$ \\
\hline & guk & $\mathrm{AH}$ \\
\hline Sese Gumuz & & $\mathrm{AH}$ \\
\hline Shambala & $\mathrm{ksb}$ & $\mathrm{AH}$ \\
\hline Sidamo & sid & $\mathrm{AH}$ \\
\hline So & teu & $\mathrm{AH}$ \\
\hline Somali & som & $\mathrm{AH}$ \\
\hline Swahili & swh & $\mathrm{AH}$ \\
\hline Tama & tma & $\mathrm{AH}$ \\
\hline Tepo & ted & $\mathrm{AH}$ \\
\hline Tigrinya & tir & $\mathrm{AH}$ \\
\hline Tira & tic & $\mathrm{AH}$ \\
\hline Tsotso & luy & $\mathrm{AH}$ \\
\hline Turkana & tuv & $\mathrm{AH}$ \\
\hline ut-Ma'in & gel & $\mathrm{AH}$ \\
\hline Vata & dic & $\mathrm{AH}$ \\
\hline Vute & vut & $\mathrm{AH}$ \\
\hline Vute & vut & $\mathrm{AH}$ \\
\hline Wolof & wol, wof & $\mathrm{AH}$ \\
\hline Xhosa & xho & $\mathrm{AH}$ \\
\hline Gbaya Kaka & $\mathrm{kkj}$ & AH (+DEP) \\
\hline Egyptian $^{\dagger}$ & egy & AH (+DEP?) \\
\hline Koegu & xwg & AH (+DEP?) \\
\hline Gbaya Kaka & kkj & $\mathrm{AH}(+\varnothing)$ \\
\hline Kpelle & xpe & AH; n.o.p. \\
\hline Jamsay & $\operatorname{djm}$ & $\mathrm{AH}(+\mathrm{V}+$ complement $)$ \\
\hline
\end{tabular}




\begin{tabular}{|c|c|c|}
\hline Ma'di & $\mathrm{mhi} / \mathrm{snm}$ & $\mathrm{AH}$ (fused/fused) S/TAM/P \\
\hline Masakin (Ngile) & jle & AH (NEG AUX) \\
\hline Talodi & tlo & AH (NEG AUX) \\
\hline Mbalanhu & $\operatorname{lnb}$ & AH (pseudo-unfused) \\
\hline Likpe & lip & AH (S/TAM/P?) \\
\hline Maasai & mas & $\mathrm{AH} ? \mathrm{LV}=\mathrm{DEP}$ \\
\hline Nkore-Kiga & nyn & $\mathrm{AH}[\mathrm{Aux}=\mathrm{DEP}(\mathrm{LOC}) !]$ \\
\hline Didinga & did & $\mathrm{AH} \sim 2 \mathrm{x}$ \\
\hline Diola-Fogny & dyo & $\mathrm{AH} \sim 2 \mathrm{x}$ \\
\hline Gimira (Benchnon) & bcq & $\mathrm{AH} \sim 2 \mathrm{X}$ \\
\hline Murle & mur & $\mathrm{AH} \sim 2 \mathrm{x}$ \\
\hline Tonga & toh & $\mathrm{AH} \sim$ fused $2 \mathrm{x}$ \\
\hline Akoose & bss & $\mathrm{AH} \sim \mathrm{V}$-Complement \\
\hline Konde & kde & $\mathrm{AH}+\mathrm{CONEG}+\mathrm{S} / \mathrm{TAM} / \mathrm{P}$ \\
\hline Ma & $\mathrm{msj}$ & $\mathrm{AH}+\mathrm{DEP}$ \\
\hline Maale & mdy & $\mathrm{AH}+\mathrm{DEP}$ \\
\hline Togbo & tor & $\mathrm{AH}+\mathrm{DEP}$ \\
\hline Ngizim & ngi & $\mathrm{AH}+\mathrm{S} / \mathrm{TAM} / \mathrm{P}$ \\
\hline Bagirmi & bmi & $\mathrm{AH}+\mathrm{DEP}$ \\
\hline Baka & bdh & $\mathrm{AH}+\mathrm{DEP}$ \\
\hline Beja & bej & $\mathrm{AH}+\mathrm{DEP}$ \\
\hline Fadicca (Nobiin) & fia & $\mathrm{AH}+\mathrm{dEP}$ \\
\hline Gula Zura & $\mathrm{kcm}$ & $\mathrm{AH}+\mathrm{DEP}$ \\
\hline Haro & kqy & $\mathrm{AH}+\mathrm{DEP}$ \\
\hline Hone & juh & $\mathrm{AH}+\mathrm{DEP}$ \\
\hline Katcha & xtc & $\mathrm{AH}+\mathrm{DEP}$ \\
\hline Mayogo & $\mathrm{mdm}$ & $\mathrm{AH}+\mathrm{DEP}$ \\
\hline Moloko & $\mathrm{mlw}$ & $\mathrm{AH}+\mathrm{DEP}$ \\
\hline Morokodo & $\mathrm{mgc}$ & $\mathrm{AH}+\mathrm{DEP}$ \\
\hline Mundu & muh & $\mathrm{AH}+\mathrm{DEP}$ \\
\hline Sapo & krn & $\mathrm{AH}+\mathrm{DEP}$ \\
\hline Sara & mwm & $\mathrm{AH}+\mathrm{DEP}$ \\
\hline Sena & seh & $\mathrm{AH}+\mathrm{dep}$ \\
\hline Uduk & udu & $\mathrm{AH}+\mathrm{DEP}$ \\
\hline Yulu & yul & $\mathrm{AH}+\mathrm{DEP}$ \\
\hline
\end{tabular}




\begin{tabular}{|c|c|c|}
\hline Barambu & brm & $\mathrm{AH}+\mathrm{DEP}[\mathrm{f} / \mathrm{f} \mathrm{S} / \mathrm{TAM} / \mathrm{P}]$ \\
\hline Sara & mwm & $\mathrm{AH}+\mathrm{DEP} \mathrm{f} / \mathrm{f} \mathrm{S} / \mathrm{TAM} / \mathrm{P}$ \\
\hline Uduk & udu & $\mathrm{AH}+\varnothing$ \\
\hline Lafofa & laf & $\mathrm{AH} \pm \mathrm{DEP}$ \\
\hline Kelo & xel & AH fused S/TAM/P \\
\hline Umbundu & umb & AH n. o. p. \\
\hline Ngambay-Moundou & sba & AH n.o.p. \\
\hline Ntandu & kon & AH n.o.p. \\
\hline 'Dogon’ & & AH or split \\
\hline Mankon & nge & AH or split \\
\hline Ongota & bxe & $\mathrm{AH}$ or split \\
\hline Boko/Busa & bqc & AH phonological DEP \\
\hline Bokobaru & bus & AH phonological DEP \\
\hline Burji & bji & AH S/TAM/P \\
\hline Daffo Ron & cla & AH S/TAM/P \\
\hline Nera & nrb & AH S/TAM/P \\
\hline Eunda & ndo, nne & $\mathrm{AH}$ \\
\hline Lese & les & AH S/TAM/P + DEP \\
\hline Ngandjera & nne & AH; pseudo-unfused \\
\hline Mabiha & kde & $\mathrm{AH}, \mathrm{LV}=\mathrm{DEP}$ \\
\hline Beja & bej & AH/Split \\
\hline Bongo & bot & $\mathrm{AH} / \mathrm{split}$ \\
\hline N Tonga & toy & $\mathrm{AH} ; \mathrm{NB}: \mathrm{S}$ Tonga $=$ fused $\mathrm{AH}$ \\
\hline Oshikwanyama & kua & AH; pseudo-unfused \\
\hline Punu & puu & $\mathrm{AH}$ \\
\hline Kuteb & kub & $\mathrm{AH} ; \mathrm{SVC}>\mathrm{AVC}$ \\
\hline Karekare & kai & $\mathrm{AH} ?$ \\
\hline Borobo & grv & AH?, Ø? \\
\hline Ejagham & etu & $\mathrm{AH}+\mathrm{DEP}$ \\
\hline Pajade (Badiaranke) & $\mathrm{pbp}$ & $\mathrm{AH}+\mathrm{DEP}$ \\
\hline Fula & ful & $\mathrm{AH}+\mathrm{DEP}$ or Split \\
\hline Koma & xom & $\mathrm{AH}+\varnothing$ \\
\hline Midob & mei & $\mathrm{AHa}$ \\
\hline Midob & mei & $\mathrm{AHb}$ \\
\hline
\end{tabular}




\begin{tabular}{|c|c|c|}
\hline Ewondo & ewo & AH-like SVC \\
\hline Banka (Samogo) & bxw & AUX on first word, LV DEP \\
\hline Uduk & udu & $\mathrm{CO}$ \\
\hline Solongo & ?kng & CO AH-like \\
\hline Kikongo & kng, kon & CO AH-like V.FOC \\
\hline Masakin (Ngile) & jle & f/f S/TAM/P AH \\
\hline $\mathrm{Ga}$ & gaa & fused "AH" \\
\hline Mambila & mzk; mcu & fused “AH” +DEP \\
\hline !Xun & knw & fused $\mathrm{AH}$ \\
\hline //Ani & $\mathrm{hnh} / \mathrm{xuu}$ & fused $\mathrm{AH}$ \\
\hline 'Dongo & doo & fused $\mathrm{AH}$ \\
\hline Aari & aiw & fused $\mathrm{AH}$ \\
\hline Acholi & ach & fused $\mathrm{AH}$ \\
\hline Afar & aar & fused $\mathrm{AH}$ \\
\hline Akan & aka & fused $\mathrm{AH}$ \\
\hline Akwa & akw & fused $\mathrm{AH}$ \\
\hline Anexo-Ewe & ewe & fused $\mathrm{AH}$ \\
\hline Anyi & any & fused $\mathrm{AH}$ \\
\hline Avatime & avn & fused $\mathrm{AH}$ \\
\hline Beja & bej & fused $\mathrm{AH}$ \\
\hline Berom/Birom & bom & fused $\mathrm{AH}$ \\
\hline Bilin & byn & fused $\mathrm{AH}$ \\
\hline Buga-/Anda & $\mathrm{hnh} / \mathrm{xuu}$ & fused $\mathrm{AH}$ \\
\hline Burak & bys & fused $\mathrm{AH}$ \\
\hline Cara & shg & fused $\mathrm{AH}$ \\
\hline Chichewa & nya & fused $\mathrm{AH}$ \\
\hline Coptic $^{\dagger}$ & cop & fused $\mathrm{AH}$ \\
\hline Dar Daju Daju & $\mathrm{djc}$ & fused $\mathrm{AH}$ \\
\hline Dogó sò & dts/dgs & fused $\mathrm{AH}$ \\
\hline Defaka & afn & fused $\mathrm{AH}$ \\
\hline Dilling & dil & fused $\mathrm{AH}$ \\
\hline Dime (Dim-Af) & $\operatorname{dim}$ & fused $\mathrm{AH}$ \\
\hline Donno So & dds & fused $\mathrm{AH}$ \\
\hline Echie & ibo & fused $\mathrm{AH}$ \\
\hline Eton & eto & fused $\mathrm{AH}$ \\
\hline
\end{tabular}




\begin{tabular}{|c|c|c|}
\hline Gik[u]yu & kik & fused $\mathrm{AH}$ \\
\hline Gimira (Benchnon) & bcq & fused $\mathrm{AH}$ \\
\hline Gogo & gog & fused $\mathrm{AH}$ \\
\hline Gokana & gkn & fused $\mathrm{AH}$ \\
\hline Hỵe & juh & fused $\mathrm{AH}$ \\
\hline Holoholo & hoo & fused $\mathrm{AH}$ \\
\hline Hungu & hum & fused $\mathrm{AH}$ \\
\hline Jibə & jib/juo & fused $\mathrm{AH}$ \\
\hline Jiddu Somali & jii & fused $\mathrm{AH}$ \\
\hline Kamba & kam & fused $\mathrm{AH}$ \\
\hline Kanuri & knc & fused $\mathrm{AH}$ \\
\hline Kenyang & ken & fused $\mathrm{AH}$ \\
\hline Kilba & $\mathrm{hbb}$ & fused $\mathrm{AH}$ \\
\hline Kinyarwanda & kin & fused $\mathrm{AH}$ \\
\hline Kolokuma Ijo & ijc & fused $\mathrm{AH}$ \\
\hline Kolokuma Izon & $\mathrm{ijc}$ & fused $\mathrm{AH}$ \\
\hline Kom & bkm & fused $\mathrm{AH}$ \\
\hline Kua & tyu & fused $\mathrm{AH}$ \\
\hline Lucazi & lch & fused $\mathrm{AH}$ \\
\hline Luguru & ruf & fused $\mathrm{AH}$ \\
\hline Lyaa & iyx & fused $\mathrm{AH}$ \\
\hline Makonde & kde & fused $\mathrm{AH}$ \\
\hline Mwera & mwe & fused $\mathrm{AH}$ \\
\hline Naro & nhr & fused $\mathrm{AH}$ \\
\hline Nawuri & naw & fused $\mathrm{AH}$ \\
\hline Ngiti & niy & fused $\mathrm{AH}$ \\
\hline Nkonya & nko & fused $\mathrm{AH}$ \\
\hline Nymawezi & nym & fused $\mathrm{AH}$ \\
\hline Obolo (Andoni) & ann & fused $\mathrm{AH}$ \\
\hline Ogbronuagom (Bukuma) & ogu & fused $\mathrm{AH}$ \\
\hline Òkó & oks & fused $\mathrm{AH}$ \\
\hline Onicha Igbo & ibo & fused $\mathrm{AH}$ \\
\hline Otoro & otr & fused $\mathrm{AH}$ \\
\hline Ruri & kya & fused $\mathrm{A}$ \\
\hline
\end{tabular}




\begin{tabular}{|c|c|c|}
\hline Sena & seh & fused $\mathrm{AH}$ \\
\hline Somali & som & fused $\mathrm{AH}$ \\
\hline Sumbwa & suw & fused $\mathrm{AH}$ \\
\hline Swahili & swh & fused $\mathrm{AH}$ \\
\hline Tennet & tex & fused $\mathrm{AH}$ \\
\hline Wannu & jub & fused $\mathrm{AH}$ \\
\hline Wapan & juk & fused $\mathrm{AH}$ \\
\hline Wap $_{\underset{\sim}{\mathrm{a}}}^{\mathrm{h}_{\mathrm{a}}}$ & juw & fused $\mathrm{AH}$ \\
\hline Wolaitta & wal & fused $\mathrm{AH}$ \\
\hline Wolof & wol, wof & fused $\mathrm{AH}$ \\
\hline Yao ?=Ciyao? & yao & fused $\mathrm{AH}$ \\
\hline Zulu & zul & fused $\mathrm{AH}$ \\
\hline Zaghawa/Beria & zag & fused AH (or split) \\
\hline Kolokuma Izon & ijc & fused $\mathrm{AH} \sim$ fused-psuedo-split \\
\hline Vamé & $\mathrm{mlr}$ & fused $\mathrm{AH}+\mathrm{DEP}$ \\
\hline Pambia & $\mathrm{pmb}$ & fused $\mathrm{AH}+\mathrm{DEP}[\mathrm{f} / \mathrm{f} \mathrm{S} / \mathrm{TAM} / \mathrm{P}]$ \\
\hline Kwama & $\mathrm{kmq}$ & fused $\mathrm{AH}$ or $\mathrm{LH}$ \\
\hline Ila & ilb & fused AH or split \\
\hline Klao & klu & fused AH S/TAM/P \\
\hline Nera & nrb & fused $\mathrm{AH}$ \\
\hline Kisi & kss & fused $\mathrm{AH}$ w/pas \\
\hline Dizi (Maji) & $\operatorname{mdx}$ & fused $\mathrm{AH}, \mathrm{LV}=\mathrm{DEP} / \varnothing$-AUX \\
\hline S Tonga & toi & fused $\mathrm{AH} ; \mathrm{NB}$ : $\mathrm{N}$ Tonga $=\mathrm{AH}$ \\
\hline Pare & asa & fused $\mathrm{AH} ?$ \\
\hline Bukusu & bxk & fused $\mathrm{AH}+\mathrm{DEP}$ \\
\hline Khwe/Khoe & xuu & fused $\mathrm{AH}+\mathrm{DEP}$ \\
\hline Midob & mei & fused $\mathrm{AHa}$, fused $\mathrm{AHb}$ \\
\hline Bushoong & buf & fused $\mathrm{CO}$ AH-like \\
\hline Tsongo & tso & fused LH/AH \\
\hline Kolonkadhi & ndo, nne & fused split or AH \\
\hline Mbandja & kua & fused split or $\mathrm{AH}$ \\
\hline Kafima & kua & fused split/AH; LV =DEP \\
\hline Doyayo & dow & Fused? AH \\
\hline Tonga & toh & $\mathrm{LH} \sim \mathrm{AH}$ \\
\hline Shambaa & $\mathrm{ksb}$ & LH/fused AH \\
\hline
\end{tabular}




$\begin{array}{lll}\text { Kanuri } & \text { knc } & \text { Light verb } \\ \text { Fur } & \text { fur/?fvr } & \text { Light vb construction AH-like } \\ \text { Koma } & \text { xom } & \text { NEG.AUX AH } \\ \text { Tumbuka } & \text { tum } & \text { new AH } \\ \text { Majang } & \text { mpe } & \text { pseudo-2x AH w/pas } \\ \text { Kolokuma Izon } & \text { ijc } & \text { pseudo-f/fS/TAM/P } \\ \text { Gùrdùy } & \text { grd } & \text { S/TAM/P }+ \text { AH } \\ \text { Fer } & \text { kah } & \text { S/TAM/P AH }+ \text { DEP } \\ \text { Kresh } & \text { krs } & \text { S/TAM/P AH }+ \text { DEP }\end{array}$

Appendix-4: Languages w/ Doubled Inflection AVCs and complex verbs derived therefrom

\section{Language}

Jalonke

Masalit

Kanuri

Tira

Muher

$\mathrm{N} \mid \mathrm{uu}$

Kirma

Tyurama

łUngkue

Wapan/Wukari

Xhosa

Nomaande

Zande

Nawuri

Alagwa

Babungo

Bagirmi

Beja

\section{ISO 639-3 code}

yal

$\mathrm{mls}$

knc

tic

sgw

ngh

cme

tuz

xam

juk

xho

lem

zne

naw

wbj

bav

bmi

bej

\section{Pattern}

$(\mathrm{S} /)_{2}$

(S/)2 +DEP

(S/)2 CAP

$(\mathrm{S} /) 2,2 \mathrm{x}$ CLS[FR $]+$ "SUBJ"

(S/)2x

"2X NEG"

" $2 \mathrm{x}$ "

" $2 \mathrm{x} "$

" $2 x "$

" $2 \mathrm{x}$ "

" $2 \mathrm{x}$ "

" $2 \mathrm{x}$ " [+DEP]

" $2 \mathrm{x}$ " + DEP SUBJ

" $2 \mathrm{x}$ " fused

$2 \mathrm{x}$

$2 \mathrm{x}$

$2 \mathrm{x}$

$2 \mathrm{x}$ 
C. B. L

Chaha Gurage

Chichewa

Dahalo

Dyola

Ejagham

Gehode

Gidar

Harar Oromo

Hune

Herero

Jamsay

Kabba

Kinyarwanda

Kunama

Kuri(y)a

Lokaa

Lungu

Ma'di

Mbe

Muyang

Mwera

Ngbandi

Ogbronuagom (Bukuma)

Òkó

Ruri

Sese Gumuz

Setswana

Siluyana

Siswati

Tigrinya

Vute

Yambasa

Zing Mumuye

Noni
$?$

sgw

nya

dal

dyu

etu

acd

gid

hae

juh

her

djm

ksp

kin

kun

kuj

yaz

mgr

$\mathrm{mhi} / \mathrm{snm}$

mfo

muy

mwe

ngb/nbw

ogu

oks

kya

guk

tsn

lyn

SsW

tir

vut

yas

mzm

nhu
$2 \mathrm{x}$

$2 \mathrm{x}$

$2 \mathrm{x}$

$2 \mathrm{x}$

$2 \mathrm{x}$

$2 \mathrm{x}$

$2 \mathrm{x}$

$2 \mathrm{x}$

$2 \mathrm{x}$

$2 \mathrm{x}$

$2 \mathrm{x}$

$2 \mathrm{x}$

$2 \mathrm{x}$

$2 \mathrm{x}$

$2 \mathrm{x}$

$2 \mathrm{x}$

$2 \mathrm{x}$

$2 \mathrm{x}$

$2 \mathrm{x}$

$2 \mathrm{x}$

$2 \mathrm{x}$

$2 \mathrm{x}$

$2 \mathrm{x}$

$2 \mathrm{x}$

$2 \mathrm{x}$

$2 \mathrm{x}$

$2 \mathrm{x}$

$2 \mathrm{x}$

$2 \mathrm{x}$

$2 \mathrm{x}$

$2 \mathrm{x}$

$2 \mathrm{x}$

$2 x$

$2 \mathrm{x}$

2x [1sg only?] 
Fur

(I)Rigwe

Mangbetu

Shona

Kua

Dar Daju Daju

Gula Méré

Sukuma(-Kiiya)

Gula Sara

Temein

Tumbuka

Meje

Ngiti

Sonjo

Ebang

Otoro

Heiban

Gworok/Kagoro

Tumale

Aka

Gade

Oromo of Wellega

Turkana

Bukusu

Duala

Hemba

Kana

Maasai

Akan

Bongo

Twi

Gùrdùy

Linda

Gaam fur/?fvr

iri

mdj

sna

tyu

djc

$\mathrm{kcm}$

suk

$\mathrm{kcm}$

teq

tum

mdj

niy

soz

hbn

otr

hbn

$\mathrm{kcg}$

tag

soh

ged

gaz

tuv

bxk

dua

hem

ogo

mas

aka

bot

aka

grd

liy

tbi 2x (not yet)

$2 \mathrm{x}$ (+origin)

$2 \mathrm{x}$ ( \pm DEP) $\mathrm{S} / \mathrm{TAM} / \mathrm{P}$

$2 \mathrm{x}$ (SUBJ +DEP?)

$2 \mathrm{x} \sim \mathrm{AH}$

$\{2 \mathrm{x} / \mathrm{AH} / \mathrm{split}$ \}

$2 \mathrm{x} \sim \mathrm{AH}+\mathrm{DEP}$

$2 \mathrm{x} \sim \mathrm{LH}$

$2 \mathrm{x} \sim \mathrm{LH}+\mathrm{DEP}$

$2 \mathrm{x}+\mathrm{DEP}$

$2 \mathrm{x}+$ DEP $<$ say

$2 \mathrm{x}+\mathrm{S} / \mathrm{TAM} / \mathrm{P}$

$2 \mathrm{X}$ AUX $=$ DEP

$2 \mathrm{X}$ AUX $=\mathrm{DEP}$ !

2x CLS[FR]

$2 \mathrm{x}$ CLS[FR]

2x CLSFR

$2 \mathrm{x}$ for $1 \mathrm{SG} \mathrm{w} /$ some $\mathrm{Vs}$

$2 \mathrm{x}$ fused/LH

$2 x \mathrm{LV}=\mathrm{DEP}$

$2 x L V=D E P$

$2 x L V=D E P$

$2 x L V=D E P$

$2 x L V=D E P$

$2 x L V=D E P$

$2 x L V=D E P$

$2 x L V=D E P$

$2 x L V=D E P$

$2 \mathrm{x}$ NEG

2x NEG

$2 \mathrm{x}$ NEG

2X NEG Ø-AUX?

$2 \mathrm{x}$ or pseudo- $2 \mathrm{x}$ with pas

2x S/TAM/P 


\begin{tabular}{|c|c|c|}
\hline Shatt & shj & $2 \mathrm{x}$ SUBJ $( \pm \mathrm{DEP})$ \\
\hline Berta & wti & $2 \mathrm{x}$ SUBJ $+\mathrm{DEP}$ \\
\hline Moro & mor & 2x SUBJ! (NOT CLS[FR]) \\
\hline Songye & sop & $2 \mathrm{X} \mathrm{SVC}$ \\
\hline Ngambay-Moundou & $\mathrm{sba}$ & 2x vs. AH n.o.p. \\
\hline Venda & ven & $2 \mathrm{x}, \mathrm{LV}=\mathrm{DEP}$ \\
\hline Ateso & teo & $2 \mathrm{x}, \mathrm{LV}=\mathrm{DEP}$ \\
\hline Degema & $\operatorname{deg}$ & $2 x ?$ \\
\hline Egyptian $^{\dagger}$ & egy & $2 x ?$ \\
\hline Akoose & bss & $2 \mathrm{x}$-SUBJ \\
\hline Mursi & muz & $\mathrm{AH} \sim ? 2 \mathrm{x} ?$ \\
\hline Didinga & did & $\mathrm{AH} \sim 2 \mathrm{x}$ \\
\hline Diola-Fogny & dyo & $\mathrm{AH} \sim 2 \mathrm{x}$ \\
\hline Gimira (Benchnon) & bcq & $\mathrm{AH} \sim 2 \mathrm{x}$ \\
\hline Murle & mur & $\mathrm{AH} \sim 2 \mathrm{x}$ \\
\hline Tonga & toh & $\mathrm{AH} \sim$ fused $2 \mathrm{x}$ \\
\hline $\mathrm{Ik}$ & $\mathrm{ikx}$ & $2 \mathrm{x} / \mathrm{AH}$ \\
\hline Tima & $\mathrm{tms}$ & fused $(\mathrm{S} /)_{2}$ \\
\hline Krongo & kgo & fused $+2 x ?$ \\
\hline Amharic & $\mathrm{amh}$ & fused $2 x$ \\
\hline Coptic $^{\dagger}$ & cop & fused $2 \mathrm{x}$ \\
\hline Hamer & $\mathrm{amf}$ & fused $2 x$ \\
\hline Kemantney & ahg & fused $2 x$ \\
\hline Kunama & kun & fused $2 x$ \\
\hline Ogbronuagom (Bukuma) & ogu & fused $2 x$ \\
\hline Tama & tma & fused $2 x$ \\
\hline Tennet & tex & fused $2 x$ \\
\hline Tonga & toh & fused $2 \mathrm{x}$ \\
\hline Lango & laj & fused $2 \mathrm{x}$ \\
\hline Molo & zmo & fused $2 x$ \\
\hline Khoe & xuu & fused 2x 'DEP' \\
\hline Aiki [Runga] & rou & fused $2 \mathrm{x}$ FUT of come/go? \\
\hline Koegu & xwg & fused $2 \times \mathrm{LV}=\mathrm{DEP}$ \\
\hline Tira & tic & fused $2 \mathrm{x}$ OBJ \\
\hline Majang & mpe & fused/pseudo-2x AH w/pas \\
\hline
\end{tabular}


Nera

Gonga (Kefa/Kafa)

Mbay

Kuteb

Afar

Gidar nrb

$\mathrm{kbr}$

myb

kub

aar

gid fused $2 \mathrm{x} \mathrm{S} / \mathrm{TAM} / \mathrm{P}$

fused $\mathrm{LH} / 2 \mathrm{x}$

$2 \mathrm{x} \sim \mathrm{LH}$

Pseudo-2x w/ICP

$\mathrm{SVC}>\mathrm{AVC} 2 \mathrm{x} L V=\mathrm{DEP}$

fused $2 x[V-A U X]$

Appendix-5: Languages with LEX-Headed AVCs and complex verbs derived therefrom

\section{Language}

Sango

Gbaya 'Buli

Sukuma(-Kiiya)

Gula Sara

Kwama

Aari

Beja

Diola

Evale

Ewe

Hamer

Hdi

Karimojong

Katla

Kemantney

Kunama

Langi

Mbembe

Nyimang

Vamé

Berta

Mamvu

\section{ISO 639-3 Code}

sag

gso

suk

$\mathrm{kcm}$

$\mathrm{kmq}$

aiw

bej

?jol

kua

ewe

amf

xed

kdj

kcr

ahg

kun

lag

$\mathrm{mfn}$

nyi

$\mathrm{mlr}$

wti

mdi

\section{Pattern}

"LH"

"LH" +DEP.AUX!

$2 \mathrm{x} \sim \mathrm{LH}$

$2 \mathrm{x} \sim \mathrm{LH}+\mathrm{DEP}$

fused $\mathrm{AH}$ or $\mathrm{LH}$

fused LH

fused LH

fused $\mathrm{LH}$

fused LH

fused LH

fused LH

fused $\mathrm{LH}$

fused LH

fused LH

fused LH

fused LH

fused $\mathrm{LH}$

fused LH

fused LH

fused LH

fused LH (FUT)

fused $\mathrm{LH}=\mathrm{V}$ AUX 


\begin{tabular}{lll} 
Nandi & kln & fused LH, LV =DEP - $~$ \\
Gonga (Kefa/Kafa) & kbr & fused LH/2x \\
Tumale & tag & fused LH/2x \\
Tsongo & tso & fused LH/AH \\
Koegu & xwg & fused LH? \\
Ndamba & ndj & fused LH? \\
Mwera & mwe & fused LH+DEP \\
Gidar & gid & fused split/LH \\
!Ora & kqz & LH \\
'Berber' & ber & LH \\
Acholi & ach & LH \\
Baale & koe & LH \\
Bongo & bot & LH \\
Burak & bys & LH \\
Doyayo & dow & LH \\
Ejagham & etu & LH \\
Evale & kua & LH \\
Ewe & ewe & LH \\
Gidar & gid & LH \\
& ?gry; grv; gec; gbo; & \\
Grebo & grj? & LH \\
Hamer & amf & LH \\
Harar Oromo & hae & LH \\
Ik & akx & LH \\
Ju/'hoan & ktz & LH \\
Katla & kcr & LH \\
Kerewe & ked & LH \\
Kolokuma Ijo & ijc & LH \\
Kunama & kun & LH \\
Laal & gdm & LH \\
Lele & lln & \\
Mödö & ?bex & LH \\
Nama & LH \\
Noni & LH \\
Obolo (Andoni) & LH \\
\hline
\end{tabular}




$\begin{array}{lll}\text { Orig } & \text { tag } & \text { LH } \\ \text { Sele } & \text { snw } & \text { LH } \\ \text { Supyire } & \text { spp } & \text { LH } \\ \text { Turkana } & \text { tuv } & \text { LH } \\ \text { ut-Ma'in } & \text { gel } & \text { LH } \\ \text { Vamé } & \text { mlr } & \text { LH } \\ \text { Kabba } & \text { ksp } & \text { LH (in 2PL) } \\ \text { Sandawe } & \text { sad } & \text { LH (or split?) } \\ \text { Mbay } & \text { myb } & \text { LH } \sim 2 x \\ \text { Tonga } & \text { toh } & \text { LH } \sim \text { AH } \\ \text { Gidar } & \text { gid } & \text { LH }+ \text { ICP } \\ \text { Tennet } & \text { tex } & \text { LH }+ \text { DEP } \\ \text { Ik } & \text { ikx } & \text { LH }=\text { V AUX } \\ \text { Dar Daju Daju } & \text { djc } & \text { LH IRR } \\ \text { Mada } & \text { mda } & \text { LH or “S/TAM/P” } \\ \text { Otoro } & \text { otr } & \text { LH source } \\ \text { Tamashek } & \text { taq } & \text { LH/(?pseudo)split clitic } \\ \text { Shambaa } & \text { ksb } & \text { LH/fused AH } \\ \text { Koyo } & \text { god } & \text { LH? } \\ \text { Nyimang } & \text { nyi } & \text { LH? } \\ \text { Twi } & \text { aka } & \text { pseudo- }\{\text { LH } \sim \text { AH }\} \\ \text { Inor } & \text { ior } & \text { split }>\text { LH } \\ \text { Maasai } & \text { mas } & \text { split }>\text { LH } \\ \text { N. Sotho } & \text { nso } & \text { split, LV }=\text { DEP or LH } \\ \text { Tasawaq } & \text { twq } & \text { SVC }>\text { AVC LH } \\ & & \end{array}$


Appendix-6: Languages with Split and Split/Doubled Inflectional AVCs and complex verbs derived therefrom

\section{Language}

Jalonke

Tira

Masalit

Kanuri

Muher

Tama

W. !Xoon

Yakoma

Zing Mumuye

Dar Daju Daju

'Dogon'

Mankon

Ongota

Beja

Bongo

Tima

Pero

Zaghawa/Beria

Ila

Gidar

Gawwada Dullay

Mbalanhu

Otoro

Pero

Berta

Bolanci

Dho-Alur

Gawwada Dullay

Karekare

Kemantney

Pero

\section{ISO 639-3 Code}

yal

tic

mls

knc

sgw

tma

nmn

yky

mzm

djc

nge

bxe

bej

bot

tms

pip

zag

ilb

gid

gwd

lnb

otr

pip

wti

bol

alz

gwd

kai

ahg

pip

\section{Pattern}

$(\mathrm{S} /)_{2}$

$(\mathrm{S} /)^{2}$

(S/)2 +DEP

$(\mathrm{S} / 2 \mathrm{CAP}$

(S/)2x

(S/)2x

?split

"S/2"

"split"

2x/AH/split?

AH or split

AH or split

AH or split

AH/Split

AH/split

fused (S/)2

fused $2 x+$ split

fused $\mathrm{AH}$ (or split)

fused $\mathrm{AH}$ or split

fused ICP

fused $\mathrm{S} / 2$

fused $\mathrm{S} / 2$

fused $\mathrm{S} / 2$

fused $\mathrm{S} / 2$

fused split

fused split

fused split

fused split

fused split

fused split

fused split 


\begin{tabular}{|c|c|c|}
\hline Ebang/Heiban & hbn & fused split $+\mathrm{S} / 2$ \\
\hline Egyptian $^{\dagger}$ & egy & fused split $+\mathrm{DEP}$ \\
\hline Sese Gumuz & guk & fused split? \\
\hline Langi & lag & fused split+DEP \\
\hline Sandawe & sad & LH (split?) \\
\hline Tamashek & $\operatorname{taq}$ & LH/(?pseudo)split clitic \\
\hline Rashad & ras & NEG split \\
\hline Tagoi & tag & NEG split \\
\hline Tumale & $\operatorname{tag}$ & NEG split \\
\hline (Ki)Matumbi & mgw & $\mathrm{S} / 2$ \\
\hline ‘Dogon’ & & $\mathrm{S} / 2$ \\
\hline Beja & bej & $\mathrm{S} / 2$ \\
\hline Bemba & bem & $\mathrm{S} / 2$ \\
\hline Bolanci & bol & $\mathrm{S} / 2$ \\
\hline Bungu & wun & $\mathrm{S} / 2$ \\
\hline Ciyao & yao & $\mathrm{S} / 2$ \\
\hline Doyayo & dow & $\mathrm{S} / 2$ \\
\hline Egyptian Arabic & arz & $\mathrm{S} / 2$ \\
\hline Ejagham & etu & $\mathrm{S} / 2$ \\
\hline Eleme & elm & $\mathrm{S} / 2$ \\
\hline Giryama & nyf & $\mathrm{S} / 2$ \\
\hline Harar Oromo & hae & $\mathrm{S} / 2$ \\
\hline Haya & hay & $\mathrm{S} / 2$ \\
\hline Ibibio & $i b b$ & $\mathrm{~S} / 2$ \\
\hline Karekare & kai & $\mathrm{S} / 2$ \\
\hline Kemantney & ahg & $\mathrm{S} / 2$ \\
\hline Kinyarwanda & kin & $\mathrm{S} / 2$ \\
\hline Kirundi & run & $\mathrm{S} / 2$ \\
\hline Kuri(y)a & kuj & $\mathrm{S} / 2$ \\
\hline Lamba & lam & $\mathrm{S} / 2$ \\
\hline Lango & laj & $\mathrm{S} / 2$ \\
\hline Luba & lua, lub & $\mathrm{S} / 2$ \\
\hline Luganda & $\operatorname{lug}$ & $\mathrm{S} / 2$ \\
\hline Mbalanhu & $\operatorname{lnb}$ & $\mathrm{S} / 2$ \\
\hline
\end{tabular}




$\begin{array}{lll}\text { Mbay } & \text { myb } & \mathrm{S} / 2 \\ \text { Nkore-Kiga } & \text { nyn } & \mathrm{S} / 2 \\ \text { Oromo of Wellega } & \text { gaz } & \mathrm{S} / 2 \\ \text { Pero } & \text { pip } & \mathrm{S} / 2 \\ \text { Pimbwe } & \text { piw } & \mathrm{S} / 2 \\ \text { Pokomo } & \text { poj or pkb } & \mathrm{S} / 2 \\ \text { Ruri } & \text { kya } & \mathrm{S} / 2 \\ \text { Setswana } & \text { tsn } & \mathrm{S} / 2 \\ \text { Shambala } & \text { ksb } & \mathrm{S} / 2 \\ \text { Siswati } & \text { ssw } & \mathrm{S} / 2 \\ \text { Songye } & \text { sop } & \mathrm{S} / 2 \\ \text { Sukuma(-Kiiya) } & \text { suk } & \mathrm{S} / 2 \\ \text { Swahili } & \text { swh } & \mathrm{S} / 2 \\ \text { Vamé } & \text { mlr } & \mathrm{S} / 2 \\ \text { Xhosa } & \text { xho } & \mathrm{S} / 2 \\ \text { Yao ?=Ciyao? } & \text { yao } & \mathrm{S} / 2 \\ \text { Lango } & \text { laj } & \mathrm{S} / 2 \\ \text { Sena } & \text { seh } & \mathrm{S} / 2+\mathrm{DEP} \\ \text { Lungu } & \text { mgr } & \mathrm{S} / 2 \pm \mathrm{DEP} \\ \text { Akoose } & \text { bss } & \mathrm{S} / 2 \text { NEG } \\ \text { Baule } & \text { bci } & \mathrm{S} / 2 \text { origin } \\ \text { Gehode } & \text { acd } & \mathrm{S} / 2 \text { origin } \\ \text { Echie } & \text { ibo } & \mathrm{S} / 2 \text { PHB } \\ \text { Oshikwanyama } & \text { kua } & \mathrm{S} / 2 \text { pseudo-unfused } \\ \text { Ogbronuagom (Bukuma) } & \text { ogu } & \mathrm{S} / 2 ; \text { split } \\ \text { Makua-Maverone } & \text { xme } & \mathrm{S} / 2 \mathrm{x} \\ \text { Polci } & \text { plj } & \mathrm{S} / \mathrm{TAM} / \mathrm{P}+\text { split } \\ \text { Afuzare/Zarek/Izere } & \text { fiz } & \mathrm{split} \\ \text { Akwa } & \text { akw } & \mathrm{split} \\ \text { Anexo-Ewe } & \text { ewe } & \mathrm{split} \\ \text { Bolanci } & \text { bol } & \mathrm{split} \\ \text { Dagaare } & \text { dgi } & \mathrm{split} \\ \text { Dho-Alur } & \text { slz } & \\ \text { Eleme } & & \mathrm{split} \\ \text { Ewe } & \text { elm } & \\ & & \end{array}$




\begin{tabular}{|c|c|c|}
\hline Gidar & gid & split \\
\hline Gimira (Benchnon) & bcq & split \\
\hline Harar Oromo & hae & split \\
\hline Katcha & xtc & split \\
\hline Laal & $\mathrm{gdm}$ & split \\
\hline Ma'di & $\mathrm{mhi} / \mathrm{snm}$ & split \\
\hline Mbe & mfo & split \\
\hline Òkó & oks & split \\
\hline Orig & tag & split \\
\hline Oromo of Wellega & gaz & split \\
\hline Pero & pip & split \\
\hline Shabo & $\mathrm{sbf}$ & split \\
\hline Sil'te & stv & split \\
\hline Supyire & spp & split \\
\hline Swahili & swh & split \\
\hline Tiv & tiv & split \\
\hline Turkana & tuv & split \\
\hline Vute & vut & split \\
\hline Hadza & hts & split (+ DEP) \\
\hline Tennet & tex & split +DEP \\
\hline Inor & ior & split $>$ LH \\
\hline Maasai & mas & split $>$ LH \\
\hline Kolokuma Ijo & ijc & split NEG.LV \\
\hline Dasenech & dsh & split [+S/TAM/P?] \\
\hline N. Sotho & nso & split, LV =DEP; or LH \\
\hline Kana & ogo & split, pseudo-split \\
\hline Gidar & gid & split/LH, \\
\hline Kana & ogo & split/pseudo-split \\
\hline Anywa & anu & split? \\
\hline $\mathrm{Ju} /$ 'hoan & ktz & split? \\
\hline Kanuri & knc & split? \\
\hline Obolo (Andoni) & ann & split? \\
\hline Yoruba & yor & split? \\
\hline Fur & fur/?fvr & split? $k-$ \\
\hline
\end{tabular}


Bijogo

bjg

$\mathrm{SVC}>$ split origin

Appendix-7: Languages with fused Subject/TAM/Polarity AVCs and complex fused/fused verbs derived therefrom

$\begin{array}{lll}\text { Language } & \text { ISO 639-3 Code } & \text { Pattern } \\ \text { (I)Rigwe } & \text { iri } & \mathrm{S} / \mathrm{TAM} / \mathrm{P} \\ \text { Ader Hausa } & \text { hau } & \mathrm{S} / \mathrm{TAM} / \mathrm{P} \\ \text { Angas } & \text { anc } & \mathrm{S} / \mathrm{TAM} / \mathrm{P} \\ \text { Bagirmi } & \text { bmi } & \mathrm{S} / \mathrm{TAM} / \mathrm{P} \\ \text { Baka } & \text { bdh } & \mathrm{S} / \mathrm{TAM} / \mathrm{P} \\ \text { Baule } & \text { bci } & \mathrm{S} / \mathrm{TAM} / \mathrm{P} \\ \text { Bejamso-Grubi Nchumuru } & \text { ncu } & \mathrm{S} / \mathrm{TAM} / \mathrm{P} \\ \text { Boko/Busa } & \text { bqc } & \mathrm{S} / \mathrm{TAM} / \mathrm{P} \\ \text { Bokobaru } & \text { bus } & \mathrm{S} / \mathrm{TAM} / \mathrm{P} \\ \text { Bongo } & \text { bot } & \mathrm{S} / \mathrm{TAM} / \mathrm{P} \\ \text { Buem/Lelemi } & \text { lef } & \mathrm{S} / \mathrm{TAM} / \mathrm{P} \\ \text { Daba } & \text { dbq } & \mathrm{S} / \mathrm{TAM} / \mathrm{P} \\ \text { Dangme } & \text { ada } & \mathrm{S} / \mathrm{TAM} / \mathrm{P} \\ \text { Dewoin } & \text { dee } & \mathrm{S} / \mathrm{TAM} / \mathrm{P} \\ \text { Ebira/Igbirra } & \text { igb } & \mathrm{S} / \mathrm{TAM} / \mathrm{P} \\ \text { Ega } & \text { ega } & \mathrm{S} / \mathrm{TAM} / \mathrm{P} \\ \text { Eggon } & \text { ego } & \mathrm{S} / \mathrm{TAM} / \mathrm{P} \\ \text { Ewe } & \text { ewe } & \mathrm{S} / \mathrm{TAM} / \mathrm{P} \\ \text { Frafra } & \text { gur } & \mathrm{S} / \mathrm{TAM} / \mathrm{P} \\ \text { Fyem } & \text { pym } & \mathrm{S} / \mathrm{TAM} / \mathrm{P} \\ \text { Ga } & \text { gaa } & \mathrm{S} / \mathrm{TAM} / \mathrm{P} \\ \text { Gehode } & \text { acd } & \mathrm{S} / \mathrm{TAM} / \mathrm{P} \\ \text { Genyanga } & \text { ayg } & \mathrm{S} / \mathrm{TAM} / \mathrm{P} \\ \text { Gidar } & \text { gid } & \mathrm{S} / \mathrm{TAM} / \mathrm{P} \\ \text { Guus/Sigidi } & \text { say } & \mathrm{S} / \mathrm{TAM} / \mathrm{P} \\ \text { Hausa } & \text { hau } & \mathrm{S} / \mathrm{TAM} / \mathrm{P} \\ \text { Idu(n) } & \text { ldb } & \mathrm{S} / \mathrm{TAM} / \mathrm{P}\end{array}$




$\begin{array}{lll}\text { Ikaan } & \text { kcf } & \mathrm{S} / \mathrm{TAM} / \mathrm{P} \\ \text { Jo[wulu] } & \text { jow } & \mathrm{S} / \mathrm{TAM} / \mathrm{P} \\ \text { Karang } & \text { kzr } & \mathrm{S} / \mathrm{TAM} / \mathrm{P} \\ \text { Karekare } & \text { kai } & \mathrm{S} / \mathrm{TAM} / \mathrm{P} \\ \text { Kom } & \text { bkm } & \mathrm{S} / \mathrm{TAM} / \mathrm{P} \\ \text { Kulango } & \text { kzc/nku } & \mathrm{S} / \mathrm{TAM} / \mathrm{P} \\ \text { Limbum } & \text { lmp } & \mathrm{S} / \mathrm{TAM} / \mathrm{P} \\ \text { Ma'di } & \text { mhi/snm } & \mathrm{S} / \mathrm{TAM} / \mathrm{P} \\ \text { Mbay } & \text { myb } & \mathrm{S} / \mathrm{TAM} / \mathrm{P} \\ \text { Mbuko } & \text { mqb } & \mathrm{S} / \mathrm{TAM} / \mathrm{P} \\ \text { Mende } & \text { men } & \mathrm{S} / \mathrm{TAM} / \mathrm{P} \\ \text { Mundabli } & \text { boe } & \mathrm{S} / \mathrm{TAM} / \mathrm{P} \\ \text { Nafaara } & \text { nfr } & \mathrm{S} / \mathrm{TAM} / \mathrm{P} \\ \text { Ndemli } & \text { nml } & \mathrm{S} / \mathrm{TAM} / \mathrm{P} \\ \text { Neyo } & \text { ney } & \mathrm{S} / \mathrm{TAM} / \mathrm{P} \\ \text { Nyo } & \text { ?ney } & \mathrm{S} / \mathrm{TAM} / \mathrm{P} \\ \text { Oko/Ogori } & \text { oks } & \mathrm{S} / \mathrm{TAM} / \mathrm{P} \\ \text { Sara } & \text { mwm } & \mathrm{S} / \mathrm{TAM} / \mathrm{P} \\ \text { Shabo } & \text { sbf } & \mathrm{S} / \mathrm{TAM} / \mathrm{P} \\ \text { Supyire } & \text { spp } & \mathrm{S} / \mathrm{TAM} / \mathrm{P} \\ \text { Tira } & \text { tic } & \mathrm{S} / \mathrm{TAM} / \mathrm{P} \\ \text { Tiv } & \text { tiv } & \mathrm{S} / \mathrm{TAM} / \mathrm{P} \\ \text { Vata } & \text { dic } & \mathrm{S} / \mathrm{TAM} / \mathrm{P} \\ \text { Wobé } & \text { wob } & \mathrm{S} / \mathrm{TAM} / \mathrm{P} \\ \text { Wolof } & \text { wol, wof } & \mathrm{S} / \mathrm{TAM} / \mathrm{P} \\ \text { Yemba } & \text { ybb } & \mathrm{S} / \mathrm{TAM} / \mathrm{P} \\ \text { Yulu } & \text { yul } & \mathrm{S} / \mathrm{TAM} / \mathrm{P} \\ \text { Dan-Gweeta } & \text { daf } & \mathrm{S} / \mathrm{TAM} / \mathrm{P}[\mathrm{NEG}] \\ \text { Gokana } & \text { gkn } & \mathrm{S} / \mathrm{TAM} / \mathrm{P}[\mathrm{NEG}] \\ \text { Mano } & \text { mev } & \mathrm{S} / \mathrm{TAM} / \mathrm{P}[\mathrm{NEG}] \\ \text { Nupe } & \text { nup } & \mathrm{S} / \mathrm{TAM} / \mathrm{P}[\mathrm{NEG}] \\ \text { Meeka } & \text { rkm } / \mathrm{P}[\mathrm{NEG]+} \\ \text { Neyo } & \mathrm{S} / \mathrm{TAM} / \mathrm{P}[\mathrm{NEG}][\mathrm{AH}] \\ \text { Guro } & \mathrm{S} / \mathrm{TAM} / \mathrm{P}[\mathrm{NEG]} \text { Tone }=\mathrm{TNS} \\ & & \end{array}$




\begin{tabular}{|c|c|c|}
\hline Ngizim & ngi & $\mathrm{S} / \mathrm{TAM} / \mathrm{P}+\mathrm{AH}$ \\
\hline Likpe & lip & $\mathrm{S} / \mathrm{TAM} / \mathrm{P}+\mathrm{DEP}$ \\
\hline ‘Bozom & $\mathrm{gbq}$ & $\mathrm{S} / \mathrm{TAM} / \mathrm{P}+\mathrm{DEP}$ \\
\hline Polci & $\mathrm{plj}$ & $\mathrm{S} / \mathrm{TAM} / \mathrm{P}+$ split \\
\hline Gaam & tbi & S/TAM/P 2x \\
\hline Meje & mdj & $\mathrm{S} / \mathrm{TAM} / \mathrm{P} 2 \mathrm{x}$ \\
\hline Daffo Ron & cla & $\mathrm{S} / \mathrm{TAM} / \mathrm{P} \mathrm{AH}$ \\
\hline Kelo & xel & S/TAM/P AH \\
\hline Klao & klu & S/TAM/P AH \\
\hline Fer & kah & $\mathrm{S} / \mathrm{TAM} / \mathrm{P} \mathrm{AH}+\mathrm{DEP}$ \\
\hline Kresh & krs & $\mathrm{S} / \mathrm{TAM} / \mathrm{P} \mathrm{AH}+\mathrm{DEP}$ \\
\hline Okpamberi & opa & $\mathrm{S} / \mathrm{TAM} / \mathrm{P}$ PRF \\
\hline Duka & dud & S/TAM/P some \\
\hline Dasenech & dsh & S/TAM/P split \\
\hline Hadza & hts & S/TAM/P? \\
\hline Kpelle & xpe & $\mathrm{S} / \mathrm{TAM} / \mathrm{P} ?+\mathrm{AH}$ \\
\hline Ukaan & $\mathrm{kcf}$ & S/TAM/P(+DEP, split) \\
\hline Fyem & pym & $\mathrm{S} / \mathrm{TAM} / \mathrm{P}+2 \mathrm{x}$ \\
\hline Afuzare/Zarek & fiz & $\mathrm{S} / \mathrm{TAM} / \mathrm{P}+\mathrm{AH}$ \\
\hline Gerka (Yiwom) & gek & $\mathrm{S} / \mathrm{TAM} / \mathrm{P}+\mathrm{AH}$ \\
\hline Gùrdùn & grd & $\mathrm{S} / \mathrm{TAM} / \mathrm{P}+\mathrm{AH}$ \\
\hline Montol & mtl & $\mathrm{S} / \mathrm{TAM} / \mathrm{P}+\mathrm{AH}$ \\
\hline Burrum (Boghom) & bux & $\mathrm{S} / \mathrm{TAM} / \mathrm{P}+$ split \\
\hline Krachi & kye & $\mathrm{S} / \mathrm{TAM} / \mathrm{P}+$ split \\
\hline Siwu & akp & $\mathrm{S} / \mathrm{TAM} / \mathrm{P}+$ split \\
\hline Yakoma & yky & $\mathrm{S} / \mathrm{TAM} / \mathrm{P}+$ split \\
\hline Montol & $\mathrm{mtl}$ & $\mathrm{S} / \mathrm{TAM} / \mathrm{P}+2 \mathrm{x}$ \\
\hline Tarok & yer & $\mathrm{S} / \mathrm{TAM} / \mathrm{P}+\mathrm{AH}$ \\
\hline Tarok & yer & $\mathrm{S} / \mathrm{TAM} / \mathrm{P}+\mathrm{AH}+\mathrm{DEP}$ \\
\hline Dott/Zodi & dot & $\mathrm{S} / \mathrm{TAM} / \mathrm{P}+\mathrm{AH}+\mathrm{DEP}$ \\
\hline Burak & bys & $\mathrm{S} / \mathrm{TAM} / \mathrm{P}+\mathrm{DEP}$ \\
\hline Dinik (Afitti) & aft & $\mathrm{S} / \mathrm{TAM} / \mathrm{P}+\mathrm{DEP}$ \\
\hline Kilba & $\mathrm{hbb}$ & $\mathrm{S} / \mathrm{TAM} / \mathrm{P}+\mathrm{DEP}$ \\
\hline Nomaande & lem & $\mathrm{S} / \mathrm{TAM} / \mathrm{P}+\mathrm{DEP}$ \\
\hline Wobé & wob & S/TAM/P+DEP \\
\hline
\end{tabular}


Dott/Zodi

Idũ

Kohumono

Dadiya

Merey

Awak

Baule

Fali

Mofu-Gudur

Ndut-Falor

Non

Zing Mumuye

Chip

Dadiya

Dera-Kanakuru

Malgwa

Anyi

Bagirmi

Baka

Banda Nchumuru

Barambu

Baule

Bekwarra

Berom/Birom

Bongo

Buem/Lelemi

Coptic $^{\dagger}$

Egyptian, Ancient

Egyptian, Later

Ejagham

Ekpeye

Eloyi

Karekare

Kresh dot

$\mathrm{ldb}$

bcs

$\mathrm{dbd}$

meq

awo

bci

fli

mif

ndv/fap

snf

mzm

mjs

$\mathrm{dbd}$

kna

mfi

any

bmi

mgc

ncu

brm

bci

bkv

bom

bot

lef

cop

egy

egy/egx

etu

ekp

afo

kai

krs
S/TAM/P+ICP

S/TAM/P+ICP

$\mathrm{S} / \mathrm{TAM} / \mathrm{P}+\mathrm{OBJ}$

S/TAM/P+REDPL

$\mathrm{S} / \mathrm{TAM} / \mathrm{P}+\mathrm{S} / 2$

$\mathrm{S} / \mathrm{TAM} / \mathrm{P}+$ split

$\mathrm{S} / \mathrm{TAM} / \mathrm{P}+$ split

S/TAM/P+split

$\mathrm{S} / \mathrm{TAM} / \mathrm{P}+$ split

S/TAM/P+split

$\mathrm{S} / \mathrm{TAM} / \mathrm{P}+$ split

$\mathrm{S} / \mathrm{TAM} / \mathrm{P}+$ split

S/TAM/P+split/DEP

$\mathrm{S} / \mathrm{TAM} / \mathrm{P} \pm \mathrm{DEP}$

fused/fused S/TAM/P

fused/fused $\mathrm{S} / \mathrm{TAM} / \mathrm{P}$

fused/fused $\mathrm{S} / \mathrm{TAM} / \mathrm{P}$

fused/fused S/TAM/P

fused/fused S/TAM/P

fused/fused S/TAM/P

fused/fused S/TAM/P

fused/fused S/TAM/P

fused/fused $\mathrm{S} / \mathrm{TAM} / \mathrm{P}$

fused/fused $\mathrm{S} / \mathrm{TAM} / \mathrm{P}$

fused/fused S/TAM/P

fused/fused S/TAM/P

fused/fused S/TAM/P

fused/fused S/TAM/P

fused/fused S/TAM/P

fused/fused S/TAM/P

fused/fused S/TAM/P

fused/fused S/TAM/P

fused/fused S/TAM/P

fused/fused S/TAM/P 


\begin{tabular}{|c|c|c|}
\hline $\mathrm{Ma}$ & $\mathrm{msj}$ & fused/fused $\mathrm{S} / \mathrm{TAM} / \mathrm{P}$ \\
\hline Ma'di & $\mathrm{mhi} / \mathrm{snm}$ & fused/fused S/TAM/P \\
\hline Mamvu & mdi & fused/fused $\mathrm{S} / \mathrm{TAM} / \mathrm{P}$ \\
\hline Masakin (Ngile) & jle & fused/fused S/TAM/P \\
\hline Mayogo & mdm & fused/fused S/TAM/P \\
\hline $\mathrm{Mba}$ & $\mathrm{mfc}$ & fused/fused S/TAM/P \\
\hline Mbembe & $\mathrm{mfn}$ & fused/fused $\mathrm{S} / \mathrm{TAM} / \mathrm{P}$ \\
\hline Mbuko & $\mathrm{mqb}$ & fused/fused S/TAM/P \\
\hline Merey & meq & fused/fused $\mathrm{S} / \mathrm{TAM} / \mathrm{P}$ \\
\hline Moloko & $\mathrm{mlw}$ & fused/fused S/TAM/P \\
\hline Morokodo & $\mathrm{mgc}$ & fused/fused $\mathrm{S} / \mathrm{TAM} / \mathrm{P}$ \\
\hline Mundu & muh & fused/fused $\mathrm{S} / \mathrm{TAM} / \mathrm{P}$ \\
\hline Ndemli & $\mathrm{nml}$ & fused/fused $\mathrm{S} / \mathrm{TAM} / \mathrm{P}$ \\
\hline Ngbandi & ngb/nbw & fused/fused $\mathrm{S} / \mathrm{TAM} / \mathrm{P}$ \\
\hline Pajade (Badiaranke) & pbp & fused/fused $\mathrm{S} / \mathrm{TAM} / \mathrm{P}$ \\
\hline Pambia & $\mathrm{pmb}$ & fused/fused $\mathrm{S} / \mathrm{TAM} / \mathrm{P}$ \\
\hline Rashad & ras & fused/fused $\mathrm{S} / \mathrm{TAM} / \mathrm{P}$ \\
\hline Sele & snw & fused/fused S/TAM/P \\
\hline Togbo & tor & fused/fused S/TAM/P \\
\hline Tumale & tag & fused/fused $\mathrm{S} / \mathrm{TAM} / \mathrm{P}$ \\
\hline Moru & $\operatorname{mgd}$ & fused/fused $\mathrm{S} / \mathrm{TAM} / \mathrm{P}+\mathrm{DEP}$ \\
\hline Lugbara & $\operatorname{lgg}$ & fused/fused $\mathrm{S} / \mathrm{TAM} / \mathrm{P} \pm \mathrm{DEP}$ \\
\hline Sara & mwm & fused/fused $\mathrm{S} / \mathrm{TAM} / \mathrm{P} \mathrm{AH}+\mathrm{DEP}$ \\
\hline Likpe & lip & fused/fused $\mathrm{S} / \mathrm{TAM} / \mathrm{P}+\mathrm{AH}+\mathrm{DEP}$ \\
\hline Lese & les & fused/fused S/TAM/P AH+DEP \\
\hline Mangbetu & mdj & fused/fused S/TAM/P 2x ( \pm DEP) \\
\hline
\end{tabular}


Appendix 8 Index of Constructions Cited in Text

\begin{tabular}{|c|c|c|}
\hline Language & Example & Construction/What is exemplified \\
\hline !Ora & $(459)$ & LV NEG-SUBJ AV or LV-NEG SUBJ AV \\
\hline !Xun & (127) & 'go' > FUT \\
\hline ‘Bozom & (756) & SUBJ:PRON ${ }_{<\mathrm{TAM}>} \mathrm{LV}: \mathrm{ASP}[: \mathrm{DEP}]$ \\
\hline ‘Dongo & $(660)$ & SUBJ-AV LV \\
\hline ‘Dongo & $(661)$ & SUBJ- $a-A V-L V$ \\
\hline (I)Rigwe & (727) & SUBJ:PRON ${ }_{<\mathrm{TAM}>} \mathrm{LV}$ \\
\hline [A]Teso & (489)-(490) & SUBJ-AV SUBJ <SBNCTV> $_{\text {-LV }}$ \\
\hline$[\mathrm{A}]$ Teso & (f) & INF complement \\
\hline$\neq$ Hoan & $(151)$ & 'be'.LOC > PRG \\
\hline$\|$ Ani & $(171)$ & 'do'/'make' > PROSP \\
\hline$\|$ Ani & $(175)$ & 'want' > PROSP \\
\hline$\|$ Ani & $(453)$ & LV-INTAV-I/II-TA \\
\hline$\|$ Ani & $(462)$ & LV-JNCT-TA $<?^{*}$ LV-JNCT AV \\
\hline Aari & $(623)$ & LV:TA:SUBJ-AV $<?^{*}$ LV:TA:SUBJ AV \\
\hline \multirow[t]{2}{*}{ Aari } & $(625)$ & LV:NEG:TA:SUBJ-AV \\
\hline & & $<$ ?* LV:NEG:TA:SUBJ AV \\
\hline Acholi & (208) & $\mathrm{LH}<\mathrm{VCC}$ \\
\hline Acholi & $(510)$ & $\mathrm{AV}_{\langle * 3-\mathrm{AV}-\mathrm{TA}\rangle} \quad$ SUBJ-LV \\
\hline Acholi & (518) & SUBJ-TA-LV[:INF] <*'SUBJ-AV LV:INF \\
\hline Adamawa Fulani & $(645)$ & SUBJ-AV:TA LV-INF \\
\hline Ader Hausa & $(431)$ & SUBJ:AV $\mathrm{AVAM}_{<\mathrm{T}>} \mathrm{LV}$ \\
\hline Afar & (17) & AH+PRTCPL V AUX \\
\hline Afar & (105) & SUBJ-LV-MOD.DEP AV-SUBJ-TAM \\
\hline \multirow[t]{2}{*}{ Afar } & (611) & LV-INF-TA:SUBJ \\
\hline & & $<$ LV-INF AV-TA:SUBJ \\
\hline Aiki & (174) & 'do'/'make' > light verb stem \\
\hline Aiki & (786) & LV SUBJ-AV-TAM-ASSRTV \\
\hline Aiki & (793) & LV OBJ-SUBJ-LightVerb-ASSRTV \\
\hline Akan & (194) & SVC \\
\hline Akan & $(673)$ & NEG-AV NEG-LV \\
\hline Akan & (773) & SUBJ-TA-LV $<*$ ? SUBJ-AV LV \\
\hline Akoose & (248) & SUBJ-'AV’ INF-LV-Ø \\
\hline Akoose & (270) & SUBJ-AV SUBJ-LV-Ø \\
\hline
\end{tabular}




\begin{tabular}{|c|c|c|}
\hline Alaaba & $(150)$ & 'be'> PRF \\
\hline Alaaba & $(581)$ & $L V: \mathrm{VN}_{<_{\mathrm{AB}}>} \mathrm{AV}$-SUBJ:TA \\
\hline Alaaba & $(635)$ & LV-SUBJ:TAM $<?^{*}$ LV[-CV <SUB〉> $\left._{1}\right]$ AV:SUBJ \\
\hline Alagwa & $(528)$ & AV-SUBJ LV-SUBJ \\
\hline Amharic & (613) & LV-SUBJ-AV-SUBJ $<$ ?*LV-SUBJ AV-SUBJ \\
\hline Amo & (706) & SUBJ-AV SUBJ-LV-OBJ \\
\hline Amo & (776) & SUBJ.TA-LV $<$ SUBJ-AV LV \\
\hline Amo & (778) & SUBJ-TA-SUBJ-LV $<?^{*}$ SUBJ-AV SUBJ-LV \\
\hline Amo & (780) & SUBJ-TA-LV-OBJ <?*SUBJ-AV LV-OBJ \\
\hline Ancient Egyptian & $(815)$ & AV LV:TA SUBJ \\
\hline Angas & $(432)$ & SUBJ:AV ${ }_{<T A M>} L V$ \\
\hline Anywa & $(483)$ & AV-SUBJ LV-INF \\
\hline Anywa & $(485)$ & AV-SUBJ $\quad$ LV $<$ VN $>$ \\
\hline Ateso & (202)-(203) & $2 \mathrm{x}<\mathrm{VCC}$ modal subordination \\
\hline Ateso & $(481)-(482)$ & SUBJ-AV $\quad$ SUBJ SSBNCTV $_{\text {S }}-\mathrm{LV}$ \\
\hline Ateso & (51) & $2 \mathrm{x}+$ modal subordination \\
\hline Ateso & (123) & 'come' > PRF/PST \\
\hline Babungo & $(682)$ & SUBJ AV SUBJ LV \\
\hline Bagirmi & (760) & SUBJ:PRON:TA INF-LV SUBJ-AV STA> $_{\langle\text {INF-LV }}$ \\
\hline Bagirmi & (762) & SUBJ.PRON.TA SUBJ-LV ASP \\
\hline & & $<$ ?*SUBJ-AV ${ }_{<T A}>$ SUBJ-LV ASP \\
\hline Bambara & (124) & 'come'> PRF \\
\hline Bang[er]i Me & $(643)$ & SUBJ-AV $n$-LV \\
\hline Barambu & $(638)$ & SUBJ-AV DEP-LV \\
\hline Bari & $(467)$ & SUBJ:TA-AV LV \\
\hline Basaa & (253) & SUBJ-TAM-AV LV- $a$ \\
\hline Beja & (216) & fused $\mathrm{AH}<* \mathrm{~V}$ AUX \\
\hline Beja & (573) & LV-GER SUBJ-MOD-AV \\
\hline Berber & (817) & AV SUBJ-LV:TA \\
\hline Beria/Zaghawa & (785) & LV OBJ-AV-SUBJ-DECL/AFFRM/ASSRTV \\
\hline Berta & $(629)$ & LV-SUBJ:TA $<? *$ LV AV:SUBJ \\
\hline Bijogo & $(649)$ & SUBJ-AV yo-LV[:ACCOMPLI] \\
\hline Bijogo & (651) & SUBJ-AV $n$-LV \\
\hline Bijogo & $(653)$ & SUBJ-AV $\tan n-\mathrm{LV}$ \\
\hline Bijogo & $(693)$ & SVC:SUBJ-V ${ }_{1}[\mathrm{sv}]-\mathrm{OBJ}-\mathrm{V}_{2}$ \\
\hline & & $\gg \mathrm{V}_{1}>\mathrm{AV} \mathrm{V}_{2}>\mathrm{LV}$ in $\mathrm{AVC}$ \\
\hline Bilin & (186) & 'say' > light verb stem \\
\hline
\end{tabular}


Bilin

Birom

Bolanci

Bongo

Buduma

Buga-/Anda

Bukusu

Bukusu

Bukusu

Bungu

Burji

Burunge

Burushaski

Chichewa

Chichewa

Ciyao

Coptic

Coptic

Dabarro Somali

Dadiya

Dadiya

Dar Daju Daju

Dar Daju Daju

Dar Daju Daju

Dasenech

Dasenech

Datooga

Datooga

Datooga

Dho-Alúr

Dho-Alúr

Dho-Alúr
LV-SUBJ:TA $<$ ? $^{*}$ LV/say/:SUBJ:TA

FUT

SUBJ-AV LV-OBJ

$\mathrm{AV}$ INF:LV-/=SUBJ

'be'.LOC $>$ PRG

LV-JNCT-TA $<$ ? LV-JNCT AV

'see' not 'be'

SUBJ-TAM-AV INF-LV- $a$

$? *$ SUBJ-AV SUBJ-LV $: e>$ SUBJ-TAM-LEX:e

SUBJ-AV-ASP- $a$ SUBJ-LV- $a$

LV-CONJ AV:TA:SUBJ

SUBJ-OBJ LV:PL-SUBJ

fused $\mathrm{S} / 2 \mathrm{OBJ} / \mathrm{SUBJ}$

$2 \mathrm{x}+\mathrm{INF}$

*SUBJ-TAM-AV INF-LV: $a$

$>$ SUBJ-TAM-TAM-INF-LV: $a$

SUBJ-AV SUBJ-TAM-LV

TA-SUBJ-LV:INF $<$ AV-SUBJ LV:INF

TA-SUBJ-LV:INF-SUBJ

$<$ ?*AV-SUBJ LV:INF-SUBJ

$\mathrm{AH}+\mathrm{INF} \mathrm{V}$ AUX

SUBJ:PRON TTAM $\quad$ LV

SUBJ:PRON $\mathrm{N}_{<\mathrm{TAM}>} \quad$ LV:ASP

'AV'-TA REDPL:LV-INF

AV LV-TA

LV-SUBJ:TA $<? *$ LV SUBJ:TA

$<$ ? ${ }^{*}$ LV SUBJ-AV $\mathrm{ATA}_{<\mathrm{A}}$

$\mathrm{S} / \mathrm{TAM} / \mathrm{P}+$ split

AV:SUBJ NEG-LV:TA

(SUBJ)-AV-SUBJ $\quad$ SUBJ $_{\angle \text { SBNNCTV }>}-\mathrm{LV}$

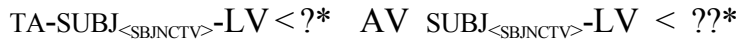

SUBJ-AV SUBJ SSBNCTV $>-\mathrm{LV}$

TA-SUBJ-LV-SUBJ $<$ ?*AV-SUBJ LV-SUBJ

SUBJ-AV LV-NEG

SUBJ-TA-LV-INDEP $<*$ SUBJ-AV LV-INDEP

SUBJ-TA-SUBJ-LV-INDEP $<*$ SUBJ-AV SUBJ-LV-INDEP 
Dholuo

Dilling Hill Nubian

Dinik

Dinka

Diola Fogny

Dizi/Maji

Dizi/Maji

Dongolese Nubian

Donno So

Dott

Doyayo

Doyayo

Doyayo

Doyayo

Doyayo

Doyayo

Duala

Duala

Duka

Duka

Duma

Dyola

Ebang

Echie

Echie

Egyptian

Egyptian Arabic

Egyptian Arabic

Egyptian Arabic

Ejagham

Ejagham

EkeGusii

Eleme
(766)

(799)

(107)-(108)
SUBJ-AV LV:INF

LV-TA-SUBJ $<? *$ LV AV-SUBJ

SUBJ:AV $\mathrm{<TAM>}_{<\mathrm{L} \text { :DEP }}$

AV:SUBJ/OBJ LV

$\mathrm{AH} \sim 2 \mathrm{x}$

$\mathrm{AH}$ CCC ss

AV-SUBJ LV-TA-DEP $<$ СONEC $>$

'say' > light verb stem

'be' $>$ PROG

SUBJ:AV ${ }_{<\mathrm{TAM}>} \mathrm{LV}[-\mathrm{PL}]$

$\mathrm{S} / 2$ orig $<\mathrm{SVC}$

AV-SUBJ-OBJ LV-TAM

“SUBJ" AV “SUBJ” LV-OBJ

'go' > PRF

AV-OBJ[-SUBJ] LV-TA

SUBJ AV SUBJ LV-OBJ

SUBJ-TAM-AV LV- $a$

SUBJ AV SUBJ LV

SUBJ.PRON.TA $L V<*{ }^{*}$ SUBJ $-\mathrm{AV}_{\mathrm{CTA}_{\mathrm{T}} \mathrm{L}} \mathrm{LV}$

SUBJ.PRON.TA DEP-LV

$<*_{\text {SUBJ-AV }} \mathrm{ATA}_{\mathrm{TA}} \quad$ DEP-LV

SUBJ-TAM-AV LOC[:INF]-LV- $a$

SUBJ-AV SUBJ-LV

SUBJ.CLS-AV SUBJ.CLS-OBJ-LV

'be' > dummy AUX

SUBJ-AV $\quad \mathrm{LV}_{<\text {×HON.DEP> }}$

TA-SUBJ-LV:INF-OBJ

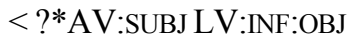

AV:TA:SUBJ LV:TA:SUBJ

AV:TA:SUBJ ASP:TA-LV:TA:SUBJ

NEG-AV:TA:SUBJ-NEGLV:TA:SUBJ

fused/fused $\mathrm{S} / \mathrm{TAM} / \mathrm{P}+(\mathrm{S}) / 2$ : $\mathrm{S} / \mathrm{T}-\mathrm{AV} \mathrm{S} / \mathrm{T}-\mathrm{LV}$-ASP

$\mathrm{S} / 2<$ VCC NEG split

SUBJ-TAM-AV INF-LV- $a$

2PL SUBJ-AV-SUBJ-APPL DEP-LV-SUBJ

2PL SUBJ.P-AV LV-ASP-SUBJ.PN

3PL SUBJ.P-AV-SUBJ.PN LV-ASP 


\begin{tabular}{|c|c|c|}
\hline Eleme & $(200)-(201)$ & Split origin $<$ SVC \\
\hline Eleme & (8) & 'very' \\
\hline Eleme & (19) & AH+DEP AUX V \\
\hline Eleme & (72) & SUBJ-AV LV-OBJ \\
\hline Eleme & $(701)$ & 2-AV LV-HAB-2PL \\
\hline Eleme & $(703)$ & 3-AV-3PL LV-HAB \\
\hline English & (26) & $\mathrm{AH}+\mathrm{DEP}_{\mathrm{i} / \mathrm{ii}}$ \\
\hline Eton & $(341)$ & SUBJ:AV [INF:]LV \\
\hline Eunda & $(342)$ & SUBJ:AV LV//NEG.SUBJ.PRON:AV LV \\
\hline Evale & $(351)$ & SUBJ:AV AV-LV: $a$ \\
\hline Ewe & $(118)$ & 'come' > FUT \\
\hline Ewe & $(154)$ & 'be'.LOC > PRG \\
\hline Ewe & $(195)$ & SVC \\
\hline Ewe & $(655)$ & SUBJ-TA-AV LV \\
\hline Ewe & $(667)$ & SUBJ-AV REDPL-LV \\
\hline Ewe & $(685)$ & SUBJ-AV LV-OBJ \\
\hline Fali & $(754)$ & SUBJ:PRON ${ }_{<T A M>} \quad L V: A S P$ \\
\hline Fer (Kara) & (116) & 'come' > FUT \\
\hline Fur & $(791)$ & LV $\quad$ SUBJ.LightVerb-TA $<$ DO $>$ \\
\hline Fyem & (728) & SUBJ:PRON ${ }_{<T A M>} \quad L V$ \\
\hline Fyem & $(770)$ & SUBJ.AV/PRON ${ }_{<\text {TAM }>}$ SUBJ.AV/PRON TTAM $>$ LV-OBJ \\
\hline $\mathrm{Ga}$ & $(758)$ & SUBJ:PRON ${ }_{<\mathrm{TAM}>}$ LV-NEG \\
\hline Gade & (49) & "2x" phonologically dependent subject \\
\hline Gade & $(679)$ & a. SUBJ AVSUBJ \\
\hline & & b. SUBJ AVSUBJ PPHON.DEP> $_{\text {L }} \quad$ LV \\
\hline Gayàr Gurduy & $(430)$ & SUBJ:AV $\mathrm{ATAM}_{<\mathrm{T}} \mathrm{LV}$ \\
\hline Georgian & $(235)$ & fused $\mathrm{S} / 2 \mathrm{SUBJ} / \mathrm{OBJ}$ \\
\hline Ghulfan & $(907)$ & LV-SUBJ:TA $<? \mathrm{LV} \mathrm{AV}_{<\mathrm{TA}}: \mathrm{SUBJ}$ \\
\hline Gidar & (228) & fused split \\
\hline Gidar & $(414)$ & $\begin{array}{l}\text { SUBJ-AV } L V_{<\text {TRRANS }>}-\text { SUBJ } \\
\text { OBJ }\end{array}$ \\
\hline Gidar & (416) & $\mathrm{SUBJ}_{<\mathrm{FEM} . \mathrm{GG}}>-\mathrm{AV} \quad \mathrm{INF}-\mathrm{LV}-\mathrm{SUBJ}_{<\mathrm{FEM} . \mathrm{SG}}>$ \\
\hline Gidar & $(418)$ & $\mathrm{SUBJ}_{<1 \mathrm{IGG}>}-\mathrm{AV} \quad \mathrm{LV}-\mathrm{SUBJ}_{<1 \mathrm{SG}>}$ \\
\hline Gidar & $(420)$ & AV-SUBJ LV-OBJ \\
\hline Gidar & (422) & AV-OBJ-TA \\
\hline
\end{tabular}


Gidar

Gidar

Gidar

Gidole

Gimira/Benchnon

Gimira/Benchnon

Gimira/Benchnon

Gimira/Benchnon

Giryama

Gisamjanga Datooga

Godie

Goemai

Gogo

Gula Meré

Gula Meré

Gula Meré

Gula Meré

Gula Sara

Gula Zura

Guro

Guus (Sigidi)

Guus (Sigidi)

Hadza

Hadza

Hadza

Hadza

Hadza

Hadza

Hamer

Hamer

Hamer

Harar Oromo

Harar Oromo
(33)-(34)

(587)
AV SUBJ-LV-SUBJ

AV LV-OBJ-SUBJ

SUBJ-LV-SUBJ-TAM $<$ ?*SUBJ-LV SUBJ-AV or < *SUBJ-LV-SUBJ $\mathrm{CICP}>\quad \mathrm{AV}$

LV-NEG:TA:SUBJ < ?*LV NEG:AV:SUBJ

AH+PRTCPL/GENDER V AUX

LV-NEG AV-SUBJ

$\mathrm{LV}:$ PRTCPL:SUBJ ${ }_{<\mathrm{GENDER} / \mathrm{NUMBER}>}$

AV:TA:SUBJ $\angle$ PERSON/GENDER/NUMBER>

LV-NEG AV-TA:SUBJ

SUBJ-TAM-AV SUBJ- $k a$-LV: $a k a$ CNSCTV

TA-SUBJ-LV-SUBJ $<$ ?*AV-SUBJ LV-SUBJ

IMPRF AUX V/V AUX

'sit' > IRR

*SUBJ-AV INF-LV: $a$

$>$ SUBJ-TAM $_{<\mathrm{INF}}>\mathrm{LV}: a$

'sit' > PRG

'sit' > PRG

SUBJ-AV INF-LV

SUBJ-AV SUBJ-LV

AV INF:LV vs. SUBJ-AV SUBJ-LV

'go'> IMM.FUT

SUBJ.OBJ.PRON.TA.[NEG] LV:ASP

$<$ ??*SUBJ-OBJ-AV ${ }_{<\mathrm{TAM} / \mathrm{NEG}>} \quad$ LV-ASP

SUBJ:AV $\mathrm{AVTM}_{<\mathrm{TA}>} \mathrm{LV}$

SUBJ:AV $\mathrm{A}_{<\mathrm{TAM}>} \mathrm{LV}$

AV-SUBJ LV

AV-SUBJ $J_{\mathrm{i}} \quad L V-S U B J_{j}$

AV:TA:SUBJ LV-OBJ

LV-SUBJ:TA $<$ ?*LV AV:SUBJ

LV-TAM-SUBJ:TA < ?*LV-TAM AV:SUBJ

LV-OBL/OBJ-SUBJ:TA <?*LV-OBL/OBJ AV:SUBJ fused $2 \mathrm{x}$ TAM

AV LV-ASP

LV-ASP AV

LV-NEG-TAM AV-SUBJ

LV-SUBJ AV-SUBJ 
Harar Oromo

Harar Oromo

Harar Oromo

Hausa

Hausa

Hausa

Hausa

Hausa

Haya

Haya

Hdi

Heiban

Hemba

Hemba

Herero

Holoholo

Holoholo

Hung'an

Hungu

Ibibio

Ibibio

Idũ

Idũ

Ik

Ila

Inor

Iraqw

Iraqw

Izi

Jalonke

Jiddu Somali

Kabba

Kabba

Kabba
(406)-(407)

$$
\begin{aligned}
& \text { NEG-LV:TA AV:SUBJ } \\
& \text { NEG.AV+DEP.AV } \\
& \text { NEG.AV+DEP.AV } \\
& \text { (402) } z a-\quad \text { AV-SUBJ LEX [<PHON.DEP>] } \\
& \mathrm{S} / \mathrm{TAM} / \mathrm{P}+\mathrm{AH} \\
& \text { (404) -kan SUBJ-AV LV } V_{\text {[<PHON.DEP>] }} \\
& \text { (405) -na SUBJ-AV LV-DEP } \\
& \text { (403) } b a \text { - AV-SUBJ LV-DEP } \\
& 2 \mathrm{x}+\text { DEP.AV } \\
& \text { SUBJ-TM-AV SUBJ-TA-LV: } a \\
& \text { AV LV-TAM:OBJ-SUBJ } \\
& \text { SUBJ.CLS-AV SUBJ.CLS-LV } \\
& 2 \mathrm{x}+-e \\
& \text { SUBJ-TAM-AV SUBJ-LV- } a \\
& \text { SUBJ-TAM-AV LV- } a \\
& \text { fused AH+CONEG A-V } \\
& \text { *SUBJ-AV LOC-INF-LV: } a \\
& >\text { SUBJ-TAM }_{\angle A U X}>- \text { LOC-INF-LV: } a
\end{aligned}
$$

NEG

*SUBJ-AV INF-LV: $a$

$>$ SUBJ-TAM $_{\angle \mathbb{N N F}>}-\mathrm{LV}: a$

SUBJ-TAM-AV-NEG SUBJ-LV

SUBJ-AV-[TA]-NEG SUBJ-LV

SUBJ:PRON ${ }_{<T A M>} \quad$ LV

SUBJ:PRON ${ }_{<T A M \gg} \quad$ LV SUBJ:DEP

LH V AUX

*SUBJ-TAM-AV LV:ile $e_{\mathrm{PRF}}>$ SUBJ-TAM-TAM-LV-ile $e_{\mathrm{PRF}}$ SUBJ-LV-ASP AV <*SUBJ-LV-ASP *AV:TA:3M

LV-CON AV-SUBJ

OBJ-AV LV:PL-SUBJ

[SUBJ] AV-TALV

SUBJ AV SUBJ LV

fused $\mathrm{AH}<* \mathrm{~V}$ AUX

AH vs. $2 x$ paradigms

AH vs. $2 x$ paradigms

AH vs. 2x paradigms 


\begin{tabular}{|c|c|c|}
\hline Kabba & $(66)$ & AH vs. $2 x$ paradigms \\
\hline Kabba & (b) & AH vs. 2 x paradigms \\
\hline Kaguru & $(260)$ & SUBJ-NEG.AV INF-LV- $a$ \\
\hline Kana & $(50)$ & $2 \mathrm{x}$ dependent subject \pm phonologically encoded \\
\hline Kana & $(74)$ & SUBJ-AV OBJ-LV \\
\hline Kana & $(75)$ & SUBJ-AV OBJ-AUX LV \\
\hline Kana & $(689)$ & SUBJ-AV OBJ-AV/LV \\
\hline Kana & $(691)$ & SUBJ-[A] $\mathrm{V}_{1}$ PRON.OBJ-[A/L] $\mathrm{V}_{2}[\mathrm{~L}] \mathrm{V}_{3} \ldots$ \\
\hline Kanuri & $(182)-(183)$ & 'say' > light verb stem \\
\hline Kanuri & $(811)$ & $\begin{array}{l}\text { AV:SUBJ:CNJCTV LV-Light.Verb:SUBJ:TA- } \\
\text { NEG[:TA:SUBJ] }\end{array}$ \\
\hline Kanuri & $(825)$ & $\begin{array}{l}\text { LV-SUBJ:TA:NEG } \\
<\quad \text { LV } \quad \text { SUBJ:LightVerb:TA.NEG }\end{array}$ \\
\hline Kara & $(125)$ & 'go'> FUT \\
\hline Karekare & $(243)$ & $\mathrm{S} / \mathrm{T}+\mathrm{S} / 2$ \\
\hline Karimojong & $(500)$ & $\mathrm{AV}_{:<\mathrm{TAM} / \mathrm{POL}>} \quad$ SUBJ-LV \\
\hline Katcha & $(129)$ & 'go'> FUT \\
\hline Katcha & $(180)$ & 'be lacking/absent' > NEG.AV \\
\hline Katcha & $(845)$ & SUBJ $_{\mathrm{i}}-\mathrm{AV}-\mathrm{SUBJ}_{\mathrm{j}} \quad$ INF-LV \\
\hline Katcha & $(878)$ & SUBJ $-A V-S U B J_{j}$ \\
\hline Katla & $(889)$ & AV SUBJ-LV \\
\hline Kemantney & $(104)$ & LV-SUBJ-GER AV-SUBJ-TAM \\
\hline Kemantney & $(231)$ & fused $\mathrm{S} / 2 \mathrm{OBJ} / \mathrm{SUBJ}$ \\
\hline Kemantney & (599) & LV-SUBJ-GER AV-SUBJ-TA \\
\hline Kemantney & $(627)$ & $\begin{array}{l}\text { LV-SUBJ-AV-SUBJ-ASP-GEND/NUMB }<?^{*} \text { LV-SUBJ } \\
\text { AV-SUBJ-ASP-GEND/NUMB }\end{array}$ \\
\hline Kerewe & $(31)$ & LH AUX V \\
\hline Kerewe & $(334)$ & AV SUBJ-LV: $a$ \\
\hline Kerewe & $(336)$ & AV SUBJ-AV SUBJ-LV-ile $e_{\text {PRF }}$ \\
\hline Kerewe & $(338)$ & SUBJ-AV INF-LV: $a$ \\
\hline Khwe & $(121)$ & 'come' > PROSP \\
\hline Kikongo & $(251)$ & SUBJ-TAM-AV LV- $a$ \\
\hline Kimbu & $(546)$ & SUBJ-TA-AV SUBJ-INF-LV \\
\hline Kinnauri & $(230)$ & fused split \\
\hline Kinyarwanda & $(48)$ & 2X PHON.DEP.SUBJ \\
\hline Kinyarwanda & $(106)$ & SUBJ-TAM-AV SUBJ-NEG-LV- $a$ \\
\hline Kinyarwanda & $(115)$ & 'come' > FUT \\
\hline
\end{tabular}


Kinyarwanda

Kinyarwanda

Kinyarwanda

Kinyarwanda

Kinyarwanda

Kirma

Kirma

Kirundi

Kisi

Klao

Koegu

Kohumuno

Kokit Gumuz

Kokit Gumuz

Kolokuma Izon

Kolonkadhi

Kpelle

Kresh

Kresh

Krongo

Krongo

Krongo

Kua

Kulango

Kunama

Kunama

Kunama

Kunama

Kuri(y)a

Kuriya

Kùrùkù Gurdun

Kwambi

Kwami

Kwerba

Kxoe
(166)-(167)

(236)

(601)

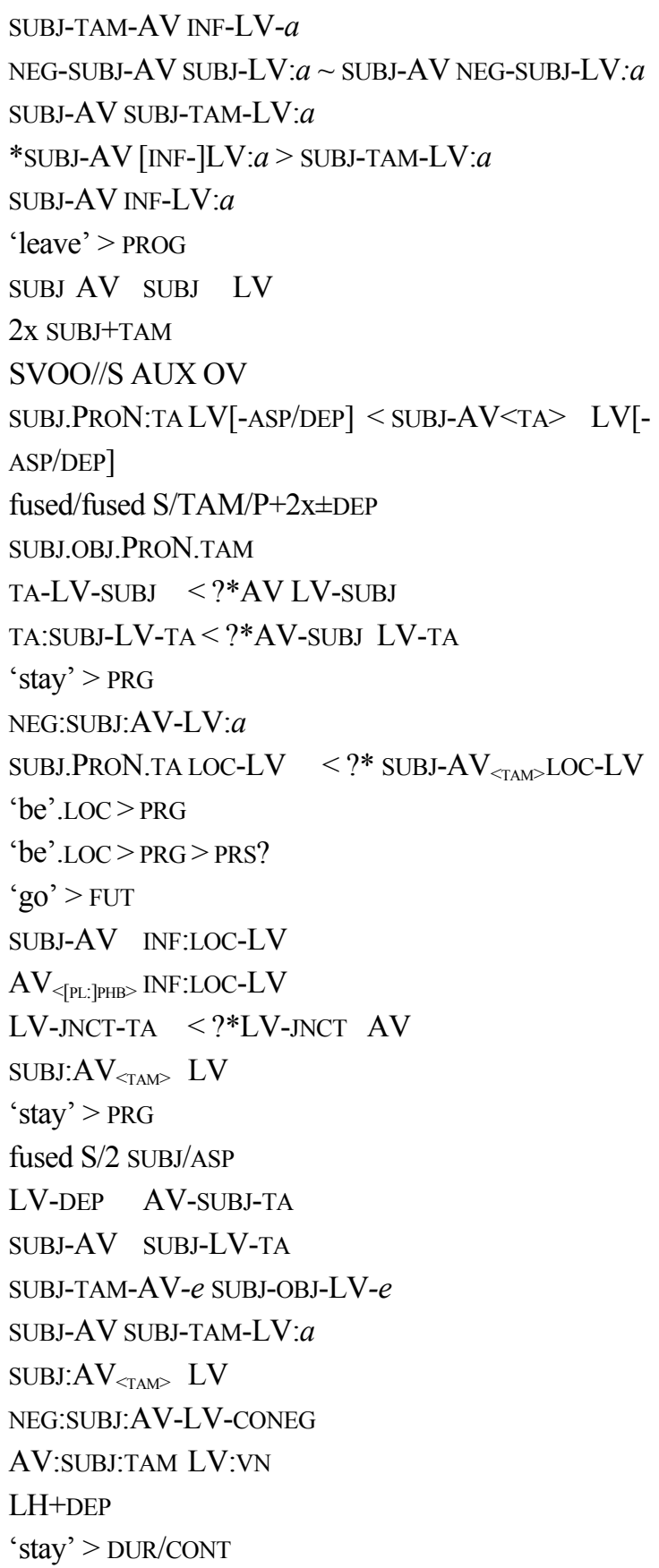




\begin{tabular}{|c|c|c|}
\hline Laal & $(47)$ & $" 2 x "$ \\
\hline Laal & $(677)$ & SUBJ AV SUBJ LV \\
\hline Laal & $(688)$ & SUBJ AV LV-OBJ \\
\hline Lafofa & $(851)$ & SUBJ-AV LV \\
\hline Lafofa & $(876)$ & SUBJ-AV LV-ASP \\
\hline Lamba & $(87)$ & SUBJ-TAM-AV SUBJ-TAM-OBJ-LV \\
\hline Lamba & $(205)$ & $\mathrm{S} / 2<\mathrm{VCC}$ OBJ/SUBJ split \\
\hline Lango & (176)-(177) & 'want' > PROSP \\
\hline Lango & $(6)$ & NEG \\
\hline Lango & $(111)$ & 'come'> FUT \\
\hline Lango & $(469)$ & SUBJ-AV LV:INF \\
\hline Lango & $(471)$ & SUBJ-AV LV-INF \\
\hline Lango & $(492)$ & SUBJ-AV[:TA] SUBJ-LV:TA \\
\hline Lango & $(496)$ & SUBJ-AV-TA SUBJ-LV-TA-OBJ \\
\hline Lango & $(498)$ & SUBJ-AV SUBJ-LV-TA \\
\hline Lango & $(512)$ & $\mathrm{AV}_{<* 3-[\mathrm{TA}]-\mathrm{AV}>} \quad \mathrm{SUBJ}-\mathrm{LV}[-\mathrm{TA}-\mathrm{OBJ}]$ \\
\hline Lango & $(517)$ & SUBJ-AV LV:INF \\
\hline Later Egyptian & $(839)$ & LightVerb-SUBJ.TA LV \\
\hline & & $<$ ?*LightVerb $\mathrm{AV}_{<\mathrm{TA}>}$ SUBJ $\mathrm{LV}$ \\
\hline Lotuko & $(112)$ & 'come' > FUT \\
\hline Lotuko & $(473)$ & SUBJ-AV LV:INF \\
\hline Luba & $(324)$ & SUBJ-TAM-AV SUBJ-ASP-LV: $a$ \\
\hline Luguru & $(114)$ & 'come'> FUT \\
\hline Lungu & $(42)$ & $2 \mathrm{x}+-a$ \\
\hline Lungu & $(274)$ & SUBJ-TAM-AV SUBJ-LV- $a$ \\
\hline Lungu & $(308)$ & SUBJ-TAM-AV SUBJ-LV:e \\
\hline Lyaa & $(371)$ & *SUBJ-AV LOC-INF-LV: $a$ \\
\hline & & $>$ SUBJ-TAM ${ }_{<\mathrm{AUX}>}>-\mathrm{LOC}-\mathrm{LV}: a$ \\
\hline $\mathrm{Ma}$ & $(782)$ & SUBJ.TA-AV INF-LV \\
\hline & & $<* \quad$ SUBJ-AV [SUBJ-]AV INF-LV \\
\hline Ma'di & $(45)$ & $2 \mathrm{x}$ NPST \\
\hline Maale & $(569)$ & LV-INF \\
\hline Maasai & $(475)$ & SUBJ-AV INF-LV \\
\hline Maasai & $(477)$ & SUBJ-AV INF-LV-INF \\
\hline Maasai & $(479)$ & 3-AV SUBJ-LV \\
\hline Maasai & $(481)$ & 3-AV CONJ-SUBJ-LV \\
\hline Maba & $(787)$ & LV SUBJ-AV-DECL \\
\hline
\end{tabular}


Majang

Makua-Maverone

Mamvu

Mamvu

Manding

Maninka

Masakin

Masakin

Masalit

Masalit

Masalit

Masalit

Masalit

Masalit

Masalit

Mbalanhu

Mbalanhu

Mbandja

Mbay

Mbay

Mbay

Mbay

Mbay

Mbay

Mbe

Mbodomo

Mbugwe

Mbugwe

Mbuko

Mbuko

Mbya Guarani

Meje

Mende

Mende (c)

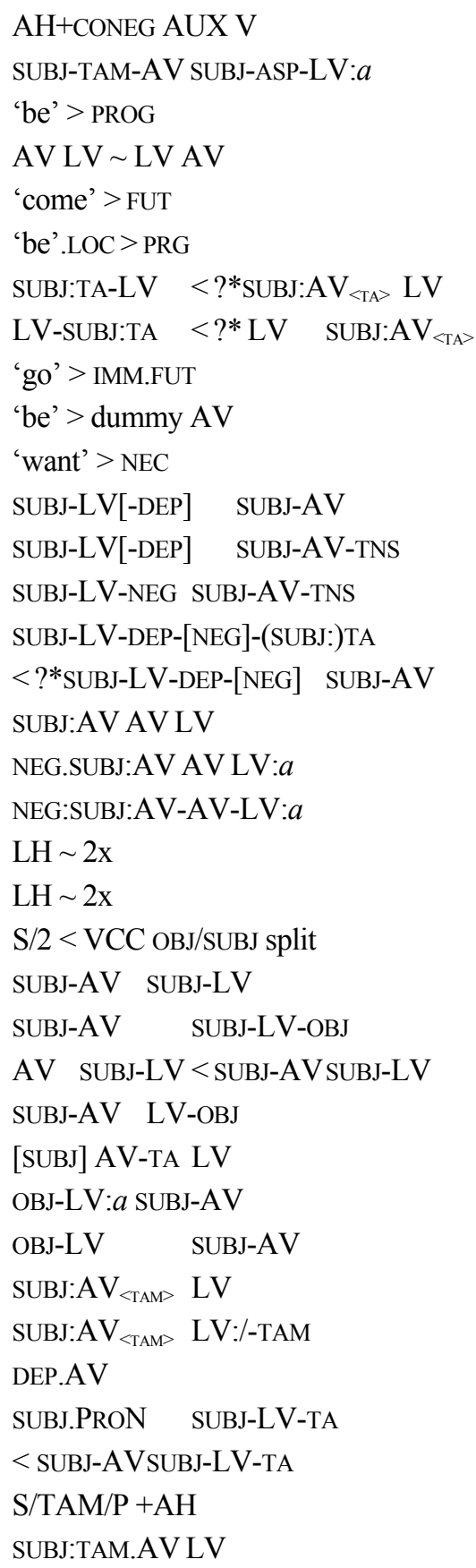




\begin{tabular}{|c|c|c|}
\hline Merey & $(438)$ & SUBJ:AV ${ }_{<\mathrm{PRS}>} \quad$ LV-PRS \\
\hline Merey & $(440)$ & SUBJ:AV $\mathrm{APST}_{<\mathrm{L}} \mathrm{LV}$ \\
\hline Midob & $(795)$ & LV:INF 'AV':SUBJ.TA \\
\hline Midob & $(835)$ & LV-SUBJ:TA $<?^{*}$ LV SUBJ:TA \\
\hline & & $<? *$ LV SUBJ:AV ${ }_{<\mathrm{TA}>}$ \\
\hline Modern Khwe & (163)-(164) & 'stand' $[>$ PRG] $>$ PRS \\
\hline Modern Khwe & $(455)$ & LV-CV AV-I/II-TA \\
\hline Modern Khwe & $(457)$ & LV-DEP AV-I/II-TA \\
\hline Modern Khwe & $(464)$ & TAM origin from AVCs/SVCs \\
\hline Mödö & $(28)$ & LH AUX V \\
\hline Mödö & $(712)$ & AV SUBJ-LV \\
\hline Mofu-Gudur & $(436)$ & SUBJ:AV ${ }_{<\mathrm{TAM}>}$ LV-OBJ \\
\hline Mojave & $(213)$ & $\mathrm{S} / 2 \mathrm{CCC}$ ss \\
\hline Molo & $(245)$ & fused/fused $\mathrm{S} / \mathrm{TAM} / \mathrm{P}+2 \mathrm{x}$ \\
\hline Mono & $(229)$ & fused-split \\
\hline Moro & $(855)$ & SUBJ-AV SUBJ-LV \\
\hline Morokodo & $(640)$ & SUBJ-AV INF-LV \\
\hline Mpoto & $(262)$ & SUBJ-TAM-AV LOC-INF-LV- $a$ \\
\hline Mudung Somali & (14) & AH+INF V AUX \\
\hline Murle & $(126)$ & 'go'> FUT \\
\hline Mursi & $(56)$ & $\mathrm{AH} \sim 2 \mathrm{x}(\mathrm{MOD})$ \\
\hline Muyang & (39) & ?S/2 AUX V \\
\hline Muyang & $(120)$ & 'come' > PROSP \\
\hline Muyang & $(137)$ & 'be' > PROG \\
\hline Muyang & $(412)$ & SUBJ-AV SUBJ-LV \\
\hline Mwera & $(275)$ & SUBJ-TAM-AV SUBJ-LV- $a$ \\
\hline Mwera & $(392)$ & TAM-SUBJ-LV- $e_{\text {SBJNCTV }}<? ?$ \\
\hline Mwera & $(393)$ & SUBJ-TAM-LV: $a$ \\
\hline Mwera & $(394)$ & SUBJ-AV SUBJ-[TAM]-LV: $a$ \\
\hline N. Sotho & $(69)$ & $2 \mathrm{x}+$ DEP.AV \\
\hline N. Sotho & $(290)$ & SUBJ-AV OBJ-LV: $a$ \\
\hline N. Tonga & $(288)$ & SUBJ-AV INF-LV: $a$ \\
\hline Nafaara & $(747)$ & SUBJ:PRON $\mathrm{CTAM}_{<\mathrm{T}>} \mathrm{LV}$ \\
\hline Nafaara & $(749)$ & SUBJ:PRON ${ }_{<\mathrm{TAM}>} \quad$ LV:ASP \\
\hline Nandi & $(502)-(504)$ & TA-SUBJ-LV-(é) $<*$ AV SUBJ-LV(-é) \\
\hline Nandi & $(179)$ & 'want'> FUT \\
\hline Nandi & $(238)$ & fused LH \\
\hline
\end{tabular}


Naro

Naro

Ndamba

Ndemli

Ndendeule

Ndogo

Ndut-Falor

Ndut-Falor

Ndut-Falor

Nera

Nera

Neyo

Ngambay-Moundou

Ngambay-Moundou

Ngambay-Moundou

Ngambay-Moundou

Ngandjera

Ngiti

Ngizim

Nkonya

Nkore-Kiga

Nkore-Kiga

Noni

Noni

Nyaturu

Nyaturu

Nyimang

Ogbronuagom

Ogbronuagom

Ogbronuagom

Ogbronuagom

Òkó

Òkó

Ongota

Orig

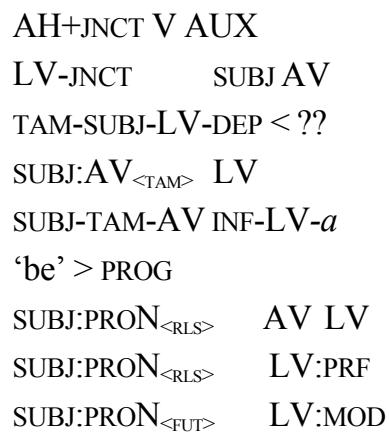

'say' > light verb stem

LV-GER AV-TA-SUBJ

SUBJ.PRON:TA LV[-ASP/DEP] < SUBJ-AV <TA $>$

LV[-ASP/DEP]

$\mathrm{PREP}+\mathrm{NOM} / \mathrm{AUX}$ variation

$\mathrm{AH} \sim 2 \mathrm{x}$

'stand' > PRG

$\mathrm{S} / 2$ origin $<\mathrm{SVC}$

SUBJ:AV AV-LV: $a$

2x AUX V

$\mathrm{S} / \mathrm{T}+\mathrm{AH}+$ dependent

SUBJ.TA-LV < SUBJ-AV LV

SUBJ-TAM-AV PROG-SUBJ-LV- $a$

SUBJ-TAM-AV SUBJ-LV: $a$

2X AUX V

SUBJ-AV SUBJ-AV SUBJ-AV ... SUBJ-LV

SUBJ-AV SUBJ-ASP-LV: $a$

SUBJ-AV SUBJ-NEG-LV

AV LV:DEP

CAP

SUBJ-NEG-AV SUBJ-LV

SUBJ-TA/NEG-AV INF-LV

SUBJ-TA/NEG-AV SUBJ-LV

'come' $>$ MODAL $<$ SHOULD $>$

SUBJ-TA-AV SUBJ-LV

LV-PROG/DEP SUBJ-AV

'be' > dummy AV 


\begin{tabular}{|c|c|c|}
\hline Orig & $(880)$ & NEG-LV SUBJ-AV $V_{<T A}$ \\
\hline Oromo of Wellega & (16) & AH+PRTCPL V AUX \\
\hline Oromo of Wellega & (43) & $2 \mathrm{x}+$ fused/fused S/TAM/P LV-AV \\
\hline Oromo of Wellega & (589) & LV-SUBJ:TA AV-SUBJ:TA \\
\hline Oromo of Wellega & $(603)$ & NEG-LV-SUBJ:TA AV-SUBJ:TA \\
\hline OshiKwanyama & $(353)$ & SUBJ:AV-LEX-ćl $\dot{\varepsilon}_{\mathrm{PRF}}$ \\
\hline Otoro & (173) & 'do'/'make' > UNACCMPL \\
\hline Otoro & $(181)$ & 'be lacking/absent' > NEG.AV \\
\hline Otoro & (847) & SUBJ.CLS-AV PREP INF:LV \\
\hline Otoro & (858) & SUBJ.CLS-AV SUBJ.CLS-LV \\
\hline Otoro & $(860)$ & SUBJ.CLS-AV ${ }_{\triangle \mathrm{NEG}>}>$ SUBJ.CLS-LV CONEG \\
\hline Otoro & $(862)$ & Subj.ProN SUBJ.CLS-AV SUBJ.CLs-LV \\
\hline \multirow[t]{2}{*}{ Otoro } & (903) & ABS/OBJ-TA-ERG/SUBJ-ABS/OBJ-LV \\
\hline & & $<?^{*}$ ABS/OBJ-AV ERG/SUBJ-ABS/OBJ-LV \\
\hline Pare & (113) & 'come' > FUT \\
\hline Pengo & (233) & fused $\mathrm{S} / 2 \mathrm{OBJ} / \mathrm{SUBJ}$ \\
\hline Pero & (226)-(227) & Pseudo fused $2 \mathrm{x}+\mathrm{ICP}$; fused-split \\
\hline Pero & (401) & SUBJ-AV LV[-STAT] \\
\hline Pokomo & $(320)$ & SUBJ-AV SUBJ-TAM-LV: $a$ \\
\hline Polci & $(435)$ & SUBJ:AV ${ }_{<T A M>}$ LV-OBJ \\
\hline Rashad & (134) & 'be'> PROG \\
\hline Rashad & $(881)$ & NEG-LV $\quad$ SUBJ-AV $V_{<T A}$ \\
\hline Rashad & (909) & SUBJ:TA-LV $\quad<?^{*}$ SUBJ:- $\mathrm{V}_{\langle\mathrm{TA}\rangle} \quad$ LV \\
\hline S. Tonga & (289) & SUBJ-TAM-LV: $a$ \\
\hline Sai Gumuz & (618) & TA-LV-SUBJ $<? * A V$ LV-SUBJ \\
\hline Sai Gumuz & (619) & TA:SUBJ-LV-TA $<? * A V$-SUBJ LV-TA \\
\hline Sandawe & (168) & 'stay' > PRG \\
\hline Sandawe & $(550)$ & LV-SUBJ:TA-CNNCTV AV \\
\hline \multirow[t]{2}{*}{ Sandawe } & $(552)$ & AV-CNNCTV LV-SUBJ:TA-NEG \\
\hline & & LV-SUBJ:TA-NEG AV-CNNCTV \\
\hline \multirow[t]{2}{*}{ Sandawe } & $(559)$ & LV(-TA)-SUBJ:TAM $\quad$ LV-SUBJ:TAM $<$ \\
\hline & & $? * \mathrm{LV}(-\mathrm{TA}) \mathrm{AV}-\mathrm{SUBJ}$ \\
\hline Sayanci & (399) & SUBJ-AV LV-VN \\
\hline Sena & $(255)$ & SUBJ-TAM-AV INF-LV- $a$ \\
\hline Sena & (280) & SUBJ-TAM-AV SUBJ-LV-e \\
\hline Sena & $(361)$ & *SUBJ-AV INF-LV: $a>$ SUBJ-TAM-LV: $a$ \\
\hline Sepedi/N. Sotho & (222) & fused $\mathrm{AH}<*$ AUX V +INF \\
\hline
\end{tabular}


Sese Gumuz

Sese Gumuz

Sese Gumuz

Sese Gumuz

Sesotho

Setswana

Setswana

Setswana

Setswana

Setswana

Setswana

Setswana

Shabo

Shambaa

Shambala

Shambala

Shambala

Shatt Daju

Shatt Daju

Shatt Daju

Shatt Daju

Shatt Daju

Shatt Daju

Shona

Siluyana

Siluyana

Siswati

Siswati

So

So

Standard Ewe

Standard Ewe

Standard Somali

Sukuma

Sukuma

Sukuma 'be' > dummy AuX

INF-LV AV:SUBJ:TA

TA-LV-SUBJ $<$ ?*AV LV-SUBJ

TA:SUBJ-LV-TA $<$ ?*AV-SUBJ LV-TA

fused $\mathrm{AH}<*$ AUX V + INF

$2 \mathrm{x}$ orig $<\mathrm{SVC}$

$2 \mathrm{x}<\mathrm{CCC}$

SUBJ-TAM-AV SUBJ-LV- $a$

SUBJ-AV SUBJ-NEG-LV:e

SUBJ-TAM-AV SUBJ-NEG-LV:e

SUBJ-NEG-AV SUBJ-LV: $a$

NEG-SUBJ-AV SUBJ-LV: $a$

'be' > PST

AV SUBJ-TA ${ }_{\triangle \mathrm{AUX}}>-\mathrm{LV}: a \sim$ SUBJ-AV-LV: $a$

$\mathrm{AH} \sim 2 \mathrm{x}(\mathrm{MOD})$

SUBJ-TAM-AV SUBJ-LV:e

TAM-SUBJ-LV- $e_{\text {SBNCTV }}<?$

'come' $>$ FUT

'sit' > PRG

$\mathrm{SUBJ}_{\mathrm{a}}-\mathrm{AV}_{\langle n\rangle>} \quad \mathrm{SUBJ}_{\mathrm{a}}-\mathrm{LV}-e_{<\mathrm{DEP}>}$

$\mathrm{SUBJ}_{\mathrm{b}}-\mathrm{AV}_{<n\rangle} \quad \mathrm{SUBJ}_{\mathrm{a}}-\mathrm{LV}-e_{<\mathrm{DEP}>}$

$\mathrm{SUBJ}_{\mathrm{a}}-\mathrm{AV}_{<\text {wum }}>\mathrm{SUBJ}_{\mathrm{b}}-\mathrm{LV}$

$\mathrm{SUBJ}_{b}-\mathrm{AV}_{<w u \eta\rangle} \mathrm{SUBJ}_{\mathrm{b}}-\mathrm{LV}$

'say' > TAM

PROG

SUBJ-TAM-AV SUBJ-LV- $a$

SUBJ-TAM-AV SUBJ-TAM-LV- $a=b e$ PROSP

SUBJ-FUT-AV SUBJ-LV- $a=b e$ PROG

$\mathrm{AH} \sim 2 \mathrm{x}$

'come' > FUT

'stay' > HAB

SUBJ-TA-LV <*? SUBJ-AV LV

fused $\mathrm{AH}<* \mathrm{~V}$ AUX

$2 \mathrm{x}+$ DEP.AV

SUBJ-TAM-AV SUBJ-DEP-LV: $a$

AV:e SUBJ-LV-e 
Sukuma

Sukuma

Sukuma-Kiiya

Sumbwa

Sumbwa

Swahili

Swahili

Swahili

Swahili

Swahili

Swahili

Tagoi

Tagoi

Tama

Tama

Tama

Tama

Tamashek

Tarok

Temein

Temein

Temein

Tennet

Tigrinya

Tima

Tima

Tima

Tima

Tira

Tira
SUBJ-AV-e SUBJ-TAM-LV- $a$

SUBJ-TA-AV [SUBJ-TA-AV] SUBJ-DEP-LV:a

LH AV:DEP

*SUBJ-AV [INF-]LV: $a>$ SUBJ-TAM-LV: $a$

${ }^{*}$ SUBJ-AV LV:ile $e_{\mathrm{PRF}}>$ SUBJ-TAM-LV-ile PRF

$\mathrm{S} / 2+\mathrm{CONEG}$

SUBJ-TAM-AV NEG-SUBJ-LV

fused $\mathrm{AH}<*$ AUX V

SUBJ-AV NEG-SUBJ-LV- $i_{\text {CONEG }}$

SUBJ-TAM-AV SUBJ-PRTCPL-LV: $a$

${ }^{*}$ SUBJ-AV INF-LV: $a>$ SUBJ-TAM $_{<\mathrm{AV}>-\mathrm{LV}: a}$

'be' > PROG

NEG-LV SUBJ-AV $<$ TA $>$

'say' > light verb stem

LV SUBJ.LightVerb-TA $<$ SAY $>$

LV SUBJ.LightVerb-TA $<$ DO $>$

SUBJ-LV-SUBJ:LightVerb-TA

$<$ ?*SUBJ-LV SUBJ-LightVerb-TA

$\mathrm{AV}=\mathrm{OBJ} \quad \mathrm{LV}: \mathrm{ASP}-\mathrm{SUBJ}$

mimics AV-OBJ LV-SUBJ structure

SUBJ:PRON $\mathrm{N}_{<\mathrm{TAM}>} \mathrm{LV}$

'do'/'make' > INT.FUT

SUBJ-AV-FIN SUBJ-LV:DEP

AV SUBJ-TA-LV-FIN

$\mathrm{NEG}_{<\mathrm{AUX}>}>\mathrm{SUBJ}-\mathrm{SBJNCTV}-\mathrm{LV}$

CONJ-LV AV:SUBJ

NEG-SUBJ-LV ... $=$ CONEG

$<?^{*} \mathrm{AV}_{<\mathrm{NEG}}>-\mathrm{SUBJ}$ LV ... $=\mathrm{CONEG}$

TA-SUBJ-LV-SUBJ $\angle D E P>$

$<$ ?*AV-SUBJ LV-SUBJ $<$ DEP $>$

NEG-SUBJ-LV-SUBJ $<$ DEP $>\ldots=$ CONEG

$<$ ? $^{*} \mathrm{AV}_{<\mathrm{NEG} . \mathrm{PST}>}-\mathrm{SUBJ} \mathrm{LV}-\mathrm{SUBJ}_{<\mathrm{DEP}>} \ldots=\mathrm{CONEG}$

TA-SUBJ-LV-SUBJ ${ }_{\triangle \mathrm{DEP}}>-\mathrm{OBJ}$

$<$ ?*AV-SUBJ $\quad$ LV-SUBJ <DEP $>-O B J$

'be' > dummy AV

SUBJ-AV INF-LV 
Tira

Tiv

Tofa

Tonga

Tonga

Tonga

Tsongo

Tsotso

Tumale

Tumale

Tumale

Tumbuka

Turkana

Turkana

Tuvan

Twi

Twi

Tyurama

Tyurama

Umbundu

Umbundu

Umbundu

Venda

Venda

Venda

Venda

Venda

Wobé

Wolof

Xhosa

Xhosa

Xhosa

Xhosa

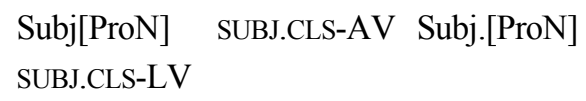






